DOE/NV/13052-41

ITLV/13052-041

UC-700

Value of Information Analysis for

Corrective Action Unit Nos. 101 and 102: Central and Western Pahute Mesa, Nevada Test Site, Nevada

RECEIVED SEP 28 S998

OSTI

September 1998

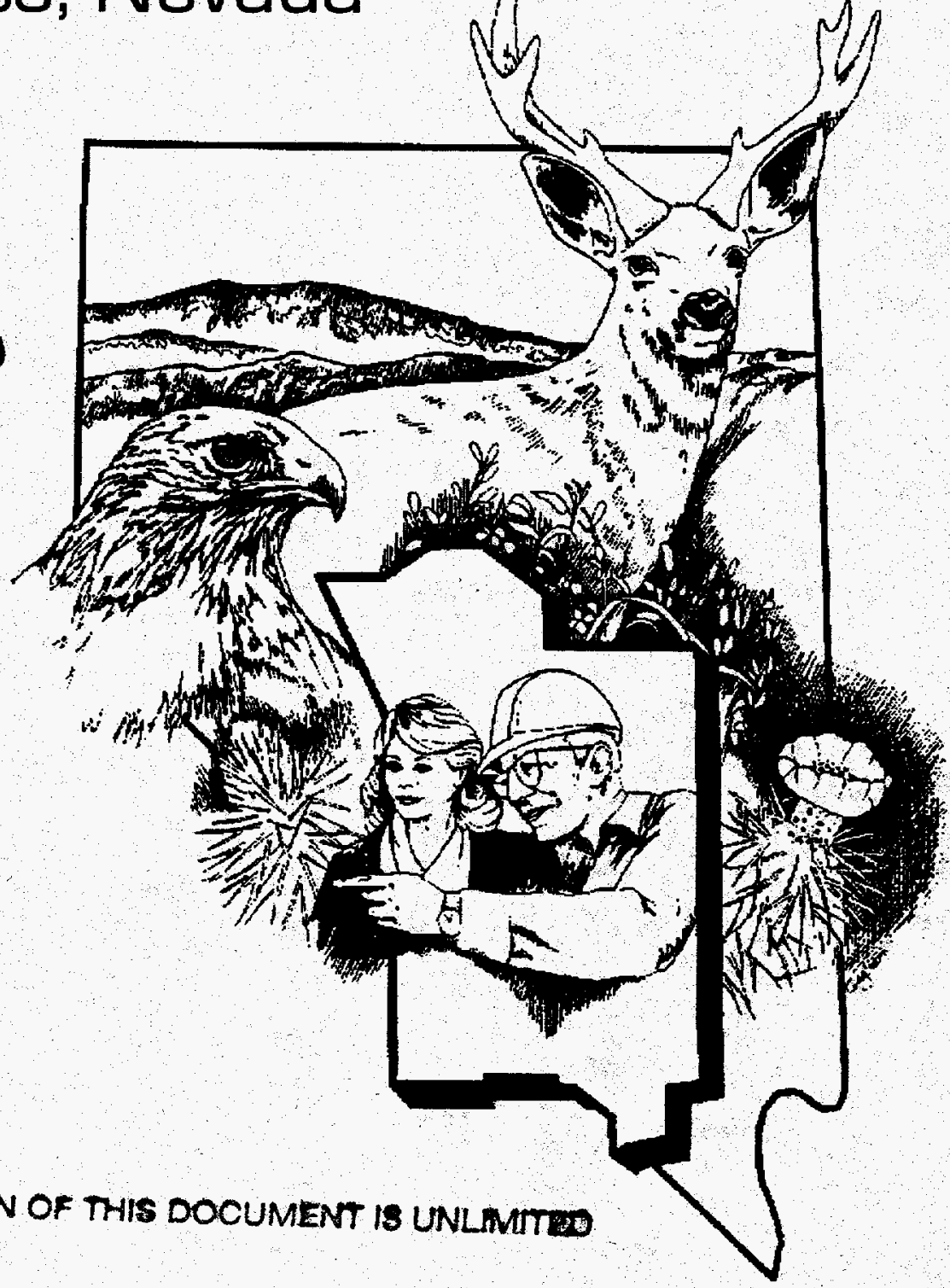

Approved for public release; further dissemination unlimited.

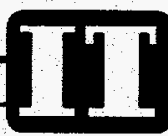


Available to the public from -

U.S. Department of Commerce

National Technical Information Service

5285 Port Royal Road

Springfield, VA 22161

(703) $487-4650$

Available electronically at http://www.doe.gov/bridge. Available to U.S. Department of Energy and its contractors in paper form -

U.S. Department of Energy

Office of Scientific and Technical Information

P.O. Box 62

Oak Ridge, TN 37831-0062

(423) 576-8401 


\section{VALUE OF INFORMATION ANALYSIS FOR CORRECTIVE ACTION UNIT NOS. 101 AND 102: CENTRAL AND WESTERN PAHUTE MESA, NEVADA TEST SITE, NEVADA}

\section{IT CORPORATION}

2621 Losee Road, Bldg. B-1

Suite 3050-01

North Las Vegas, NV 89030

Approved for public release, further dissemination unlimited

September 1998

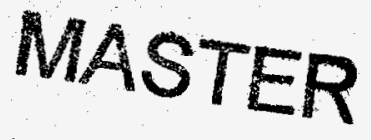

This work performed for the U.S. Department of Energy by IT Corporation under Contract No.: DE-AC08-97NV13052 


\section{DISCLAIMER}

This report was prepared as an account of work sponsored by an agency of the United States Government. Neither the United States Government nor any agency thereof, nor any of their employees, make any warranty, express or implied, or assumes any legal liability or responsibility for the accuracy, completeness, or usefulness of any information, apparatus, product, or process disclosed, or represents that its use would not infringe privately owned rights. Reference herein to any specific commercial product, process, or service by trade name, trademark, manufacturer, or otherwise does not necessarily constitute or imply its endorsement, recommendation, or favoring by the United States Government or any agency thereof. The views and opinions of authors expressed herein do not necessarily state or reflect those of the United States Government or any agency thereof. 


\section{DISCLAIMER}

Portions of this document may be illegible in electronic image products. Images are produced from the best available original document. 


\section{VALUE OF INFORMATION ANALYSIS FOR CORRECTIVE ACTION UNIT NOS. 101 AND 102: \\ CENTRAL AND WESTERN PAHUTE MESA, NEVADA TEST SITE, NEVADA}
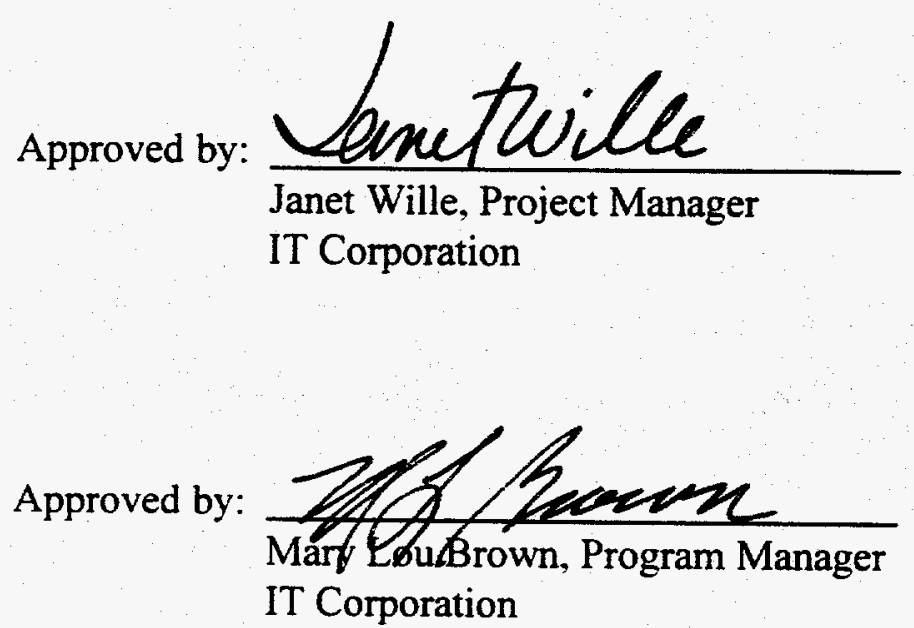

Date: $9-16-98$

Date: $\quad q-16-18$ 


\section{Acknowledgments}

The Pahute Mesa Value of Information task was led by IT Corporation; HSI-GeoTrans, Inc.; and Applied Decision Analysis, Inc., in cooperation with the U.S. Department of Energy. The task was completed with the cooperation of several organizations involved in work at the Nevada Test Site. These organizations are listed in alphabetical order:

- Bechtel Nevada

- Desert Research Institute

- Lawrence Livermore National Laboratory

- Los Alamos National Laboratory

- U.S. Geological Survey, Water Resources Division

The task consisted of analysis and report preparation and was led and completed by a core group. The core group included the following individuals, listed in alphabetical order:

$\begin{array}{ll}\text { Claeys, Justin } & \text { Applied Decision Analysis, Inc. } \\ \text { Deshler, Barbara } & \text { IT Corporation } \\ \text { Drici, Warda } & \text { IT Corporation } \\ \text { Fryer, William } & \text { HSI-GeoTrans, Inc. } \\ \text { Jenni, Karen } & \text { Applied Decision Analysis, Inc. } \\ \text { Merkhofer, Lee } & \text { Applied Decision Analysis, Inc. } \\ \text { Rehfeldt, Ken } & \text { HSI-GeoTrans } \\ \text { Wille, Janet } & \text { IT Corporation }\end{array}$

Special recognition is granted to the members of the Technical Working Group Subcommittee whose contributions were essential to the completion of the Value of Information task. The subcommittee included the following individuals, listed in alphabetical order:
Crowe, Bruce
Los Alamos National Laboratory
Laczniak, Randall
U.S. Geological Survey
Pawloski, Gayle
Lawrence Livermore Laboratory
Russell, Chuck
Desert Research Institute
Sully, Michael
Bechtel Nevada
Waddell, Rick
HSI-GeoTrans, Inc.

Also, many thanks to the technical editors, document production department staff, and library staff of IT Corporation for their constant support. This document could not have been prepared without their invaluable assistance. 


\section{Table of Contents}

Acknowledgments

List of Figures V

List of Tables vii

List of Acronyms and Abbreviations viii

Executive Summary ES-1

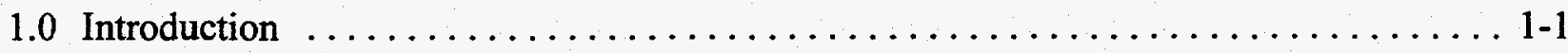

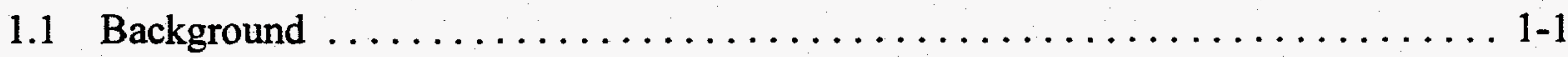

1.1.1 Project Description $\ldots \ldots \ldots \ldots \ldots \ldots \ldots \ldots \ldots \ldots \ldots \ldots \ldots \ldots \ldots \ldots \ldots \ldots \ldots \ldots$

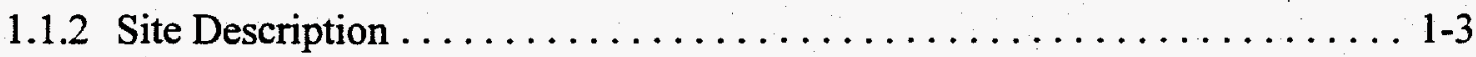

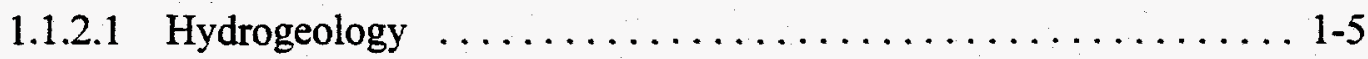

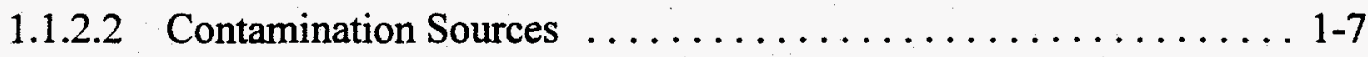

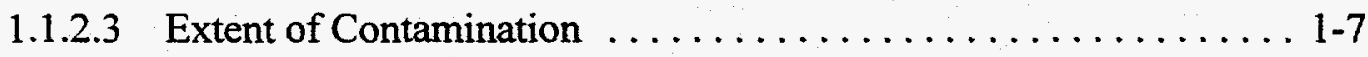

1.1.2.4 Uncertainties ............................. 1-8

1.2 Task Objectives, Scope, and Limitations $\ldots \ldots \ldots \ldots \ldots \ldots \ldots \ldots \ldots \ldots \ldots \ldots \ldots \ldots$

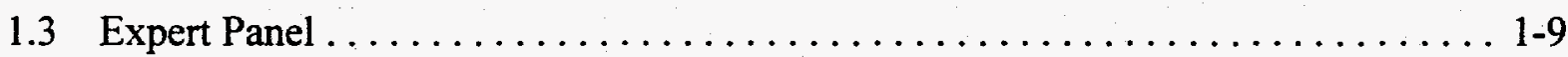

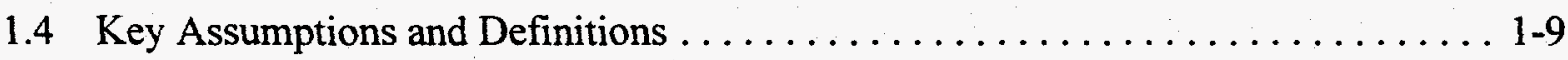

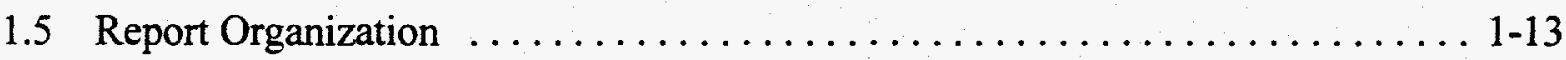

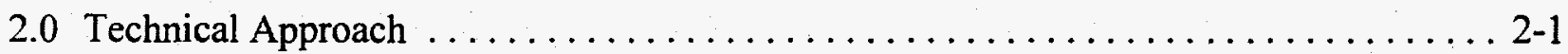

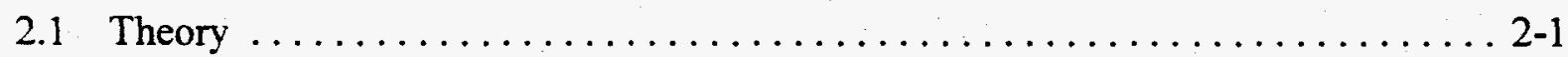

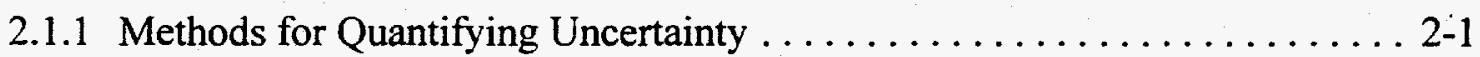

2.1.2 Methods for Estimating and Analyzing Uncertainty $\ldots \ldots \ldots \ldots \ldots \ldots .4$

2.1.3 Methods for Specifying Probability Distributions on Input Variables ... . . 2-6

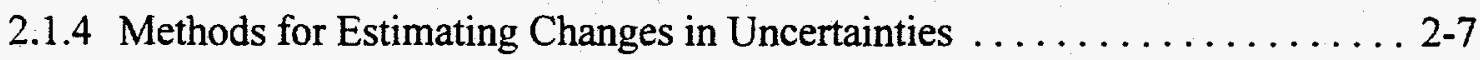

2.1.5 Relationship Between Bayesian Analysis and Value of Information Analysis $\ldots \ldots \ldots \ldots \ldots \ldots \ldots \ldots \ldots \ldots \ldots \ldots \ldots \ldots \ldots \ldots .2-9$

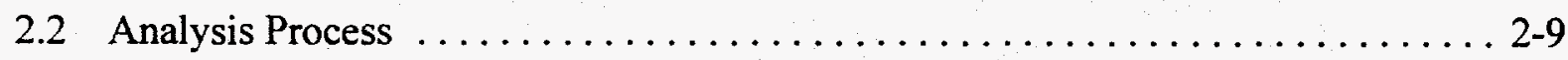




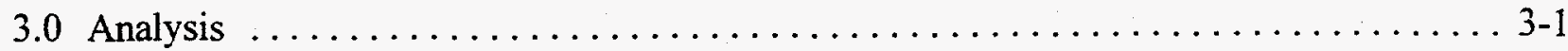

3.1 Sensitive Parameters $\ldots \ldots \ldots \ldots \ldots \ldots \ldots \ldots \ldots \ldots \ldots \ldots \ldots \ldots \ldots \ldots \ldots \ldots \ldots \ldots \ldots .1$

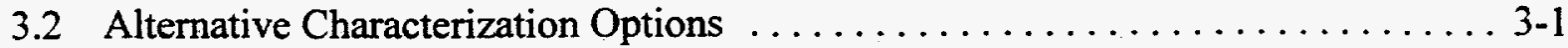

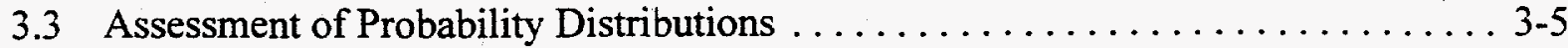

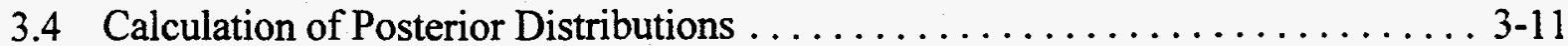

3.5 Calculation of the Maximal Extent of the Contaminant Boundary .......... 3-13

3.5.1 Preliminary Contaminant Boundary Calculations .............. 3-13

3.5.2 Calculation of the Contaminant Uncertainty Measures ........... 3-14

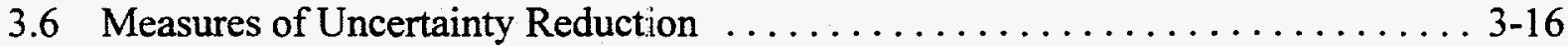

3.6.1 Average Expected Reduction in Parameter Uncertainty ............ 3-16

3.6.2 Expected Reduction in Contaminant Boundary Uncertainty ......... 3-17

3.6.3 Expected Change in the Upper Bound $\left(95^{\text {th }}\right.$ Fractile) of the

Contaminant Boundary ........................... 3-19

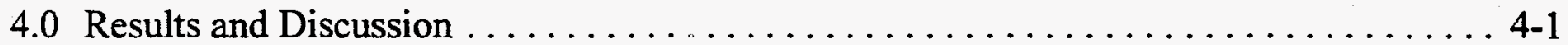

4.1 Ability of Characterization Options to Reduce Parameter Uncertainty . . . . . . 4-1

4.2 Ability of Characterization Options to Reduce Contaminant Boundary

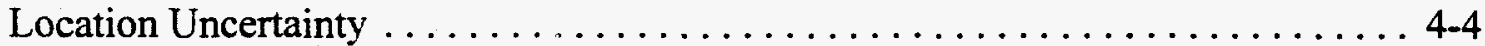

4.3 Ability of Characterization Options to Reduce the Upper-Bound Estimate of the Distance to the Contaminant Boundary $\ldots \ldots \ldots \ldots \ldots \ldots \ldots \ldots .7$

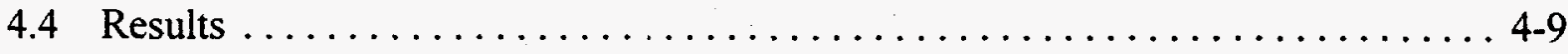

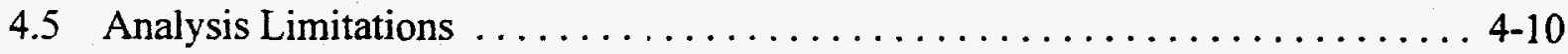

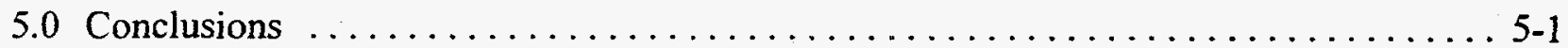

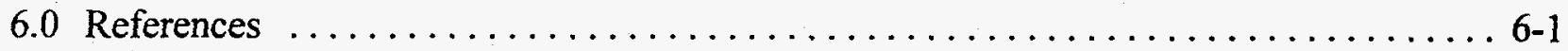

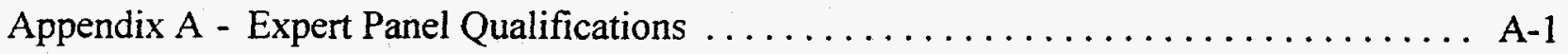

Appendix B - Description of Groundwater Flow and Transport Regional Model ........ B-1

Appendix C - Alternative Characterization Options ....................

Appendix D - Prior Probability Assessment ...................... D-1 


\section{Table of Contents (Continued)}

Appendix E - Assessment of Distributions Describing the Accuracy of Characterization Options $\ldots \ldots \ldots \ldots \ldots \ldots \ldots \ldots \ldots \ldots \ldots \ldots \ldots \ldots \ldots$

Appendix $\mathrm{F}-$ Bayesian Updating . . . . . . . . . . . . . . . . . . . . .

Appendix G - Transport Simulations for Individual Activities, Subgroups, and Groups ... . G-1 


\section{List of Figures}

Number

1-1 Location of Underground Test Area Corrective Action Units and Corrective Action Sites on the Nevada Test Site

1-2 Nevada Test Site Regional Groundwater Flow System $\ldots \ldots \ldots \ldots \ldots \ldots \ldots$ 1-4

1-3 Example of Contaminant Boundary Confidence Levels $\ldots \ldots \ldots \ldots \ldots$ 1-11

1-4 Illustrative Probability Density Function Describing Uncertainty of Contaminant Boundary

2-1 Illustrative Cumulative Distribution Function

2-2 Box Plot Representation of a Probability Distribution $\ldots \ldots \ldots \ldots \ldots \ldots .2-2$

2-3 Pathline of Groundwater Flow from TYBO $\ldots \ldots \ldots \ldots \ldots \ldots \ldots \ldots \ldots \ldots$

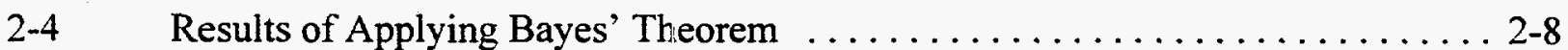

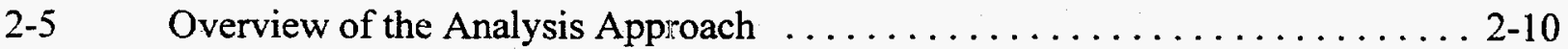

3-1 Process for Assessing Probabilities for Calculating Prior and Posterior Distributions

3-2 Influence Diagram Showing Factors Influencing the Accuracy of Characterization Activities . . . . . . . . . . . . . . . . . .

3-3 Activity Accuracy Estimates Indicate Uncertainty, Asymmetry, and Sensitivity of Test Outcomes

3-4 Displays Used to Facilitate Accuracy Estimates for Activity Subgroups . . . . 3-11

3-5 Typical Relationship Between Posterior and Prior Distributions 3-12 


\section{List of Figures (Continued)}

Number

Title

Page

3-6 Example of Prior and Posterior Distributions for the Flux Multiplier . . . . . . 3-12

3-7 Multiple Monte Carlo Simulations Were Required for

Groups Composed of Activities Addressing Different Parameters

4-1 Results: Activity Groups, Subgroups, and Activities Ranked by

Expected Average Reduction in Parameter Uncertainty

4-2 Results: Expected Average Parameter Uncertainty Reduction Versus Cost . . . . 4-4

4-3 Results: Activity Groups, Subgroups, and Activities Ranked by

Expected Contaminant Boundary Location Uncertainty Reduction 4-5

4-4 Expected Contaminant Boundary Location Uncertainty

Reduction Versus Cost

4-5 Results: Activity Groups Ranked by Expected Reduction in

Upper Bound ( $95^{\text {th }}$ fractile) of the Distance to the Contaminant Boundary

4-6 Results: Expected Contaminant Boundary Location Upper Bound

(95th fractile) Reduction Versus Costs . . . . . . . . . . . . . . . . . . 4-8 
3-1 Sensitive Parameters for Computing the Contaminant Boundary $\ldots \ldots \ldots \ldots$ 3-2

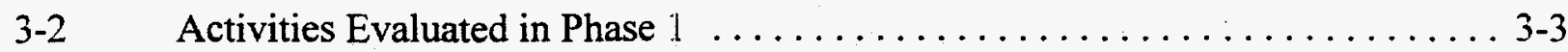

3-3 Groups and Subgroups Evaluated in Phase $2 \ldots \ldots \ldots \ldots \ldots \ldots \ldots \ldots \ldots \ldots$

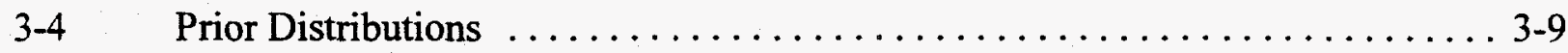

3-5 Example Illustrating the Computation of the Average Expected

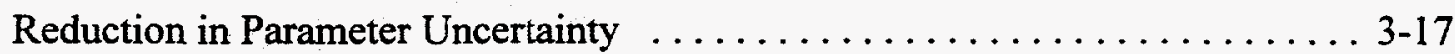




\section{List of Acronyms and Abbreviations}

\begin{tabular}{ll} 
AMT/MT & Audiomagnetotelluric/Magnetotelluric \\
ATV & All-terrain vehicle \\
CAI & Corrective Action Investigation(s) \\
CAIP & Corrective Action Investigation Plan \\
CAU & Corrective Action Unit(s) \\
CDF & Cumulative distribution function \\
DC & Direct current \\
DoD & U.S. Department of Defense \\
DOE & U.S. Department Energy \\
DOE/NV & U.S. Department of Energy, Nevada Operations Office \\
EPA & U.S. Environmental Protection Agency \\
ER & Environmental Restoration \\
ERC & Environmental Remediation Contractor \\
FFACO & Federal Facility Agreement and Consent Order \\
ft & Foot (feet) \\
HSU & Hydrostratigraphic unit(s) \\
K & Distribution coefficient \\
km & Kilometer(s) \\
LCA & Lower Carbonate Aquifer \\
LLNL & Lawrence Livermore National Laboratory \\
$\mathrm{m}$ & Meter(s) \\
mL/g & Milliliter(s) per gram \\
mi & Mile(s) \\
mrem/yr & Millirem(s) per year \\
NTS & Nevada Test Site \\
PBMC & Performance-Based Management Contractor \\
pCi/L & Picocurie(s) per liter \\
PDF & Probability density function \\
SS & Stainless steel \\
TTBT & Threshold Test Ban Treaty \\
TWG & Technical Working Group \\
UGTA & Underground Test Area \\
VOIA & Value of Information Analysis \\
yr & Year \\
\hline &
\end{tabular}




\section{Executive Summary}

The objective of the value-of-information analysis was to evaluate and compare data collection options for characterizing groundwater transport of contamination associated with the Pahute Mesa underground test area of the Nevada Test Site (NTS). Pahute Mesa is one of several areas of the NTS used for nuclear underground testing until 1992, with testing on Pahute Mesa starting in 1965. Most of the underground nuclear tests in Pahute Mesa were conducted within fractured rocks near or below the water table. The tests have resulted in the deposition of radionuclides and other contaminants into the ground and groundwater in the vicinity of the underground test area. The extent of contaminated groundwater (exceeding contaminant boundary specifications) is expected to gradually expand downgradient of the testing areas over the next few hundred years, due to transport within the groundwater flow system. Ultimately, the extent of contamination will shrink due to radionuclide decay.

Officials would like to know, among other things, how large the extent of contamination will become. Estimates of the maximum extent of the contamination in groundwater (the contaminant boundary) are highly uncertain due to limited understanding of the geologic and hydrologic characteristics of the area and how contaminants move away from the nuclear test locations. This study was intended to help decision makers evaluate cost-effective information-collection (characterization) options to reduce these uncertainties.

A group of experts knowledgeable about the NTS was selected by U.S. Department of Energy, Nevada Operations Office (DOE/NV) to define and evaluate options for characterizing the Pahute Mesa underground test area. Thirty six characterization options were evaluated, ranging from a single, inexpensive study using existing data and intended to address a single question or uncertainty, to a forty-million-dollar suite of activities designed to collect and analyze new information to address multiple uncertainties. The characterization options were compared and ranked based on how effective the experts thought the information collection would be in reducing uncertainties, how this effected the distance to contaminant boundary, and the cost of the option.

\section{Theory}

The value-of-information analysis is based on a well-established theory for analyzing uncertainty. The theory is based on the assumption that uncertainty can be described using 
probabilities, or a measure of how likely it is that an outcome will occur. A statistical technique known as Bayesian analysis can be used to explore how estimated probabilities should be changed, or updated, based on new information. In a value of information analysis, expert opinion on the potential result of collecting new information is used to update probabilities. Probabilities based on existing information are called prior probability distributions, while the updated probabilities that account for the potential new information are called posterior probability distributions.

The new posterior distributions that result from a characterization option depend on the outcome of the activities that constitute that option. For example, a characterization activity might produce results that confirm current suspicions or it might produce an unanticipated "surprise." Results that confirm current thinking tend to reduce uncertainty. Surprise results may increase uncertainty. Although the results of the new data collection activities cannot be known ahead of time because either outcome could occur, it is possible to estimate how the posterior or revised distributions might change if the new information is what was "expected" or if it came as a "surprise." Thus, it is possible to compare how much the uncertainty changes between the prior and posterior probabilities as a result of the characterization activities or options. The most effective options or activities, according to this theory, are those that produce the greatest reductions in uncertainty. In this analysis, that means we are more certain of how far the contaminant boundary will extend in the future. The cost-effectiveness of options can be determined by comparing how much uncertainty reduction is expected with the estimated cost.

\section{Approach}

The contaminant transport component of the regional model was used to assess the ability of each characterization option to reduce uncertainty on the location of the contaminant boundary. The regional model was developed to determine if any immediate risks to human health and the environment exist from radionuclide migration in groundwater downgradient of the underground test areas. The regional model includes a three-dimensional groundwater flow model of the area encompassing the Nevada Test Site and a one-dimensional contaminant transport model from test locations on the Nevada Test Site. It is documented in a report titled: Regional Groundwater Flow and Tritium Transport Modeling and Risk Assessment of the Underground Test Area, Nevada Test Site, Nevada, published by the U.S. Department of Energy in 1997. The contaminant transport component of the regional model was used alone in this value-of information analysis, and the groundwater fluxes and flow paths were assumed to be as previously simulated by the three-dimensional regional groundwater flow model. 
The pathline originating at TYBO, a single underground nuclear test on Pahute Mesa, and ending at the Oasis Valley discharge area, was selected for radionuclide transport simulations. The TYBO test was selected because results of the regional model indicate that contaminants originating from the TYBO location have a higher potential to reach public lands than those originating from other nuclear tests. The transport model was used to simulate the movement of two radionuclides: tritium and carbon- 14 to predict the contaminant boundary distance. Initial evaluation of transport for the seven most important radionuclides (tritium, iodine-129, uranium-238, plutonium-239/240, carbon-14, cesium-137, and strontium-90) found that these two radionuclides determined the contaminant boundary within the timeframe of concern.

Because a one-dimensional transport model was used, the contaminant boundary is represented as a maximum distance. The specification of the contaminant boundary for this analysis was defined as that distance beyond which the total dose of 4 millirem per year would not be exceeded within a 1,000-year timeframe. This definition was approved by the DOE/NV Underground Test Area (UGTA) Subproject Manager after discussions with the State of Nevada and the UGTA Technical Working Group. Based on preliminary transport simulations of mobility in the groundwater system, tritium and carbon-14 are the only radionuclides that contribute to the 4 millirem per year contaminant boundary, within the 1,000-year timeframe.

The key inputs to the regional contaminant transport model include the hydrologic and geochemical parameters of flux multiplier, source term, effective porosity, diffusion parameter, and distribution coefficient. Brief descriptions of these parameters and their importance in contaminant transport follow.

- Flux Multiplier: Flux, the amount of groundwater moving through a given area of the flow system, is currently the most important parameter in the prediction of potential contaminant migration. Uncertainty in the flux, resulting from lack of knowledge about the geology and groundwater flow system characteristics, is accounted for in the flux multiplier.

- Source Term: As applied to this modeling effort, this term refers to the concentration of radionuclides left by the nuclear test in the groundwater available for groundwater. transport. Some of the radionuclides are contained deep within the glass that was formed from the melted rock following the nuclear test detonation, and are not readily available for transport. Others may be sorbed or held onto the surfaces of the glass and rock. The rate at which a radionuclide enters the groundwater either by leaching out of the glass or desorbing from the cavity materials controls the concentration of that radionuclide in the groundwater. A rapid release rate produces a short-term, high concentration source term. A slow release rate produces a long-term contamination source at a lower concentration. The concentration of a radionuclide in groundwater as it leaves the location of the nuclear 
test is one of the factors determining the downgradient extent and concentration of the contamination. For this modeling, all of the radionuclides were released at the start.

- Effective porosity: In fractured rocks, not all fractures may be connected such that groundwater flow through the area actually moves through all or all parts of the fractures. Some fractures or parts of fractures, or networks of fractures may only be connected over the space of inches or feet, and the water contained within these "dead" networks is essentially stagnant. Effective porosity is a measure of the interconnected network of fractures along the flow path where groundwater predominantly flows and contaminant migration occurs. The effective porosity is a major factor determining the speed with which groundwater moves in an aquifer. For a given flux, the smaller the effective porosity, the faster groundwater will move through an aquifer.

- Diffusion Parameter: In saturated fractured rocks, most movement of groundwater in the aquifer occurs in the fractures. However, within the rock itself, slower movement occurs in interconnected pores. Similarly, most of the radionuclides will move within the fractures, particularly if the water is moving quickly. However, a fraction of the radionuclides will move into the rock pore spaces, or they will diffuse into the rock matrix and move even more slowly. By diffusing into the rock, the concentration within the fractures is reduced, and the rate of migration slows. The larger the diffusion parameter, the smaller the migration distance.

- Distribution coefficients $\left(\mathrm{K}_{\alpha}\right)$ : Some radionuclides have a chemical tendency to attach to rock matrix material for a period of time. This process, called sorption, causes those radionuclides to move slower than the groundwater. Radionuclides may also attach themselves to very small particulates such as clay or iron minerals called colloids and travel with the groundwater. Depending on a number of factors related to their size, the nature of the aquifer materials, and the chemistry of both the radionuclide and the groundwater, colloids may either slow down or speed up radionuclide transport. The distribution coefficient $\left(\mathrm{K}_{\mathrm{d}}\right)$ is a value that describes how likely the radionuclide is to be sorbed.

The first four parameters were selected based on a sensitivity analysis of the regional model. In a sensitivity analysis, the value of a parameter is varied and the model is run many times to see how much the contaminant boundary will change, or how sensitive it is to changes in that parameter. The fifth parameter, distribution coefficient or $K_{d}$, was selected because the movement of many radionuclides is affected by sorption.

A panel of experts, familiar with the NTS and experienced and knowledgeable in the areas of geology, hydrology, geochemistry, and statistical analysis, was convened to provide expert 
judgement for the analysis. They identified potential characterization activities for Pahute Mesa designed to address each of the key parameters. Fourteen individual characterization activities were identified. They are as follows:

- Activity 1, fault-zone characterization, was designed to evaluate whether major fault zones in Pahute Mesa and its vicinity have significant effects on groundwater flow.

- Activity 2, Timber Mountain investigation, was designed to evaluate the effect of the Timber Mountain caldera, a major geologic structure in the Pahute Mesa area, on groundwater flow directions in that area.

- Activity 3, exploratory drilling southwest of Pahute Mesa, was designed to characterize the geologic structure, stratigraphy, and groundwater flow characteristics downgradient of Pahute Mesa.

- Activity 4, test-cavity sampling, was designed to characterize the hydrologic source term.

- Activity 5, injection-withdrawal tracer testing, was designed to measure representative diffusion parameter values for the geologic layers of the groundwater flow system.

- Activity 6, BULLION-type tracer testing, was designed to measure representative values for effective porosity and the diffusion parameter for the geologic layers of the groundwater flow system.

- Activity 7, geochemistry-based investigation, would provide an alternate basis for determining flow paths and flow velocities from which values for effective porosity and the diffusion parameter could be estimated.

- Activity 8,2-D seismic surveys, was designed to characterize the geologic structure in the specific locations southwest of Pahute Mesa in sufficient detail to refine the geologic model used in modeling flow and transport from Pahute Mesa.

- Activity 9, geophysical surveys, was designed to characterize the geologic structure and stratigraphy in the area southwest of Pahute Mesa.

- Activity 10 , laboratory study of diffusion parameters, was designed to measure representative diffusion parameter values for the geologic layers of the groundwater flow system.

- Activity 11 , study of radionuclide release from test cavities, was designed to characterize the hydrologic source term.

- Activity 12, geologic and geophysical modeling, was designed to test the model of geologic structure and stratigraphy in the area southwest of Pahute Mesa. 
- Activity 13 , analysis of barometric and earth-tide responses, was designed to determine representative effective porosity values for the various hydrogeologic layers of the flow system.

- Activity 14 , laboratory study of distribution coefficients for radionuclides, was designed to estimate the $K_{d}$ values for radionuclides of concern.

The panel of experts also designed groups of characterization activities based on various themes. Smaller subgroups addressing individual parameters such as flux or matrix diffusion were also derived during the analysis. Including all individual, subgroups, and groups of activities, a total of 36 options were considered.

Based on existing data and best professional judgment, the panel defined the prior probability distributions describing the current uncertainty over each of the key parameters. Then the panel defined posterior distributions for the key parameters; namely, estimates of the ability of each characterization option to provide information that would reduce uncertainty on each parameter. Using the prior and posterior parameter probability distributions as inputs, the transport model was used to calculate probability distributions describing uncertainty of the contaminant boundary location.

The uncertainty that is advanced in a probability distribution can be expressed in many ways. For this study, three measures were selected to rank the characterization options. These can represent three different objectives for perlorming characterization activities. They are:

1. Ability to reduce uncertainty over key parameters: Variance is a measure of uncertainty; the higher the variance, the higher the uncertainty. Expected posterior variances were compared with the variances of the prior distributions. Characterization options were ranked based on the expected decrease in the parameter variances that they were estimated to produce. This measure did not include calculating how the newly acquired data would affect the location of the contaminant boundary, but considered only reduction in parameter uncertainty.

2. Ability to reduce uncertainty in the average prediction of the contaminant boundary: The transport model was used to calculate the overall change in the location of the boundary. What is being measured is the average change in the boundary prediction across the entire distribution of predictions, or how much the distribution of distances to the contaminant boundary changes as a result of each of the activities or groupings. The characterization options were then ranked based on their expected reduction in the uncertainty. 
3. Ability to reduce uncertainty in the 95 percent confidence-level prediction of the contaminant boundary: Another way of describing the change in location of the boundary is to look at how the characterization options affect the more extreme predictions, defined using the 95 percent confidence level. What this measure looks at is how options are able to affect boundary distance estimates that have only one chance in 20 of being exceeded. The options were then ranked on their expected reduction in uncertainty.

To account for costs, characterization options were also ranked based on their cost effectiveness; that is, their effectiveness in achieving the above objectives per estimated cost.

\section{Results}

A summary of the value of information results follows.

1. Characterization options differed significantly in estimated costs and in estimated reductions in uncertainty. The estimated cost of options ranged from $\$ 75,600$ to $\$ 40,200,000$. The impact of options on uncertainties varied by an even wider range. The estimated uncertainty reduction per dollar of cost varied by over three orders of magnitude, with some options performing poorly regardless of how the reduction in uncertainty was measured.

2. Different measures of uncertainty reduction produced different rankings; therefore, the choice of characterization options depends (to some degree) on the objectives of uncertainty reduction.

3. In general, the analysis suggests that activities providing information that clarifies the groundwater flow system (related to the flux multiplier) have relatively high value regardless of the measure used. Activities providing information related to matrix diffusion and $K_{d}$ were estimated to have less value. Activities related to effective porosity and source term generally ranked intermediate. However, the relatively low uncertainty-reducing potential of activities focused on source term may be due to the low estimates of the amount of current uncertainty about the source term. That is, the prior distribution may have been estimated to be unreasonably small.

4. Despite the fact that different measures produced different rankings, some options ranked high regardless of the measure of uncertainty used. Groups of activities generally ranked higher than single activities and the groups with the most activities generally ranked the highest.

5. Several options consistently ranked at or near the top in terms of producing the largest expected uncertainty reduction at the smallest total estimated cost. An option was defined as "optimal" if it provided at least as much uncertainty reduction as any other option that costs the same or more. Between four and seven options were identified as 
optimal depending on the uncertainty-reduction measure used. Three options were consistently identified as optimal regardless of the measure used.

6. In some cases, conducting a characterization option may increase the uncertainty measures associated with contaminant boundary. As noted previously, any characterization activity that can produce surprising results may increase uncertainty. This means that collecting additional data, in some cases, may increase the predicted distance to the boundary. For example, some of the activities associated with effective porosity produce an increase in the distance to the contaminant boundary. If characterization activities produce smaller estimated values of effective porosity, faster flow velocities will result, and thus extend the boundary beyond what is currently anticipated.

\section{Conclusions}

Major conclusions of this value-of-information analysis are as follows:

- Characterization activities that help resolve uncertainty regarding the groundwater flow system (i.e., activities that help determine the flux multiplier for the regional model) are particularly important for predicting contaminant transport from Pahute Mesa. Such activities include geochemistry-based investigations and exploratory drilling southwest of Pahute Mesa. Characterization options that include at least one of these activities appear to be relatively effective at reducing uncertainty regarding the maximal extent of contaminant transport.

- Other very effective activities for resolving uncertainty regarding the groundwater flow system include the geophysical activities (gravity, resistivity, and audiomagnetotelluric/ magnetotelluric surveys) and geologic and geophysical modeling.

- Although activities focused on groundwater flow are particularly effective, focusing all efforts in this area will not greatly decrease the overall uncertainty. There is a declining benefit from including more and more of these activities in a characterization program. Most of the uncertainty reduction in an option occurs when only a few activities of this type are included.

- Activities that do not require additional drilling are the most cost-effective.

- Adding activities that focus on other sources of uncertainty to one or more of the strongest activities focused on the groundwater flow system can increase the uncertainty reduction performance of the group. For example, by conducting geochemistry-based investigations plus a limited number of additional balanced and cost-effective activities, it appears possible to obtain a large uncertainty reduction for a total cost under $\$ 5$ million.

- The accuracy of the results is limited by the various approximations and assumptions required to perform the analysis. F'otential sources of error include errors in the input judgments provided by the expert panel, limitations of the regional transport model, and 
errors introduced by the analytic methods used to compute posterior probability distributions. When making real choices, decision makers should interpret the results presented in this report in light of the approximations and limitations of the analysis, and account for factors outside the scope of the analysis. 


\subsection{Introduction}

The purpose of this report is to describe the basis for and present the results of a value of information analysis (VOIA) for the Pahute Mesa underground test area of the Nevada Test Site (NTS), one of several areas of the Nevada Test Site used for underground nuclear testing in the past. The value of information analysis was used to evaluate and compare potential characterization options at the Pahute Mesa underground test area for site remediation purposes.

\subsection{Background}

Background information described here includes a brief synopsis of the Underground Test Area (UGTA) Subproject of the Nevada Test Site Environmental Restoration Project Program. A summary description of the Pahute Mesa Underground test area is also presented to familiarize the reader with the problem at hand.

\subsubsection{Project Description}

Underground nuclear testing was conducted at the NTS, in southern Nevada, until 1992 by the U.S. Department of Energy (DOE) and the U.S. Department of Defense (DoD). These tests resulted in contamination of the ground and groundwater in the vicinity of the underground test areas. To ensure protection of the public and the environment, the U.S. Department of Energy, Nevada Operations Office (DOE/NV) established a long-term program to monitor groundwater for radionuclides, and an environmental restoration program to investigate and remediate the underground test areas.

The Nevada Division of Environmental Protection regulates DOE/NV's corrective actions through the Federal Facility Agreement and Consent Order (FFACO) (1996). Appendix VI of the agreement, "The Corrective Action Strategy," describes the processes that will be used to complete the corrective actions (remediation alternatives), including those in the UGTA. The individual sites covered by the agreement are known as Corrective Action Sites, and they are grouped into Corrective Action Units (CAU) (Figure 1-1). The UGTA consists of six CAUs, generally reflecting the geographic locations and geologic and hydrologic environments of the underground nuclear testing areas. The UGTA CAUs are Frenchman Flat, Central Pahute Mesa, Yucca Flat, Western Pahute Mesa, Climax Mine, and the Rainier Mesa/Shoshone Mountain CAUs. Central Pahute Mesa (CAU No. 101), and Western Pahute Mesa (CAU No. 102) have 


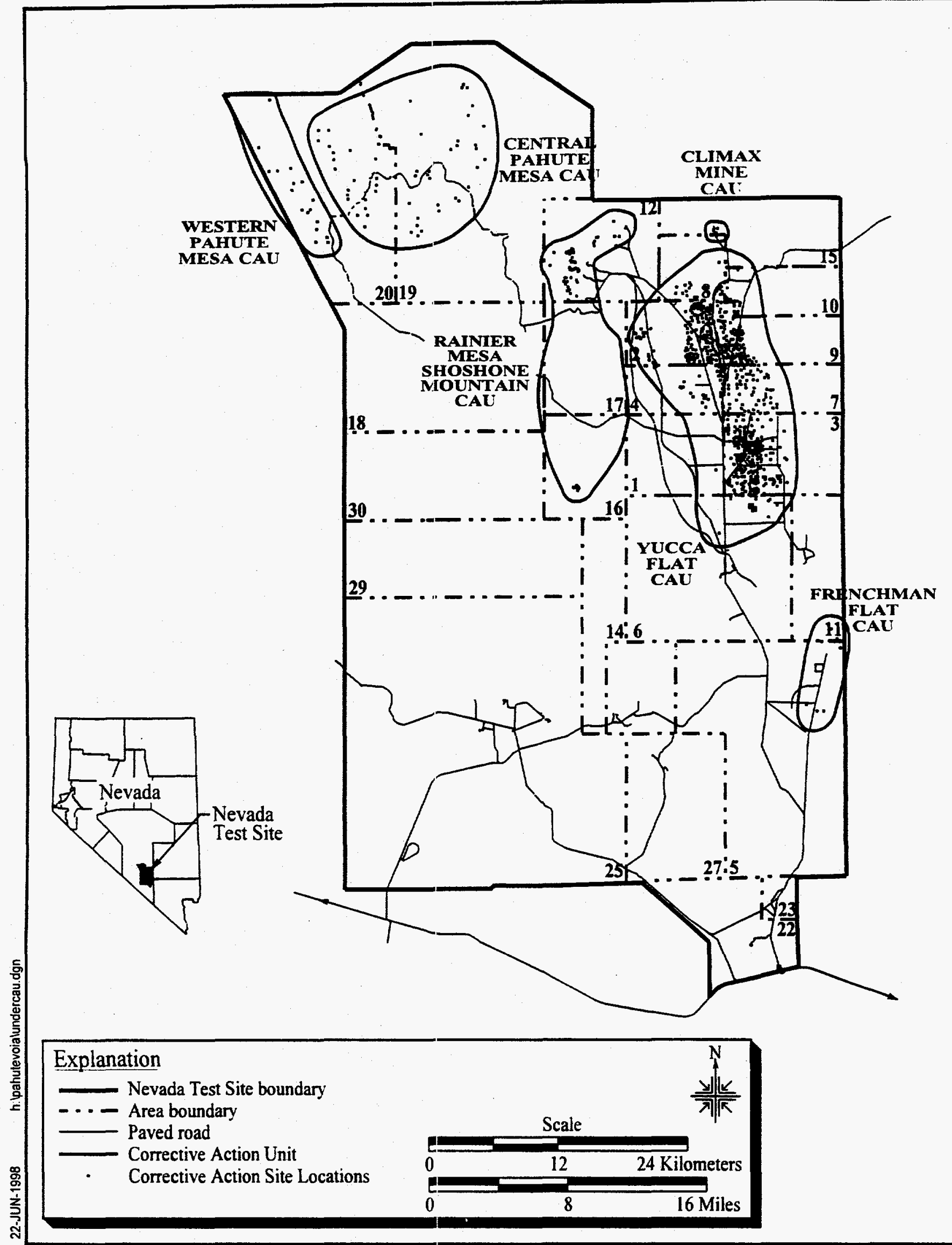

Figure 1-1

Location of Underground Test Area Corrective Action Units and Corrective Action Sites on the Nevada Test Site 
been addressed together in this value of information analysis due to their adjacent locations and common groundwater regime as well as similarities in testing practices, geology, and hydrology.

Major components of the UGTA strategy include a regional evaluation of contaminant transport from the underground test areas and local investigations of contaminant transport from each CAU called corrective action investigations (CAI). The work plan describing the CAI is called a corrective action investigation plan (CAIP). The value of information analysis is performed prior to the preparation of the CAIP to evaluate and compare potential characterization options. The results of the VOIA and the regional model will be used by DOE to determine the appropriate CAI. Following site characterization, a CAU-scale flow and transport model is developed and used to predict the maximum extent of the contamination.

DOE has recently completed the regional evaluation of the underground test areas to determine if any immediate risks to human health and the environment exist (DOE/NV, 1997). During the regional evaluation a groundwater flow and transport model was developed for the region encompassing the NTS. This model was used to simulate contaminant migration using tritium as the contaminant of concern from the underground test locations along pathlines identified by the regional flow model. Although the groundwater flow model was fully three-dimensional, the transport model was one-dimensional to allow for stochastic simulations. The regional model and associated results are summarized in Appendix B. A full description is provided in the regional evaluation report (DOE/NV, 1997). As discussed in Section 2.0, this model has been used to support the value of information analyses for the CAUs, including the Pahute Mesa CAUs. The regional evaluation was also used to identify significant data gaps and provide focus and priorities for the corrective action investigations of the CAUs.

\subsubsection{Site Description}

Pahute Mesa is located in the northwestern part of the NTS. It includes NTS areas 19 and 20 (Figure 1-1). The mesa is an elevated plateau of about 500 square kilometers (200 square miles) at an altitude that ranges from 1,676 meters $(\mathrm{m})(5,500$ feet [ $\mathrm{ft}])$ on the western edge to over $2,134 \mathrm{~m}(7,000 \mathrm{ft})$ above mean sea level throughout the eastern range (Blankennagel and Weir, 1973). The area of interest for the Pahute Mesa underground test area is defined by the potentially affected portion of the groundwater flow system, which includes a region stretching from the northern side of Pahute Mesa south and southwestward to Oasis Valley (Figure 1-2). This area encompasses Black Mountain, Pahute Mesa including Timber Mountain, Oasis Valley, and may also include Yucca Mountain, Fortymile Canyon, and Jackass Flat. Brief descriptions 


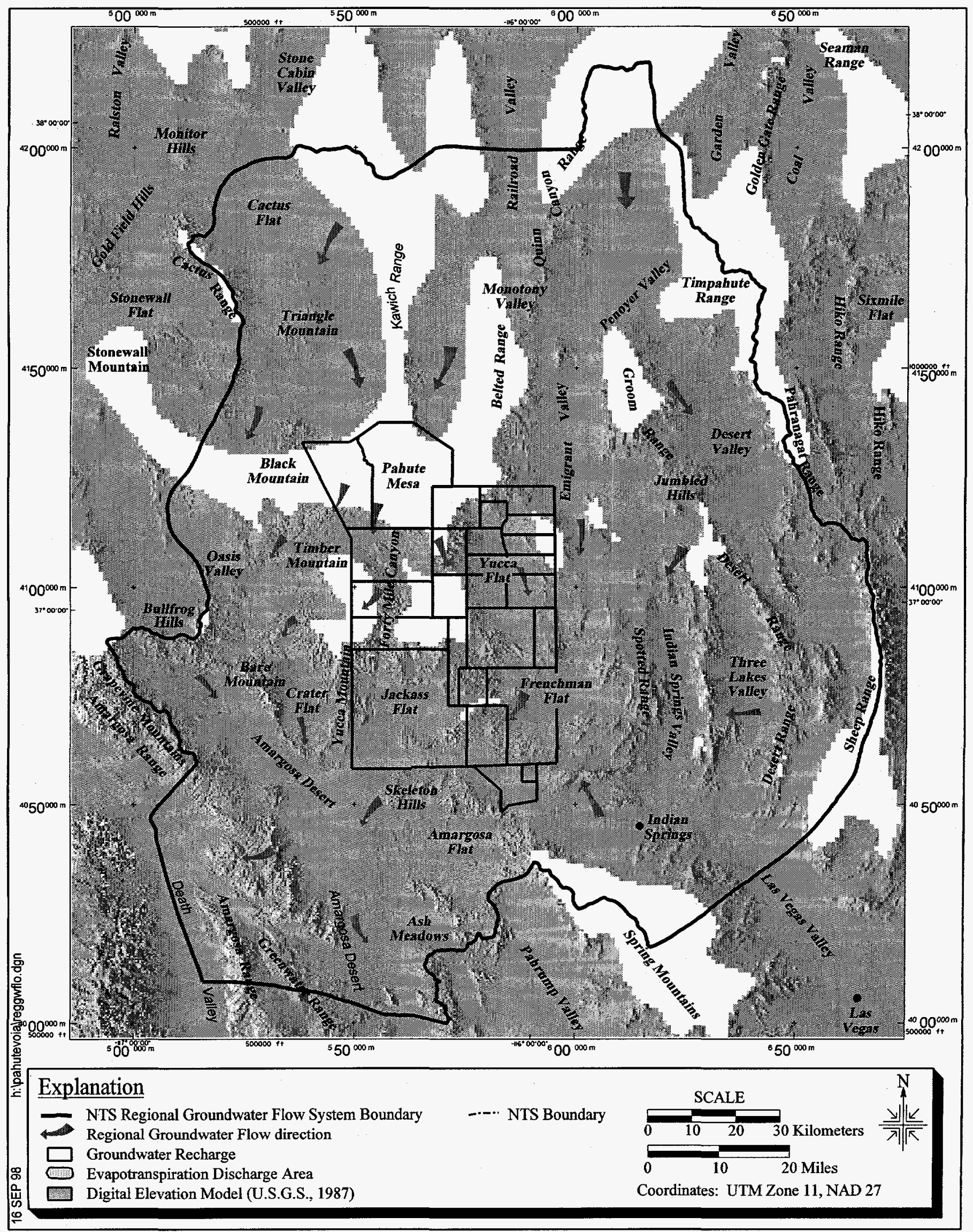

Figure 1-2

Nevada Test Site Regional Groundwater Flow System 
of the hydrogeology, groundwater sources of contamination, contamination extent, and associated uncertainties are presented.

\subsubsection{Hydrogeology}

The Pahute Mesa geology is dominated by volcanic eruptions from nested calderas of the southwestern Nevada volcanic field. All rocks known to underlie Pahute Mesa are volcanic.

The younger caldera complex of hydrologic significance is the Timber Mountain Caldera. This caldron collapse and its filling with volcanic materials affects the southern portion of the Western Pahute Mesa CAU. The Timber Mountain caldera erupted volcanic ash flows that covered much of Pahute Mesa to the north.

On Pahute Mesa the rocks from Timber Mountain Caldera cover an older series of calderas that make up the Silent Canyon caldera complex. This caldera complex consists of at least two nested calderas, the Area 20 caldera and the older Grouse Canyon caldera (Sawyer and Sargent, 1989). Both calderas were formed and subsequently filled by voluminous eruptions of tuff and lava of generally rhyolitic composition. Total thickness of volcanic rocks beneath Pahute Mesa approaches 5 kilometers $(\mathrm{km})(16,000 \mathrm{ft})$ (Ferguson et al., 1994).

The volcanic rocks that control groundwater flow beneath Pahute Mesa can be grouped into four volcanic hydrogeologic units based mainly on lithology and secondary alteration. These units are lava-flow aquifers, welded-tuff aquifers, vitric-tuff aquifers, and tuff confining units.

Groundwater beneath Pahute Mesa generally flows in a southwest direction, primarily through fractures in the lava-flow and tuff aquifers. Zeolitized bedded and nonwelded tuffs act as confining units which inhibit the flow of groundwater. The spatial distribution of permeable aquifers relative to the confining units is not well understood. Thickness variations of aquifers and confining units and their connectivity across faults or caldera boundaries are important hydrostratigraphic relationships that are also not understood.

Groundwater-elevation data in the area of interest are sparse. A number of wells provide waterlevel information in the area of Pahute Mesa and Oasis Valley, but water levels in the area between Pahute Mesa and Oasis Valley are less well defined. However, what data are available suggest that groundwater elevations mimic the topography to some extent. Groundwater elevations are highest beneath northern Pahute Mesa, ranging in elevation from approximately 
1,280 to nearly $1,500 \mathrm{~m}(4,200$ to $4,900 \mathrm{ft})$. Groundwater elevations drop off gradually to the south and west, ranging from 1,100 to $1,250 \mathrm{~m}(3,600$ to $4,100 \mathrm{ft})$ in Oasis Valley. Some groundwater discharges to the surface within the Oasis Valley discharge area (Figure 1-2) in the form of springs.

The following interpretation of groundwater flow is taken from the regional evaluation report (DOE/NV, 1997). Groundwater recharge occurs locally from precipitation and by underflow from areas located to the north of Pahute Mesa. Groundwater then flows south-southwestward to the Oasis Valley and Death Valley discharge areas, through Crater Flat, western Jackass Flat, and the Amargosa Desert. Groundwater from Pahute Mesa flows around both sides of Timber Mountain toward Oasis Valley to the southwest. Several factors are believed to account for the flow around Timber Mountain. Due to its elevation, Timber Mountain receives excess precipitation compared to surrounding areas of lower elevation, which leads to additional groundwater recharge beneath Timber Mountain. In addition, extensive zeolitization and clay alteration of the tuffs within the Timber Mountain caldera causes these volcanic units to behave more like confining units than aquifers. Both of these factors are expected to lead to a mounding of the groundwater levels beneath the mountain, which affects groundwater flowpaths from Pahute Mesa such that they go around both sides of Timber Mountain.

The bulk of the groundwater flow from Pahute Mesa to Oasis Valley occurs around the northwest side of Timber Mountain. However, a significant portion flows south along the east side of Timber Mountain and makes an abrupt turn to the west to converge with the remaining flow at Oasis Valley (Figure 1-2). This westerly turn appears to be caused by a structural high of the Lower Clastic Confining Unit associated with the Belted Range thrust system, which forces the groundwater to turn west at this point and flow towards the discharge areas. Pathlines from nuclear tests on Pahute Mesa generally move downgradient in volcanic aquifers above the Lower Carbonate Aquifer (LCA) before discharging in Oasis Valley.

The east-west striking boundary of the Timber Mountain and Claim Canyon calderas may line up with a geophysically inferred east-west structure (Hot Springs fault) (Grauch et al., 1997). The combination of these structures may inhibit southerly flow of groundwater in the vicinity, and impart an east-west gradient to groundwater flow south of Timber Mountain. 


\subsubsection{Contamination Sources}

Eighty-two of 85 nuclear tests on Pahute Mesa were conducted near or below the water table.

Eighteen of these tests are located in Western Pahute Mesa and 64 are located in Central Pahute Mesa. All the tests were conducted in vertical emplacement holes. It is estimated that 19 megatons of cumulative explosive yield or about two-thirds of the total nuclear yield of all NTS underground nuclear tests are attributable to Pahute Mesa testing (Laczniak et al., 1996). Detonation of the nuclear devices has released various contaminants to the subsurface including radionuclides. Major radionuclides of include tritium, carbon-14, cesium-135/137, iodine-129, plutonium-239/240, strontium-90, and uranium-238 (Adams, 1996a).

\subsubsection{Extent of Contamination}

The lateral and vertical extent of contamination were estimated using tritium transport from the regional model (DOE/NV, 1997). Laterally, the contaminants are currently located within the vicinity of the 82 test cavities and downgradient of the test locations in Western and Central Pahute Mesa. Considering uncertainty, tritium may have transported from a few hundred meters away from an underground test location to as far as Oasis Valley in extreme cases. If only the median case is considered, the maximum predicted downgradient migration of tritium is about $20-25 \mathrm{~km}$ from the edge of the NTS.

The vertical extent of contamination may be as much as $1,130 \mathrm{~m}(3,770 \mathrm{ft})$, extending from the

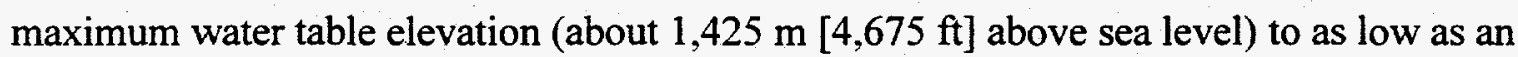
elevation of $275 \mathrm{~m}(900 \mathrm{ft})$.

Also, based on the regional modeling results, the predicted direction of contaminant movement is southwest from Pahute Mesa toward Oasis Valley and to the south to the Amargosa Desert (Figure 1-2). The direction of contaminant movement will vary spatially because of geologic variability and temporally due to changes in the amount and timing of recharge. Uncertain knowledge about the geology covered by basin-fill deposits southwest of Pahute Mesa coupled with parameter uncertainty has led to a range of possible contaminant movement scenarios. 


\subsubsection{Uncertainties}

Major uncertainties associated with the conceptual model of the Pahute Mesa CAUs include the following:

- A lack of subsurface characterization for the area southwest of Pahute Mesa, between the underground test area and the Oasis Valley discharge area

- No knowledge about the role of major faults in groundwater flow

- Lack of subsurface characterization of the Timber Mountain area

- Limited understanding of the contamination sources

- Limited knowledge about the contaminant transport processes and associated parameters

\subsection{Task Objectives, Scope, and Limitations}

The objective of the VOIA task was to evaluate and compare data-collection options for characterizing groundwater transport of contamination associated with Pahute Mesa nuclear testing. More specifically, the task involved developing a model to rank characterization options based on their expected ability to reduce uncertainty over the current and future geographic extent of contamination. As defined in this report, characterization options include both individual characterization activities and groups of characterization activities.

The ultimate goal of the task was to provide information to assist decision makers who must determine what characterization activities, if any, to conduct. Like any model, the model developed for this effort involves approximations and assumptions. When making real choices, decision makers should interpret the results presented in this report in light of the approximations and limitations of the analysis, and account for factors outside the scope of the analysis. Thus, the rankings and other results documented here do not represent the sole or even primary basis for developing a characterization plan. Rather, the results are intended to serve as an aid to the decision-making process.

One important purpose of characterization is to reduce uncertainties regarding the nature and magnitude of risk that complicate and hamper the mitigation and management of that risk. The degree to which alternative characterization activities can be expected to reduce key uncertainties is useful information when deciding what characterization activities to conduct. Cost is also a consideration for choosing characterization activities. The project described by this report 
evaluated and ranked characterization options based on both their estimated uncertaintyreducing potential and their estimated costs. Uncertainty reduction is the only benefit produced by characterization that was considered formally in this analysis. The analysis did not attempt to account for any other benefits of characterization, nor to answer the question of which characterization options produce benefits that justify their costs. However, it did attempt to estimate the relative uncertainty-reducing capability of various options and compare the estimates with corresponding estimates of costs. In this way, the results are intended to help decision makers identify cost-effective strategies for reducing uncertainty.

\subsection{Expert Panel}

The value of information analysis was supported by a panel of experts (Appendix A) chosen by the UGTA TWG. The primary role of the expert panel was to provide technical input for the decision model. The experts selected for this panel are familiar with the Nevada Test Site and are experienced and knowledgeable in the areas of geology, hydrology, geochemistry and statistical analysis. The role of the expert panel members in the VOIA was as follows:

- Assign prior probability distributions describing the current uncertainty over each of the key parameters, based on existing data and best professional judgment.

- Identify potential characterization activities for Pahute Mesa designed to address each of the key parameters.

- Estimate the accuracies of each characterization activity on each key parameter.

- Evaluate results of the analysis and make recommendations at major decision points.

\subsection{Key Assumptions and Definitions}

A critical component of the VOIA was to determine how to quantify and measure the uncertainty-reducing potential of characterization options. The key uncertainty in this analysis is the geographic extent of contamination found to be above regulatory limits. Due to radionuclide transport processes within the groundwater flow system, the area of contamination is expected to initially expand for some period of time, and then, due to radionuclide decay, contract. To delineate the area of contamination, a contaminant boundary has been defined in the FFACO (1996) as follows:

"CAU models utilizing tritium as the source term will be used to establish the contaminant boundary for each CAU. The boundary will be composed of a perimeter boundary and a 
lower hydrostratigraphic unit boundary. The perimeter boundary will define the aggregate maximum extent of contamination transport at or above the concentration of concern for the CAU. The lower hydrostratigraphic unit boundary will define the lowest aquifer unit affected by the contamination. Long-lived radionuclides, besides tritium. will be included to evaluate the relative extent of migration of different radionuclides in the future. If it is predicted that another radionuclide will migrate farther than tritium at concentrations of concern, the contaminant boundary will include that prediction."

Also, as explained in the FFACO (1996), uncertainties will be associated with the contaminant boundary predictions using the CAU models. These uncertainties can be expressed as confidence levels as shown on Figure 1-3 of the FFACO (1996).

"Each contour reflects an increased level of confidence that no contaminants exceeding a given regulatory concentration will ever cross that boundary. As confidence increases, the distance from the $\mathrm{CAU}$ increases. The confidence levels could lead to the development of different contaminant boundaries, depending on the degree of certainty decision makers need to select appropriate controls."

The distance from the CAU (the source of the contamination) to a given contaminant boundary increases as the level of confidence increases (Figure 1-3).

Because of the use of a one-dimensional transport model in this VOIA, the contaminant boundary is reduced to a single point along a flow path (or pathline) originating at a contaminant source, which is generated by using the regional flow model. For the purposes of this VOIA, the regulatory limit (level of contamination) for the boundary was defined as the combined doses from each radionuclide concentration that wrould produce exposures to individuals at levels of 4 millirem per year (mrem/yr) (Adams, 1996a). Simulated radionuclide concentrations were converted to dose equivalents using a drinking water ingestion exposure model (Adams, 1996b). The timeframe selected for this VOIA was 1,000 years. The specifications for the contaminant boundary used in this analysis were developed with reference to various related regulations for radionuclides. This definition of the contaminant boundary was approved for use by the DOE/NV UGTA Subproject Manager after discussions with the State of Nevada and the UGTA TWG. 
Regulators, policy makers, and scientists would like to say with confidence that the contaminant boundary will remain within some specified distance of the CAU. Based on this reasoning, alternative characterization options were evaluated according to their impact on uncertainties relevant to the calculation of the contaminant boundary. As described in Section 2.1.1, probability distributions may be characterized by various statistical measures, including the median (50th fractile), mean, variance, and 95 th fractile (the value which has only a 5 percent probability of being exceeded) (Figure 1-4.). Statistical measures computed from probability distributions were used to quantify the uncertainty-reducing potential of characterization options. Specifically, characterization activities and groups of characterization activities were evaluated and ranked using measures intended to reflect three distinct concepts of uncertainty reduction:

1. Ability to reduce uncertainty of key geohydrologic parameters (parameters to which the calculation of contaminant boundary is most sensitive), as characterized by a reduction in the standard deviation to the parameter value.

2. Ability to reduce uncertainty in the location of the contaminant boundary, represented by the reduction in the average distance to the contaminant boundary.

3. Ability to reduce uncertainty in the upper bound $\left(95^{\text {th }}\right.$ fractile) estimate of the distance to the contaminant boundary.

Section 3.6 describes in detail how each of these concepts of uncertainty reduction was implemented.

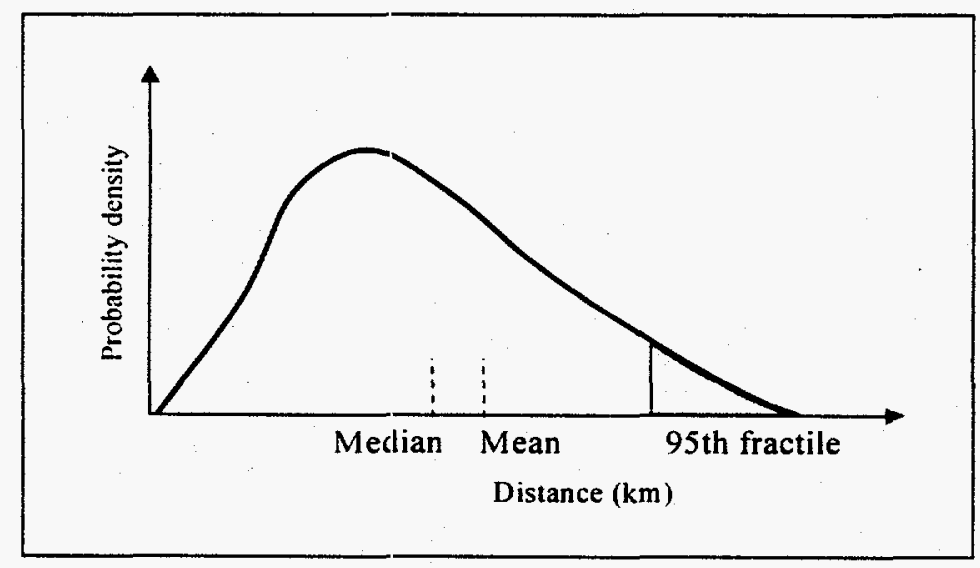

Figure 1-4

Illustrative Probability Density Function

Describing Uncertainty of Contaminant

Boundary 
Many assumptions are required to quantify the concepts of uncertainty reduction. The source of the numerous input judgments for the analysis was the expert panel (see Appendix A). Among other inputs, the expert panel defined the activities and groups of activities for evaluation, the estimates of the levels of current uncertainties, and the estimates necessary to compute the ability of activities to reduce current uncertainties.

The analytical techniques employed for the analysis are complex, and a number of simplifying assumptions were made. Some assumptions were needed to reduce computational complexity and to limit the number of input judgments. Two such assumptions are most significant. First, it was assumed that the uncertainties that would be impacted by conducting any activity can be identified. The expert panel was asked to identify the parameters whose uncertainties would be most impacted by conducting each individual characterization activity. The panel concluded that individual characterization activities would primarily resolve uncertainty on one or at most two parameters (out of the five parameters identified as most critical to contaminant boundary uncertainty). The analysis disregarded any ability that activities may have to reduce uncertainty in areas unrelated to the parameter(s) identified by the expert panel. Furthermore, the analysis assumed that the ability of a group of activities to resolve uncertainty on a specified parameter depends only on the activities contained in the group that address that parameter. In other words, any synergisms by which uncertainty reductions in one area might facilitate uncertainty reduction in another area were not considered. The implication of these assumptions is that the analysis may have underestimated the uncertainty-reducing potential of some characterization options.

\subsection{Report Organization}

This report is divided into six sections and seven appendices. Brief descriptions of each section and appendix are provided here.

- Section 1.0 is the introduction.

- Section 2.0 describes the technical approach, including the theory behind the value-ofinformation analysis, the contaminant transport model used to simulate the migration of radionuclides in groundwater, and the analysis process used to complete the VOIA.

- Section 3.0 describes how the analysis of the characterization options was done. This section includes descriptions of sensitive flow and transport parameters, the characterization options and their costs, the assessment of probability distributions, and the calculation of posterior distributions for the sensitive variables. Descriptions of the measures of uncertainty reduction are provided. 
- Section 4.0 describes the results of the analysis of the characterization options for each of the selected measures of uncertainty reduction described in Section 3.0. It provides a report on the associated uncertainties.

- Section 5.0 presents the major conclusions derived from the VOIA.

- Section 6.0 is a list of the references cited.

- Appendix A contains a list of the expert panel members and their qualifications.

- Appendix B provides a summary description of the regional groundwater flow and transport model, and its results.

- Appendix $\mathrm{C}$ provides descriptions and estimated costs for the individual (and groups) characterization activities identified for the Pahute Mesa investigation.

- Appendix D includes descriptions of the prior probability distributions of the sensitive parameters elicited from the expert panel. A description of the elicitation process is provided, followed by the details associated with each sensitive parameter.

- Appendix E provides the details on the assessment of distributions describing the accuracy of characterization options.

- Appendix F provides a description of Bayesian updating using prior and posterior probability distributions.

- Appendix $G$ describes results of preliminary transport simulations, and the procedure and results of the transport simulations for individual characterization activities, and activity subgroups and groups. 


\subsection{Technical Approach}

This section describes both the theory underlying the approach and the process by which the theory was applied.

\subsection{Theory}

The analyses conducted for this project are based on well-established theory (e.g., Clemen, 1990; Fisz, 1963) for analyzing uncertainty. This section provides introductory descriptions of some aspects of the theory. Those familiar with the theory of uncertainty analysis may wish to disregard this section.

\subsubsection{Methods for Quantifying Uncertainty}

According to probability theory, an uncertain quantity may be described by a probability distribution. The three most common ways of displaying a probability distribution are as a probability density function (PDF), cumulative distribution function (CDF), and box plot.

Figure 1-4 displays a probability distribution in the form of a PDF, the form most commonly used. With the PDF, the height of the curve at any given point is proportional to the relative likelihood of the uncertain quantity having that value. Many standard statistical measures can be conveniently related to the PDF. The $95^{\text {th }}$ fractile is that value on the $\mathrm{x}$-axis such that 95 percent of the area under the curve lies to its left and the remaining 5 percent lies to its right. The median is the point along the horizontal axis at which a vertical line would bisect the area under the PDF. The median of the distribution is the equal probability value (the odds are 50:50) that the uncertainty will fall above or below the median. The expected value or mean $(\mu)$ is the integral (sum) of all values ( $v$ ) weighted by their probabilities. Mathematically, if $f(v)$ is the probability density function for a continuous distribution:

$$
\mu=\int_{-\infty}^{\infty} v f(v) d v
$$

Figure 2-1 illustrates a CDF. The height of a CDF curve denotes the probability that the actual value of the uncertainty quantity will be less than or equal to any value along the horizontal axis. 


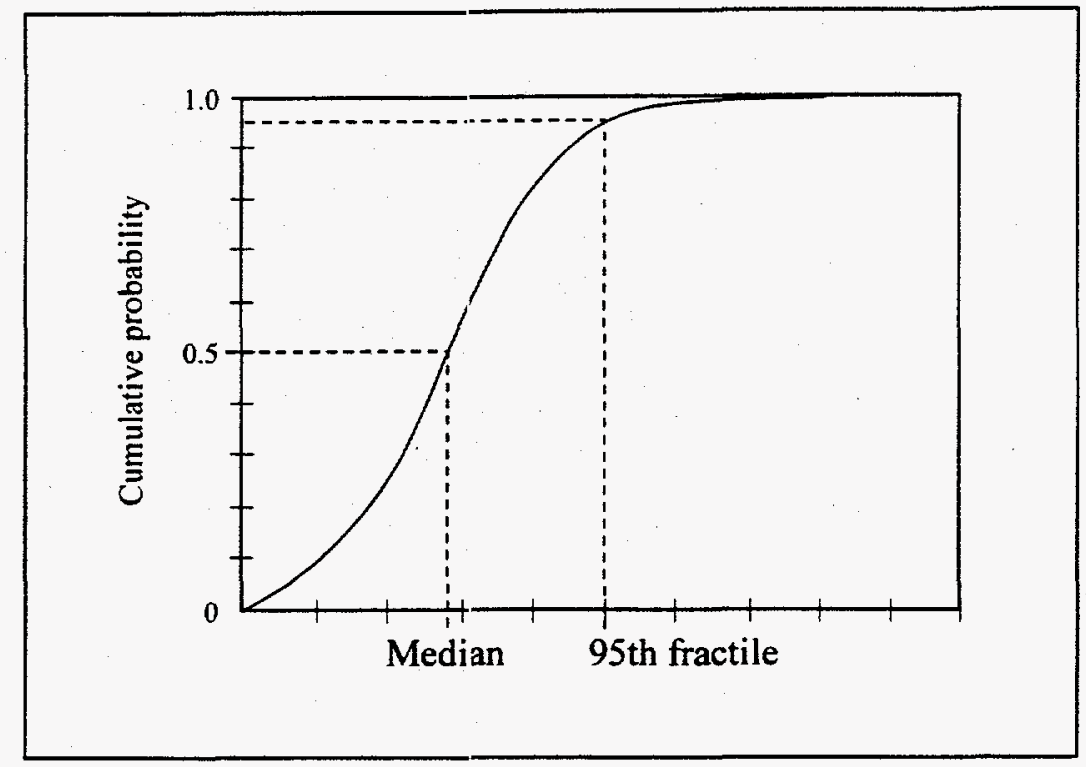

Figure 2-1

Illustrative Cumulative Distribution Function

The PDF and CDF are related; the PDF is the derivative of the CDF, and the CDF is the integral of the PDF. Thus, the height of the PDF at any point is proportional to the slope of the CDF at that point. The CDF displays the distribution's fractiles. For example, the $95^{\text {th }}$ fractile is the point along the horizontal axis where the height of the CDF curve reaches 0.95 cumulative probability. The median is that point along the horizontal axis where the CDF curve reaches 0.5 cumulative probability.

Whereas CDFs and PDFs display the complete probability distribution, box plots are more simple representations that display only confidence bands constructed from specified fractiles of the distribution. For example, the box plot in Figure 2-2 shows a horizontal line from the $5^{\text {th }}$ to $95^{\text {th }}$ fractile and a vertical line at the median.

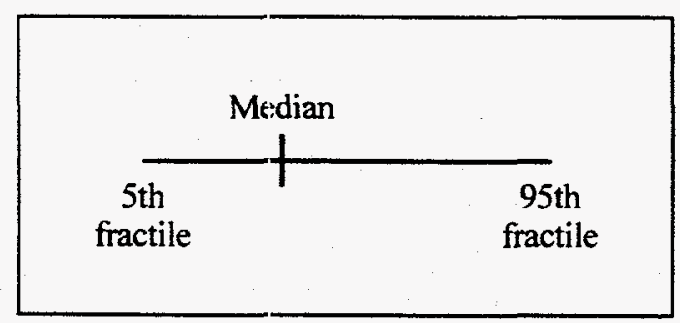

Figure 2-2

Box Plot Representation of a Probability Distribution 
There is no single, universal measure of the magnitude of the uncertainty represented by a probability distribution. Among the more common measures used for this purpose are average deviation from the mean, standard deviation, and variance. The average deviation from the mean is computed by subtracting the mean from each possible value (v), taking the absolute value (i.e., ignoring negative signs), and integrating over the probability distribution. If $f(v)$ is the probability density function and $\mu$ is its mean, the formula is:

$$
\text { average deviation from the mean }=\int_{-\infty}^{\infty}|v-\mu| f(v) d v
$$

The variance, $\sigma^{2}$, is computed by subtracting the mean from each possible value, squaring the result, and integrating:

$$
\text { variance }=\sigma^{2}=\int_{-\infty}^{\infty}(v-\mu)^{2} f(v) d v
$$

The standard deviation is the square root of the variance:

$$
\text { Standard deviation }=\sigma
$$

For a symmetric, bell-shaped PDF, the mean plus or minus one standard deviation contains roughly 66 percent of the area under the PDF.

Another common measure of uncertainty is the difference between the $95^{\text {th }}$ and $5^{\text {th }}$ fractiles of the distribution. In the case of the type of box plot shown in Figure 2-2, this difference is just the length of the line.

Several statistical measures of uncertainty were used, including the average deviation, the variance, and the $95^{\text {th }}$ fractile (see Section 3.6). In general, the amount of uncertainty reduction is determined by comparing the value of the uncertainty measure before conducting the characterization option with the expected value of the uncertainty measure after the information provided has been received and used to update probability distributions describing uncertainty. 


\subsubsection{Methods for Estimating and Analyzing Uncertainty}

While experts agree that probability is the preferred means for quantifying uncertainty, there is less agreement on methods for obtaining probabilities and on what sources of uncertainty ought to be quantified. The most common apprcach for generating probability distributions on uncertainties critical for risk management involves constructing a model that identifies the relationships among variables that affect the uncertainty of interest. In this VOIA, the uncertainty of interest is the location of the contaminant boundary, and the model is a contaminant transport model. Uncertainty analysis is implemented using the Monte Carlo method.

For the purpose of this VOIA, the one-dimensional contaminant transport component of the regional model (Appendix B) was applied. The groundwater fluxes and flow paths were assumed to be as previously simulated by the three-dimensional regional groundwater flow model. The pathline originating at TYBO, a single underground nuclear test and ending at the Oasis Valley discharge area (Figure 2-3), was selected for radionuclide transport simulations. The TYBO test was selected because results of the regional model indicate that contaminants originating from this nuclear test have a higher potential to reach public lands than from other nuclear test cavities (Appendix B). Therefore, this pathline represents the worst-case scenario in terms of radionuclide transport to the nearest potential receptor. The TYBO pathline used for the transport model originates and continues downgradient for its entire length in the Timber Mountain Aquifer. At the discharge end the pathline would briefly traverse alluvium, but this detail was not included since it was ill-defined and considered irrelevant to the objective.

The transport model was set up to simulate the movement of five of the seven radionuclides of concern identified earlier: tritium, iodine-129, uranium-238, plutonium-239/240, carbon-14. Cesium-137 and strontium- 90 were eliminated from further consideration because they are expected to decay to concentrations that will produce less than $4 \mathrm{mrem} / \mathrm{yr}$ in less than 200 years. This is due to their relatively short half-lives, low starting concentrations, and ability to sorb to the rock material.

The transport model consists of functional relationships between the contaminants (the five radionuclides of concern in this case), the various factors that affect their movement in groundwater, and the location of the boundary over time. Uncertainty over the output of the model (location of the contaminant boundary) is quantified by assessing uncertainty on the model's various input parameters, and then using the model to translate input uncertainties into 


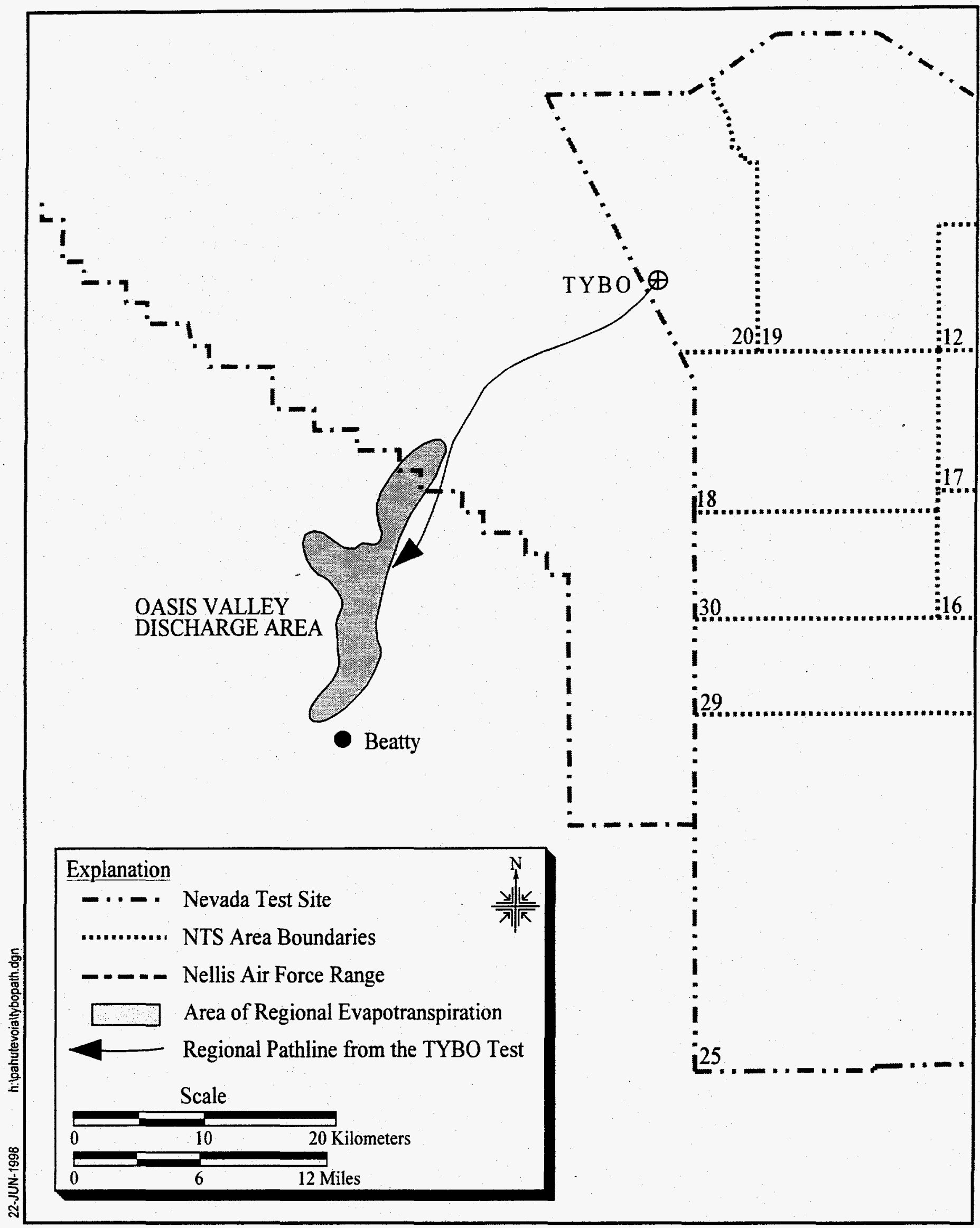

Figure 2-3

Pathline of Groundwater Flow from TYBO 
the uncertainties associated with the model output. Next, model output uncertainty ranges are predicted. The problem of characterizing uncertainty then becomes how to characterize the input variables and propagate these uncertainties through the model. The approach assumes that the processes associated with contaminant transport are sufficiently well understood and that functional relationships among the important variables can be presumed, but that the values of some of the variables are not precisely known.

An efficient approach for integrating and propagating probability distributions through a model is the Monte Carlo method. As explained more fully in Section 3.0 and Appendix G, Monte Carlo analysis was used to compute probability distributions for the contaminant boundary under various assumptions regarding the probability distributions for its key inputs. Monte Carlo simulation involved computing the output of the contaminant transport model for many sets of combinations of inputs. The combinations of input values were obtained by random sampling from the probability distributions assigned to the input variables. The resulting distribution of outputs was then interpreted as an approximation of the probability distribution describing uncertainty over the contaminant boundary.

\subsubsection{Methods for Specifying Probability Distributions on Input Variables}

The predominant view of decision making under uncertainty is that probability numbers are subjective and represent an individual's state of knowledge or degree of belief about a quantity, and that this belief depends on the information, experience, and theories of the individuals who assign the probability numbers. This view is known as the subjective, or Bayesian view of probability, as it is associated with the 18 th century mathematician Reverend Thomas Bayes (Bayes, 1958). Although they are subjective, Bayesian probabilities are not arbitrary. Subjective probabilities must satisfy the same basic axioms as other concepts of probability. Probability numbers must lie between 0 and 1 . If two events are disjoint, the probability that either will occur is the sum of the probability that the first will occur plus the probability that the second will occur. Also, if a scientist says he believes the probability of some event is 25 percent, for example, it means that he is as confident in the statement as he is in randomly drawing a red ball from an urn containing three white balls and one red ball. Although Bayesian probabilities are "subjective" in the sense that they describe a state of knowledge, they are "objective" (that is, independent of the observer) in the important sense that two "idealized" individuals faced with the same total background of knowledge would assign the same probabilities. 
Under the Bayesian perspective, estimates of uncertain quantities are elicited from experts. Bayesians believe that individuals with the greatest knowledge and familiarity with the uncertainty in question are the logical sources of judgments regarding that uncertainty. Research has identified various biases that can distort probabilities provided by experts. Consequently, probability-encoding methods have been developed for countering such biases and improving the quality of probabilities elicited from experts (Spetzler and Stael von Holstein, 1975;

Merkhofer, 1987). Probability encoding is typically conducted in a process wherein a trained interviewer elicits probability judgments from a person using a systematic series of steps.

\subsubsection{Methods for Estimating Changes in Uncertainties}

A major advantage of the Bayesian view of probability is the ability to quantify the effect of obtaining new information on uncertainty (Apostolakis, 1981). The approach assumes that the unknown "true" value of an uncertain variable can be described by a "prior" probability distribution. The prior probability distribution is elicited from experts and is based on the current state of information and knowledge about that variable, as discussed above. When new information about the unknown value is obtained, it should cause the experts to alter or "update" the prior distributions. Bayes' theorem provides a method for determining what the updated or "posterior" distribution should be. One way to express Bayes' theorem is as follows (Fisz, 1963). Let $\mathrm{p}(\mathrm{H})$ be the prior probability of some hypothesis $H$ and $\mathrm{p}(\mathrm{D} \mid \mathrm{H})$ be the probability that datum $\mathrm{D}$ will be observed given that $\mathrm{H}$ is true. Bayes' theorem states that the posterior probability that $\mathrm{H}$ is true given that $\mathrm{D}$ has been observed is:

$$
p(H \mid D)=\frac{p(D \mid H) p(H)}{p(D)}
$$

The probability $\mathrm{p}(\mathrm{D} \mid \mathrm{H})$ is often called the "likelihood," since it specifies the likelihood of obtaining the data given the hypothesis. Thus, Bayes' theorem states that the posterior probability is proportional to the prior probability and the likelihood of the data, so estimating the posterior distribution requires estimates of both the prior and the likelihood. Note that if there are several different hypotheses and different sets of data that might result from a test, then likelihood must be specified for each combination (the specification is called the likelihood function).

In the case of the tests associated with characterization activities, there is typically a continuum of possible test outcomes. One way to apply Bayes' theorem in such circumstances is to approximate the continuum by a finite number of discrete possibilities. For example, suppose a 
characterization activity provides information relevant to estimating the large-scale, average effective porosity, a parameter needed for the contaminant transport model. The appropriate parameter value is uncertain and a prior probability distribution for the uncertainty would indicate the relative likelihood of values within a range of possibilities. If tests are conducted to clarify effective porosity, the tests might report estimated parameter values near the mean of the current (prior) probability distribution, or, they might suggest that values either lower or higher than the current mean are more likely. Figure 2-4 indicates how such situations can be addressed using Bayes' theorem. The prior probability distribution is discretized and the resulting possibilities are interpreted as hypotheses for the actual value of the parameter. The continuum of possible test outcomes is also discretized into several possibilities, ranging from values indicating parameter values much lower than expected to values indicating parameter values much higher than expected. The possible test outcomes are the data potentially produced by the characterization activities, and their likelihoods depend on hypotheses for the actual value of the parameter. Bayes' theorem can be applied to convert the prior probabilities into posterior probabilities, which depend on the possible outcomes of the test. Although the resulting posterior distributions are discrete, continuous probability distributions can be selected to fit the discrete posterior probabilities and thereby make them continuous. Figure 2-4 illustrates how the resulting posterior distributions for the parameter might relate to the prior distribution.

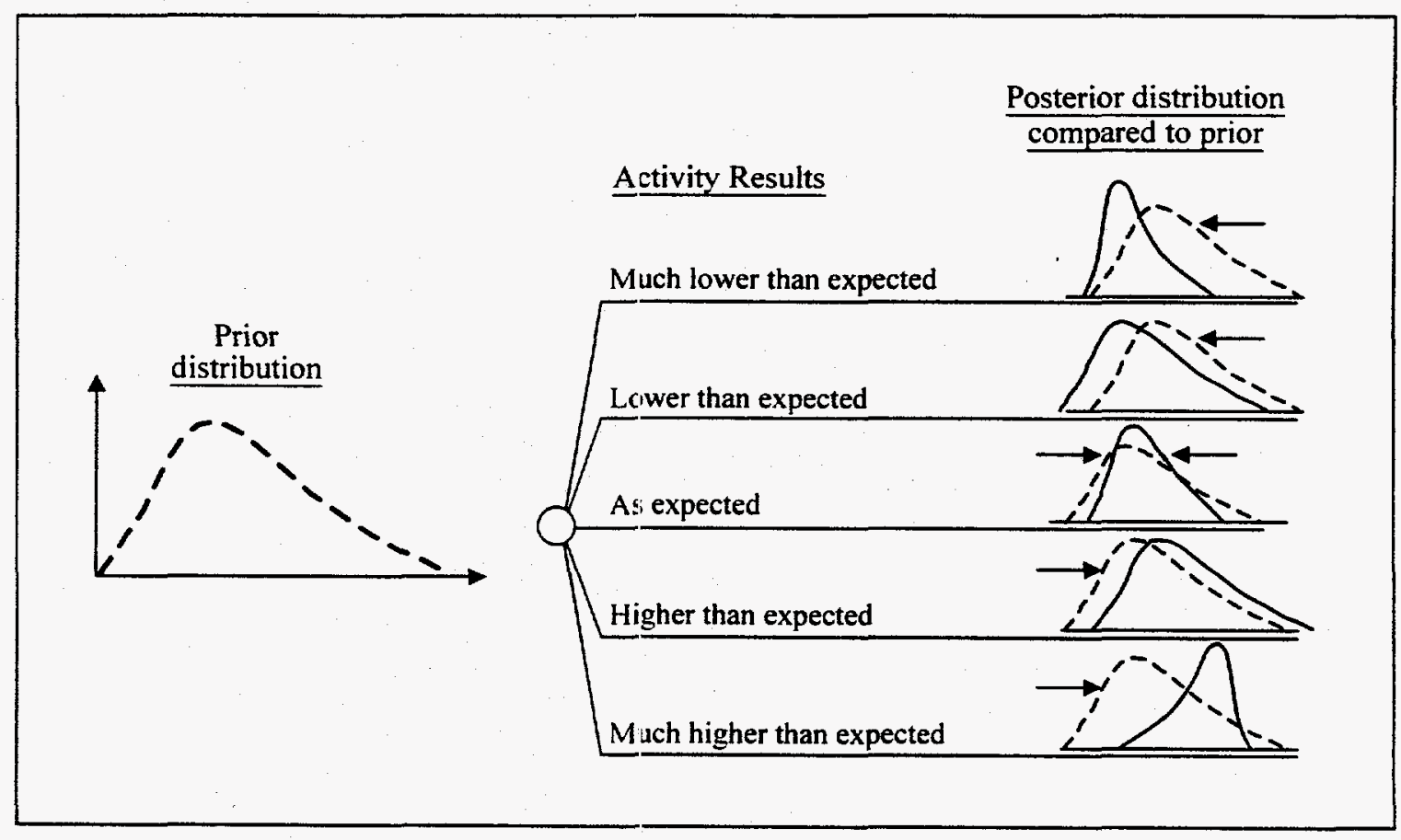

Figure 2-4

Results of Applying Bayes' Theorem 


\subsubsection{Relationship Between Bayesian Analysis and Value of Information Analysis}

Because Bayesian analysis allows the uncertainty-reducing ability of information-collection options to be quantified, it provides a means for estimating the value of the information to be provided by such options. However, Bayesian analysis by itself does not allow the value of uncertainty reductions to be expressed in dollar terms. Consequently, at best, Bayesian analysis provides a relative, not absolute, measure for the value of information. A theory does exist for developing an absolute, dollar measure of the value of information (Demski, 1972). However, this form of value of information analysis requires modeling the decisions and values that might be impacted by the information that is collected. For this application, decisions that might change depending on the results of characterization include DOE/NV's proposed remediation (risk management) alternatives and the decisions of regulators to accept or reject the conclusions and proposals from DOE/NV. The values that are potentially impacted by these decisions include the health and safety of future generations and the desire to not unreasonably restrict community use of public lands. Such issues were not explicitly addressed in this analysis. To do so would have required a more complex approach with a much broader scope which would have considered many speculative assumptions that cannot yet be reliably addressed. Because the approach used here did not explicitly address such issues, it is not a VOIA in the strict sense of decision analytic value-of-information literature. Nevertheless, the more limited definition of value of information employed here was viewed as sufficient to provide a useful tool for decision makers.

\subsection{Analysis Process}

The evaluation was conducted as a two-phased effort. Phase 1 focused on individual activities and was intended to support the selection of potentially attractive activity groupings. Phase 2 evaluated groups of activities and accounted for interdependencies among those activities.

Both phases were conducted using the same basic logic. The contaminant boundary location can be estimated using the regional contaminant transport model. Uncertainty over the location of the contaminant boundary can be quantified by estimating the uncertainty in the key input parameters for the transport model. If the results of a characterization activity alter the probability distributions for any of the key input parameters, then the transport model can be used to infer the resulting change in the uncertainty over its main output, the contaminant boundary. 
Figure 2-5 summarizes the major steps used to apply this logic. The first step was to identify the parameters of the transport model to which the computed contaminant boundary is most sensitive. Next, a prior probability distribution was developed for each sensitive parameter. Candidate characterization activities (Phase 1) and potentially attractive groupings of activities (Phase 2) were identified. Each activity and group of activities was then evaluated to assess its accuracy for estimating the sensitive parameters. Specifically, likelihood functions were developed for each activity and group of activities for use in a Bayesian analysis. The prior probability distributions and likelihood functions were combined in the Bayesian analysis to obtain posterior distributions for the sensitive parameters. The contaminant transport model was then used to translate changes in the probability distributions for the sensitive parameters into the changes that they imply over the uncertainty in the maximal extent of the contaminant boundary. Finally, the posterior distributions were compared with the prior distributions to compute the three measures defined to quantify uncertainty reduction: reduction in uncertainty over key geohydrologic parameters, reduction in uncertainty over the maximal extent of the contaminant boundary, and reduction in uncertainty over the upper bound $\left(95^{\text {th }}\right.$ fractile) estimate of the maximal extent of the contaminant boundary. The details and results of each step are described in Sections 3.0 and 4.0 of this report.

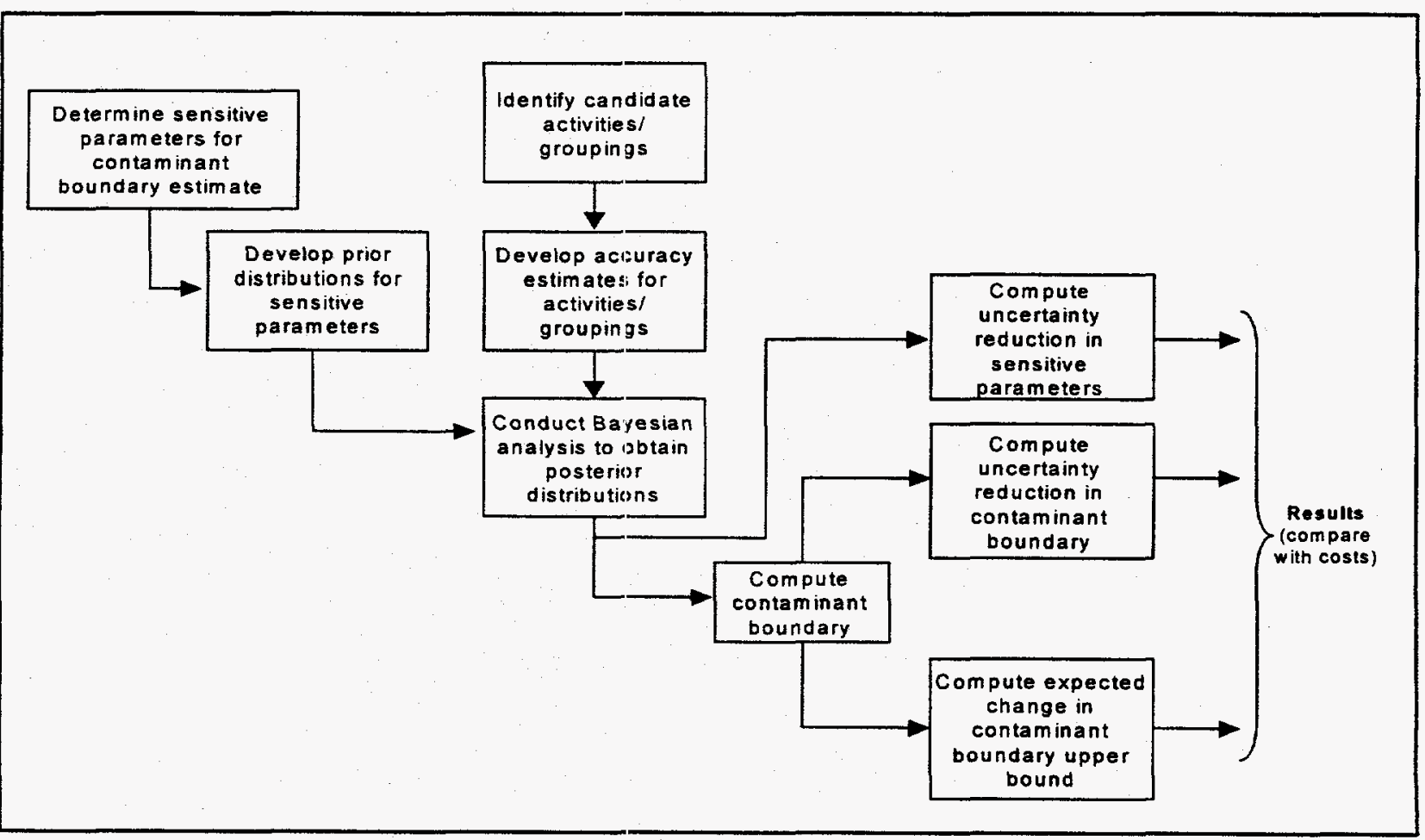

Figure 2-5

Overview of the Analysis Approach 


\subsection{Analysis}

\subsection{Sensitive Parameters}

Sensitive parameters are defined as those that, when varied across their range of uncertainty while holding other variables constant, produce the greatest change in the estimate of the contaminant boundary. During the sensitivity analysis performed on the regional transport model results, the simulated tritium concentrations were found to be sensitive to several parameters (Appendix B). To simplify the VOIA, the number of important parameters governing the transport of radionuclides in groundwater was reduced to five. The five selected parameters are source term, effective porosity, diffusion parameter (a combination of matrix porosity, block width, and diffusion coefficient), flux multiplier, and distribution coefficient $\left(\mathrm{K}_{\mathrm{d}}\right)$. The first four parameters were selected on the basis of the previous sensitivity analysis and the fifth parameter, $\mathrm{K}_{\mathrm{d}}$, was added because sorbing radionuclides were included in the analysis (Appendix B). Additional information about these parameters is provided in Table 3-1.

\subsection{Alternative Characterization Options}

The expert panel held a workshop to identify candidate characterization activities. Panel members initially identified 27 potential activities and then refined and screened those down to 19 possibilities. To further screen the options, panel members were asked to group the activities into viable combinations. This step encouraged participants to identify activities that tended to produce redundant information or that for other reasons would not simultaneously be included within a cost-effective characterization. Five of the 19 candidate activities were not included in any of the potential groups. These five activities were removed from consideration, leaving 14 activities for detailed evaluation. The 14 activities were further refined, and descriptions and cost estimates were developed for each. Additional discussions and activity descriptions are provided in Appendix C. Table 3-2 summarizes the selected activities.

The expert panel was next asked to consider which of the sensitive parameters each activity addressed most effectively. As indicated in Table 3-2, in every case but one (Activity 6 ) the individual activities were concluded to provide information that primarily affects only a single parameter. Table 3-3 also indicates the parameter(s) each activity was estimated to impact. 
Table 3-1

Sensitive Parameters for Computing the Contaminant Boundary

\begin{tabular}{|c|c|c|}
\hline Parameter & Description & Importance \\
\hline Diffusion ( $\alpha$ ) & $\begin{array}{l}\text { The diffusion mass transfer } \\
\text { coefficient }(a) \text { controls, in part, } \\
\text { the movement of radionuclides } \\
\text { between the fractures and the } \\
\text { rock matrix. It combines } \\
\text { diffusion, matrix and fracture } \\
\text { characteristics }\end{array}$ & $\begin{array}{l}\text { In saturated fractured rocks, most movement of groundwater and } \\
\text { radionuclides occurs in the fractures. However, a fraction of the } \\
\text { radionuclides will move into the rock's pore spaces, or diffuse in the } \\
\text { rock matrix, and move back out into the fractures at a later time. This } \\
\text { process reduces the concentration within the fractures and slows down } \\
\text { the rate of radionuclide migration. Matrix diffusion is quantified by the } \\
\text { diffusion parameter. The larger the diffusion parameter, the smaller the } \\
\text { migration distance. }\end{array}$ \\
\hline Source term & $\begin{array}{l}\text { As used here, this term refers to } \\
\text { the concentration of } \\
\text { radionuclides within the nuclear } \\
\text { shot cavity and chimney region } \\
\text { that is available for groundwater } \\
\text { transport. }\end{array}$ & $\begin{array}{l}\text { Some of the radionuclides are contained deep within the glass that } \\
\text { cooled from the melted rock following the detonation and are not readily } \\
\text { available for transport. Others may be sorbed or held onto the surfaces } \\
\text { of the glass or rock inside the cavity or chimney. The rate at which a } \\
\text { radionuclide enters the groundwater either by leaching out of the near } \\
\text { surface of the glass or desorbing from the cavity materials controls the } \\
\text { concentration of that radionuclide in the groundwater. A rapid release } \\
\text { rate produces a short-term but high concentration source term. A slow } \\
\text { release rate produces a long-term contamination source at a smaller } \\
\text { concentration. }\end{array}$ \\
\hline Effective porosity & $\begin{array}{l}\text { Average large-scale effective } \\
\text { porosity along the flow path }\end{array}$ & $\begin{array}{l}\text { In fractured rocks, not all fractures may be connected such that } \\
\text { groundwater flow through the area actually moves through all or all } \\
\text { parts of the fractures. Some fractures or parts of fractures, or networks } \\
\text { of fractures may only be connected over the space of inches or feet, } \\
\text { and the water contained within these "dead" networks is essentially } \\
\text { stagnant. Effective porosity is a measure of the interconnected network } \\
\text { of fractures along the flow path where groundwater predominantly flows } \\
\text { and contaminant migration occurs. The effective porosity is a major } \\
\text { factor determining the speed with which groundwater moves in an } \\
\text { aquifer. For a given flux, the smaller the effective porosity, the faster } \\
\text { groundwater will move through an aquifer. }\end{array}$ \\
\hline $\begin{array}{l}\text { Distribution } \\
\text { coefficient }\end{array}$ & $\begin{array}{l}\text { The large-scale distribution } \\
\text { coefficient for each of the } \\
\text { radionuclides. }\end{array}$ & $\begin{array}{l}\text { Some radionuclides have a chemical tendency to attach to rock matrix } \\
\text { material for a period of time. This process, called sorption, causes } \\
\text { radionuclides to move slower than the groundwater. Radionuclides } \\
\text { may also attach themselves to very small particles of clay or iron } \\
\text { minerals calied colloids and travel with the groundwater. Depending on } \\
\text { a number of factors related to their size, the nature of the aquifer } \\
\text { materials, and the chemistry of both the radionuclide and the } \\
\text { groundwater, colloids may either slow down or speed up radionuclide } \\
\text { transport. The distribution coefficient }\left(K_{t}\right) \text { is a value that describes how } \\
\text { likely the radionuclide is to be sorbed. }\end{array}$ \\
\hline Flux multiplier & $\begin{array}{l}\text { Multiplicative factor applied to } \\
\text { base groundwater flux } \\
\text { simulated by the regional flow } \\
\text { model to account for geologic } \\
\text { and flow model uncertainty. }\end{array}$ & $\begin{array}{l}\text { The amount of groundwater moving through an area is represented by } \\
\text { the groundwater flux. Flux is currently the most important parameter in } \\
\text { the prediction of potential contaminant migration. Uncertainty in the } \\
\text { flux, resulting from lack of knowledge about the geology, aquifer } \\
\text { parameters, or recharge is accounted for in the flux multiplier. }\end{array}$ \\
\hline
\end{tabular}


Table 3-2

Activities Evaluated in Phase 1

\begin{tabular}{|c|c|c|c|}
\hline No. & Activity/Description & $\begin{array}{c}\text { Primary } \\
\text { Parameter Impacted }\end{array}$ & $\begin{array}{l}\text { Estimated } \\
\text { Activity Cost } \\
\text { (\$M) }\end{array}$ \\
\hline$\overline{\mathrm{A} 1}$ & $\begin{array}{l}\text { Fault-Zone Characterization } \\
\text { Drill four boreholes and install four separate welis at one } \\
\text { location at a major fault }\end{array}$ & Flux & 10.22 \\
\hline$A 2$ & $\begin{array}{l}\text { Timber Mountain Investigation } \\
\text { Drill and install one well on Timber Mountain }\end{array}$ & Flux & 2.94 \\
\hline A3 & $\begin{array}{l}\text { Exploratory Drilling Southwest of Pahute Mesa } \\
\text { Drill and install wells at five locations in study area }\end{array}$ & Flux & 17.16 \\
\hline A4 & $\begin{array}{l}\text { Test-Cavity Sampling } \\
\text { Reenter existing potshot holes and drill into cavities at Bullion } \\
\text { and Cheshire; drill new hole at Benham }\end{array}$ & Source Term & 6.69 \\
\hline A5 & $\begin{array}{l}\text { Injection-Withdrawal Tracer Testing } \\
\text { Conduct single well huff-puff multiple-tracer tests at three } \\
\text { locations; requires both well workover and a new well }\end{array}$ & Diffusion (alpha) & 6.45 \\
\hline$A 6$ & $\begin{array}{l}\text { Bullion-Type Tracer Testing } \\
\text { Conduct three-well forced-gradient multiple-tracer tests at three } \\
\text { locations; requires installation of nine wells }\end{array}$ & $\begin{array}{l}\text { Diffusion (alpha) }(6 a)^{a} \\
\text { Effective Porosity }(6 b)^{a}\end{array}$ & 24.94 \\
\hline A7 & $\begin{array}{l}\text { Geochemistry-Based Investigation } \\
\text { Sample } 16 \text { existing wells in the Oasis Valley subbasin and } \\
\text { analyze }\end{array}$ & Flux & 1.13 \\
\hline A8 & $\begin{array}{l}\text { 2-D Seismic Surveys } \\
\text { Conduct 2-D seismic surveys }\end{array}$ & Flux & 0.73 \\
\hline$A 9$ & $\begin{array}{l}\text { Geophysical Surveys } \\
\text { Conduct audiomagnetotelluric/magnetotelluric (AMTMM) } \\
\text { surveys, direct current resistivity, and gravity surveys }\end{array}$ & Flux & 0.50 \\
\hline A10 & $\begin{array}{l}\text { Laboratory Study of Diffusion Parameters } \\
\text { Characterize existing cores from Pahute Mesa boreholes }\end{array}$ & Diffusion (alpha) & 0.25 \\
\hline A11 & $\begin{array}{l}\text { Study of Radionuclide Release from Test Cavities } \\
\text { Conduct laboratory investigations and modeling of radionuclide } \\
\text { release process }\end{array}$ & Source Term & 1.10 \\
\hline A12 & $\begin{array}{l}\text { Geologic and Geophysical Modeling } \\
\text { Use estimates of deposition from volcanic centers to develop } \\
\text { comparisons with geologic model. Use measured gravity field } \\
\text { to adjust model. }\end{array}$ & Flux & 0.34 \\
\hline A13 & $\begin{array}{l}\text { Analysis of Barometric and Earth-Tide Responses } \\
\text { Locate existing and collect additional data records for } \\
\text { barometric and earth-tide response for the study area (15 data } \\
\text { records total) and analyze. }\end{array}$ & Effective porosity & 0.08 \\
\hline A14 & $\begin{array}{l}\text { Laboratory Study of } \mathrm{K}_{\mathrm{d}} \mathrm{S} \\
\text { Characterize existing cores from Pahute Mesa boreholes }\end{array}$ & $\mathrm{K}_{\mathrm{d}}$ & 0.28 \\
\hline
\end{tabular}

${ }^{a}$ Note that Activity 6 may subsequently be referenced as $6 a$ or $6 \mathrm{~b}$ if a distinction is to be made between the Diffusion and the Effective Porosity components. 
Table 3-3

Groups and Subgroups Evaluated in Phase 2

\begin{tabular}{|c|c|c|c|c|c|c|c|}
\hline \multirow{3}{*}{$\begin{array}{l}\text { Groupl } \\
\text { Subgroup }\end{array}$} & \multirow{3}{*}{ Group Name } & \multicolumn{6}{|c|}{ Parameter } \\
\hline & & Diffusion & \begin{tabular}{|c|}
$\begin{array}{c}\text { Source } \\
\text { Term }\end{array}$ \\
\end{tabular} & \begin{tabular}{l|} 
Effective \\
Porosity
\end{tabular} & $\mathbf{K}_{\mathbf{d}}$ & $\begin{array}{c}\text { Flux } \\
\text { Multiplier }\end{array}$ & $\begin{array}{l}\text { Estimated } \\
\text { cost (SM) }\end{array}$ \\
\hline & & \multicolumn{6}{|c|}{ Activity } \\
\hline G1 & Broad-based & 10 & 11 & & & $3,7,9$ & 20.1 \\
\hline G2 & Faults & & & & & $1,8,9$ & 11.45 \\
\hline G3 & Groundwater & & - & & & $1,2,3,8,9,12$ & 31.89 \\
\hline G4 & Transport (general) & 5,10 & & 13 & $14^{*}$ & 7 & 8.18 \\
\hline G5 & Source term & & 4,11 & & & 7 & 8.92 \\
\hline G6 & Low cost & 10 & & 13 & $14^{*}$ & $7,8,9,12$ & 3.3 \\
\hline G7 & Transport (specific) & $5,6,10$ & & 6,13 & & & 31.72 \\
\hline G8 & Value & 10 & & 13 & & $2,7,12$ & 4.74 \\
\hline G9 & Comprehensive & 6,10 & 11 & 6,13 & & $3,7,8,9,12$ & 40.22 \\
\hline G10 & Acceptance & & 4,11 & & & $1,3,7$ & 36.31 \\
\hline s1 & & & 4,11 & & & & 11.32 \\
\hline $\mathrm{S2}$ & & & & 6,13 & & & 25.01 \\
\hline S3 & & 5,10 & & & & & 6.7 \\
\hline S4 & & $5,6,10$ & & & & & 31.64 \\
\hline S5 & & & & & & $3,7,9$ & 18.79 \\
\hline 56 & & & & & & $7,8,9,12$ & 2.7 \\
\hline 57 & & & & & & $3,7,8,9,12$ & 19.86 \\
\hline 58 & & & & & & $1,8,9$ & 11.45 \\
\hline s9 & & & & & & $1,2,3,8,9,12$ & 31.89 \\
\hline$S 10$ & & & & & & $1,3,7$ & 28.52 \\
\hline$S 11$ & & & & & & $2,7,12$ & 4.41 \\
\hline $\mathrm{S} 12$ & & 6,10 & & & & & 25.19 \\
\hline
\end{tabular}

*Although Activity 14 was included in the group definition, it was omitted in the formal analysis of the group because the uncertainty-reduction potential was too small to be measured. Because the possible informational value of Activity 14 were excluded from the analysis, its incremental cost were ignored as well and was not included in the group cost estimates.

Phase 1 evaluated the uncertainty-reducing potential of these activities. In a second workshop, the expert panel used the Phase 1 results to help select promising combinations (groups) of the 14 individual activities. Table 3-3 summarizes the 10 activity groups selected for analysis in Phase 2. As suggested by the names assigned by the expert panel to the groups, the groups were defined to represent a range of strategies. Cost estimates were developed for each activity group, taking into account possible cost savings from coordinating the work for multiple activities. As indicated in the table, the groups span a wide range of costs. 
The Phase 2 evaluation of activity groups was conducted by first evaluating subgroups of activities representing various combinations of activities that address the same parameter (e.g., a collection of activities focused on porosity). The 10 groups contained 12 subgroups (Table 3-2 includes an identification of the subgroups evaluated in Phase 2). The evaluation of subgroups was intended to determine the combined ability of activities to resolve uncertainty on a single parameter, and to explore whether the contributions to uncertainty reduction in the contaminant boundary were additive. Additivity was explored because it would greatly simplify the analysis. If the reduction in contaminant-boundary uncertainty from a group of activities that address parameter $\mathrm{X}$ and $\mathrm{Y}$ is approximately the sum of the reductions obtained individually from the subgroups addressing parameters $\mathrm{X}$ and $\mathrm{Y}$, then the number of necessary calculations using the contaminant transport model would be greatly reduced (see Section 3.4 ). In addition, results for other combinations of activities and activity subgroups could be easily generated. For this reason, the subgroups were identified and evaluated in Phase 2.

In summary, Phases 1 and 2 together provided results for:

1. Ten activity groups (denoted G1 through G10) selected by the expert panel based on the results of Phase 1

2. Twelve activity subgroups (denoted S1 through S12) composed of various combinations of activities addressing the same parameter

3. Fourteen individual activities (denoted A1 through A14)

Unlike the 10 activity groups, the activity subgroups and individual activities were not intended to represent viable, stand alone characterization efforts. However, the results for the individual activities and subgroups are included for completeness and to aid understanding.

\subsection{Assessment of Probability Distributions}

Figure 3-1 summarizes the steps used to obtain the probabilities for calculating prior and posterior distributions for the sensitive parameters. Probabilities were obtained from the expert panel through group probability encoding sessions facilitated by a team of two decision analysts trained in probability assessment. Three sessions were held to: (1) obtain prior probability estimates for the key sensitive variables, (2) obtain likelihood functions representing activity accuracies for the Phase 1 evaluation of individual activities, and (3) obtain likelihood functions representing the accuracies of activity groups. 


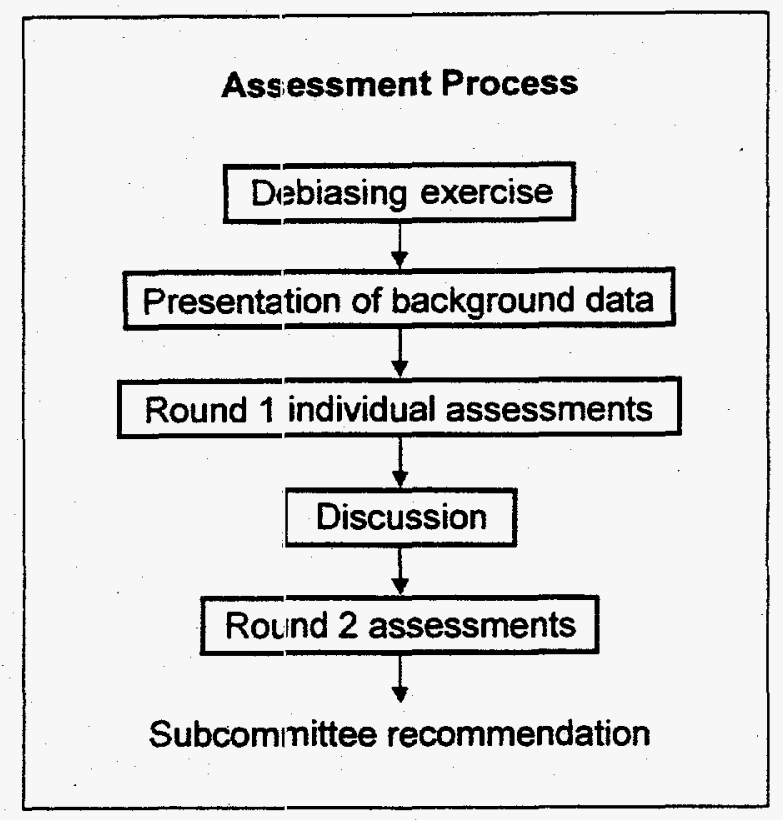

\section{Figure 3-1 \\ Process for Assessing Probabilities for Calculating Prior and Posterior Clistributions}

Prior to providing probability numbers, panel members participated in a debiasing exercise. The debiasing exercise was intended to counter: the well-known tendency of individuals to be overconfident and provide probability distributions that are too narrow (Lichtenstein and Fischhoff, 1977). The debiasing exercise involved having each participant estimate the fractiles of probability distributions describing their uncertainties over the values of quantities (e.g., the height of Niagara Falls) selected from the World Almanac (Merkhofer, 1987). The probability estimates were calibrated by comparison with the frequency with which actual values fell within the ranges defined by the various fractiles. Participating in such exercises has been shown to improve people's abilities to provide probabilities that accurately reflect their uncertainties (Tversky and Kahnaman, 1974).

Next, background information and data relevant to the estimation of each parameter were presented. Also, factors influencing the uricertainty in the sensitive parameters were discussed. For the assessment of the prior distributions, background was provided on the values for the key input parameters used in the sensitivity analyses (see Appendix D). In the assessments of activity and subgroup effectiveness, information on other factors affecting test interpretation was 
discussed. These factors are summarized in the diagram shown in Figure 3-2. The diagram is known as an influence diagram, it identifies (through nodes and arrows) the relationships among factors thought to influence the uncertainty of interest (Oliver and Smith, 1989). The influence diagram documents the considerations that participants were asked to bear in mind when providing estimates of existing uncertainty over parameters and when making estimates of the ability of characterization activities to produce accurate estimates of the parameters.

Probability estimates were elicited in a process having two stages or rounds. In round 1, participants provided individual probability estimates. The individual round 1 estimates were summarized and displayed and participants discussed points of agreement and disagreement. These discussions were intended to promote the sharing of information. Finally, round 2 assessments were conducted as a group activity, with participants providing consensus recommendations over the probabilities that should be assumed for the analysis.

Participants generated prior distributions by providing the 5 percent and 95 percent fractiles and specifying the form (e.g., normal, lognormal, etc.) of the distribution. The indicated form was then fit to the specified fractiles by identifying the numeric values for parameters (e.g., mean and variance) of the distributions which would ensure the resulting distribution had the specified fractiles. Appendix D provides details. As discussed in Section 3.5, the prior distribution for the flux multiplier was scaled toward smaller values to reduce the number of unrealistic Monte Carlo simulations observed during the initial transport simulations. Table 3-4 summarizes the final consensus judgments of the expert panel.

Estimates of the activity and subgroup test accuracies provided likelihood functions for the Bayesian analysis. To estimate activity accuracies, the expert panel provided probability distributions for the parameter estimates that would be generated by the activities and activity groups, assuming what the actual values of the parameters might be. The approach was similar to that used for generating prior distributions; $5^{\text {th }}$ and $95^{\text {th }}$ fractiles were specified along with the form of the distribution. The resulting probability distributions were interpreted to represent the estimated accuracy of activities by indicating how closely activity results are expected to match actual site conditions. 


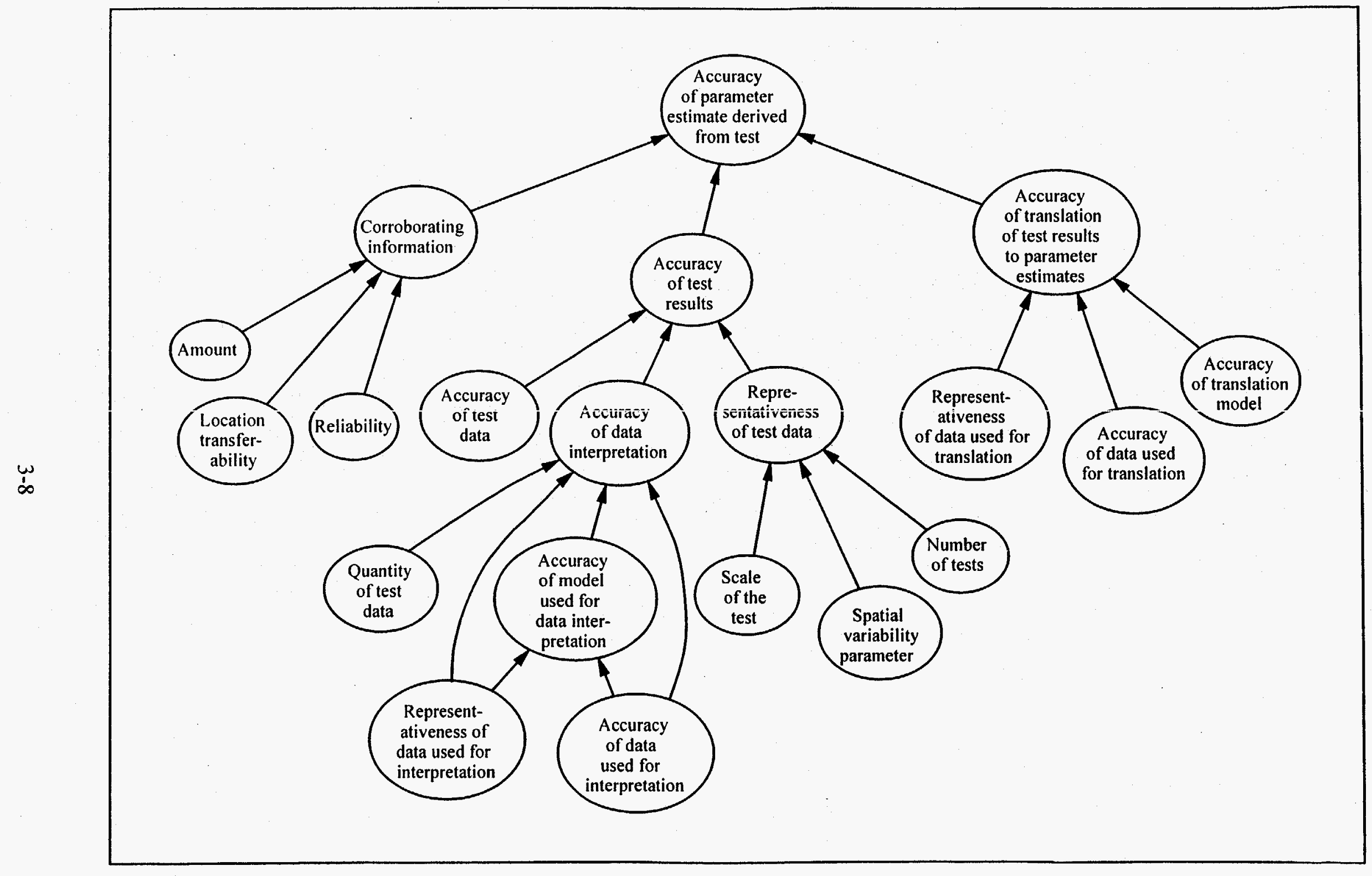

Figure 3-2

Influence Diagram Showing Factors Influencing the Accuracy of Characterization Activities 
Table 3-4

Prior Distributions

\begin{tabular}{||l|c|c|c|l||}
\hline \multicolumn{1}{|c|}{ Parameter } & $\begin{array}{c}\text { Low } \\
(\mathbf{5 \% )}\end{array}$ & $\begin{array}{c}\text { High } \\
(\mathbf{9 5 \% )}\end{array}$ & $\begin{array}{c}\text { Distribution } \\
\text { Form }\end{array}$ & \multicolumn{1}{|c|}{ Comments $^{\text {a }}$} \\
\hline \hline Flux multiplier & 0.01 & 1.0 & lognormal & $\begin{array}{l}\text { Scaled down from initial prior distribution to } \\
\text { reduce number of unrealistic realizations }\end{array}$ \\
\hline Effective porosity & $1 \times 10^{-4}$ & $3 \times 10^{-2}$ & lognormal & \\
\hline $\begin{array}{l}\text { Diffusion parameter } \\
(1 / \mathrm{yr})\end{array}$ & $8.5 \times 10^{-5}$ & $1.3 \times 10^{-2}$ & lognormal & $\begin{array}{l}\text { Calculated from assessments of the effective } \\
\text { porosity of the mobile domain, the mobile } \\
\text { zone hydrodynamic dispersion coefficient, } \\
\text { and the average length of the immobile } \\
\text { domain }\end{array}$ \\
\hline Source term (pCi/L) & 1 & 1000 & normal & $\begin{array}{l}\text { Range scaled to individual radionuclides } \\
\text { assumed completely correlated }\end{array}$ \\
\hline $\mathrm{K}_{\mathrm{d}}^{\mathrm{b}}(\mathrm{mL} \mathrm{g})$ & $0^{c}$ & $10^{c}$ & uniform & $\begin{array}{l}\text { Range scaled to individual radionuclides } \\
\text { assumed completely correlated }\end{array}$ \\
\hline
\end{tabular}

\footnotetext{
${ }^{2}$ For uniform distribution, low and high values are minimum and maximum, respectively

barameter values generally estimated for fractured welded tuffs/lava

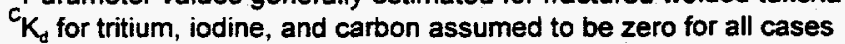

$1 / y r=$ Per year

$\mathrm{pCi} / \mathrm{L}=$ Picocurie(s) per liter

$\mathrm{mL} / \mathrm{g}=$ Millititer(s) per gram
}

Using the process, the following summarizes the logic and types of questions posed to obtain accuracy estimates. First, a specific activity was specified (e.g., Activity 1). The parameter addressed by the activity was noted (flux multiplier), and the activity was discussed by the participants to ensure a common understanding of the work that would be conducted. Next, the participants were asked to assume that the actual, best value for the flux multiplier (value that if used in the transport model would produce the most accurate simulations) was known to be a specified value, for example 0.5 (the exercise was repeated using various high, medium, and low values for the parameter selected from the range of values spanned by the prior distribution). The group was then asked to imagine that a team of individuals, who do not know the actual value of parameter, was tasked with conducting the activity and, based on the results, reporting back their best estimate of parameter. The group specified the range of possible values that the team might report (i.e., they specified the $5^{\text {th }}$ and $95^{\text {th }}$ fractiles of their range of uncertainty). Appendix E provides more detail. In effect, participants were asked to indicate the accuracies that would be obtained if the model was well understood and activities were calibrated by application to a geologic setting of known characteristics. 
To summarize the results, the uncertainty ranges were displayed for participants as box charts. As shown in Figure 3-3, when compared with the specified actual values, the assessed ranges indicate activity uncertainty, whether uncertainties are symmetric or asymmetric, and the sensitivity of activity accuracy to the actual parameter value. The expert panel used such plots to help verify that their accuracy estimates matched understanding and intuition regarding the characteristics of the activities.

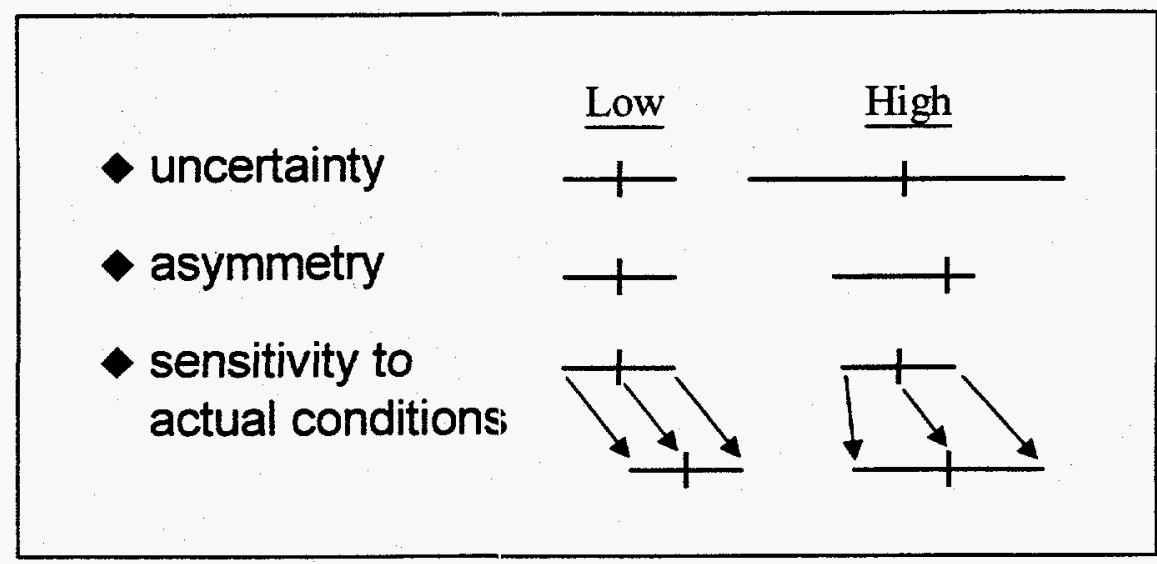

Figure 3-3

Activity Accuracy Estimates Indicate Uncertainty, Asymmetry, and Sensitivity of Test Outcomes

Estimates of the accuracy of activity subgroups (groups of activities addressing the same parameter) were obtained in a similar fashion, except that the participants were provided with additional information. To facilitate the assessment of group accuracy, box plots similar to Figure 3-4 were provided for the assessment of each subgroup. The box plots for the individual activities represent the assessments provided by the Panel in Phase 1. The box plot labeled "composite accuracy" shows the 5 to 95 percent uncertainty range that would exist if the uncertainties combined as they do in random sampling, specifically, as independent observations used to estimate a population mean. The analysis involved estimating the number of samples under the random sampling analogy, and then computing the resulting uncertainty range for the combined case. The combined case is that which would result for a number of samples that was the sum of the number of samples corresponding to each component activity. The participants were well aware that accuracy uncertainties do not necessarily combine as they do in random sampling. However, they found the results provided a helpful starting point for generating accuracy estimates for subgroups. Details of the subgroup accuracy assessments are in Appendix E. 
Activity subgroup \#10:

Actual flux multiplier

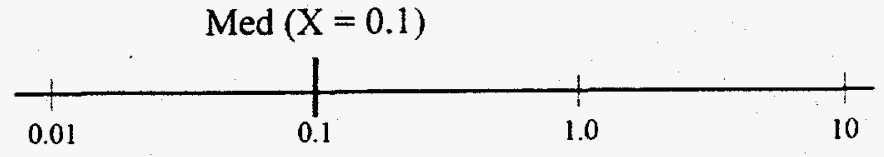

Accuracies

Activity 1

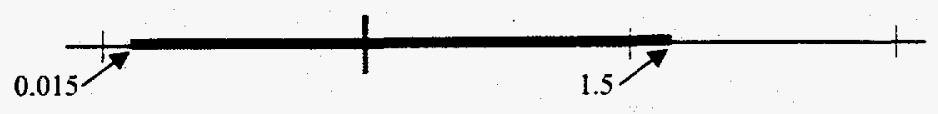

Activity 3

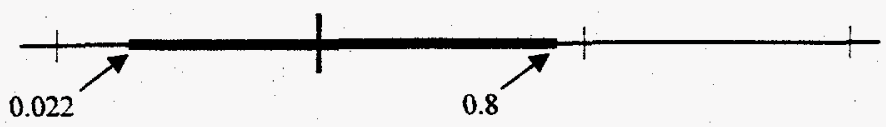

Activity 7

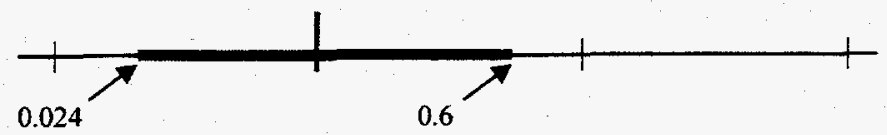

Composite accuracy

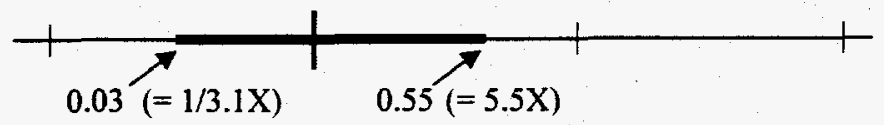

Considering the accuracies of the individual activities and their interdependencies, the uncertainty range for the estimate derived from the activity subgroup ( 5 to $95 \%$ confidence range) is:

to

Figure 3-4

Displays Used to Facilitate Accuracy Estimates for Activity Subgroups

\subsection{Calculation of Posterior Distributions}

Posterior distributions for the sensitive parameters were computed using Bayes' theorem to combine the prior distributions with the activity and subgroup activity accuracy estimates. As noted earlier, the process required discretizing the probability distributions. Appendix $F$ describes the details.

Figure 3-5 illustrates the general nature of the results. As indicated, the posterior uncertainty depends on the prior uncertainty plus the estimated ability of the activities to accurately predict actual site conditions. If uncertainty over activity results is large, posterior (solid lines) and prior distributions (dashed lines) tend to be very similar. If uncertainty over activity results is narrow, the posterior distributions tend to be tighter and/or shifted from the prior.

To illustrate, Figure 3-6 shows the prior and posterior distributions for Subgroup 10, which addresses the flux parameter and is composed of Activities 1,3, and 7. In this case, the 
- If uncertainty over activity results is large, posterior and prior are very similar

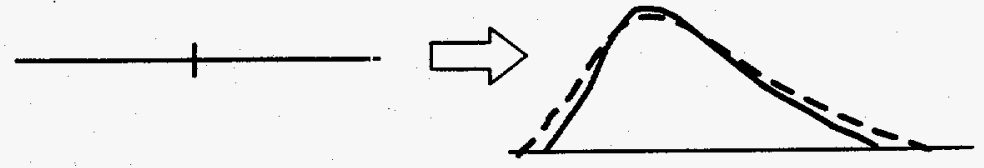

- If uncertainty over activity results is narrow, posterior is tighter and/or shifted from the prior

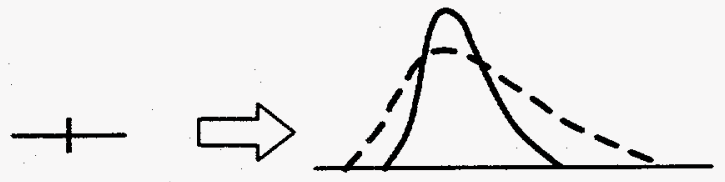

Figure 3-5

Typical Relationship Between Posterior and Prior Distributions

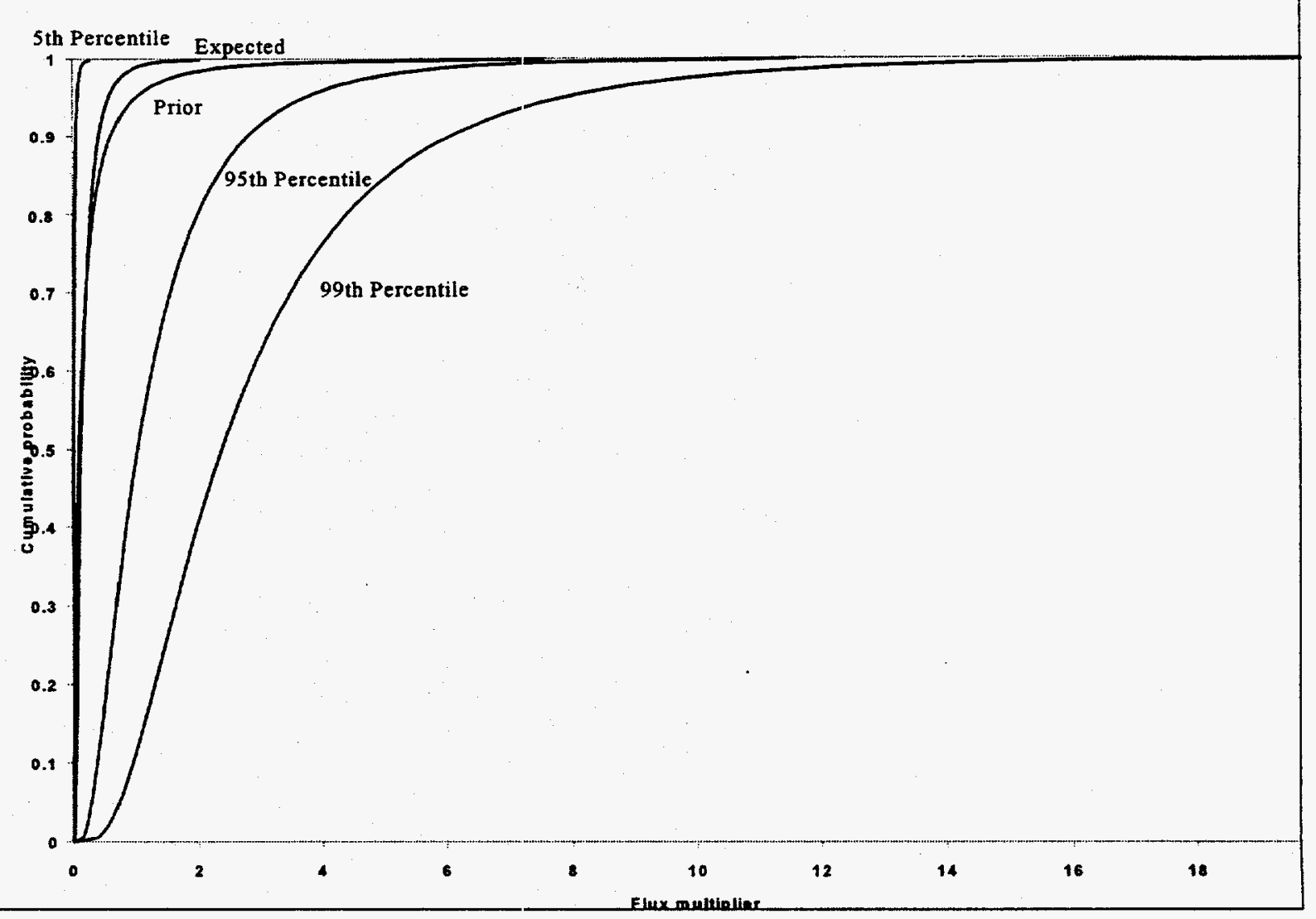

Figure 3-6

Example of Prior and Posterior Distributions for the Flux Multiplier 
discretizing process defined four possible outcomes; two showing reduced uncertainty compared to the prior, and two showing greater uncertainty. These outcomes correspond to four possible estimates for the flux parameter that might be produced as a result of conducting Subgroup 10 , specifically estimates that are approximately at the $5^{\text {th }}, 50^{\text {th }}, 95^{\text {th }}$, and $99^{\text {th }}$ fractiles of the prior distribution for the flux parameter. The posterior distributions differ depending on the test outcomes. As illustrated, outcomes suggesting the flux multiplier is near the lower end of the range currently considered possible (i.e., near the 5 th fractile of the prior) would make the posterior distribution tighter and shifted lower. Conversely, test outcomes suggesting the flux multiplier is at the upper end of the range currently considered possible (i.e., near the $95^{\text {th }}$ or $99^{\text {th }}$ fractiles), would make the posterior distribution broader and shifted upward.

\subsection{Calculation of the Maximal Extent of the Contaminant Boundary}

The preliminary transport simulations performed during Phase I are presented following by the final simulations for all characterization options considered.

\subsubsection{Preliminary Contaminant Boundary Calculations}

Several preliminary simulations were performed to refine the VOIA modeling process. First, simulations were performed to assess the importance of each of the 5 radionuclides of concern considered for transport simulations. In the preliminary simulations, tritium, iodine-129, uranium-238, plutonium-239/240, and carbon-14 were evaluated separately to ascertain their impact on the location of the contaminant boundary. From these simulations it was shown that only tritium and carbon- 14 contributed to the contaminant boundary distance over the 1,000 year timeframe of interest. As a result, only tritium and carbon-14 were used in the remainder of the VOIA. Additional details on the preliminary simulations are provided in Appendix G.

Second, it was observed during the preliminary simulations that approximately 32 percent of all the realizations produced a distance to the $4 \mathrm{mrem} / \mathrm{yr}$ boundary of $30.5 \mathrm{~km}$ (19.0 miles [mi]), which represents discharge at Oasis Valley. This created a situation where a significant number of realizations provided no information with which to discriminate among the various characterization options. Samples taken from springs in Oasis Valley in February 1997 (sampling by the U.S. Geological Survey, analysis by IT) all had tritium concentrations less than 300 picocuries per liter $(\mathrm{pCi} / \mathrm{L})(0.013 \mathrm{mrem} / \mathrm{yr}$ using the drinking water ingestion scenario.) This suggests that realizations that produce discharge dose levels in excess of $4 \mathrm{mrem} / \mathrm{yr}$ at Oasis Valley (in less than 22 years, the time since the TYBO test) are not representative of reality. In a Monte Carlo analysis, it would be expected that a small number of realizations would produce unrealistic results. This would be an indicator that the range of variability is sufficiently broad to encompass all possible outcomes. 
The fact that approximately 32 percent of the simulations cannot represent reality indicated that one or more of the parameter ranges were too broad. In discussions with the expert panel, the decision was made to reduce the flux multiplier by scaling the flux-prior distribution toward smaller values. This maintained the amount of variability in the flux multiplier, but resulted in a smaller mean value which in turn reduced the number of unrealistic realizations to 11 percent. The scaled flux multiplier is the one presented in Table 3-4. Additional explanation of the scaling of the flux is provided in Appendix $D$.

\subsubsection{Calculation of the Contaminant Uncertainty Measures}

As noted in Section 3.2, subgroups of activities addressing the same parameter were defined and evaluated, in part, because it was hoped that uncertainty reduction could be shown to be additive across subgroups. Further defined, the uncertainty reduction achieved through activities addressing two parameters would be approximately the uncertainty reduction achieved by the activities addressing one parameter plus the uncertainty reduction achieved by the activities addressing the other parameter. In the absence of additivity, it would be necessary to calculate the contaminant boundary for all possible combinations of activity and subgroup outcomes. Because distributions for the contaminant boundary were developed through a Monte Carlo analysis of contaminant transport model, lack of additivity would mean that a very large number of Monte Carlo simulations would be required.

Unfortunately, tests conducted to explore additivity demonstrated that additivity could not be assumed. Therefore, because each activity and subgroup of activities addressing a different parameter may produce several different outcomes (e.g., greater effect than expected, about as expected, lesser effect than expected) and because different posterior distributions result for each possible outcome, multiple Monte Carlo simulations had to be conducted for each option. In the case of activity groups that contain multiple subgroups (i.e., options that contain activities addressing more than one parameter) it was necessary to analyze all of the possible combinations of activity and subgroup outcomes. Figure 3-7 illustrates that nine separate analyses would be needed for a group that contained subgroups addressing two different parameters if each subgroup were represented as potentially producing three possible outcomes. As noted in Appendix F, it was necessary to consider up to five possible outcomes for some of the subgroups in order to provide an adequate discrete approximation to the continuous probability distributions. Thus, some of the groups required a very large number of simulations. In fact, the largest group (Group 9) would have required 320 separate simulations for each radionuclide, 


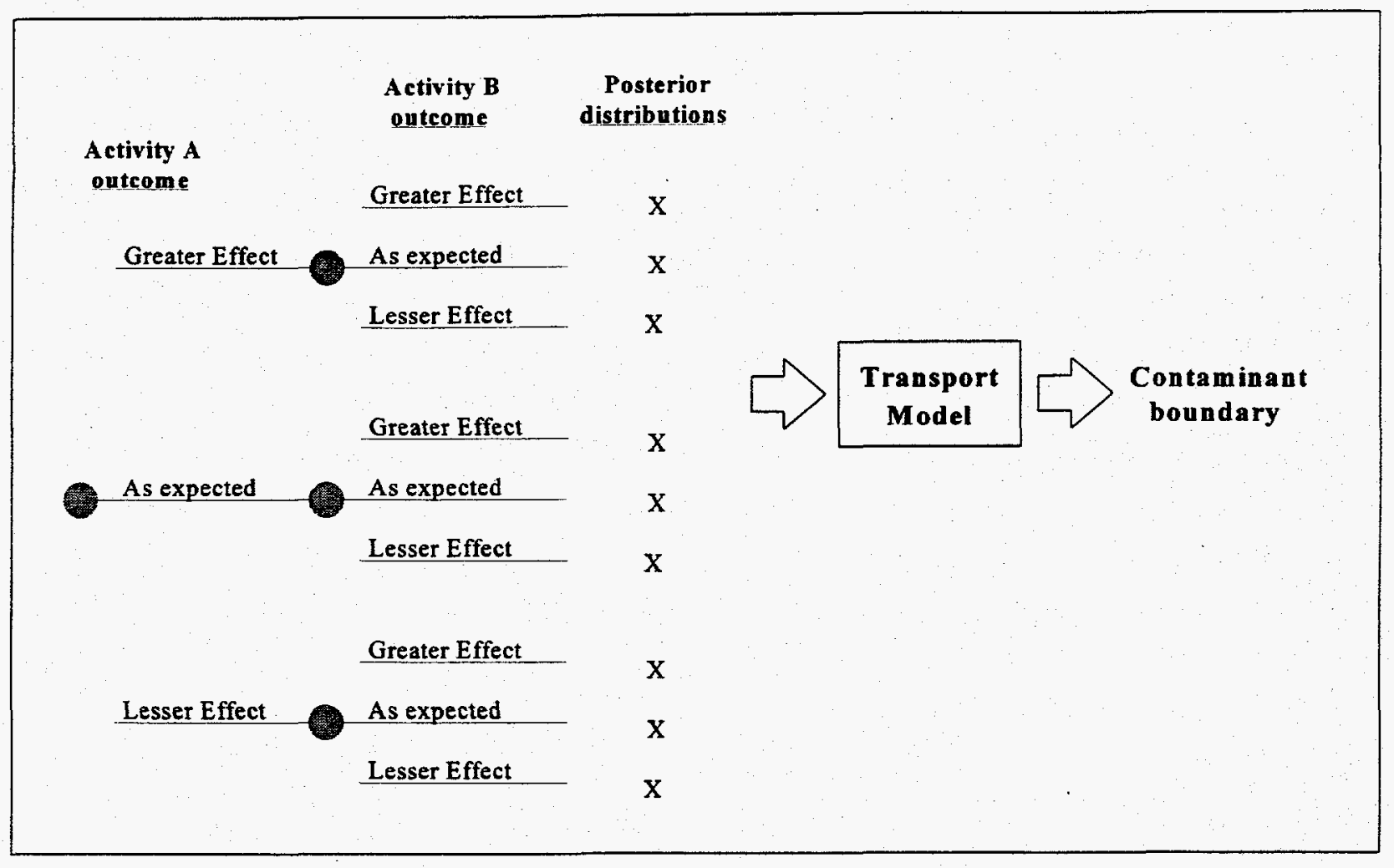

\section{Figure 3-7 \\ Multiple Monte Carlo Simulations Were Required for Groups Composed of Activities Addressing Different Parameters}

each with 200 realizations. It was not possible to analyze this case, given logistical and computational limitations. Therefore, the impact of this group was not analyzed in terms of the two measures that required contaminant boundary simulations.

The contaminant boundary simulations were performed for each of the parameter characterization options, subgroups, and groups using the regional transport model. Within each option or group four or five possible outcomes were chosen. If four outcomes were used, the possible outcomes were chosen to be at the 5,50,95, and 99 percent fractiles of the prior cumulative distribution. If five outcome values were used, the 1 percent fractile was added. For each possible outcome, a mean and standard deviation of the posterior parameter distribution was determined by elicitation of the expert panel members.

Two hundred realizations of the parameters were generated using the Latin Hypercube Sampling method (Iman et al., 1980) for each possible outcome of each characterization option or groups of options. In addition, each radionuclide, tritium and carbon-14, required separate simulations. A total of 188,800 model runs were performed. Each model run produced concentration values 
at 60 equidistant locations along a $30.5 \mathrm{~km}(19.0 \mathrm{mi})$ path, recorded at 201 times representing every five years from 0 to 1,000 years. This produced a matrix $(60 \times 201)$ of concentration values for each Monte Carlo realization. For each possible outcome and characterization activity, or group of activities, the concentration matrices for each of the 200 realizations were combined into a single file representing the output of one set of Monte Carlo runs.

The output of each set of Monte Carlo runs was postprocessed through two separate programs, one which calculated the distance to the $4 \mathrm{rnrem} / \mathrm{yr}$ boundary for different fractiles of the realizations and a second which calculated the contaminant boundary uncertainty in terms of the average duration of the boundary location. The results for all model runs are presented in Appendix G.

\subsection{Measures of Uncertainty Reduction}

Three measures of uncertainty reduction were computed.

\subsubsection{Average Expected Reduction in Parameter Uncertainty}

This measure is intended to represent the ability of characterization options to reduce uncertainty in key parameters important to the calculation of the location of the contaminant boundary. This measure is in some ways simpler than the other two. It does not involve the contaminant transport model directly and, therefore, is not affected by any uncertainties or questions regarding the accuracy of that model. It accounts for the levels of existing uncertainty in parameters, the specific parameters that are addressed by the characterization options, and the degree to which the option is anticipated to reduce those uncertainties. However, it does not account for differences in the sensitivity of the contaminant boundary to uncertainty reductions in the various parameters. Rather, it treats percentage reductions in parameter uncertainty equally regardless of which parameter has its uncertainty reduced.

To calculate the value of the measure for a characterization option, the variances of the posterior distributions were calculated for each pararneter addressed by the option. The variances depend on the outcomes because a different posterior distribution results for each possible outcome of the subgroup of activities within the option that addresses that parameter. Therefore, the expected posterior variance is calculated by weighting the individual posterior variances by the probabilities of the corresponding test outcomes. The resulting expected posterior variance is then divided by the variance of the prior distribution for the parameter and the result is subtracted 
from the number 1 . Thus, for each parameter addressed by the characterization option, parameter uncertainty reduction is calculated as:

$$
\begin{aligned}
& \text { Parameter } \\
& \text { Uncertainty } \\
& \text { Reduction }
\end{aligned}=1-\frac{\text { Expected posterior variance }}{\text { Prior variance }}
$$

Finally, the results are expressed as percentages, and the percentage reductions are averaged across the four parameters to provide the average parameter uncertainty reduction. If an option does not address one or more parameters, no uncertainty reductions are assumed for those parameters. Table 3-5 provides an example illustrating the calculations.

Table 3-5

Example Illustrating the Computation of the Average Expected Reduction in Parameter Uncertainty

\begin{tabular}{|l|c|c|}
\hline $\begin{array}{c}\text { Sensitive } \\
\text { Parameter }\end{array}$ & $\begin{array}{c}\text { Exp posterior } \\
\text { prior variance }\end{array}$ & $\begin{array}{c}\text { Parameter } \\
\text { uncertainty reduction }\end{array}$ \\
\hline \hline Diffusion & 0.8 & $20 \%$ \\
\hline Source & 0.6 & $40 \%$ \\
\hline Porosity & 1 & $0 \%$ \\
\hline Flux & 0.4 & $60 \%$ \\
\hline & $\begin{array}{c}\text { Avg. Uncertainty } \\
\text { reduction }\end{array}$ & $30 \%$ \\
\hline
\end{tabular}

\subsubsection{Expected Reduction in Contaminant Boundary Uncertainty}

This measure was designed to indicate the impact of characterization options on the probability distribution for the maximal extent of the contaminant boundary. Expected average deviation from the mean was selected as a measure of uncertainty. To calculate this measure, the mean deviations were calculated from the posterior distributions describing the maximal extent of the contaminant boundary, which were obtained from Monte Carlo analyses of the transport model using the posterior distributions for the sensitive parameters as input.

For each of the 200 realizations, the transport model creates a matrix of concentration values at 60 distances and 201 times. The concentrations are converted to yearly dose using a drinking water ingestion scenario model (Adams, 1996a) and summed by radionuclide to produce a 
composite dose matrix in distance and time. The location of the $4 \mathrm{mrem} / \mathrm{yr}$ dose as a function of distance and time is then determined from the composite dose values. The maximum distance of the $4 \mathrm{mrem} / \mathrm{yr}$ contour can occur at any time from 0 to 1,000 years and may range from the first observation distance at $1 \mathrm{~km}(0.6 \mathrm{mi})$ to the discharge area at Oasis Valley $(30.5 \mathrm{~km}[19.0 \mathrm{mi}])$. The maximum distance is recorded for each realization and is considered a random variable because it is dependent upon the outcome of simulations with random input parameters. Then the average deviation was calculated using for formulation:

$$
\text { average deviation }=\sum_{i=1}^{200}\left|\mathrm{~d}(\mathrm{i})-\mu_{\mathrm{d}}\right|
$$

Where

$\mathrm{d}(\mathrm{i})=$ the maximum distance of the $4 \mathrm{mrem} / \mathrm{yr}$ contour for realization $\mathrm{i}$

$\mu=$ the average maximum distance of the $4 \mathrm{mrem} / \mathrm{yr}$ contour for the 200 realizations

The average deviation was chosen over the standard deviation because it is more robust and less susceptible to outlier values (Press et al., 1986). The average deviation is a measure of the spread of the distribution about its mean value. Therefore, if data are collected for a parameter of interest, and that data collection results in a reduction in the uncertainty in a parameter value, then one would expect that the uncertainty in the contaminant boundary location would also be reduced. Therefore, this measure of the contaminant boundary is focused on the uncertainty in the boundary location and not on the location of the boundary itself.

As with the previous measure, different characterization option outcomes produce different posterior distributions. Thus, for each characterization option, the tree of possible outcome combinations was identified, the mean deviation for each possibility was computed, and expected mean deviation was obtained by adding all possibilities weighted by their respective probabilities. 
The expected reduction in contaminant boundary uncertainty was calculated by comparing the expected mean deviation calculated from the posterior distributions on the maximal extent of the contaminant boundary with the expected mean deviation of the prior distribution.

$$
\begin{aligned}
& \text { Contaminant } \\
& \text { Boundary } \\
& \text { Uncertainty Reduction }
\end{aligned}=1-\frac{\text { Posterior expected mean deviation }}{\text { Prior expected mean deviation }}
$$

Contaminant boundary uncertainty reductions were expressed as percentages.

\subsubsection{Expected Change in the Upper Bound (95 $5^{\text {th }}$ Fractile) of the Contaminant Boundary}

This measure is very similar to the previous measure. Both measures quantify changes in the shape of the probability distribution describing uncertainty of the location of the contaminant boundary. However, where the previous measure considers the average reduction in the spread or dispersion of the distribution, this measure focuses on the upper tail of the distribution. Specifically, the measure indicates how characterization options affect the $95^{\text {th }}$ fractile of the distance distribution. As with the previous measure, this measure was calculated for each characterization option by identifying the tree of possible outcome combinations for that option. Then, the $95^{\text {th }}$ fractiles for the contaminant boundary distributions corresponding to each path through the tree were identified. The expected $95^{\text {th }}$ fractile was computed by weighting the possible values by the path probabilities.

For each Monte Carlo realization, the concentration at each observation location and at 5-year time intervals was stored in a file. The concentrations were each converted to a dose using the drinking water scenario and summed for the various radionuclides. For each realization, this process produced a matrix of composite dose values in distance and time. The results from each realization were stacked to create a three dimensional array of composite dose values with time, distance, and realization along the three axes. The dose values at each distance and time were sorted from smallest to largest, across the realizations. This sorting process does not preserve each realization as a unique outcome, but rather insures that there will be a monotonic increase in dose at each distance and time. Once sorted, the array was sliced along the realization axis at various fractiles such as 50 or 95 percent to represent a level for which 50 or 95 percent of the data at that point in distance and time had smaller values. The data at this sliced level were contoured and the maximal extent of the $4 \mathrm{mrem} / \mathrm{yr}$ line was determined. 
The fractiles selected for the VOIA were $50,65,75,85$, and 95 percent. These five levels were at or above the median because results that yielded greater distances of transport are expected to be of most concern to the majority of stakeholders. It was not clear at the outset which level would be most useful in the VOIA. The 50 percent fractile represents a measure of expected behavior but does not account for the uncertainty. The other four fractiles account for various levels of uncertainty.

As with the other two measures, the measure of the expected change in the upper bound estimate of the location of the contaminant boundary was calculated by comparing the posterior estimate with the prior estimate.

\begin{tabular}{|c|c|}
\hline $\begin{array}{l}\text { Change in } \\
\text { upper bound } \\
\text { estimate }\end{array}$ & $\begin{array}{l}\text { Posterior } \\
\text { expected } \\
95^{\text {th }} \text { fractile }\end{array}$ \\
\hline
\end{tabular}

Results were expressed as the change in distance using kilometers. 


\subsection{Results and Discussion}

This section summarizes the results of evaluating and comparing the uncertainty-reducing capability of alternative characterization options. As indicated previously, 36 characterization options were evaluated. Ten of these options were intended to represent potentially attractive groups of activities (Table 3-3). In addition, 12 subgroups of activities were also evaluated (Table 3-3). A subgroup consists of two or more activities that primarily resolve uncertainty on a single parameter needed as input for the computation of the location of the contaminant boundary (diffusion, source term concentration, effective porosity, or flux multiplier). Finally, the characterization options included 14 individual activities (Table 3-2). Note that two of the subgroups, S8 and S9, were the same as two of the groups, G2 and G3 respectively.

Three alternative measures were used to quantify uncertainty reducing potential:

1. Average expected reduction in parameter uncertainty: This measure was computed to quantify the ability of options to reduce uncertainty over key geohydrologic and source term parameters.

2. Expected change in average deviation from the mean of the distribution of the maximal extent of the contaminant boundary: This measure was computed to quantify the ability of options to reduce uncertainty in the maximal extent of the contaminant boundary.

3. Expected change in the $95^{\text {th }}$ fractile of the distribution of the maximal extent of the contaminant boundary: This measure was computed to quantify the ability of options to reduce uncertainty in the upper bound estimate of the maximal extent of the contaminant boundary.

Options were ranked with respect to each of these measures. In addition, options were compared based on their performance on these measures per unit of cost.

\subsection{Ability of Characterization Options to Reduce Parameter Uncertainty}

Figure 4-1 displays the results obtained with this measure. All 36 options are included in the comparison. In all cases, the average expected change in parameter uncertainty is a reduction. In other words, none of the options is expected to produce an increase in parameter uncertainty. This is not as obvious a conclusion as it might seem. As illustrated by Figure 3-6, activities may increase or decrease parameter uncertainty, depending on the nature of test results. 


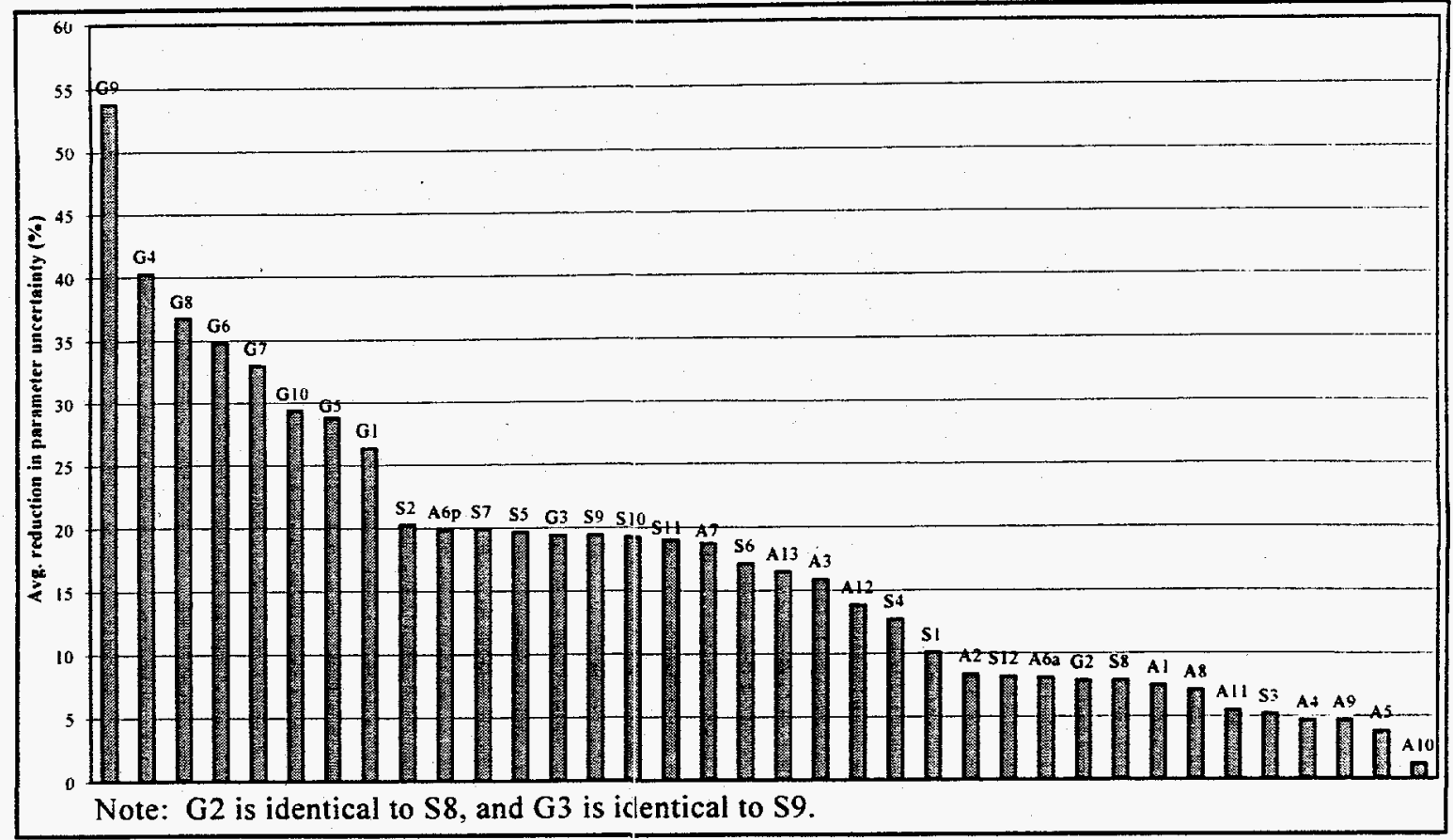

Figure 4-1

Results: Activity Groups, Subgroups, and Activities Ranked by Expected
Average Reduction in Parameter Uncertainty

These results may, in turn, lead to parameter values that produce more or less extensive maximal extent of the contaminant boundary than previously thought. Thus, it is entirely possible that the estimate of the maximal extent of the contaminant boundary will be larger after conducting an activity than it is prior to conducting the activity. However, when the possibilities are weighted by the probabilities, in all cases it is more likely that conducting characterization options will lead to a decrease rather than an increase in parameter uncertainty. The average reductions in parameter uncertainty range from a low of about 2 percent (Activity 10) to a high of about 54 percent (Group 9).

Appendix E provides the expert panel's inputs for the analysis. Specifically, these inputs indicate the estimated ability of the various characterization options to provide accurate estimates of the sensitive parameters. Accuracy, of course, is a complex concept. As noted in Section 3.3, the accuracy estimates convey not only the range of estimates that might be produced by an activity, but also whether the activity tends to produce biased estimates (estimates that tend to be above or below the true value), and whether the uncertainty ranges depend on the magnitude of the actual value that the activity attempts to estimate. Nevertheless, a comparison of Tables E-1 to E-9 in Appendix E with Figure 4-1 confirms that tests that were generally estimated to be more accurate 
tend to produce greater reductions in parameter uncertainty. In general, activity groups that contain more activities are more accurate than individual activities and groups that contain only a subset of the activities in the larger group. Similarly, activity groups that contain more accurate activities are estimated to produce greater reductions in parameter uncertainty.

The one exception to this rule is the relative ranking of Activity 7 and Subgroup 6. Subgroup 6 consists of Activities 7, 8,9, and 12. Thus, it would appear illogical that Activity 7 should rank above Subgroup 6, as it does in Figure 4-1. Input anomalies cause Activity 7 to rank higher than Subgroup 6. As can be deduced from the tables in Appendix E, Activity 7 is estimated to be the most accurate of the activities addressing flux. The accuracy of Subgroup 6 is almost equal to the accuracy of Activity 7 alone. Logically, the input estimates provided by the expert panel ought to have indicated that, on balance, Subgroup 6 is slightly more accurate than Activity 7 alone. However, because the accuracy of an option is a function of a great many inputs, it is difficult to predict, without doing the calculations, the net effect of all of these inputs. When presented with this anomaly, the expert panel agreed that small errors in the activity accuracy estimates probably account for the nonintuitive ranking order.

Figure 4-2 is a plot of the expected average parameter uncertainty reduction of the characterization options versus cost. From a cost-effectiveness point of view, the options that produce the greatest uncertainty reduction (score highest on the $y$-axis) at any given cost level are optimal. These options can be identified by starting at the origin and identifying the option for each increment of cost that produces the largest uncertainty reduction (i.e., by choosing the specific points that lie on upper left-hand edge of the envelope that encloses all of the points). The options identified in this way are on the Pareto Frontier. The Pareto Frontier is defined as the set of options that no other option dominates (Anderson et al., 1981). Option A dominates another option B when A is at least as good as B on all dimensions and better than B on at least one dimension. In this instance, the evaluation involves only two dimensions, uncertainty reducing potential and cost. Thus, an option is defined as "optimal" (on the Pareto Frontier) if it provides at least as much uncertainty reduction as any other option that costs the same or less. With this logic, Figure 4-2 identifies six characterization options as "optimal" in terms of parameter uncertainty reduction per unit of cost. 


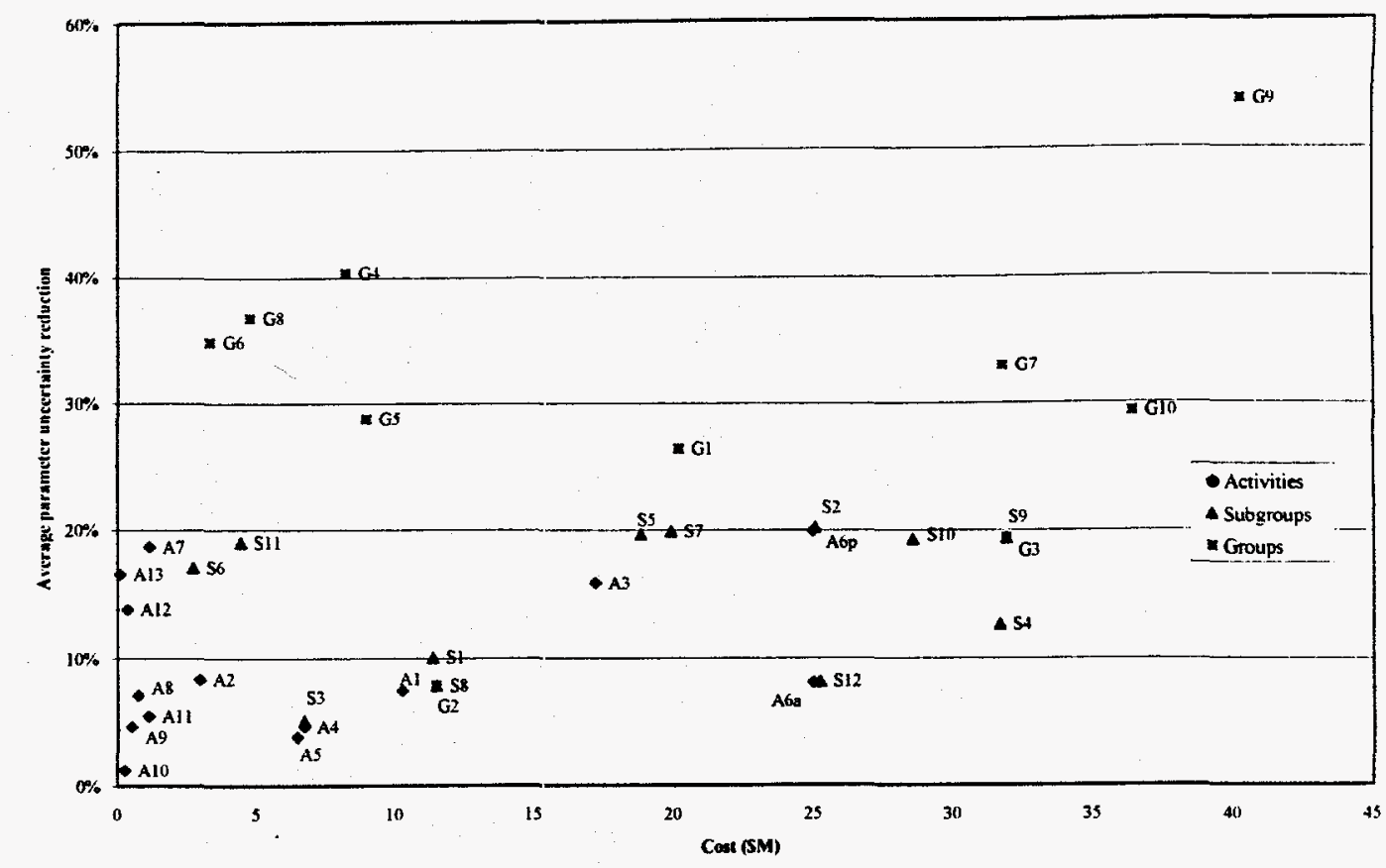

Note: $\mathrm{G} 2$ is identical to $S 8$, and $\mathrm{G} 3$ is identical to $S 9$.

Figure 4-2

Results: Expected Average Parameter Uncertainty Reduction Versus Cost

These activities are as follows:

- Activity 13 (barometric and earth-tide responses)

- Activity 7 (geochemistry-based investigations)

- Group 6 ("low-cost," composed of A10,13,7,8,9, and 12)

- Group 8 ("value," composed of A10,13,2, 7, and 12)

- Group 4 ("transport (specific)," composed of A5, 7, 10, and 13)

- Group 9 ("comprehensive," composed of A3, 6,7, 8,9, 10,11,12, and 13)

\subsection{Ability of Characterization Options to Reduce Contaminant Boundary Location Uncertainty}

Figure 4-3 displays the results obtained with this measure. Only 35 options are included since, as noted in Section 3.5.2, it was not possible to evaluate Group 9 using this measure, due to the very large number of Monte Carlo simulations that would have been required. It is likely, however, that Group 9 would have been ranked number one with respect to the measure. 


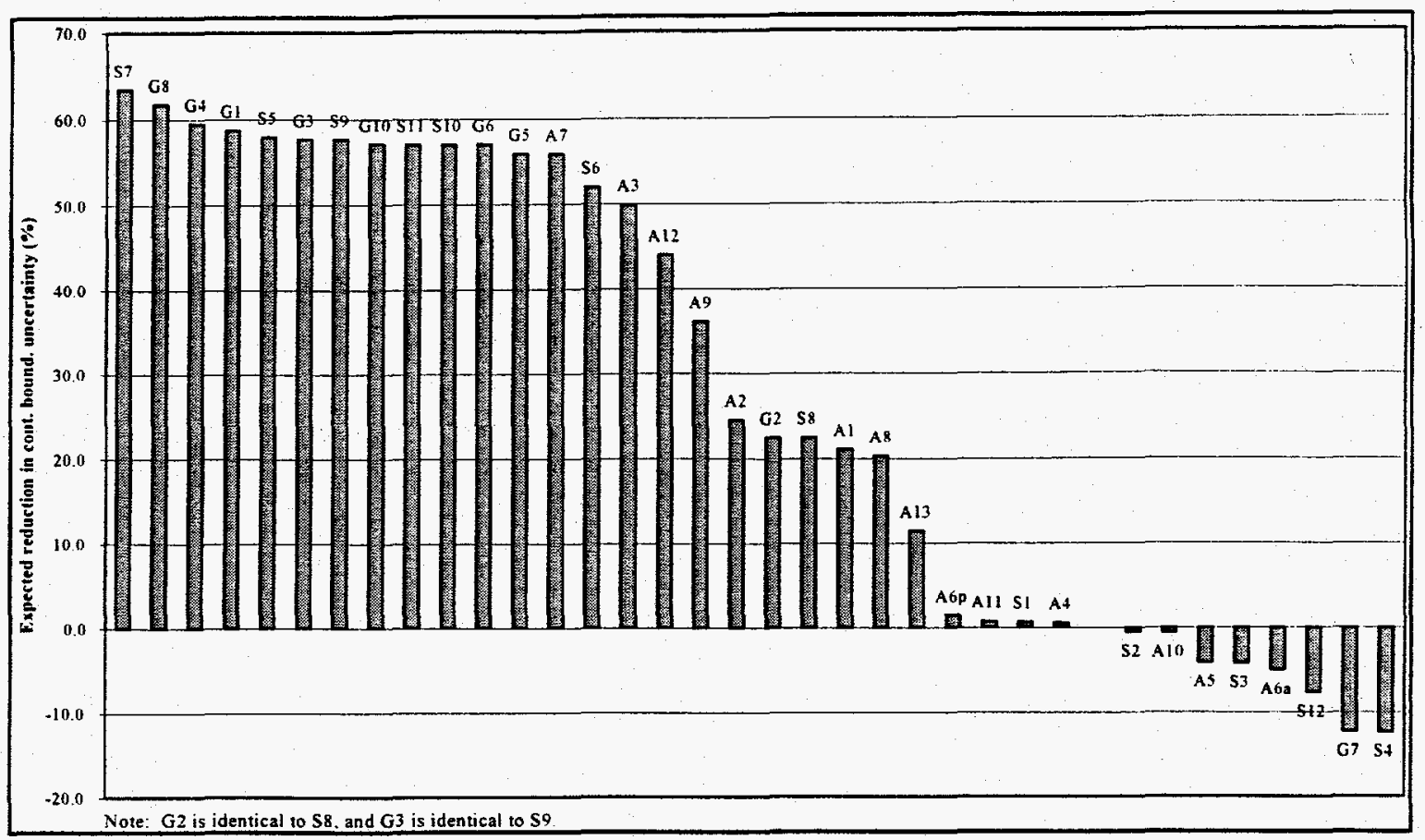

Figure 4-3

Results: Activity Groups, Subgroups, and Activities Ranked by Expected Contaminant Boundary Location Uncertainty Reduction

Note from Figure 4-3 that some options are expected to produce an increase in the uncertainty measure. The options that are expected to increase uncertainty are options that focus on diffusion and porosity. These options also generally rank lower with regard to this measure than they do using the parameter-uncertainty-reduction measure.

There are several reasons for the poor performance with respect to this measure of options focused on matrix diffusion and porosity. First, unlike the other parameters, lower values for matrix diffusion and porosity tend to produce larger contaminant boundaries, all else being equal. Lognormal probability distributions were selected by the expert panel to represent the uncertainties in these parameters. The lognormal distribution is skewed. As with the distribution shown in Figure 1-4, the mean of the lognormal distribution is above the median. Consequently, the lognormal assumption results in values lower than the mean that is likely for these cases. Thus, the lognormal assumption produces a situation where tests are more likely to produce results leading to increased predicted distances. Furthermore, the location of the contaminant boundary is more sensitive to decreases in values for the diffusion parameter and effective porosity than it is to increases. In other words, a decrease from the mean of the diffusion parameter or effective porosity results in a larger increase in estimated maximal extent of the contaminant boundary than the 
decrease in the distance to the contaminant boundary that results from a comparable increase in the values of these parameters. The net effect of these assumptions is a tendency for changes in diffusion parameter and effective porosity to increase the "tail" of the distribution for the distance to the contaminant boundary, which increases the value of the uncertainty measures. Finally, the accuracy estimates provided for activities focused on diffusion and effective porosity generally suggest that they tend to report lower values more reliably than greater values, and can be expected to increase uncertainty. If the actual values are lower, test results will show it; if they are not, the test results will be ambiguous. The net result of these judgments is that some groups with activities focused on the diffusion parameter and effective porosity are expected to increase, rather than decrease the measure.

Figure 4-4 plots the expected uncertainty in the maximal extent of the contaminant boundary versus cost.

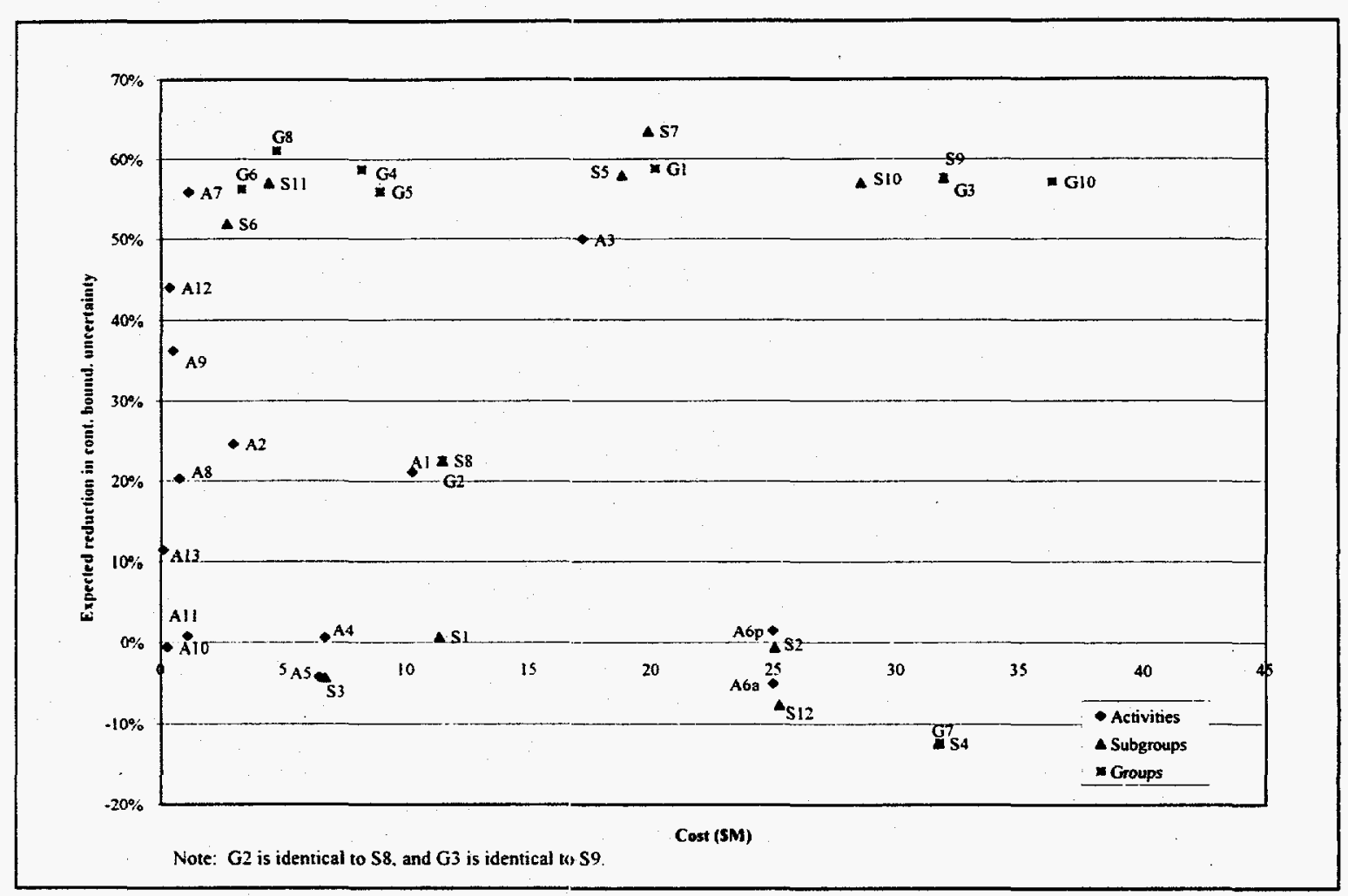

Figure 4-4

Expected Contaminant Boundary Location Uncertainty Reduction Versus Cost 
Seven options are identified as "optimal" (on the Pareto Frontier):

- Activity 13 (barometric and earth-tide responses)

- Activity 12 (geological and geophysical modeling)

- Activity 7 (geochemistry-based investigations)

- Group 6 ("low cost," composed of A7, 8, 9, 10,12, and 13)

- Subgroup 11 (A2, 7, and 12)

- Group 8 ("value," composed of A2, 7, 10, 12, and 13)

- Subgroup 7 (A3, 7, 8, 9, and 12)

Note that four of these options, Activities 13 and 7 and Group 6 and 8, were also identified as optimal using the previous measure.

\subsection{Ability of Characterization Options to Reduce the Upper-Bound Estimate of the Distance to the Contaminant Boundary}

Figure 4-5 displays the results obtained with this measure. Again, the results exclude Group 9, since it was not possible to conduct the very large number of Monte Carlo simulations that would have been required. As with the previous measure, options that focus on the diffusion parameter and effective porosity are ranked lower than with the parameter uncertainty reduction measure and,

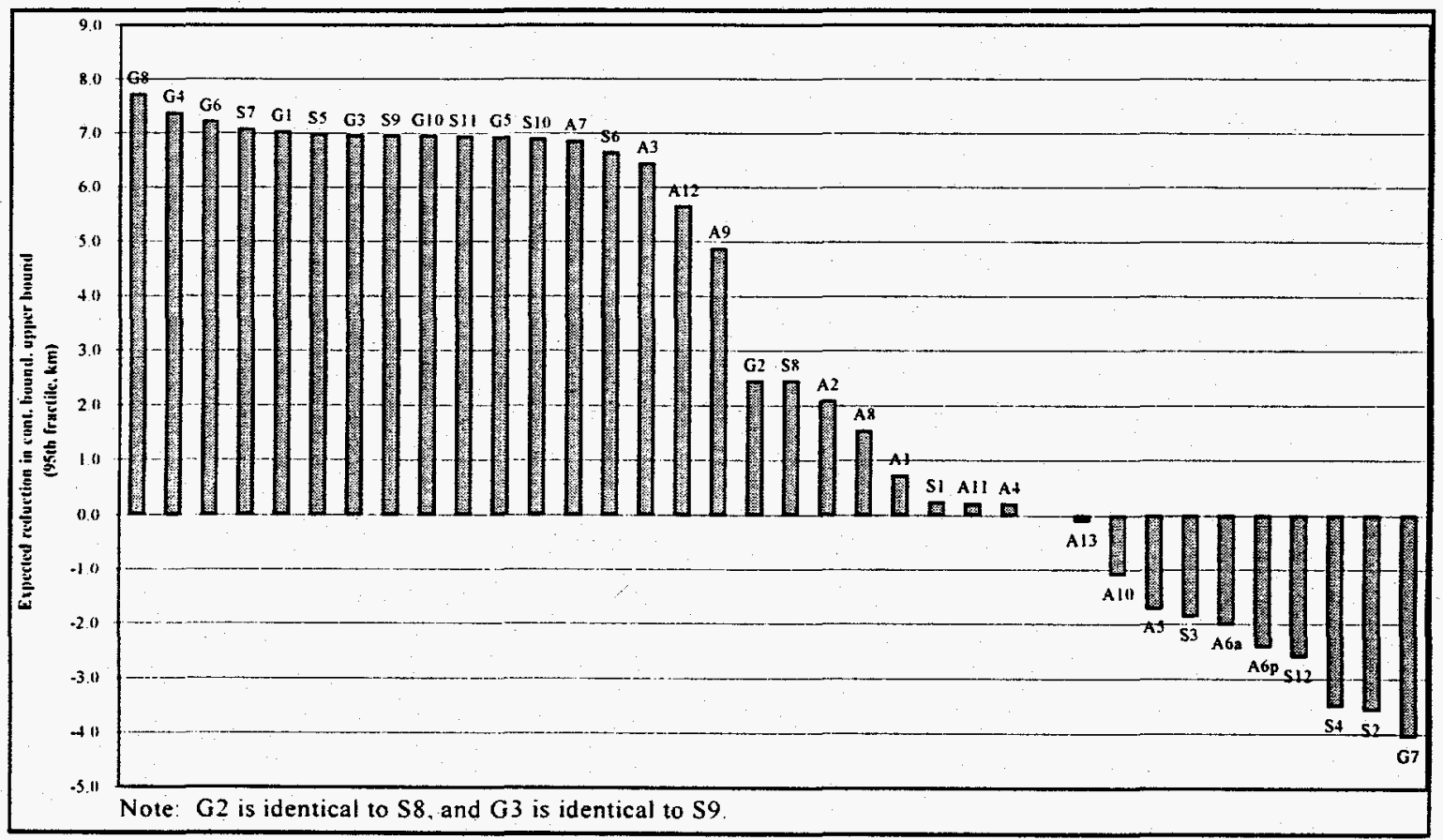

Figure 4-5

Results: Activity Groups Ranked by Expected Reduction in Upper Bound (95 ${ }^{\text {th }}$ fractile) of the Distance to the Contaminant Boundary 
in some cases, are expected to produce increases rather than decreases. The reasons are the same as for the previous measure. Overall, the ranking order is similar but there are some differences. Options focused on the diffusion parameter and effective porosity did even worse with respect to this measure than with the previous measure, and even more options are expected to increase rather than decrease uncertainty.

Figure 4-6 plots the expected reduction in the upper-bound estimate of the maximal extent of the contaminant boundary versus cost. Four options are identified as "optimal" (on the Pareto Frontier):

- Activity 12 (geological and geophysical modeling)

- Activity 7 (geochemistry-based investigations)

- Group 6 ("low cost," composed of $A 7,8,9,10,12$, and 13)

- Group 8 ("value," composed of A2, 7, 10,12, and 13)

Note that each of these was also identified as optimal on at least one of the other measures.

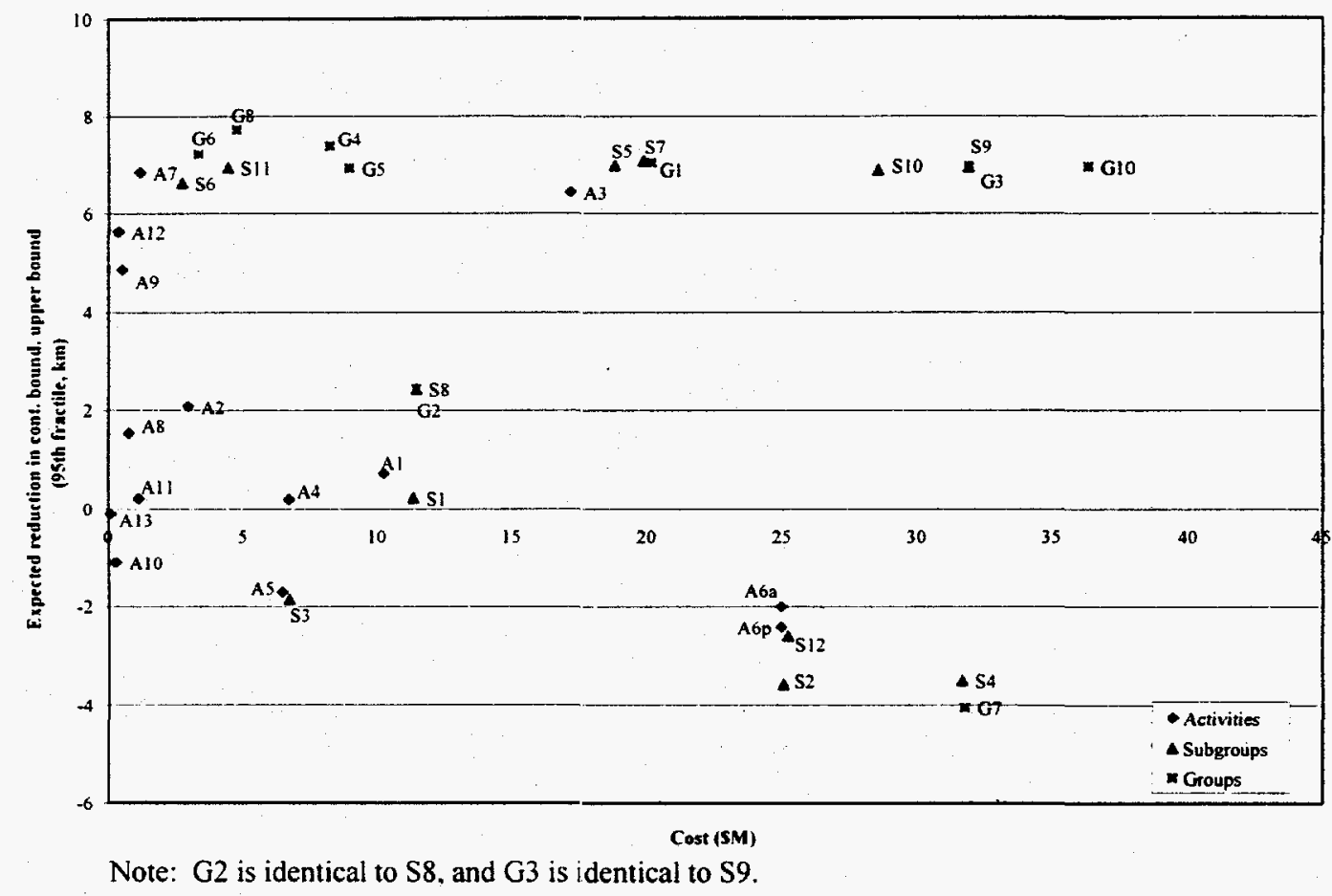

Figure 4-6

Results: Expected Contaminant Boundary Location Upper Bound (95th fractile) Reduction Versus Costs 


\subsection{Results}

The results of the Pahute Mesa VOIA may be summarized as follows:

- Characterization options were found to differ significantly in terms of their costs and in terms of the estimated reductions in uncertainty that they would produce. The costs of options ranged from $\$ 75.6 \mathrm{~K}$ to $\$ 40.2 \mathrm{M}$. The impact of options on uncertainties varied by an even wider range.

- Different measures of uncertainty reduction produced different rankings. Some measures were better at reducing parameter uncertainty, other measures were better in producing reductions in the uncertainty over the maximal extent of the contaminant boundary, and others were better at reducing uncertainty over the upper bound estimate of the maximal extent of the contaminant boundary. This result suggests that the choice of characterization options depends (to some degree) on the objectives of uncertainty reduction.

- In some cases, conducting a characterization option may be expected to increase one or more of the uncertainty measures. As noted previously, any information-collection activity that can produce surprising results can increase uncertainty. To account for this, the analysis computed the expected change in the uncertainty measure or the probabilityweighted average of the possible changes. Roughly speaking, if an option is expected to increase uncertainty, then that option is judged likely to produce surprising results and/or surprising results are judged to produce larger increases in uncertainty than the decreases that would occur if outcomes confirm current views.

- Despite the fact that different measures produced different rankings, some options ranked high regardless of the measure of uncertainty used. The uncertainty reduction estimated for options containing multiple activities was typically greater than the uncertainty reductions estimated for any of the component activities alone (although, the combined uncertainty reduction of two activities was often less than the sum of the uncertainty reductions estimated for the activities alone). Thus, groups of activities generally ranked higher than single activities, and the groups with the most activities generally ranked the highest.

- Several options consistently ranked at or near the top in terms of producing the largest expected uncertainty reduction at the smallest total cost. An option was defined as "optimal" if it was estimated to provide at least as much uncertainty reduction as any other option that costs the same or more. Between four and seven options were identified as optimal depending on the uncertainty-reduction measure used. Three options were consistently identified as optimal regardless of the measure used:

- Activity 7 (isotopic and geochemical investigations)

- Group 6 ("low cost," composed of Activities 7, 8, 9, 10, 12, and 13)

- Group 8 ("value group," composed of Activities 2, 7, 10,12, and 13) 
- In general, the analysis suggests that activities providing information related to the flux multiplier appear to have relatively high value regardless of the measure used. Activities related to porosity were of the next highest value for the parameter-uncertainty measure and the contaminant-boundary uncertainty measure. With respect to the 95 percent fractile measure, porosity ranked below source term. Activities providing information related to diffusion and source term were estimated to have less value. However, the relatively low uncertainty-reducing potential of activities focused on source term may be due to inappropriately low estimates of the amount of current uncertainty about the source term.

- Although activities related to diffusion were estimated to provide little uncertainty-reducing capability when applied alone, they were found, in some cases, to add significant uncertainty-reducing potential when included in groups of activities that contain one or more activities addressing flux.

\subsection{Analysis Limitations}

In theory, the comparative evaluations presented in this section account for many factors that should logically affect the choice of characterization options. However, despite the comprehensive consideration of relevant factors and the well-founded theoretical basis for the analysis, the reliability of the rankings and the uncertainty-reduction estimates produced is necessarily limited.

Major factors incorporated into the analysis include the following:

- The specific uncertainties that the option is likely to impact. The analysis distinguishes between options that address only one or two uncertainties and those that address most or all key uncertainties.

- The sensitivity of the distance to the contaminant boundary as it relates to the impacted uncertainty. The analysis accounts for whether contaminant transport is believed to be very sensitive to the impacted uncertainties, or not very sensitive.

- The current level of information/urderstanding regarding the impacted uncertainties. The analysis accounts for whether the option is expected to add information to an area that is already relatively well understood or add information to an area about which very little is known.

- The accuracy/reliability/sensitivities of activities. The analysis accounts for the estimated capabilities of the individual activities that make up the option; namely, their uncertainties, whether they tend to give biased estimates, and whether their accuracy varies depending on actual site conditions. 
- Informational interdependencies. The analysis accounts for the degree to which informational synergies may exist among the component activities of an option and whether the information that is collected is complementary or redundant.

- Cost and cost interdependencies. The analysis accounts for the costs of conducting the activities that make up the option plus whether cost savings or cost increases may be expected due to economies of scale, synergisms or antagonisms over resource use, or other factors.

Among the limitations that must be taken into account when interpreting results are the following:

- Limited quality of input judgments. The expert panel was required to provide numerous, difficult assessments as input to the analysis. Although panel members were selected for their expertise and understanding of the specific issues addressed, the estimates that they were required to provide are inherently difficult. In particular, the estimates of the accuracies of activities and subgroups of activities were especially difficult to generate. Understanding about the activities and their accuracies is limited, and the expression of uncertainty in terms of probabilities is a difficult task. Errors in input judgments may produce errors in results.

- Limitations of the regional transport model. The transport model is an interim model that will be replaced by a more sophisticated model as additional work focuses on the CAU scale transport. It involves many approximations and assumptions which limit its ability to translate geohydrologic and other parameters into reliable estimates of contaminant transport. Approximations in the transport model may produce errors in the rankings calculated for the two measures related to contaminant boundary location.

- Precision of Monte Carlo results. To ensure that Monte Carlo analyses accurately translate distributions over model input variables into the distributions that they imply over model outputs, it is necessary to run the model many times to ensure that the number of input values sampled from input distributions is very large. For practical reasons, the Monte Carlo analyses conducted for this evaluation were limited (in most cases) to 200 model simulations per analysis. Tests were conducted to determine the magnitude of errors possibly introduced by limiting the number of Monte Carlo simulations. These indicated that errors of roughly 10 percent can be produced in the estimates of fractiles of the distributions of the maximal extent of the contaminant boundary when compared with simulations that included 1,000 realizations. Thus, limited precision of the Monte Carlo analyses limits the precision of the rankings and estimates produced by the analysis.

- Appropriateness of named distributions. The process of generating input probability distributions for the analysis was simplified by allowing the expert panel to specify two-parameter probability distributions and the $5^{\text {th }}$ and $95^{\text {th }}$ fractiles of those distributions. However, named distributions, while mathematically convenient, may have 
characteristics that do not well-reflect the uncertainties they are intended to represent. The named distributions were truncated to eliminate the possibility of infeasible parameter values (e.g., negative values for parameters that cannot be negative). However, the resulting truncated distributions still contain features (such as the potential for values higher than possible) that may distort results. Sensitivity analyses show that rankings are sensitive to the functional form of the probability distributions assumed.

- Discrete approximations. The discretizing process used for Bayesian updating introduces errors. Discretizing errors can be made small by using a very large number of levels for discrete approximations. However, increasing the number of levels increased the number of Monte Carlo analyses required. Thus, for the calculations using the two measures related to the contaminant boundary location, practical considerations required that discrete approximations utilize a smaller number of levels than would otherwise be desirable. Sensitivity studies demonstrated that the magnitude of discretizing errors was generally less than a few percent, but in a few instances 10 percent or more.

For these and the additional reasons cited in Section 1.3, the results should be interpreted with caution. As stated at the beginning of this report, the results are best considered as an aid to decision making, to be factored along with other inputs to the decision making process. 


\subsection{Conclusions}

This section summarizes the main conclusions from the VOIA.

- In the context of predicting contaminant transport from Pahute Mesa, activities that help resolve uncertainty regarding the groundwater flow system (i.e., activities that help determine the flux multiplier for the regional model) are particularly important. Such activities include geochemistry-based investigations and exploratory drilling southwest of Pahute Mesa. Characterization options that include at least one of these activities appear to be relatively effective at reducing uncertainty regarding the maximal extent of contaminant transport.

- Other very effective activities for resolving uncertainty regarding the groundwater flow system include resistivity and audiomagnetotelluric surveys and geologic and geophysical modeling.

- Although activities focused on groundwater flow are particularly effective, there is declining incremental improvement to uncertainty reduction from including more and more of these types of activities within a characterization group. In other words, most of the uncertainty reduction benefit appears to accrue from including within the group only a few activities of this type.

- Activities that require drilling are less cost effective.

- Adding activities that focus on other sources of uncertainty to one or more of the strongest activities focused on the groundwater flow system can increase the uncertainty reduction performance of the group. By conducting geochemistry-based investigations plus a limited number of additional balanced and cost-effective activities, it appears possible to obtain most of the potential for uncertainty reduction for a total cost under about $\$ 5$ million. 


\subsection{References}

Adams, S.R., IT Corporation. 1996a. Memo to J. Wille regarding Dose Evaluation for Individuals Ingesting Radiologically Contaminated Groundwater, 17 June. Las Vegas, NV.

Adams, S.R., IT Corporation. 1996b. Memo to B.J. Deshler regarding UGTA Feasibility and Frenchman Flat Value of Information Studies Support Calculations, 8 October. Las Vegas, NV.

Anderson, B.F., D.H. Deane, K.R. Hammond, G.M. McClelland, and J.C. Shanteau. 1981. Concepts in Judgment and Decision Research. New York, NY: Praeger Scientific.

Apostolakis, G. 1981. "Bayesian Methods in Risk Assessment." In Advances in Nuclear Science Technology, 13. J. Lewins, and M. Becker (eds.). New York, NY: Plenum.

Bayes, T. 1958. "Essay Toward Solving a Problem in the Doctrine of Chances." In Biometika.

Blankennagel, R.K., and J.E. Weir, Jr. 1973. Geohydrology of the Eastern Part of Pahute Mesa. Nevada Test Site, Nye County, Nevada, USGS-PP-712-B. Denver, CO:

U.S. Geological Survey.

Clemen, R.T. 1990. Making Hard Decisions: An Introduction to Decision Analysis. Belmont, CA: Duxbury Press.

Demski, J. 1972. Information Analysis. Menlo Park, CA: Addison-Wesley.

DOE, see U.S. Department of Energy.

FFACO, see Federal Facility Agreement and Consent Order.

Federal Facility Agreement and Consent Order. 1996. Agreed to by the State of Nevada, the U.S. Department of Energy, and the U.S. Department of Defense.

Ferguson, J.F., A.H. Cogbill, and R.G. Warren. 1994. "A Geophysical-Geological Transect of the Silent Canyon Caldera Complex, Pahute Mesa, Nevada." In Journal of Geophysical Research, 99 (B3):4323-4339. Washington DC: American Geophysical Union.

Fisz, M. 1963. Probability Theory and Mathematical Statistics, 3rd Edition. New York, NY: John Wiley \& Sons.

Grauch, V.J.S., D.A. Sawyer, C.J. Fridrich, and M.R. Hudson. 1997. Geophysical Interpretations West of and Within the Northwestern Part of the Nevada Test Site, USGSOFR-97-476. Denver, CO: U.S. Geological Survey. 
Iman, R.L., J.M. Davenport, and D.K. Ziegler. 1980. Latin Hypercube Sampling (Program User's Guide), SAND79-1473. Albuquerque, NM: Sandia National Laboratories.

Laczniak, R.J., J.C. Cole, D.A. Sawyer, and D.A. Trudeau. 1996. Summary of Hydrogeologic Controls on Ground-Water Flow at the Nevada Test Site, Nye County, Nevada, USGS-OFR-96-4109. Carson City, NV: U.S. Geological Survey.

Lichtenstein, S., and B. Fischhoff. 1977. 'Do Those Who Know More Also Know More About What They Know?" In Organizational Behavior and Human Performance 20: 159-183.

Merkhofer, M.W. 1987. "Quantifying Judgmental Uncertainty: Methodology, Experiences, and Insights." In IEEE Transactions on Systems, Man, and Cybernetics, SMC-17(5):741-752.

Oliver, R.M., and J.Q. Smith (eds.) 1989. Influence Diagrams, Belief Nets, and Decision Analysis. New York, NY: John Wiley \& Sons.

Press, W.H., B.P. Flannery, S.A. Teukolsky, and W.T. Vetterling. 1986. Numerical Recipes: The Art of Scientific Computing. New York, NY: Cambridge University Press.

Sawyer, D.A., and K.A. Sargent. 1989. "Petrographic Evolution of Divergent Peralkaline Magmas from Silent Canyon Caldera Complex, Southwestern Nevada Volcanic Field." In Journal of Geophysical Research, 94: 6021-6040. Washington, DC: American Geophysical Union.

Spetzler, C.S., and C.A. Stael von Holstein. 1975. "Probability Encoding in Decision Analysis." In Management Science, 22: 340-358. Stanford, CA: The Institute of Management Science.

Tversky and Kahnaman. 1974. "Judgmen: Under Uncertainty: Heuristics and Biases." In Science, September 26: 1124-1131.

U.S. Department of Energy, Nevada Operations Office. 1997. Regional Groundwater Flow and Tritium Transport Modeling and Risk Assessment of Underground Test Area, Nevada Test Site, $N V$, DOE/NV-477. Las Vegas, NV: Environmental Restoration Division. 


\section{Appendix A}

\section{Expert Panel Qualifications}


The expert panel consisted of members of the Technical Working Group Subcommittee and members of the core group. The primary role of the expert panel members was to provide expert technical input for the decision model. The expert panel members are listed alphabetically along with a summary of their qualifications.

\section{Bruce Crowe - Los Alamos National Laboratory}

Bruce Crowe is a Science Advisor for the Nevada Test Site (NTS) Environmental Management programs with Los Alamos National Laboratory. He received a Ph.D. and an M.A. in Geology from the University of California, Santa Barbara, and a B.A. in Geology from Fresno State University. His areas of expertise include geology, volcanology, probabilistic risk assessment, performance assessment, application of expert judgment, and the geology and hydrology of the NTS. Mr. Crowe has prepared multiple refereed papers, book chapters, and consulting publications in geology, volcanology, probabilistic hazard assessment, tectonic processes, and impact on society and geological aspects of disposal of radioactive waste. He has extensive experience with the geology and tectonics of the NTS, and extensive experience with probabilistic hazard and risk assessment. He has been a participant in national and international committees and panels on performance assessment and probabilistic hazard assessment. $\mathrm{He}$ is a member of the National Research Council Panel on Active Tectonics and Impact on Society. Mr. Crowe has acquired management experience as group leader of the geological applications group and isotope and geochemistry group of Los Alamos National Laboratory. He was the recipient of various awards, including the Los Alamos Distinguished Performance Award and the Los Alamos Directors Postdoctoral Award.

\section{Barbara J. Deshler - IT Corporation}

Barbara Deshler has eleven years of environmental consulting experience as a project manager, principal technical resource, and line manager, primarily as contractor at the NTS, the Waste Isolation Pilot Plant in New Mexico, and other U.S. Department of Energy (DOE) sites. She has experience in the areas of risk assessment, regulatory compliance, and strategic planning, and she is a Nevada Certified Environmental Manager and IT Corporation Project Management Associate. She has facilitated negotiations among DOE, U.S. Environmental Protection Agency (EPA), and state regulatory authorities on agreements, permits, risk assessments, and other compliance-related documents. Her expertise includes compliance with the requirements of federal regulations, DOE orders, EPA guidance, and state policies and regulations for assessment and remediation of contaminated sites and treatment, storage, and disposal of contaminated media. She has a B.S. in Geological Sciences from the University of Texas at El Paso. 


\section{Warda Drici - IT Corporation}

Warda Drici is a senior hydrogeologist with IT Corporation in Las Vegas, Nevada. She received an M.S. degree in Petroleum Engineering and an M.S. degree in Petroleum Management (Honors) from the University of Kansas. She also holds a B.S. in Mathematics. Ms. Drici has more than 14 years of experience in research and applied hydrogeology in the governmental and commercial sectors. She co-authored and presented several technical papers and was the recipient of several professional awards. Her experience includes water resource management using optimization techniques, characterization and remediation of hazardous sites, and groundwater flow and transport modeling. Over the past 6 years, she has worked on various tasks relating to the UGTA Subproject of the DOE Nevada Operations Environmental Restoration Program. She manages various tasks in support of groundwater flow and contaminant transport modeling. She has also prepared various technical documents relating to the UGTA Subproject.

\section{William Fryer - HSI GeoTrans, Inc.}

William Fryer, CPG, is a senior hydrogeologist with HSI-GeoTrans, Inc. in Las Vegas, Nevada, working on the Nevada DOE Environmental Restoration contract for the NTS. He has been dedicated to the UGTA project since its inception almost six years ago. Mr. Fryer has a B.S. in Geology from Michigan State University, and has worked in various aspects of hydrogeology for over 18 years, primarily conducting groundwater and contamination characterization investigations. At the NTS he initially managed hydrologic testing activities for the UGTA program, and continues to consult on well design and testing. In recent years he has participated in the development of the Federal Facility Agreement and Consent Order technical strategy for UGTA and the Frenchman Flat Value of Information Analysis, as well as managing development of the BULLION forced-gradient tracer experiment. He is currently working on the analysis of the tracer experiment.

\section{Randall J. Laczniak - U.S. Geological Survey}

Randall J. Laczniak is a senior hydrologis: with the U.S. Geological Survey in Las Vegas, Nevada. He received degrees in geology from Virginia Polytechnic Institute (M.S.) and the University of Wisconsin-Madison (B.S.). Mr. Laczniak has conducted numerous groundwater investigations over the past 18 years while employed by the U.S. Geological Survey in Virginia and Nevada. During these years he has served as staff research scientist and Principal Investigator and has published many U.S. Geological Survey reports and journal articles on a variety of groundwater topics. Over the past five years, he has served on various committees and 
review boards established to address groundwater issues at the NTS. His current interests and projects include research in fluid-pressure and aquifers-system responses to natural and man-induced stress, atmospheric water loss from shallow flow systems, and the application of remotely sensed data for addressing groundwater issues of the arid southwest.

\section{Gayle Pawloski - Lawrence Livermore National Laboratory}

Gayle Pawloski is a geologist for Lawrence Livermore National Laboratory (LLNL). She received a B.S. in Earth Sciences from California State University Hayward. She has been working at LLNL for eighteen years, supporting a wide variety of programs, including Nuclear Test Containment Program, Threshold Test Ban Treaty (TTBT) treaty verification, Underground Coal Gasification, and the Office of Basic Energy Sciences Continental Scientific Drilling Program. She has been part of the Underground Test Area Subproject since its inception. Ms. Pawloski has worked at the NTS since 1980, specializing in NTS geology, interpretation of geologic and geophysical data, site characterization, nuclear explosion phenomenology, and information management. She is currently the Task Leader for Site Characterization for the LLNL Containment Program and serves as the geologic representative to the UGTA Technical Working Group.

\section{Kenneth R. Rehfeldt - HSI GeoTrans, Inc.}

Kenneth R. Rehfeldt is a Principal Hydrogeologist with HSI GeoTrans in Las Vegas, Nevada. He has a Ph.D. in Civil Engineering from the Massachusetts Institute of Technology, an M.S. in Hydrology from the New Mexico Institute of Mining and Technology, and a B.A. in Geological Sciences from the University of Wisconsin-Milwaukee. Mr. Rehfeldt currently serves as technical lead of hydrogeological data analysis and groundwater modeling for the underground test area project of the environmental restoration program at the NTS. He provides technical oversight of potentiometric, water balance, aquifer test, porosity, dispersivity, and sorption data compilation and analysis as well as performs solute transport modeling to simulate radionuclide migration from the underground testing areas of the NTS. He has authored or coauthored more than 50 publications, reports, and presentations related to characterization of heterogeneous porous media, geostatistical analyses of aquifer and compacted soil liner properties, regional characterization of groundwater quality, the fate and transport of solutes in saturated and unsaturated flow, the development of a methodology to define well-head protection areas around municipal wells, and the analysis and modeling of the groundwater flow system at the NTS. 


\section{Charles Russell - Desert Research Institute}

Charles Russell is an Assistant Research Hydrogeologist with the Desert Research Institute in Las Vegas, Nevada. Mr. Russell has a B.S. Degree in Geology from Eastern Washington University and a M.S. Degree in Geosciences, with special emphasis on stable isotope geochemistry, from the University of Nevada, Las Vegas. Mr. Russell has conducted studies of groundwater hydrology and aqueous geochemistry of the NTS for over thirteen years. Specific research areas include studies of the hydrogeology of fractured rocks using stable isotopes, tritium reduction utilizing air-stripping, and the variability of aqueous chemistry associated with bacteria in the deep subsurface. Applied research include the reduction of aquifer test data, geochemical analyses and interpretation, and utilization of the chloride mass-balance approach to determine groundwater recharge. The results of these studies have been published in numerous Desert Research Institute publications, journals, and monograms. Mr. Russell has served on many DOE groundwater committees and working groups, providing technical expertise and guidance as required.

\section{Michael Sully - Bechtel Nevada}

Michael Sully is a hydrologist with Bechtel Nevada. He received a Ph.D. in Soil Science from the University of California, Davis, an M.S. in Atmospheric Science from the University of California, Davis, and a B.A. in Physics from the University of Montana, Missoula. Mr. Sully has contributed to site characterization efforts, performance assessments, closure cover development and monitoring system design through activities including developing hydrogeologic conceptual models for heterogeneous porous media, characterizing transport parameters, numerical modeling of flow and transport and soil-plant atmosphere interactions, and conducting field experiments to verify and calibrate numerical models. He also served as an assistant professor in the Department of Hydrology and Water Resources in the College of Engineering at the University of Arizona, and as an experimental scientist at CSIRO Division of Environmental Mechanics in Canberra, Australia.

\section{Rick K. Waddell - HSI GeoTrans, Inc.}

Richard K. Waddell is a Principal Hydrogeologist and Vice President of HSI GeoTrans. He received a Ph.D. in Geology from the Pennsylvania State University, and M.A. and B.S. degrees in geology from the University of Texas at Austin. He has 20 years of post-graduate experience in evaluating ground-water flow and transport processes. He was a member of the National Research Program, U.S. Geological Survey, performing studies of the regional hydrology of the Nevada Test Site, developing approaches for characterizing fractured volcanic rocks, and 
evaluating radionuclide transport at Yucca Mountain. During the past twelve years, he has worked as a consultant on projects ranging from water-resource management to characterization, risk assessment, and remediation of contaminated waste sites. The majority of his work over the past six years has been on characterization and modeling of radionuclide transport processes at the NTS.

\section{Janet Wille - IT Corporation}

Janet Wille has extensive training in low-temperature aqueous geochemistry, hydrogeology, and computer modeling of aqueous reactions. She completed her doctoral dissertation on the use of geochemistry in preliminary screening studies for the siting of hazardous and nuclear waste repositories. While at IT Corporation, she has been involved in disposal permitting activities and remedial investigation and feasibility studies. She has been the principal investigator for extent of contamination studies at hazardous waste disposal sites. Her responsibilities in these studies include the design and implementation of monitoring well sampling and analysis programs, the interpretation of laboratory data on soil and groundwater decontamination, and report preparation for submittal to state and federal agencies. Ms. Wille is currently the project manager for the underground test areas at the NTS and has worked on technical issues related to the characterization, remediation, and disposal of radioactively contaminated soils at the NTS. Because of her professional achievements, Ms. Wille has been named an IT Technical Associate. She has a Ph.D. in Geochemistry from the Colorado School of Mines in Golden, Colorado, and a B.S. in Geological Sciences from the University of Illinois in Chicago. 


\section{Appendix B}

Description of Groundwater Flow and Transport Regional Model 


\section{Table of Contents}

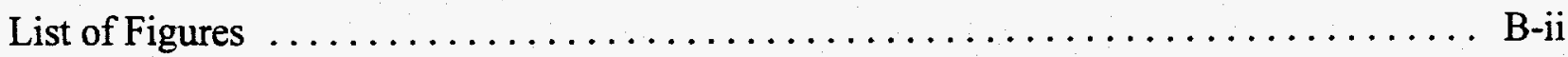

B.1.0 Introduction $\ldots \ldots \ldots \ldots \ldots \ldots \ldots \ldots \ldots \ldots \ldots \ldots \ldots \ldots \ldots \ldots \ldots \ldots \ldots \ldots \ldots \ldots, 1$

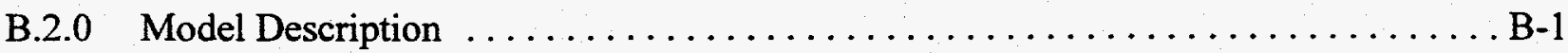

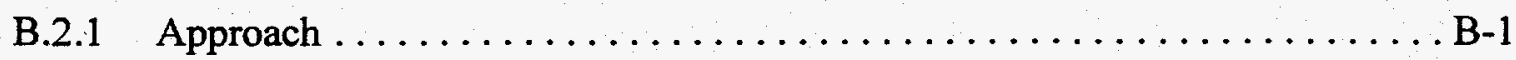

B.2.1.1 Groundwater Flow and Particle Tracking Codes .......... B-1

B.2.1.2 Contaminant Transport Code ....................

B.2.1.2.1 Mobile Domain .....................

B.2.1.2.2 Immobile Domain $\ldots \ldots \ldots \ldots \ldots \ldots \ldots \ldots \ldots \ldots \ldots$

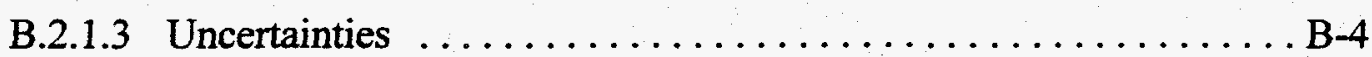

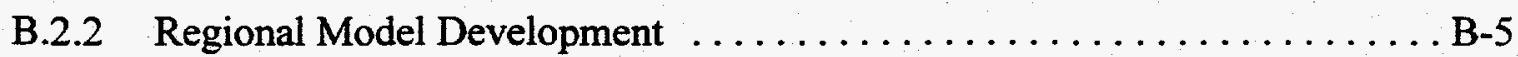

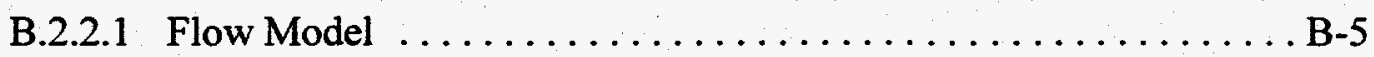

B.2.2.2 Transport Model ...........................

B.3.0 Simulation and Sensitivity Analysis Results $\ldots \ldots \ldots \ldots \ldots \ldots \ldots \ldots \ldots$ B-10

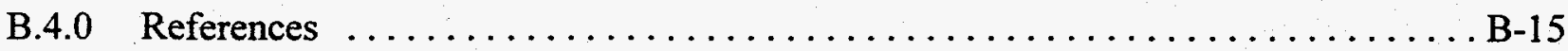


B-1 Groundwater Pathlines from Nuclear Test Locations Near or Below the Water Table for a 200-Year Period

B-2 Groundwater Pathlines, from Source to Receptor, Chosen for the Regional Transport Simulations

B-3 Concentration Uncertainty Due to Each Parameter for the TYBO Pathline at a Distance of $1 \mathrm{~km}$

B-4 Concentration Uncertainty Due to Each Parameter for the TYBO Pathline at a Distance of $10 \mathrm{~km}$

B-5 Concentration Uncertainty Due to Each Parameter for the TYBO Pathline at a Distance of $30 \mathrm{~km}$ 


\section{B.1.0 Introduction}

The regional model (DOE/NV, 1997) was developed to determine if any immediate risks to human health and the environment exist as the result of radionuclide transport by groundwater from the underground test areas. The model was used to simulate the migration of tritium from the underground test locations. The regional model was used to support the VOIA for the Pahute Mesa CAUs.

\section{B.2.0 Model Description}

\section{B.2.1 Approach}

The regional model was developed using three codes. The first was MODFLOW, a threedimensional groundwater flow modeling code developed by the U.S. Geological Survey (McDonald and Harbaugh, 1988). The second, to characterize three-dimensional pathlines through the groundwater flow model, used MODPATH (Pollock, 1989). The transport simulations were performed along the pathlines using the third, a one-dimensional transport code, MC_TRANS (IT, 1996), developed specifically for the UGTA Subproject.

\section{B.2.1.1 Groundwater Flow and Particle Tracking Codes}

MODFLOW (McDonald and Harbaugh, 1988) is a numerical code that uses a finite-difference formulation to approximate the partial differential equation for three-dimensional groundwater flow of constant density fluid in a heterogeneous, anisotropic medium. The code uses the Block Centered Flow package (McDonald and Harbaugh, 1991) to calculate conductances and flow between adjacent cells.

The particle tracking computer code, MODPATH (Pollock, 1989), takes the output of the MODFLOW computer code and calculates the groundwater pathways. In MODPATH, an imaginary particle is followed as it flows through the groundwater system as defined by the numerical groundwater flow model. Using the PATHLINE output option of MODPATH, the location coordinates of the particle, in model space, are recorded where the particle crosses a grid cell boundary. 


\section{B.2.1.2 Contaminant Transport Code}

The one-dimensional code MC_TRANS simulates the concentration of dissolved radionuclides along the pathlines obtained from the regional flow model. MC_TRANS was developed to simulate the transport of chains of dissolved chemical constituents contained in fractured or porous media, where the diffusion of solute mass into matrix or dead-end pore space is an important factor. The code can be used in a deterministic mode or probabilistic mode incorporating uncertainty through the Monte Carlo method.

The transport code accounts for tritium advection, dispersion, radioactive decay, and matrix diffusion (IT, 1996) by solving a set of coupled equations that govern the transport of radionuclides in a dual porosity medium with a mobile and an immobile zone. The mobile zone is conceptualized by flow in fractures, and the immobile zone represents the matrix between fractures. The fracture flow portion is conceptualized as a porous medium with a small effective porosity consistent with fracture porosity.

A set of coupled equations governs the radionuclide transport in the fracture zone (mobile domain) and diffusion into and out of the matrix (immobile domain). Generic units are shown upper case and in square brackets, while specific units are lower case and in parentheses.

\section{B.2.1.2.1 Mobile Domain}

The transport in the mobile, or fracture, zone is given by

$$
\theta_{m} \frac{\partial C_{m}}{\partial t}=D_{m} \frac{\partial^{2} C_{m}}{\partial x^{2}}-\frac{\partial\left(\mathbf{q C}_{m}\right)}{\partial x}-\theta_{m} \lambda C_{m}-\alpha\left(C_{m}-C_{i m}\right)
$$

where

$\mathrm{C}_{\mathrm{m}} \quad=$ activity per volume of the radionuclide in fluids in the mobile zone [Activity $\left./ \mathrm{L}^{3}\right]$;

$\mathrm{C}_{\mathrm{im}}=$ activity per volume of the radionuclide in the pore fluid of the immobile zone [Activity/ $\mathrm{L}^{3}$;

$\theta_{\mathrm{m}} \quad=$ effective porosity of the mobile zone [dimensionless];

$\mathrm{D}_{\mathrm{m}} \quad=$ mobile zone hydrodynamic dispersion coefficient $\left[\mathrm{L}^{2} / \mathrm{T}\right] ;$

$\mathrm{q}=$ groundwater flux, also called Darcy flux [L/T];

$\alpha \quad=$ matrix diffusion zone mass transfer coefficient $[1 / T]$; 


$$
\begin{aligned}
\lambda & =\text { first-order constituent decay rate }[1 / \mathrm{T}] \\
\mathrm{t} & =\text { time }[\mathrm{T}] ; \text { and } \\
\mathrm{x} & =\text { space coordinate }[\mathrm{L}]
\end{aligned}
$$

and

$$
D_{m}=\theta_{m} \alpha_{1} v+\theta_{m} \tau D^{\circ}
$$

In Equation B-2, $\alpha_{1}$ is the longitudinal dispersivity [L]; $v$ is the average linear velocity of groundwater in the mobile zone $[\mathrm{L} / \mathrm{T}]$; $\tau$ is the mobile zone tortuosity; and $\mathrm{D}^{\circ}$ the molecular diffusion coefficient in free-standing solution $\left[\mathrm{L}^{2} / \mathrm{T}\right]$. The average linear velocity is defined as

$$
\mathbf{v}=\frac{\mathrm{q}}{\theta_{\mathbf{m}}}
$$

where $\theta_{m}$, the mobile zone porosity, is also called the effective porosity in this document. The first order radioactive decay constant is defined as

$$
\lambda \equiv \frac{\ln 2}{T^{1 / 2}}
$$

where $T^{1 / 2}$ is the half life of the radioactive constituent.

\section{B.2.1.2.2 Immobile Domain}

The governing equation for each constituent in the immobile zone can be written as

$$
\theta_{i m} \frac{\partial C_{i m}}{\partial t}=-\theta_{i m} \lambda C_{i m}+\alpha\left(C_{m}-C_{i m}\right)
$$

where

$$
\theta_{\mathrm{im}}=\text { effective porosity of the matrix immobile zone [dimensionless]. }
$$


The mass transfer coefficient $\alpha$ is regarded as an empirical constant (Coats and Smith, 1964). There are several definitions for $\alpha$ including those found in reports by van Genuchten (1981) and Sudicky (1990). For the dual porosity approach, the formulation of Sudicky is implemented:

$$
\alpha=\frac{3 \theta_{i m} D_{m}^{*}}{B^{2}}
$$

where $B$ is the average length dimension of the immobile domain, and $D_{m}{ }^{*}$ is the effective diffusion coefficient in the porous matrix and, for isotropic media, is defined as (Bear, 1972)

$$
D_{m}^{*}=\tau_{i m} D^{0}
$$

where $\tau_{i m}$ is the tortuosity of the porous matrix and $\mathrm{D}^{\circ}$ is the diffusion coefficient in water. In the remainder of the text, the process of radionuclide movement into the immobile domain will be referred to as matrix diffusion.

\section{B.2.1.3 Uncertainties}

The transport predictions are a function of a large number of parameters representing both flow and transport processes. Nearly all of the parameters in the equations described above are uncertain and known within a range of values that spans several orders of magnitude in many cases (DOE, 1997). Of the transport parameters, only the bulk density and the radioactive decay constant for tritium are treated as constants. The remaining transport parameters, effective porosity, matrix porosity, effective diffusion coefficient, fracture spacing, initial source concentration, and dispersivity, are assigned ranges of values based on the amount of uncertainty in measured values. Uncertainty in the groundwater flow model can be expected to also contribute to the uncertainty of the simulated concentrations. Uncertainties associated with hydraulic conductivity and recharge lead to uncertainty in the groundwater flux, which is the only parameter that links the flow model and the transport model.

The Monte Carlo approach using Latin hypercube sampling (Iman et al., 1980) was used to evaluate the impact of parameter uncertainty on the predicted concentrations. Monte Carlo is a technique for modeling a real-world situation in which one or more of the input parameters are either uncertain or may vary in a mathematically describable way. It employs random sampling from probability distributions to assign values to the uncertain parameters in the model. Use of the Latin hypercube approach reduces the number of Monte Carlo realizations required. The 
Latin hypercube method as provided by Iman et al. (1980) also allows the incorporation of parameter correlations.

The Monte Carlo technique is typically used in cases where too many parameters are uncertain or the mathematics are too complex to be solved analytically. In this case, the model that describes contaminant transport in the environment includes several parameters that are best described by probability distributions rather than single values. The probability distributions might include the normal, lognormal, uniform, exponential, or one of a number of other mathematical expressions that meet the requirements of a probability distribution function. The Monte Carlo simulation randomly selects the parameter values from the corresponding probability distributions to obtain a single model result (or realization) that is specific to that set of the parameter values. If parameters are rank-correlated, the value of one parameter will depend on the randomly selected value of another parameter. This process is then repeated over a large number of trials until the probability distributions of the model results can be described.

\section{B.2.2 Regional Model Development}

The regional model was set up to simulate the transport of tritium along a few pathlines representing the most potentially threatening routes of migration to off-site receptors.

\section{B.2.2.1 Flow Model}

The flow model was developed to define the pathlines that particles originating from each of the underground nuclear tests would follow within the three-dimensional groundwater flow system. This was accomplished by first developing a three-dimensional model, and second generating the pathlines using a particle-tracking code.

The three-dimensional groundwater flow model was calibrated to measured water levels and discharge estimates. Groundwater pathways were then determined for all underground test locations that are near (within two cavity radii) or below the water table, using MODPATH (Figure B-1). The location coordinates of a groundwater particle originating from a given test location were recorded where the particle crosses a grid cell boundary. Intermediate locations along the pathline within cells were determined and compared with the geologic model to identify the hydrostratigraphic unit at each intermediate location. Effective porosity values, appropriate for each hydrostratigraphic unit, were assigned to each point along the pathline, and travel times were computed. 


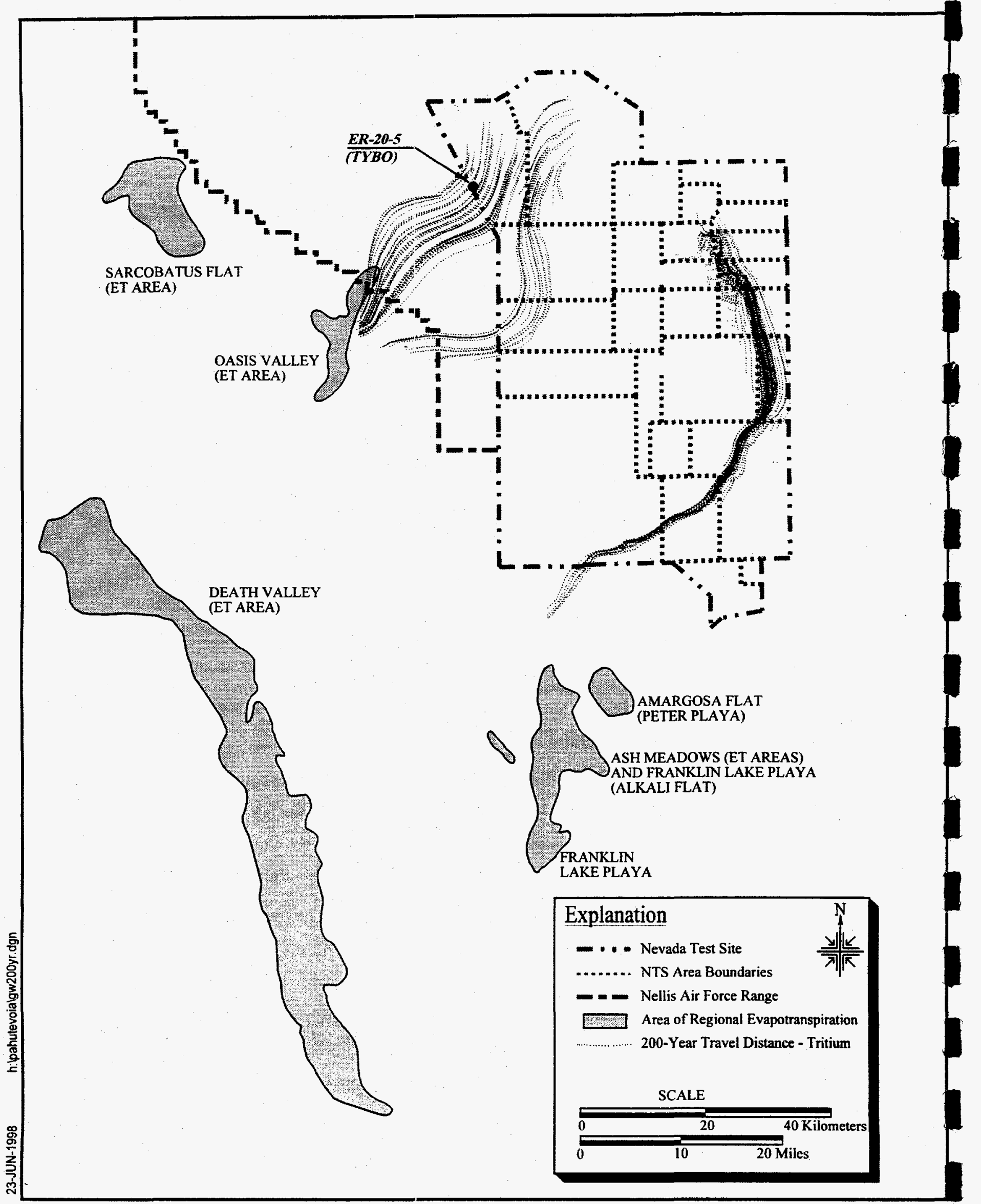

Figure B-1

Groundwater Pathlines from Nuclear Test Locations Near or Below the Water Table for a 200-Year Period 
To limit the number of transport simulations, three pathlines were selected for regional-scale transport modeling. The first one begins at PEPATO in Western Pahute Mesa and passes through KASH and TYBO, the second one begins at HOUSTON in Central Pahute Mesa, and the third one begins at KANKAKEE in Yucca Flat and passes through BOURBON and MICKEY and TORRIDO (Figure B-2). In the pathline selection process, nuclear tests with greater downgradient travel distance, which were closer to the southern boundary of an underground test area, were given priority. However, other factors such as the geology along the pathline and/or the representativeness of the pathline for flow downgradient were also considered.

\section{B.2.2.2 Transport Model}

Tritium transport simulations were performed for the selected pathline using conservative assumptions. MC-TRANS was operated using the stochastic option to account for the uncertainties associated with the input parameters. The ultimate goal was to determine the distance between the source (a given underground nuclear test location) and the maximum concentration limit of $20,000 \mathrm{pCi} / \mathrm{L}$ within a 200 year period after the test, with a 95 percent confidence level.

During the simulations, it was assumed that the initial form of the tritium source is a mass a tritium emplaced in the fractures and matrix within two cavity radii of the underground test shortly after detonation. This source term is a simplification, as stated in DOE (1997), but is considered reasonable for tritium. The source term and all other transport parameters were assigned ranges of values and probability distribution types. Uncertainty associated with the groundwater flux term was handled differently because the flux term is a combination of several parameters affecting flow. The major contributors to groundwater flux uncertainty are hydraulic conductivities and recharge rates. The impact of the uncertainty in the hydraulic conductivity parameters and the recharge on the predicted tritium concentrations was included in the transport model via sensitivity coefficients and the flux multiplier.

As described in DOE (1997), the sensitivity of the groundwater flux to hydraulic conductivity was calculated as part of the sensitivity analysis of the groundwater flow model. That sensitivity of groundwater flux to each hydraulic conductivity was defined as a sensitivity parameter and incorporated in the transport model via the groundwater flux term. Symbolically, the uncertainty 


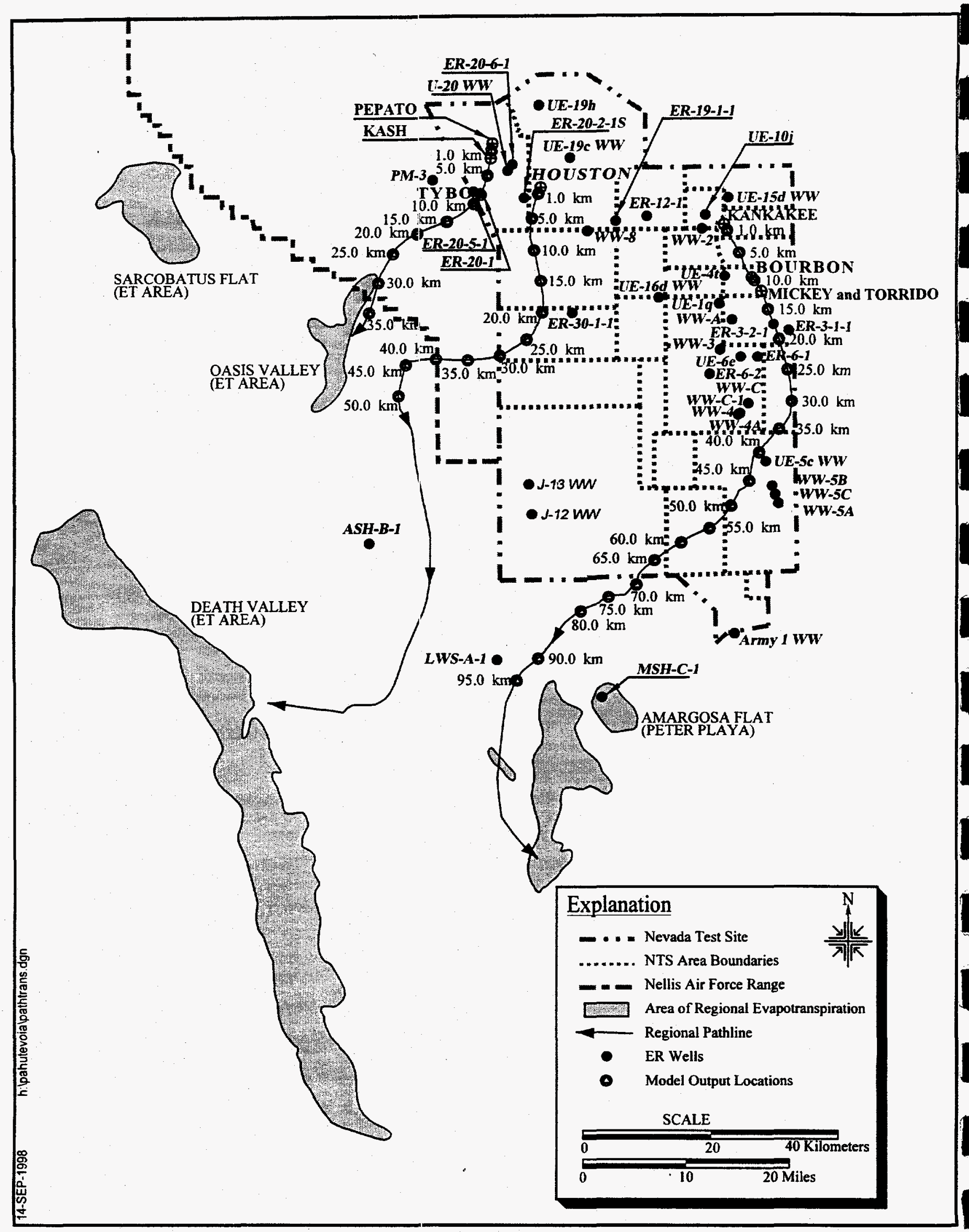

Figure B-2

Groundwater Pathlines, from Source to Receptor, Chosen for the Regional Transport Simulations 
in groundwater flux due to hydraulic conductivity parameters was determined from the expression

$$
q=q_{0}+\sum_{i=1}^{n} \beta_{i} \Delta K_{i}
$$

where

$\mathrm{q}$ = flux including the effect of uncertainty in hydraulic parameters;

$\mathrm{q}_{0}=$ base flux as determined from the calibrated groundwater flow model;

$\beta_{i}=$ sensitivity coefficient (change in flux due to a change in hydraulic parameter i); and

$\Delta \mathrm{K}_{\mathrm{i}}=$ change in the hydraulic parameter $\mathrm{i}$

For the regional model, the summation limit $\mathrm{n}$ includes all 108 hydraulic conductivity parameters used in the groundwater flow model. The sensitivity of groundwater flux to hydraulic parameters is often subdued because changing a hydraulic parameter very often leads to a corresponding, and offsetting, change in the hydraulic gradient. Flux is the product of hydraulic conductivity and hydraulic gradient. Hence, an increase in hydraulic conductivity will often be offset to some degree by a decrease in hydraulic gradient.

Uncertainty in the groundwater flux may also come from uncertainty in the recharge rate. If recharge is smaller then groundwater flux will be smaller. Conversely, if recharge is larger, then in general, the groundwater flux will also be larger.

To account for the effect of recharge, hydraulic conductivity, and flow path uncertainty on the groundwater flux, a flux multiplier was created. The flux multiplier is a constant that can range from values less than 1 to values greater than 1 . A value less than 1 represents the case of groundwater flux being less than the value determined from the calibrated regional groundwater flow model. If the flux multiplier is greater than 1 , then the flux exceeds the value from the flow model. In this manner, the flux multiplier accounts for a number of flow uncertainties that are not explicitly included in the contaminant transport model. 
The groundwater flux including the flux multiplier is given by

$$
q=\delta q_{0}
$$

where

$\delta=$ flux multiplier

$\mathrm{q}_{0}=$ base flux as determined from the regional model

The recharge was treated in this way to account for large-scale variation in the parameter value. If recharge were doubled, the hydraulic parameters could also be doubled to produce essentially the same hydraulic head distribution, but with a doubled groundwater flux.

A correlation between the flux multiplier and effective porosity was imposed in the Monte Carlo parameter generation because, in a fractured aquifer such as the Timber Mountain Aquifer, the effective porosity will increase as the fracture aperture or number of fractures increases. At the same time, the ability of the aquifer to transmit water also increases. Therefore it is not physically reasonable to allow effective porosity (i.e., fracture aperture) to decrease while pushing increasingly larger fluxes of water through the system as represented by increasing the flux multiplier.

\section{B.3.0 Simulation and Sensitivity Analysis Results}

Based on transport simulations along the BOURBON and HOUSTON pathlines, the maximum concentration limit of $20,000 \mathrm{pCi} / \mathrm{L}$ for tritium in groundwater will not likely be exceeded outside the boundaries of federal restricted-access lands (Nellis Air Force Range or the NTS). However, based on transport simulations along the TYBO pathline (Figure B-2), the maximum concentration limit of $20,000 \mathrm{pCi} / \mathrm{L}$ for tritium in groundwater could be exceeded outside of the NTS, at the Oasis Valley discharge area.

To assess the relative importance of each parameter for tritium transport along a pathline, sensitivity analyses were performed for each of the pathlines. During a given sensitivity run, one parameter was allowed to vary across its entire range of uncertainty while all other parameters 
were held constant, at their mean values. Results for the TYBO pathline, along which the maximum concentration limit is more likely to be exceeded, are summarized.

Selected potential receptor points were defined as observation locations along the TYBO pathline. The simulated maximum concentration at each observation location was recorded for each Monte Carlo realization. Then, the concentrations were sorted from smallest to largest and plotted as a function of cumulative frequency. Results representing distances of 1,10 , and $30 \mathrm{~km}$ downgradient of the TYBO test are given in Figures B-3, B-4, and B-5.

Near the underground test (Figure B-3), the dominant parameter is the source concentration, followed by the dispersivity. Uncertainty in all other parameters appears to have little effect on the tritium concentration. Farther from the test locations (Figure B-4), the source concentration is still important, but is now of equal importance compared with the flux multiplier (recharge) and the matrix diffusion parameters (matrix porosity, block width, and diffusion coefficient). Finally, near the Oasis Valley discharge area, or evapotranspiration (ET) area (Figure B-5), the most important parameters are the flux multiplier (recharge) and the diffusion parameters. A surprising feature of these figures was the apparent lack of importance of the effective porosity on the maximum tritium concentration.

The mean effective porosity for the Timber Mountain Aquifer in the regional model was 0.0015 with an associated range between the 5 percent and 95 percent fractiles of less than one order of magnitude. Additional unpublished simulations with a mean effective porosity one order of magnitude greater than 0.0015 showed a significant reduction in the distance of travel of the tritium. This suggests that if the range of effective porosity values is wider than was assumed in the Regional Model, the effective porosity may also be an important parameter. 


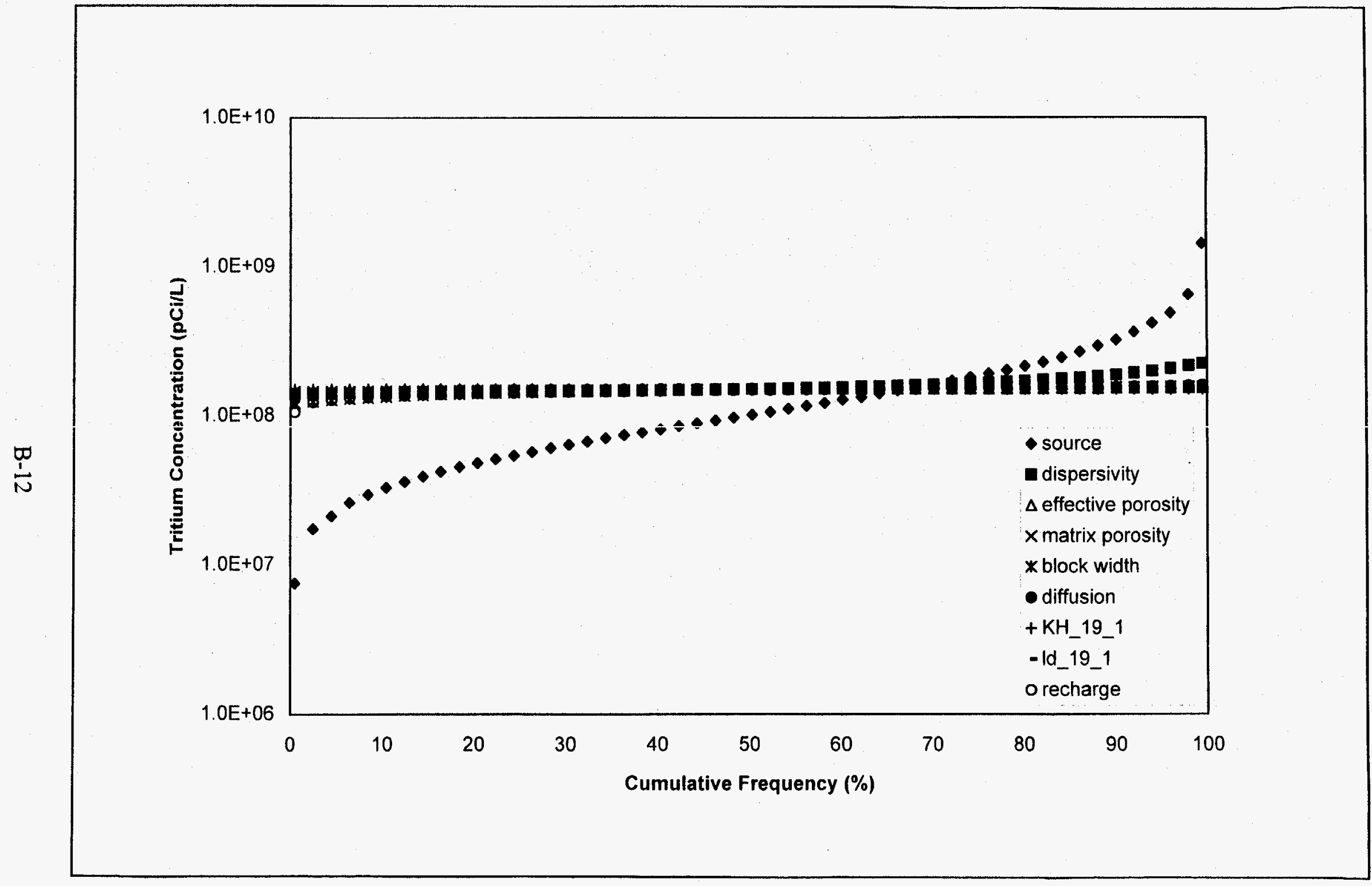

Figure B-3

Concentration Uncertainty Due to Each Parameter for the TYBO Pathline at a Distance of $1 \mathrm{~km}$ 


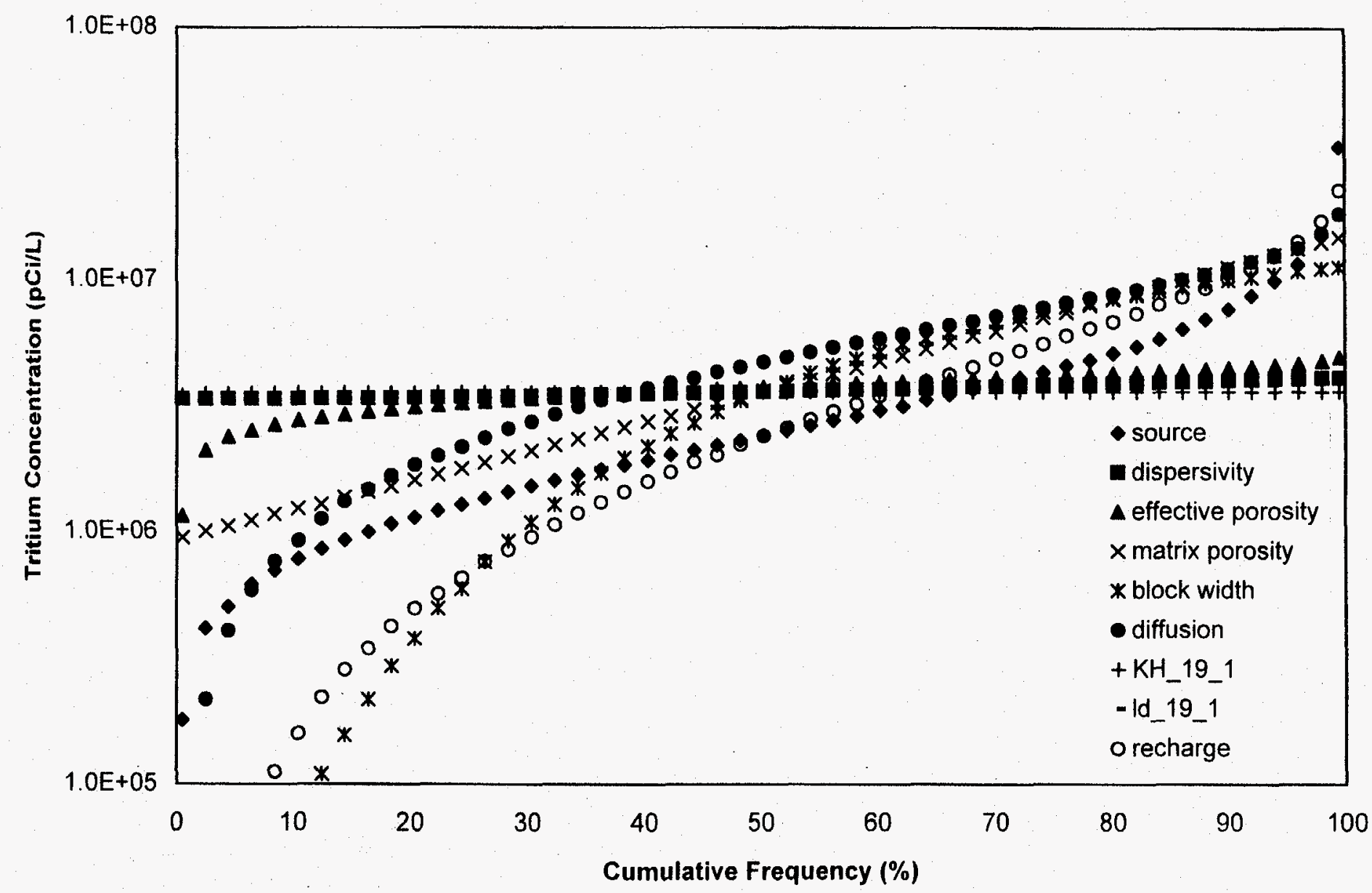

Figure B-4

Concentration Uncertainty Due to Each Parameter for the TYBO Pathline at a Distance of $10 \mathrm{~km}$ 


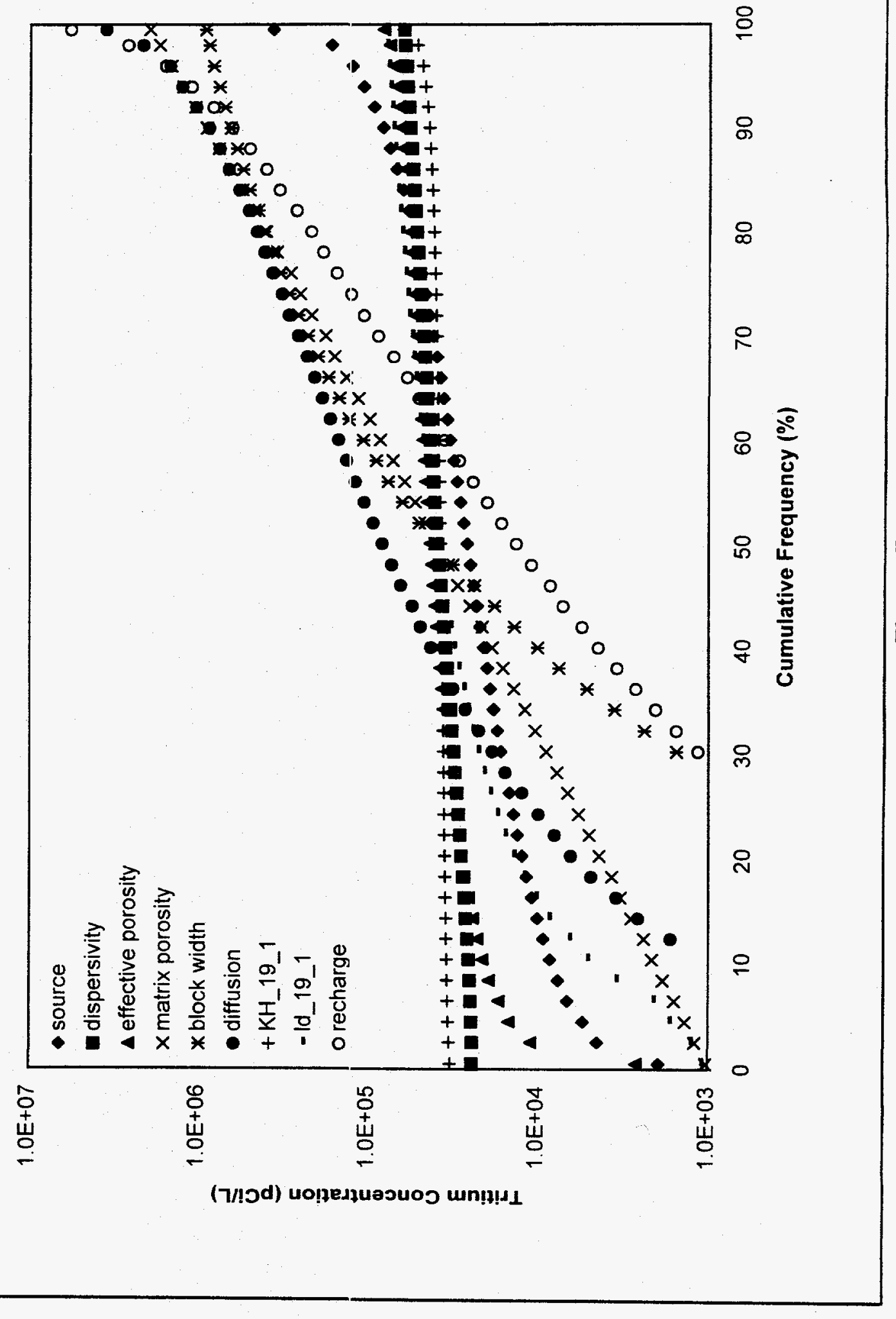

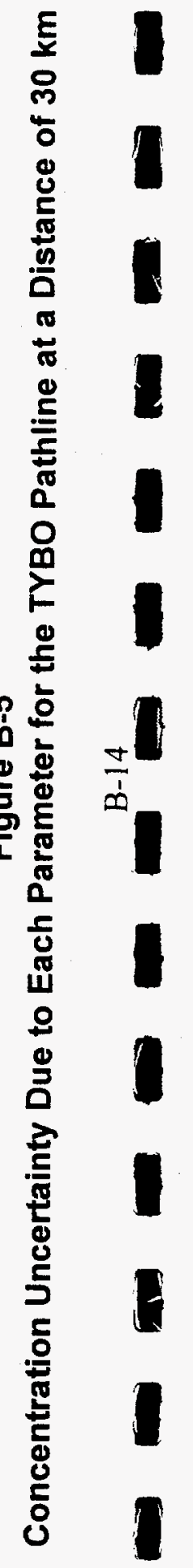




\section{B.4.0 References}

Bear, J. 1972. Hydraulics of Groundwater. New York, NY: McGraw-Hill.

Coats, K.H. and D.B. Smith. 1964. "Dead-end pore volume and dispersion on porous media." In Society of Petroleum Engineers Journal, 4:73-84. Richardson, TX.

DOE/NV, see U.S. Department of Energy, Nevada Operations Office.

Iman, R.L., J.M. Davenport, and D.K. Ziegler. 1980. Latin Hypercube Sampling (Program User's Guide), SAND79-1473. Albuquerque, NM: Sandia National Laboratories.

IT, see IT Corporation.

IT Corporation. 1996. A Stochastic Advective - Dispersive Transport Code for Multiple Constituents in Dual Porosity or Fractured Geological Media. Prepared for the U.S. Department of Energy. Las Vegas, NV.

McDonald, M.G., and A.W. Harbaugh. 1988. Techniques of Water-Resources Investigations of the United States Geological Survey, A Modular Three-Dimensional Finite-Difference Ground-Water Flow Model, Chapter A1, Book 6. Washington, DC: U.S. Geological Survey.

McDonald, M.G., and A.W. Harbaugh. 1991. A Method of Converting No-Flow Cells to Variable-Head Cells for the U.S. Geological Survey Modular Finite-Difference GroundWater Flow Model, USGS-OFR-91-356. Denver, CO: U.S. Geological Survey.

Pollock, D.W. 1989. Documentation of Computer Programs to Compute and Display Pathlines Using Results from the U.S. Geological Survey Modular Three-Dimensional, FiniteDifference Ground-Water Flow Model, USGS-OFR-89-381. Denver, CO: U.S. Geological Survey.

Sudicky, E.A. 1990. "The Laplace Transform Galerkin Technique for Efficient TimeContinuous Solution of Solute Transport in Double-Porosity Media." In Geoderma, 46:209-232. New York, NY: Elsevier Publishing Company.

van Genuchten, M.Th. 1981. Non-Equilibrium Transport Parameters for Miscible Displacement Experiments, Research Report No. 119. Prepared for the U.S. Department of Agriculture. Riverside, CA: U.S. Salinity Laboratory.

U.S. Department of Energy, Nevada Operations Office. 1997. Regional Groundwater Flow and Tritium Transport Modeling and Risk Assessment of Underground Test Area, Nevada Test Site, $N V$, DOE/NV-477. Las Vegas, NV. 
Appendix C

Alternative Characterization Options 


\section{Table of Contents}

List of Figures

List of Tables

C.1.0 Introduction

C.2.0 Characterization Activities

C.2.1 Descriptions of Characterization Activities

C.2.2 Estimated Costs for Characterization Activities

C.3.0 Characterization Activity Groups . ......................

C.3.1 Descriptions of Activity Groups $\ldots \ldots \ldots \ldots \ldots \ldots \ldots \ldots \ldots \ldots \ldots \ldots$

C.3.2 Estimated Costs for Activity Groups $\ldots \ldots \ldots \ldots \ldots \ldots \ldots \ldots \ldots \ldots$

C.4.0 References $\ldots \ldots \ldots \ldots \ldots \ldots \ldots \ldots \ldots \ldots \ldots \ldots \ldots \ldots \ldots \ldots .34$ 
C-1 Generic Characterization Well

\section{List of Tables}

Number

Title

Page

C-1 Initial List of Characterization Activities and Uncertainties Addressed

C-2 Effectiveness of Characterization Activities at Reducing Key

Uncertainties and Estimated Level of Cost of Activities

C-3 Selected Individual Characterization Activities $\ldots \ldots \ldots \ldots \ldots \ldots \ldots \ldots$ C-4

C-4 Pahute Mesa VOIA - Costs for Data Collection Activities $\ldots \ldots \ldots \ldots \ldots$ C-20

C-5 Generic Multi-Function Well, Cost Scaling $\ldots \ldots \ldots \ldots \ldots \ldots \ldots \ldots \ldots \ldots \ldots$

C-6 Groups of Characterization Activities $\ldots \ldots \ldots \ldots \ldots \ldots \ldots \ldots \ldots \ldots \ldots \ldots \ldots \ldots$

C-7 Pahute Mesa VOIA - Costs for Groups of Activities .............. C-33 


\section{C.1.0 Introduction}

The process of defining alternative characterization strategies involved several steps. First, the expert panel (Appendix A) was asked to identify characterization activities that would assist in reducing uncertainty in the location of the contaminant boundary. Second, the expert panel was asked to group the activities into potentially feasible options. Characterization activities were specified to address the key sensitive parameters identified in Section 3.1 and to improve some aspect of the state of knowledge for each parameter as it applies to flow and transport modeling for the Pahute Mesa CAUs.

\section{C.2.0 Characterization Activities}

The expert panel developed a list of 19 possible characterization activities and identified which key uncertainty each was expected to address. Table C-1 lists those activities and uncertainties. Next, the expert panel provided qualitative judgments for how effective each characterization activity is expected to be at reducing uncertainty in each of the key sensitivities that characterize the contaminant boundary (see Table C-2). Then the panel used these qualitative estimates, as well as their judgments about what activities a manager might consider implementing, to reduce the list of potential characterization activities to 14 . These activities were then defined more fully and cost estimates were made.

\section{C.2.1 Descriptions of Characterization Activities}

A detailed discussion of the basis for and objectives of each activity, and the specifications for the activity are presented in this section. A summary of the activities and the parameters they address is presented in Table C-3. 
Table C-1

Initial List of Characterization Activities and Uncertainties Addressed

\begin{tabular}{|c|c|c|c|}
\hline & Characterization Activity & $\begin{array}{l}\text { Uncertainty } \\
\text { Addressed }\end{array}$ & $\begin{array}{l}\text { Parameter } \\
\text { Addressed }\end{array}$ \\
\hline 1 & $\begin{array}{l}\text { Fault-Zone Characterization - } \\
\text { install four wells at one location straddling a major fault and } \\
\text { conduct characterization tests }\end{array}$ & $\begin{array}{l}\text { hydraulic } \\
\text { properties of a } \\
\text { fault zone }\end{array}$ & flux multiplier \\
\hline 2 & $\begin{array}{l}\text { Timber Mountain Investigation - } \\
\text { install one well for water-level measuremenis and geologic } \\
\text { characterization }\end{array}$ & flow paths & flux multiplier \\
\hline 3 & $\begin{array}{l}\text { Exploratory Drilling Southwest of Pahute Messa - } \\
\text { install five wells for geologic and hydrogeologic characterization }\end{array}$ & geology & flux multiplier \\
\hline 4 & $\begin{array}{l}\text { Test-Cavity Sampling - } \\
\text { collect groundwater samples and analyze for radionuclides, } \\
\text { re-enter BULLION and CHESHIRE, and drill into BENHAM }\end{array}$ & $\begin{array}{l}\text { source term } \\
\text { concentration }\end{array}$ & source term \\
\hline 5 & $\begin{array}{l}\text { Injection-Withdrawal Tracer Testing - } \\
\text { conduct tests at three existing locations }\end{array}$ & $\begin{array}{l}\text { transport } \\
\text { parameters }\end{array}$ & diffusion parameter \\
\hline 6 & $\begin{array}{l}\text { BULLION-Type Tracer Testing - } \\
\text { install nine wells and conduct three-well tests at three locations }\end{array}$ & $\begin{array}{l}\text { transport } \\
\text { parameters }\end{array}$ & $\begin{array}{l}\text { diffusion parameter } \\
\text { effective porosity }\end{array}$ \\
\hline 7 & Death Valley Discharge Study & flow paths & flux multiplier \\
\hline 8 & $\begin{array}{l}\text { Isotope and Geochemistry-Based Investigation - } \\
\text { sample } 16 \text { wells in the Oasis Valley sub-basin }\end{array}$ & flow paths & flux multiplier \\
\hline 9 & Gaseous Tracer Tests & $\begin{array}{l}\text { transport } \\
\text { parameters }\end{array}$ & transport parameter \\
\hline 10 & $\begin{array}{l}\text { 4-D Seismic Surveys (with air injection) - } \\
\text { characterize existing cores from Pahute Messa boreholes }\end{array}$ & geology & flux multiplier \\
\hline 11 & $\begin{array}{l}\text { 2-D Seismic Surveys - } \\
\text { conduct seismic surveys to investigate geologic structure } \\
\text { downgradient of Pahute Mesa }\end{array}$ & geology & flux multiplier \\
\hline 12 & Resistivity, AMTMMT*, and Gravity surveys & geology & flux multiplier \\
\hline 13 & $\begin{array}{l}\text { Laboratory Study of Matrix Diffusion Parameters - } \\
\text { conduct laboratory diffusion studies on existing cores from } \\
\text { Pahute Mesa }\end{array}$ & $\begin{array}{l}\text { transport } \\
\text { parameters }\end{array}$ & $\begin{array}{l}\text { diffusion transfer } \\
\text { coefficient }\end{array}$ \\
\hline 14 & $\begin{array}{l}\text { Study of Radionuclide Release from Test Cavities - } \\
\text { laboratory investigation of radionuclide release process and } \\
\text { near-cavity transport }\end{array}$ & $\begin{array}{l}\text { source term } \\
\text { concentration }\end{array}$ & source term \\
\hline 15 & Laboratory Study of $K_{d} s$ & $\begin{array}{l}\text { transport } \\
\text { parameters }\end{array}$ & $\begin{array}{l}\text { distribution } \\
\text { coefficient }\end{array}$ \\
\hline 16 & $\begin{array}{l}\text { Geologic and Geophysical Modeling - } \\
\text { model deposition/tectonics from Pahute Mesa volcanic centers } \\
\text { and compare measured gravity to synthetic gravity }\end{array}$ & geology & flux multiplier \\
\hline 17 & $\begin{array}{l}\text { Deterministic-Stochastic Analysis - } \\
\text { extension of Desert Research Institute's random field modeling }\end{array}$ & geology & flux multiplier \\
\hline 18 & Analysis of Barometric and Earth-Tide Responses & $\begin{array}{l}\text { transport } \\
\text { parameters }\end{array}$ & effective porosity \\
\hline 19 & Source Checking - is geologic model correct for cavities & $\begin{array}{l}\text { hydrologic } \\
\text { source term }\end{array}$ & source term \\
\hline
\end{tabular}

- Audiomagnetotelluric/magnetotelluric 
Table C-2

Effectiveness of Characterization Activities

at Reducing Key Uncertainties and Estimated Level of Cost of Activities

\begin{tabular}{|c|c|c|c|c|c|c|}
\hline \multirow{2}{*}{$\begin{array}{c}\text { Characterization } \\
\text { Activity }\end{array}$} & \multicolumn{5}{|c|}{ Specific Uncertainty Addressed } & \multirow[b]{2}{*}{ Cost } \\
\hline & $\begin{array}{l}\text { Flow } \\
\text { Path }\end{array}$ & $\begin{array}{c}\text { Groundwater } \\
\text { Flux }\end{array}$ & $\begin{array}{l}\text { Effective } \\
\text { Porosity }\end{array}$ & $\begin{array}{c}\text { Matrix } \\
\text { Diffusion }\end{array}$ & $\begin{array}{l}\text { Source } \\
\text { Term }\end{array}$ & \\
\hline 1 & 3 & 2 & 0 & 0 & 0 & high \\
\hline 2 & 3 & 1 & 0 & 0 & 0 & medium \\
\hline 3 & 3 & 2 & 1 & 1 & 0 & high \\
\hline 4 & 0 & 0 & 0 & 0 & 3 & high \\
\hline 5 & 0 & 0 & - & 3 & 0 & low to medium \\
\hline 6 & 1 & 1 & 3 & 3 & 1 & very high \\
\hline 7 & 2 & 2 & 0 & 0 & 0 & low \\
\hline 8 & 3 & 2 & 0 & 0 & 0 & medium \\
\hline 9 & 0 & 0 & 3 & 0 & 0 & medium \\
\hline 10 & 3 & 1 & 1 & 0 & 0 & very high \\
\hline 11 & 3 & 1 & 0 & 0 & 0 & medium to high \\
\hline 12 & 2 & 0 & 0 & 0 & 0 & medium \\
\hline 13 & 0 & 0 & 0 & 2 & 0 & low \\
\hline 14 & 0 & 0 & 0 & 0 & 3 & medium \\
\hline 15 & 0 & 0 & 0 & 0 & 2 & low \\
\hline 16 & 2 to 3 & 0 & 0 & 0 & 0 & low \\
\hline 17 & 1 & 2 & 0 & 0 & 0 & low \\
\hline 18 & 0 & 0 & 1 & 0 & 0 & low \\
\hline 19 & 2 & 0 & 0 & 0 & 1 & low \\
\hline
\end{tabular}

key:

$0=$ no effect on uncertainty

$1=$ small effect on uncertainty

2 = moderate effect on uncertainty

3 = large effect on uncertainty 


\section{Table C-3 \\ Selected Individual Characterization Activities}

\begin{tabular}{|c|c|c|}
\hline \multicolumn{2}{|r|}{ Characterization Activity } & \multirow{2}{*}{$\begin{array}{l}\text { Parameter } \\
\text { Addressed }\end{array}$} \\
\hline Number & Name & \\
\hline$\overline{\mathrm{A} 1}$ & Fault-Zone Characterization & flux multiplier \\
\hline A2 & Timber Mountain Investigation & flux multiplier \\
\hline A3 & Exploratory Drilling Southwest of Pahute Mesa & flux multiplier \\
\hline A4 & Test-Cavity Sampling & source term \\
\hline A5 & Injection-Withdrawal Tracer Testing & diffusion \\
\hline A6 & BULLION-Type Tracer Testing & diffusion, effective porosity \\
\hline$A 7$ & Geochemistry-Based Investigations & flux multiplier \\
\hline A8 & 2-D Seismic Survey & flux multiplier \\
\hline A9 & Geophysical Surveys & flux multiplier \\
\hline A10 & Laboratory Study of Diffusion Parameters & diffusion \\
\hline A11 & $\begin{array}{l}\text { Study of Radionuclide Release from Test } \\
\text { Cavities }\end{array}$ & source term \\
\hline A12 & Geologic and Geophysical Modeling & flux multiplier \\
\hline A13 & $\begin{array}{l}\text { Analysis of Barometric and Earth-Tide } \\
\text { Responses }\end{array}$ & effective porosity \\
\hline A14 & Laboratory Study of $K_{d} s$ & distribution coefficient \\
\hline
\end{tabular}

\section{Activity 1 - Fault-Zone Characterization}

Question: Do major fault zones within Pahute Mesa and its vicinity have significant effects on groundwater flow? Presently fault zones are not specifically incorporated into the flow and transport models; only juxtaposition of hydrostratigraphic units are incorporated, where known. It is not known whether and/or where fault zones may determine specific flow paths for transport of contaminants by introducing barriers or highly transmissive features in the flow system. Also, flow velocities along such flow paths may be higher or lower than present model predictions.

Characterization objectives: Determine the hydraulic characteristics of a "representative" section of one of the major faults in the Pahute Mesa CAU, and evaluate whether it acts as a barrier or a conduit for intermediate-scale (between regional and local) groundwater flow.

Parameter addressed: Flux multiplier (through the geologic model and the flow model) 
Description: This activity will be conducted at a single location on a major fault. The activity consists of drilling four boreholes and installing four separate wells at the location. The wells will be configured three across and one perpendicular to the fault to allow for water level measurements and hydraulic testing both across and along the fault zone. Data collection will include characterizing the local physical and stratigraphic structure of the fault, determining the groundwater head distribution, and determining hydraulic characteristics of the fault zone. Groundwater samples will be collected for chemical analysis. The wells should provide longterm groundwater head and groundwater chemistry monitoring, but such work is not included in this activity.

Specifications: The location will be on Pahute Mesa or in an adjacent area to the southwest. Wells spaced several hundred feet from each other, each $914 \mathrm{~m}(3,000 \mathrm{ft})$ deep. Two wells will be water-production wells with high-rate pumps, one located in the fault zone and one in the adjacent area. The other two wells will be designed for water-level monitoring and sampling with low-rate pumps, one located in the fault zone and one located adjacent to the fault zone. Specifications for all wells are identical, similar to the ER-20-6 (BULLION) wells. The wells in the fault zone must be drilled and completed without irreversibly affecting hydraulic properties in the completion zone, and all four wells will require adequate development after completion to restore/repair hydraulic properties.

Data collection during drilling and completion shall include drilling data, cuttings and core samples, standard geophysical logging suite and borehole televiewer, borehole radar and crosshole seismic surveys. After completion, pumps will be installed, and the wells will be developed and tested. Flow logging and groundwater sampling activities will also be conducted. The samples will analyzed.

Preparatory work for drilling includes a criteria document and drilling/testing plans; post-field work includes analysis of the drilling data and samples, and preparation of completion and data analysis reports. Assume a "clean" site rather than a "rad" site and discharge of "clean" water to the ground during pumping tests. The UGTA, 1996 Baseline drilling and well completion specifications and costs are the reference for well design and costs (IT, 1997).

Risks/Problems: Drilling into the fault zone and completing the required wells will be difficult, and there is a high risk of unanticipated difficulties and failure. Identifying one appropriate "representative" location, recognizing that hydrogeologic properties may vary significantly along 
faults, is questionable. Locating the fault zone accurately so that the wells may be installed in the desired configuration may also be difficult. Installing and developing a completed well that provides accurate data on the undisturbed properties of the fault zone will be very difficult. The testing specified does not provide information on the large-scale properties of the selected fault much less information on the variability of fault properties or identification and characterization of all the faults in the Pahute Mesa CAU.

\section{Activity 2 - Timber Mountain Investigation}

Questions: What is the effect of the Timber Mountain resurgent dome on groundwater flow southwest of Pahute Mesa? Do all flow paths from Pahute Mesa go to Oasis Valley, passing north of Timber Mountain, or do some go south under Timber Mountain or pass east and then south of Timber Mountain?

Characterization objectives: Collect information to support the analysis of groundwater flow in the area of Timber Mountain and the modeling of flow paths from Pahute Mesa.

Parameter addressed: Flux multiplier (by way of the geologic and flow models; specifically relevant to pathlines as derived from flow modeling)

Description: Drill and install a well at one location on Timber Mountain. Determine detailed geology and stratigraphy at drilling location, obtain water level data and groundwater samples, and analyze groundwater samples. The wells should provide long-term water level and groundwater chemistry monitoring data, but such work is not included in this activity.

Specifications: The location will be on Timber Mountain, up Cat Creek Canyon. One well, $1,067 \mathrm{~m}(3,500 \mathrm{ft})$ deep will be installed, with a completion similar to that of the BULLION wells and including an additional deep-set piezometer for vertical gradient information. Data collection during drilling and completion shall include drilling data, cuttings and core samples, a standard geophysical logging suite and borehole televiewer, borehole radar, and cross-hole seismic surveys. After well completion, the pump will be installed and the well developed and tested. Flow logging and groundwater sampling activities will also be conducted. The groundwater samples will be analyzed. Preparatory work for drilling includes a criteria document and drilling/testing plans; post-field work includes analysis of the drilling data and samples, and preparation of completion and data analysis reports. Assume a "clean" site rather 
than a contaminated site and discharge of "clean" water to the ground during pumping tests. The UGTA, 1996 Baseline drilling and well completion specifications and costs are the reference for well design and costs (IT, 1997).

Risks/Problems: One site may not provide definitive data. Access to an appropriate drilling site may be difficult.

\section{Activity 3 - Exploratory Drilling Southwest of Pahute Mesa}

Questions: What is the geologic structure, stratigraphy and hydraulic head distribution south and west of Pahute Mesa? The need is for sufficient information to define the major features in the large area of the geologic model for which geologic and geophysical map data must be supplemented. Also, what is the geochemistry of groundwater in this area and have any contaminants from Pahute Mesa already been transported into this area?

Characterization objectives: Determine the geology and hydrogeology at each drilling location. The requirement is to define the full depth of the flow system, and the suggested target depth is the pre-Tertiary surface. Also determine vertical gradients in this area, and conduct single-well pump tests to determine hydraulic parameters.

Parameter addressed: Flux multiplier (through the geologic and flow models). Associated information collection on geochemistry and contaminant transport could also affect the transport model directly.

Description: Drill investigation holes and install wells at five locations in the study area to investigate major structural features, stratigraphy, and hydrology. Determine the detailed geology at each drilling location, obtain groundwater head data and groundwater samples, and conduct single-well pump tests. Analyze the groundwater samples. The wells should provide long-term water level and groundwater chemistry monitoring data, but such work is not included in this activity.

Specifications: The investigation sites will be located between the NTS boundary and Oasis Valley. One well, approximately $1,524 \mathrm{~m}(5,000 \mathrm{ft})$ deep, will be drilled and installed at each site. Well completions will be similar to those of the ER-20-6 (BULLION) wells, but will include an additional deep-set piezometer in each well for vertical gradient information. Data 
collection during drilling and completion shall include drilling data, cuttings and core samples, a standard geophysical logging suite and borehole televiewer, and borehole radar and cross-hole seismic surveys. After well completion, the pumps will be installed and the wells developed and tested. Flow logging and groundwater sampling activities will be conducted. The groundwater samples will be analyzed. Preparatory work for drilling includes a criteria document and drilling/testing plans; post-field work includes analysis of the drilling data and samples, and preparation of completion and data analysis reports. The site will be assumed to be a "clean" site rather than a contaminated site, and discharge to the ground during pumping tests is assumed to be of "clean" water. The UGTA, 1996 Baseline drilling and well completion specifications and costs (IT, 1997) are the reference for well design and costs.

Risks/Problems: Five investigation sites are relatively few for such a large area and it would be easy to miss significant structural features. Selecting the locations for the wells to provide the most appropriate data is difficult due to the lack of information on the study area. Five sites would not provide good coverage of the possible flow paths determined by the final modeling so that these wells could also serve the monitoring function.

\section{Activity 4 - Test-Cavity Sampling}

Questions: What is the hydrologic source term that should be used for transport modeling? What are the radionuclide concentrations in the groundwater? How are the radionuclides distributed in and around the cavity? And how will radionuclides be released from solid form to groundwater solute?

Characterization objectives: To collect information on radionuclide concentrations in groundwater near-field and in test cavities, physical information on the rock matrix and melt glass, and information on geochemical conditions. Specifically, to collect samples for determining radionuclide concentrations in the groundwater in the cavity and in the fractures and the rock matrix in the several zones around the cavity. To collect samples for determining the composition and physical characteristics of the altered rocks and melt glass, and determine the geochemical conditions in each of these zones. Also, to collect information on near-field hydraulic parameters. This task could be used to supply data to Activity 11 , and the objectives and specifications revised to optimize the combination of these two tasks together.

\section{Parameter addressed: Source Term}


Description: Re-enter existing postshot holes on two sites, clean-out and drill into/through the cavities. Also drill a new hole into and through the cavity on a third site. Collect core samples from cavities and below cavities, install well completions and pumps, develop completions, conduct hydraulic and geochemical testing, sample groundwater, and analyze samples. The well completions should be used for long-term water level and groundwater chemistry monitoring, but such work is not included in this activity.

Specifications: The locations for re-entries are the BULLION and CHESHIRE test sites, and the new hole/well would be drilled on the BENHAM test site. Drilling, coring, and well completion must not irreversibly contaminate groundwater in the sampling zones or interfere with later pumping for testing and sampling. Analyze samples for water chemistry parameters, radionuclides and colloids. Preparatory work includes a criteria document (one document for all three locations), and drilling and testing plans. Analyze data, and prepare completion report and data analysis reports. Assume highly contaminated groundwater, requiring appropriate health and safety measures, and installation of sufficient lined sump capacity for handling large volumes of these fluids on the surface.

Risks/Problems: Drilling into and completing wells in test cavities, and developing completions has a high risk of failure: losing the hole, poor completion performance, or questionable quality of samples. Re-entries of existing holes may not ultimately be the least expensive or safest approach to achieving the objectives due to damage from the original drilling. Drilling in a nearfield environment is more difficult and expensive than drilling in a "clean" location due to the requirements for handling of potentially contaminated materials and equipment, and drilling into a cavity would be even more difficult. The anticipated sampling requirements for meeting the objectives for this activity do not allow use of the previous approach for drill-backs using forced lost-circulation to contain the contamination downhole. Highly contaminated fluids must be handled on the surface, and there will be problems with contamination of drilling, testing, and fluid-handling equipment. Decontamination of equipment may be difficult or impossible.

\section{Activity 5 - Injection-Withdrawal Tracer Testing}

Questions: What are representative diffusion parameter values for the hydrostratigraphic units in the study area? 
Characterization objectives: Determine effective diffusion parameter values for representative lithologies in the study area at an appropriate scale for use in the modeling of transport.

Coincidently, collect groundwater samples and information on groundwater chemistry for each well location, and determine hydraulic conductivity for each site.

\section{Parameter addressed: Diffusion}

Description: Conduct single-well huff-puff (push-pull) multiple-tracer tests at three locations, each representing a distinct, major lithology for this CAU. Collect groundwater samples and conduct testing required to support the tracer test and test analysis.

Specifications: The locations will be on Pahute Mesa and between the NTS boundary and Oasis Valley. Assume one location at an existing well location on Pahute Mesa, one location at a new exploratory well location (drilled for Activity 3), and one location requiring a new well specific for this activity. For the existing well, workover will be required to support test requirements: isolate the test zone, install two tubing strings (one with a pump) similar to the BULLION well completions. For the new exploratory well site, completion requirements for tracer test and associated testing would be incorporated into exploratory drilling completion plan. For the new well specific to this activity, the well will be $914 \mathrm{~m}(3,000 \mathrm{ft})$ deep and similar to the BULLION well completions. Data collection during drilling and completion shall include drilling data, cuttings and core samples, standard geophysical logging suite and borehole televiewer, and borehole radar. After completing the wells install the pumps, develop and test the wells, conduct flow logging, and sample the wells. Analyze the groundwater samples. Preparatory work for drilling includes a criteria document and drilling/testing plans; post-field work includes analysis of the drilling data and samples, and preparation of completion and data analysis reports. Assume a "clean" site rather than a "rad" site and discharge of "clean" water to the ground during pumping tests. The UGTA, 1996 Baseline drilling and well completion specifications and costs are the reference for well design and costs (IT, 1997). Conduct two stages of tracer testing (initial short test, then long-term test) for each well with total testing duration of eight weeks. Tracer test data collection would be similar to BULLION with on-site tracer analysis. Preparations include one criteria document and individual test plans. Analyze the data and prepare report of tests and data analysis.

Risks/Problems: Achieving a reliable result that can be definitively interpreted is not assured. Single-well characterization and tracer testing significantly limits the detailed analysis of the test 
results. The limited number of tests may not provide a good measure of "representative" matrix diffusion. There is also some question about applying results from this scale of test to the scale over which transport will be simulated.

\section{Activity 6 - BULLION-Type Tracer Testing}

Questions: What are representative effective porosities and diffusion parameter values for the hydrostratigraphic units in the study area?

Characterization objectives: Determine effective porosity and diffusion parameter values for representative lithologies in the study area at an appropriate scale for use in the modeling of transport. Collect information on groundwater chemistry for each well location, and determine hydraulic conductivity from a pumping test with observation wells. Data on local horizontal gradient and anisotropy of parameters may also be collected.

\section{Parameters addressed: Diffusion, Effective Porosity}

Description: Conduct three-well forced-gradient multiple-tracer tests at three locations, investigating the most transmissive hydrostratigraphic units for this CAU.

Specifications: Three locations on Pahute Mesa or between the NTS boundary and Oasis Valley. Install three wells at each site, similar to the BULLION layout. These wells would be $1,067 \mathrm{~m}$ $(3,500 \mathrm{ft})$ deep and of similar design and completion to the BULLION wells. Data collection during drilling and completion shall include drilling data, cuttings and core samples, standard geophysical logging suite and borehole televiewer, borehole radar and cross-hole seismic surveys. After completing the wells install the pumps, develop and test the wells, conduct flow logging, and sample the wells. Analyze the groundwater samples. Assume a "clean" site rather than a "rad" site and discharge of "clean" water to the ground during pumping tests. The UGTA, 1996 Baseline drilling and well completion specifications and costs (IT, 1997) are the reference for well design and costs. Preparatory work for drilling includes a criteria document and drilling/testing plans; post-field work includes analysis of the drilling data and samples, and preparation of completion and data analysis reports. Preparations for tracer testing includes a criteria document and test plans, and development of a flow and transport model for each tracer test for pre-test planning and post-test analysis. Conduct 12-week tracer tests similar to BULLION tracer test. Analyze the data and prepare report of tests and data analysis. 
Risks/Problems: Achieving a reliable result that can be definitively interpreted is not assured. However, multiple-well characterization and tracer testing significantly improves the detailed analysis of the test results. The limited number of tests may not provide a good measure of "representative" matrix diffusion parameter values. There is some question about applying results from this scale of test to the scale over which transport will be simulated.

\section{Activity 7 - Geochemistry-Based Investigation}

Questions: What direct evidence for flow paths and flow velocities in the study area can be derived from geochemical data for groundwater between Pahute Mesa and Oasis Valley? This approach would provide an alternate basis for determining flow paths and flow velocities, from which parameter values for effective porosity and diffusion parameter could be determined for use in flow and transport modeling.

Characterization objectives: Collect geochemical data, in particular, radioisotope data on groundwater from Pahute Mesa to Oasis Valley and use to evaluate groundwater sources, isotopic age, flow paths, and flow velocities of groundwater from Pahute Mesa.

\section{Parameter addressed: Flux Multiplier}

Description: Procure, assemble, and test dissolved organic carbon fractionating apparatus. Sample 16 existing wells in the Oasis Valley sub-basin and analyze for major ions, stable isotopes, noble gases, strontium and uranium isotopes, and carbon-14. Update the geochemical database. Analyze fracture-lining calcite in selected, existing cores. Conduct geochemical modeling of reaction paths, and assess groundwater age and implications for groundwater flow paths. Calibrate matrix diffusion parameters and effective porosities with a numerical transport model.

Specifications: The database produced will be based on the 1994, HSI-Geotrans geochemical database. Sampling well locations will be in Oasis Valley. Sample each well once; prior to sampling each well must be purged. Designated wells either have installed pumps or can be pumped using portable sampling pump.

Risks/Problems: There may be some difficulty in getting a sufficient number of high quality data points. The geochemistry approach may not be definitive in delineating flow paths or 
determining travel velocities to substantially constrain model calibration, or may produce conflicting results.

\section{Activity 8 - 2-D Seismic Survey}

Questions: What is the geologic structure and stratigraphy in the area southwest of Pahute Mesa?

Characterization objectives: Investigate specific geologic structures and stratigraphic problems in the area southwest of Pahute Mesa in sufficient detail to refine the geologic model used in modeling flow and transport from Pahute Mesa.

\section{Parameter addressed: Flux Multiplier}

Description: Conduct 2-dimensional seismic surveys and interpret the data.

Specifications: Locations - between the NTS boundary of Pahute Mesa and Oasis Valley. Seismic reflection surveys will be conducted along 3-lines, each 10-km (6 miles) long. Target depth of investigation is the pre-Tertiary interface. The main goals would be to locate stratigraphic horizons within the alluvium and/or volcanics and the top of the Paleozoic rocks and identify faults that may break these horizons. Assumptions about the seismic survey include the following: the seismic source will be explosives in shot holes; there will be no access issue for Air Force land; transportation will be by 4-wheel drive, all-terrain vehicle (ATV), or on foot; no road building or helicopter support will be required; only basic archaeologic and biologic surveys will be required, and they will not result in access restrictions, and there will be no unexploded ordnance. Prepare criteria document and report on results. Contract for, acquire and interpret the data.

Risks/Problems: Assume that geologic control available from existing or new drilling will be sufficient to provide for accurate interpretation of seismic data. Efforts to obtain data in high relief areas may not be successful due to distance from road support. Efforts to image the caldera boundary may not be successful due to technical limitations (insufficient energy source to penetrate multi-layered high density- high velocity lavas). Violation of operational assumptions listed under Specifications could substantially increase costs or restrict the location of investigations. 


\section{Activity 9 - Geophysical Surveys}

Questions: What is the geologic structure and stratigraphy in the area southwest of Pahute Mesa?

Characterization objectives: Investigate specific geologic structure and stratigraphic problems in the area southwest of Pahute Mesa, in sufficient detail to refine the geologic model used in modeling flow and transport from Pahute Mesa.

Parameter addressed: Flux Multiplier (by way of the geologic model)

Description: Conduct audiomagnetotelluric/magnetotelluric (AMT/MT) surveys, direct current (DC)-resistivity, and gravity surveys, and interpret the data.

Specifications: The surveys would be conclucted between the NTS boundary of Pahute Mesa and Oasis Valley. The surveys would consist of 5 traverses, each $3 \mathrm{~km}$ (1.8 miles) long, to investigate the north-east trending anomaly, and 5 traverses, each $3 \mathrm{~km}$ (1.8 miles) long, to investigate the east-west Hot Springs lineament. Also, 100 additional gravity measurements and 30 additional AMT/MT soundings to fill in data gaps. The target of investigation is the pre-Tertiary interface; however, maximum depth of penetration is approximately $1 \mathrm{~km}$ ( 0.6 miles) for AMT/MT and 200 meters for DC-resistivity. The main goals would be to locate stratigraphic horizons within the alluvium and/or volcanics and identify the top of the Paleozoic rocks and faults that may cut these horizons. Assumptions about conducting the surveys include the following: there will be no access issue for Air Force land; transportation will be by 4-wheel drive, ATV, or on foot; no,road building or helicopter support will be required; only basic archaeologic and biologic surveys will be required, and they will not result in access restrictions; and there will be no unexploded ordnance. Prepare criteria document and report on results. Contract for, acquire, and interpret the data.

Risks/Problems: (1) Geologic control available from existing or new drilling will be sufficient to provide for accurate interpretation, (2) Depth constraints of these methods may limit information return due to the potential depth to structures. Violation of operational assumptions listed under Specifications could substantially increase costs or restrict the location of investigations. 
Questions: What are representative diffusion parameter values for the appropriate stratigraphic units in the transport modeling?

Characterization objectives: Determine matrix diffusion coefficients for representative samples of matrix rocks and fracture coatings.

\section{Parameter addressed: Diffusion}

Description: Conduct laboratory studies to determine matrix diffusion coefficient values for representative matrix rock and fracture coatings. Representative core from the primary hydrostratigraphic units (HSUs) in the study area would be selected from existing cores from Pahute Mesa boreholes. Additional core may be available from the study area dependent on drilling in activities 1,3 , or 6 . Characterize the cores including lithology, fracture characteristics, and fracture coatings. Conduct tests to determine diffusion parameters for rock samples and effects of the fracture coatings on the diffusion rate.

Specifications: Conduct tests on 12 core samples selected from cores in the U.S. Geological Survey Core Library. Prepare report on results.

Risks/Problems: A sufficient level of consistency and representativeness with this quantity of testing may not be achieved. Determining what specifications for rock types are appropriate and the representativeness of rock and fracture coating samples is somewhat conjectural prior to other investigations proposed in this analysis. The laboratory studies are conducted at a very different scale from the transport simulation distance, and the laboratory study-derived parameter value may not be appropriate. The in situ tracer tests could provide a means of calibrating the results, if they are conducted.

\section{Activity 11 - Study of Radionuclide Release from Test Cavities}

Questions: What hydrologic source term should be used for transport modeling? 
Characterization objectives: Develop a model for specifying the hydrologic source term to be used in transport modeling. This model needs to account for concentration versus time or mass rate of release versus time, and relate this to the total inventory for each test.

\section{Parameter addressed: Source Term}

Description: Conduct laboratory investigations and modeling of the radionuclide release process.

Specifications: Experimental activities include plutonium speciation, leaching experiments on nuclear explosive debris, characterization of archived saturated debris, siting and release of volume incorporated actinides, advective and matrix diffusion studies, sorption studies including solute and non-solute species, and the relationship of cavity geometry and phenomenology to hydrologic source term. Model the geochemical stability of the cavity and chimney regions of the CHESHIRE test. This includes glass dissolution, speciation, sorption, complexation, ion exchange, and colloidal transport. Important transport mechanisms will be identified. Reactive transport will be linked to 3-dimensional flow and transport modeling to identify the hydrologic source term and its importance in volcanic rocks on Pahute Mesa. Prepare a report of results.

Risks/Problems: Achieving a definitive or reliable model with the specified scope of work may be optimistic. Access to and release of classified data to use in modeling, and release of results from a model using classified data may be a problem, either requiring only use of unclassified data or results released in a less definite form, without access to the actual support information and modeling. Determining the accuracy of the derived model for all of the varied conditions associated with all of the underground nuclear tests is not provided for.

\section{Activity 12 - Geologic and Geophysical Modeling}

Questions: What is the geologic structure and stratigraphy in the area southwest of Pahute Mesa (for use in the geologic model used in modeling flow and transport from Pahute Mesa)?

Characterization objectives: Test and refine the Pahute Mesa geologic model, and develop confidence in the interpretation.

Parameter addressed: Flux Multiplier 
Description: (a) Estimate volumes and depositional framework of lavas and tuffs erupted from the various volcanic centers on and near Pahute Mesa. Use these volumes to develop thickness estimates and depositional extents to compare to cross sections and maps of the Pahute Mesa geologic model. Faults and nested volcanic centers must be taken into account over the length of cross sections. Develop sensitivity to relative thicknesses along cross section lines, and determine appropriate adjustments to the geologic model. (b) Compare a synthetic gravity field derived from the geologic model to the measured gravity field, and determine appropriate adjustments to the geologic model.

Specifications: Prepare a report of results.

Risks/Problems: The results may not be sufficiently definitive to provide the desired guidance in refining the model or promote the desired level of confidence. Developing accurate estimates of eruptive volumes and accurate depositional models is speculative.

\section{Activity 13 - Analysis of Barometric and Earth-Tide Responses}

Questions: What are representative effective porosity values for the various hydrostratigraphic units in the flow and transport simulations?

Characterization objectives: Collect data on representative porosity values for the more transmissive hydrostratigraphic units in the study area. Correlate porosity data to effective porosity of these units, which is the required parameter value for transport modeling and has the greater uncertainty.

\section{Parameter addressed: Effective Porosity}

Description: Locate all appropriate existing data records for barometric and earth-tide response for the study area. Assume five records will be available. Collect additional data records for appropriate existing wells and new well locations installed for other data collection activities. Assume 10 additional data records will be collected. Analyze 15 data records. Data collection should focus on wells completed in the more transmissive hydrostratigraphic units in this CAU.

Specifications: The locations of data source wells will be on Pahute Mesa or between the NTS boundary and Oasis Valley. Assume that existing records can be used with basic processing. 
Assume that new data record collection will only require installation of pressure transducers and recording or responses without substantial rework of wells. Monitoring period will be 105 days per well ( $3 \times 35$ day period required for earth tide analysis). Prepare criteria document/plan (one document for all 10 data collection efforts), analyze data, and prepare report of data collection and data analysis. Assume that all other required data is available for the subject HSUs.

Risks/Problems: These methods do not directly provide information on the effective porosity parameter that is needed for modeling transport. Effective porosity parameter values may not be readily correlated to the more easily acquired data on porosity and this task does not provide for establishing the correlation. Correlation may be developed from other activities if they are pursued. There may not be a large selection of suitable existing records, and there may not be many existing wells from which to collect suitable records to analyze that are sufficiently specific to different rock types. Determining the representativeness of the derived values for the larger area to which they will be applied will be based primarily on judgement. There is no provision for determining the accuracy of the data analysis and correlation.

\section{Activity 14 - Laboratory Study of $K_{d} s$}

Questions: What are the adsorption distribution coefficients $\left(\mathrm{K}_{d} s\right)$ that should be used for each radionuclide of concern in transport modeling?

Characterization objectives: Determine and characterize distribution coefficients for the radionuclides of concern for the appropriate HSUs or rock types, both for matrix rock and for fractures (fracture coatings).

\section{Parameter addressed: Distribution Coefficient}

Description: Analyze existing NTS data on adsorption $\left(\mathrm{K}_{\mathrm{d}}\right)$ of pertinent radionuclides, Pahute Mesa CAU lithologies, water chemistry, and colloidal transport. Evaluate data and derive appropriate distribution coefficients for use in transport modeling.

Specifications: Produce report of results. 
Risks/Problems: This activity does not provide for any work to calibrate or validate the assessment of mobility coefficients, and the results may be subject to dispute. Determining values that are sufficiently definitive for specific predictions of transport may be difficult. Determining and incorporating all of the pertinent elements and property values to include in the transport modeling may not be readily accomplished.

\section{C.2.2 Estimated Costs for Characterization Activities}

The intent of this cost estimating was to assign representative costs for the generalized type of activity and specified quantity of work for use in comparing the different activities and groups. Specifications were speculative and general, and were not refined enough to produce more elaborate or accurate estimates. The estimates have been rounded to the nearest $\$ 1,000$ to avoid the appearance of specific accuracy. Table $\mathrm{C}-4$ shows the total cost for each activity, the components of the activity used to estimate the overall cost, and indicates the reference for the cost figure.

Table C-5 shows the scaling of characterization well costs from the UGTA Baseline characterization well estimate. Figure $\mathrm{C}-1$ shows the generic UGTA baseline well construction used for estimating.

\section{C.3.0 Characterization Activity Groups}

The expert panel was also asked to identify potentially attractive groups of activities. This exercise took place after completion of Phase I, so that the results of Phase I could be used as an aid to developing groups. The goal in determining groups was not to identify the single optimal group with regard to reduction of contaminant boundary uncertainty. Rather, the goal was to identify a diverse set of groups that would provide insights for a manager actually deciding which portfolio of activities to implement. Therefore, the expert panel developed groups that had varying budget levels and addressed uncertainty in different sets of parameters, as well as groups that might perform well in reducing contaminant boundary uncertainty. Descriptions and costs of the characterization activity groups are presented in this section. 


\section{Table C-4}

\section{Pahute Mesa VOIA - Costs for Data Collection Activities}

(Page 1 of 5)

ERC: Environmental Remediation Contractor PBMC : Performance-Based Management Contractor LANL: Los Alamos National Laboratory
LLNL: Lawrence Livermore Nation Laboratory DRI: Desert Research Institute USGS-WRD: United States Geological Survey, Water Resources Division SNL: Sandia National Laboratories

\section{Activity \#1 - Fault Characterization}

\begin{tabular}{lrr} 
Cost Elements & unit cost & cost \\
\hline ERC prepare criteria/plans/prep & 150,000 & 150,000 \\
drill/log/install wells, 3,000 $\mathrm{ft}_{\text {i }}$ within fault zone & $2,200,000$ & $4,400,000$ \\
drill/log/install wells, 3,000 ft, outside fault zone & $2,000,000$ & $4,000,000$ \\
pump/installation & 190,000 & 760,000 \\
ERC develop and sample wells, 1 week & 130,000 & 130,000 \\
PBMC support (per wesk) & 35,000 & 35,000 \\
flow logging & 36,000 & 144,000 \\
borehole radar/cross-hole seismic & 125,000 & 125,000 \\
ERC conduct 2 weeks of pumping tests & 130,000 & 260,000 \\
PBMC support & 35,000 & 70,000 \\
ERC analyze data, produce report & 150,000 & 150,000 \\
\cline { 2 - 3 } & & $\$ 10,224,000$
\end{tabular}

Activity \#2 - Timber Mountain investigation

\begin{tabular}{rr} 
unit cost & cost \\
115,000 & 115,000 \\
$2,400,000$ & $2,400,000$ \\
190,000 & 190,000 \\
100,000 & 100,000 \\
35,000 & 35,000 \\
36,000 & 36,000 \\
65,000 & 65,000 \\
\cline { 2 - 2 } & $\$ 2,941,000$
\end{tabular}

total cost

reference

Fryer, 1997a

Bechtel Nevada 1996; DOE, 1997b

Bechtel Nevada 1996; DOE, 1997b

Bechtel Nevada 1996; DOE, 1997b

DOE, 1997c

Dechtel Nevada, 1390

Fryer, 1996

Fryer, $1997 a$

DOE, 1997c

Bechtel Nevada, 1996

Weigand, 1997

reference

DOE, 1997d; Hampton, 1997

Bechtel Nevada 1996; DOE, 1997b

Bechtel Nevada 1996; DOE, 1997b

DOE, 1997c

Bechtel Nevada, 1996

Fryer, 1996

Weigand, 1997

total cost 
Table C-4

\section{Pahute Mesa VOIA - Costs for Data Collection Activities}

(Page 2 of 5 )

Activity \#3 - Exploratory drilling SW of Pahute Mesa

\section{Cost Elements}

ERC prepare criteria/plans/prep

drill/log/install wells, $5,000 \mathrm{ft}$

pump/installation

ERC develop/test/sample/analyze, 1 week

PBMC support (per week)

flow logging

ERC produce report

\section{Activity \#4 - Test cavity sampling}

\section{Cost Elements}

ERC prepare criteria/plans/prep

BENHAM, drill new hole, $5,000 \mathrm{ft}$

BULLION, re-enter post shot hole

CHESHIRE, re-enter post shot hole

pump/installation

ERC develop/test wells, 1 week ea.

PBMC support (per week)

PBMC Radsafe support (per week)

analyze samples/interpret/report

ERC analyze data/report

$$
\begin{array}{rr}
\text { unit cost } & \text { cost } \\
230,000 & 230,000 \\
3,000,000 & 15,000,000 \\
190,000 & 950,000 \\
100,000 & 500,000 \\
35,000 & 175,000 \\
36,000 & 180,000 \\
125,000 & 125,000 \\
\hline
\end{array}
$$

$\begin{array}{r}\text { cost } \\ 230,000 \\ 15,000,000 \\ 950,000 \\ 500,000 \\ 175,000 \\ 180,000 \\ 125,000 \\ \hline \$ 17,160,000\end{array}$

total cost

\begin{tabular}{rr} 
unit cost & cost \\
175,000 & 175,000 \\
$3,000,000$ & $3,000,000$ \\
875,000 & 875,000 \\
775,000 & 775,000 \\
190,000 & 570,000 \\
150,000 & 450,000 \\
35,000 & 105,000 \\
30,000 & 90,000 \\
650,000 & 650,000 \\
125,000 & 125,000 \\
\hline & $\$ 6,815,000$
\end{tabular}

reference

DOE, 1997d; Hampton, 1997

Bechtel Nevada 1996; DOE, 1997b

Bechtel Nevada 1996; DOE, 1997b

DOE, $1997 \mathrm{c}$

Bechtel Nevada, 1996

Fryer, 1996

Weigand, 1997

\section{reference}

DOE, 1997d; Hampton, 1997

Bechtel Nevada 1996; DOE, $1997 \mathrm{~b}$

Pawloski, 1997b

Pawloski, 1997b

Bechtel Nevada, 1996

DOE, 1997d

Bechtel Nevada, 1996

Bechtel Nevada, 1996

Pawloski, 1997b

Weigand, 1997 
Table C-4

\section{Pahute Mesa VOIA - Costs for Data Collection Activities}

Activity \#5 - Huff-puff tracer testing

(Page 3 of 5)

\section{Cost Elements \\ ERC prepare criteria/plans/prep \\ ERC flow modeling \\ workover existing well, 1 well \\ drill/log/install well $3,000 \mathrm{ft}$ \\ pump/installation \\ ERC develop/test/sample/analyze, 1 week \\ PBMC support (per week) \\ flow logging \\ ERC conduct tracer test, 8 weeks \\ PBMC support (per week) \\ ERC analyze data/report}

\section{Activity \#6 - BULLION-type tracer testing}

Cost Elements
ERC prepare criteria/plans
ERC flow modeling
dril//log/install well, $3,000 \mathrm{ft}$
pump/installation
ERC develop/test/sample/analyze, 1 week ea.
PBMC support (per week)
flow logging
ERC conduct tracer test, 12 weeks
PBMC support (per week)
ERC analyze data/report, 1 well

$$
\begin{array}{rr}
\text { unit cost } & \text { cost } \\
200,000 & 200,000 \\
80,000 & 240,000 \\
500,000 & 500,000 \\
2,000,000 & 2,000,000 \\
190,000 & 380,000 \\
100,000 & 200,000 \\
35,000 & 70,000 \\
36,000 & 72,000 \\
500,000 & 1,500,000 \\
35,000 & 840,000 \\
150,000 & 450,000 \\
\cline { 2 - 2 } & \$ 6,452,000
\end{array}
$$

\begin{tabular}{rr} 
unit cost & cost \\
200,000 & 200,000 \\
80,000 & 240,000 \\
$2,000,000$ & $18,000,000$ \\
190,000 & $1,710,000$ \\
130,000 & 390,000 \\
35,000 & 105,000 \\
36,000 & 324,000 \\
800,000 & $2,400,000$ \\
35,000 & $1,260,000$ \\
250,000 & 750,000 \\
\hline & $\$ 25,379,000$
\end{tabular}

total cost

reference

DOE, 1997a; DOE, 1997d

DOE, 1997a; DOE, 1997d

Bechtel Nevada, 1996

Bechtel Nevada 1996; DOE, 1997b

Bechtel Nevada 1996; DOE, 1997b

DOE, 1997d; Hampton, 1997

Bechtel Nevada, 1996

Fryer, 1996

DOE, 1997d; Hampton, 1997

Bechtel Nevada, 1996

DOE, 1997d; Hampton, 1997

reference

DOE, 1997a; DOE, 1997d

DOE, 1997a; DOE, 1997d

Bechtel Nevada 1996; DOE, 1997b

Bechtel Nevada 1996; DOE, 1997b

DOE, 1997c; Hampton, 1997

Bechtel Nevada, 1996

Fryer, 1996

DOE, 1997d; Hampton, 1997

Bechtel Nevada, 1996

DOE, 1997d; Hampton, 1997 
Table C-4

Pahute Mesa VOIA - Costs for Data Collection Activities

Activity \#7 - Isotopic geochemistry-based investigation (Page 4 of 5)

$\begin{array}{lrrrrrr} & \text { LLNL } & \text { USGS } & \text { ERC } & \text { DRI } & \text { cost } & \\ \text { FY } 1997 & & 51,436 & 30,000 & 62,800 & 144,236 & \\ \text { FY } 1998 & 123,000 & 252,901 & 116,000 & 62,900 & 554,801 & \\ \text { FY } 1999 & 45,000 & 116,708 & 145,000 & 125,700 & 432,408 & \\ \text { Subtotals } & 168,000 & 421,045 & 291,000 & 251,400 & \$ 1,131,445 & \text { total cost }\end{array}$

reference

USGS, 1997; DOE, 1997e

USGS, 1997; DOE, 1997e

USGS, 1997; DOE, 1997e

Activity \#8 - 2-D seismic survey

\section{Cost Elements}

NTS archeology surveys

NTS biologic surveys

mobe/demobe

conduct seismic surveys, $3 \times 10 \mathrm{~km}$ lines

data interpretation

$\stackrel{\leftrightarrow}{\omega}$ data processing

$\begin{array}{r}\text { cost } \\ 108,000 \\ 108,000 \\ 50,000 \\ 375,000 \\ 40,000 \\ 50,000 \\ \hline \$ 731,000 \quad \text { total cost }\end{array}$

Activity \#9 - Resistivity, AMT/MT, and gravity surveys

Cost Elements

NTS archeology surveys

NTS biologic surveys

conduct surveys, $3 \times 10 \mathrm{~km}$ lines cost

280,000

$\$ 496,000$ reference

Russell, 1997

Russell, 1997

Pawloski, 1997a

Pawloski, 1997a

Pawloski, 1997a

Pawloski, 1997a

\section{Activity \#10 - Laboratory study of matrix diffusion parameters}

\section{Cost Elements}

LANL approach

set-up and test of 12 core samples

cost

$225-350,000$

SNL approach

set-up and run 15 tests with 5 rock-types

$200-250,000$

estimated cost to run tests on 12 core samples

report reference

Russell, 1997

Russell, 1997

Laczniak, 1997

total cost

reference

Fryer, 1997b

Meigs, 1997

Fryer, 1997b

DOE, 1997d 


\section{Table C-4 \\ Pahute Mesa VOIA - Costs for Data Collection Activities \\ (Page 5 of 5)}

Activity \#11 - Study of radionuclide release from test cavities

Cost Elements

experimental, analytical and reporting costs

Activity \#12 - Geologic and geophysical modeling

Cost Elements

geologic modeling

gravity modeling

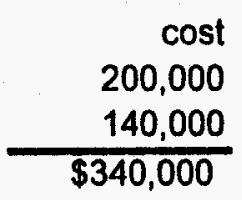

cost

$\$ 340,000$ cost $\frac{1,100,000}{\$ 1,100,000}$

total cost reference

Pawloski, 1997b

莣

Activity \#13 - Barometric response and earth-tides analysis

\section{Cost Elements}

locate and process 5 existing records

collect 10 data records

analyze 15 data records

report

\begin{tabular}{rr} 
unit cost & cost \\
4400 & 4,400 \\
3300 & 33,000 \\
880 & 13,200 \\
25,000 & 25,000 \\
\cline { 2 - 2 } & $\$ 75,600$
\end{tabular}

cost

33,000

$\$ 75,600$

Activity \#14 - Mobility coefficients for radionuclides

\section{Cost Elements}

data analysis and modeling

analysis/report cost

250,000

25,000

$\$ 275,000$ reference

DOE, 1997d

DOE, 1997d

DOE, 1997d

DOE, 19970 reference

Pawloski, 1997b

Laczniak, 1997

total cost

reference

DOE, 1997d

DOE, 1997d 


\section{Table C-5}

Generic Multi-Function Well, Cost Scaling

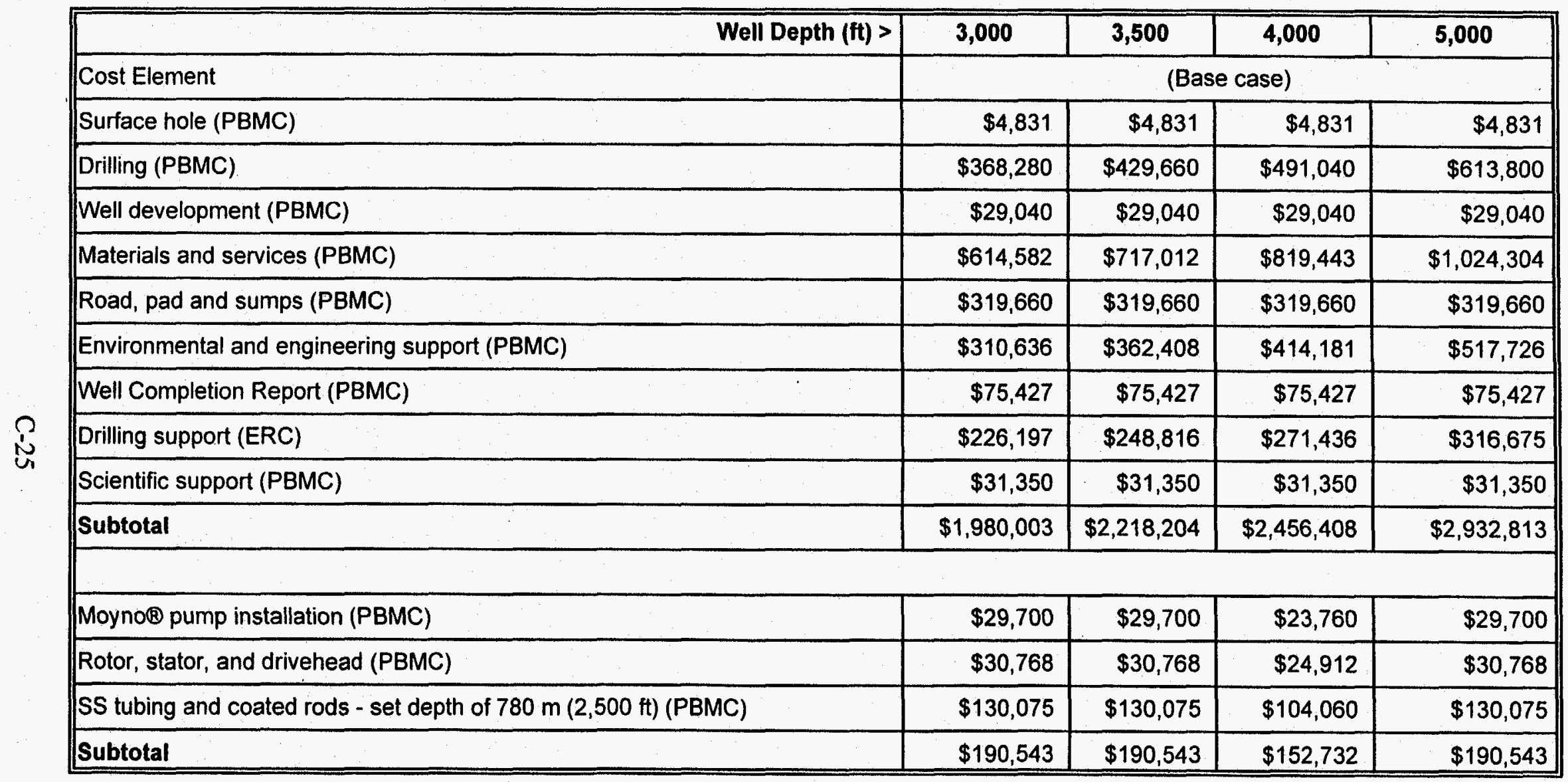

Notes:

Assumes uncontaminated drilling and standard radsafe services.

Based on 1996 UGTA Baseline Generic Characterization Well costs for a $1,250 \mathrm{~m}(4,000 \mathrm{ft})$ well, scaled to the other depths.

Costs shown are $10 \%$ higher than the UGTA 1996 Baseline to bring them into line with 1997 Baseline revisions.

ERC: Environmental Remediation Contractor

PBMC: Performance-Based Management Contractor

SS: Stainless Steel 


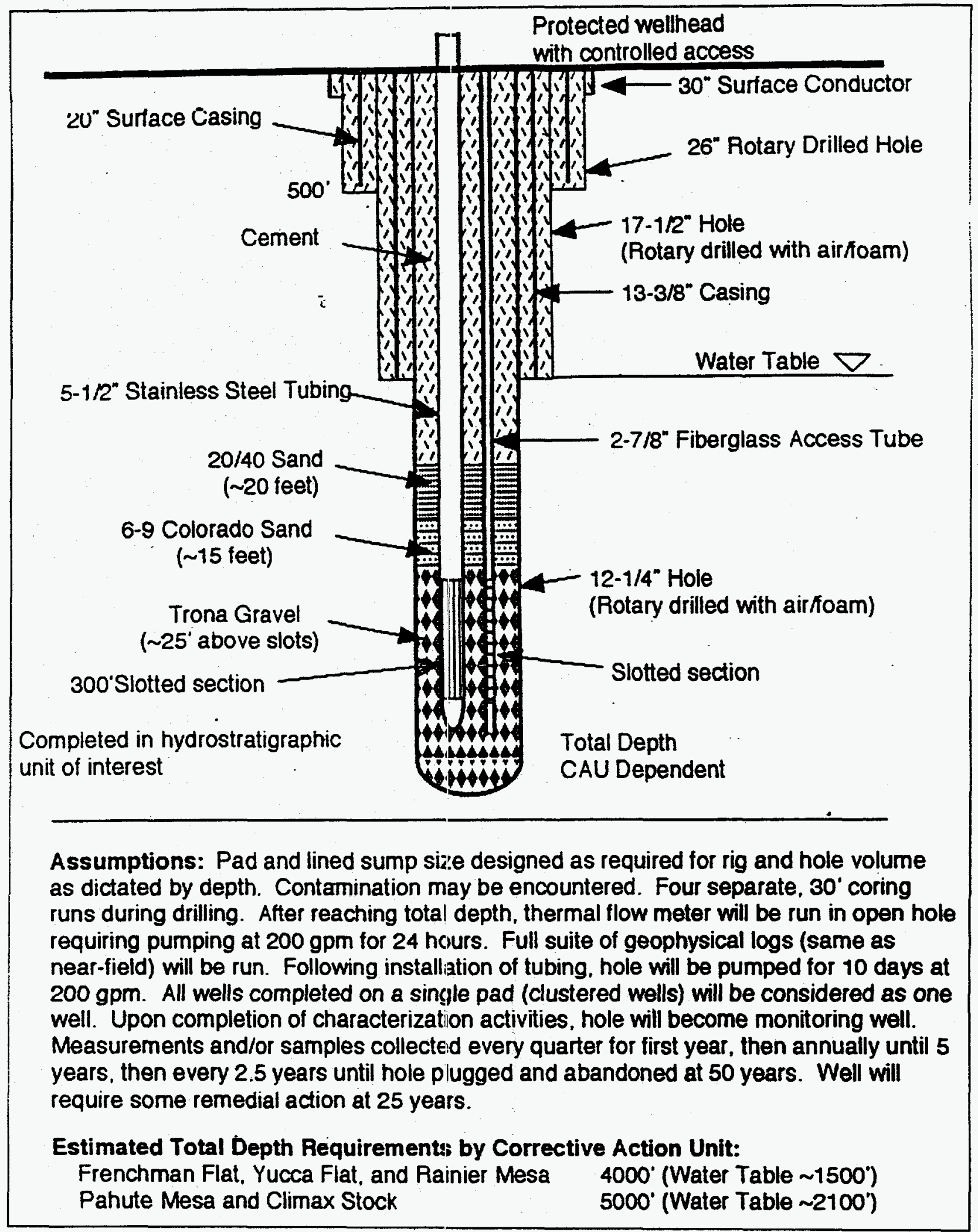

Figure C-1

Generic Characterization Well 


\section{C.3.1 Descriptions of Activity Groups}

The scheme for specifying groups was to assess combinations of activities that may be synergistic, to explore the range of combinations of parameters, to evaluate groups emphasizing individual parameters, and to span the range of total cost from low to a reasonably high values. A summary description of the groups is presented in Table C-6. Discussions of the basis for and objectives of the activity group follow:

\section{Group 1 - Broad-Based Group}

This group represents a broad-based concept for collecting comprehensive information on the groundwater flux parameter as well as supporting studies on the diffusion parameter and source term. The activities included in Group 1 are as follows:

- Activity 3 - exploratory drilling SW of Pahute Mesa

- Activity 7 - isotopic geochemistry-based investigation

- Activity 9 - resistivity, AMT/MT, and gravity surveys

- Activity 10 - laboratory study of matrix diffusion

- Activity 11 - study of radionuclide release from test activities

Activities 3,7 , and 9 address both the geologic model and flow model calibration, and are substantially synergistic and not duplicative. Activities 10 and 11 address distinct parameters with only low-level synergistic interaction with each other or the other activities.

\section{Group 2 - Faults}

The concept for this group is specific to investigating fault zones, which addresses the concern about the influence of faults on groundwater flow and a fast migration path along a highly transmissive fault. The activities included in Group 2 are as follows:

- Activity 1 - fault characterization

- Activity 8 - 2-dimensional seismic survey

- Activity 9 - Resistivity, AMT/MT, and gravity surveys

These activities only provide information about the groundwater flux parameter relative to faults. Activities 8 and 9 would be used to identify and characterize the fault zone location to be investigated under Activity 1. These activities are synergistic in the sense that Activities 8 and 9 help ensure that the well locations chosen for Activity 1 properly penetrate the fault zone and the representativeness is somewhat characterized. 
Table C-6

Groups of Characterization Activities

\begin{tabular}{|c|c|c|c|c|c|c|c|c|c|c|}
\hline Groups Designation > & G1 & G2 & G3 & G4 & G5 & G6 & G7 & G8 & G9 & G10 \\
\hline Group Description > & Broad-Based & Faults & $\begin{array}{l}\text { Groundwater } \\
\text { flux }\end{array}$ & $\begin{array}{l}\text { Transport } \\
\text { (general) }\end{array}$ & $\begin{array}{l}\text { Source } \\
\text { Term }\end{array}$ & Low Cost & $\begin{array}{l}\text { Transport } \\
\text { (specific) }\end{array}$ & Value & $\begin{array}{l}\text { Compre- } \\
\text { hensive }\end{array}$ & $\begin{array}{c}\text { Public } \\
\text { Acceptance }\end{array}$ \\
\hline A1 - Fault characterization & & $x$ & $x$ & & & & & & & $x$ \\
\hline \begin{tabular}{|c|}
$\mathrm{A} 2$ - \\
$\begin{array}{l}\text { Timber Mountain } \\
\text { investigation }\end{array}$ \\
\end{tabular} & & & $x$ & & & & & $x$ & & \\
\hline $\begin{array}{ll}\text { A3 - Exploratory drilling SW of } \\
\text { Pahute Mesa }\end{array}$ & $x$ & & $\mathrm{x}$ & & & & & & $x$ & $x$ \\
\hline A4- Test-cavity sampling & & & & & $x$ & & & & & $x$ \\
\hline A5 - Huff-puff tracer testing & & & & $x$ & & & $x$ & & & \\
\hline 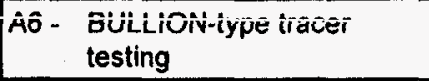 & & & & & 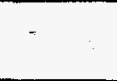 & & $x$ & & $\ddot{x}$ & \\
\hline \begin{tabular}{|c|} 
A7 - Isotopic geochemistry- \\
based investigation
\end{tabular} & $x$ & & & $x$ & $x$ & $x$ & & $x$ & $x$ & $x$ \\
\hline AB - 2-D seismic survey & & $x$ & $x$ & & & $x$ & & & $x$ & \\
\hline $\begin{array}{l}\text { A9- Resistivity, AMT/MT, and } \\
\text { gravity surveys }\end{array}$ & $\mathrm{x}$ & $x$ & $x$ & & & $x$ & & & $x$ & \\
\hline $\begin{array}{l}\text { A10 - Laboratory study of matrix } \\
\text { diffusion parameters }\end{array}$ & $x$ & & & $x$ & & $\mathrm{x}$ & $x$ & $x$ & $x$ & \\
\hline $\begin{array}{l}\text { A11 - Study of radionuclide } \\
\text { release from test cavities }\end{array}$ & $x$ & & & & $x$ & & & & $x$ & $x$ \\
\hline $\begin{array}{l}\text { A12 - Geologic and geophysical } \\
\text { modeling }\end{array}$ & & & $x$ & & & $\mathrm{x}$ & & $x$ & $x$ & \\
\hline $\begin{array}{l}\text { A13 - Barometric response and } \\
\text { earth-tide analysis }\end{array}$ & & & & $x$ & & $\mathrm{x}$ & $\mathrm{x}$ & $x$ & $x$ & \\
\hline A14 - Mobility coefficients for & & & & $x$ & & $x$ & & & & \\
\hline
\end{tabular}


The information from Activities 8 and 9 also will be useful for interpretation of the testing data obtained under Activity 1.

\section{Group 3 - Groundwater Flux}

This group represents a comprehensive focus on the flux multiplier parameter, specifically characterization of the geologic framework and water level information, and potentially some contaminant data useful for calibration of transport. The activities included in Group 3 are as follows:

- Activity 1 - fault characterization

- Activity 2 - Timber Mountain investigation

- Activity 3 - exploratory drilling SW of Pahute Mesa

- Activity 8 - 2-dimensional seismic survey

- Activity 9 - resistivity, AMT/MT, and gravity surveys

- Activity 12 - geologic and geophysical modeling

These activities work together synergistically at a low level, but mainly complement each other.

\section{Group 4 - Transport (general)}

The focus of this group is the general investigation of transport parameters at the basic level. The activities included in Group 4 are as follows:

- Activity 5 - huff-puff tracer testing

- Activity 7 - isotopic and geochemistry-based investigation

- Activity 10 - laboratory study of matrix diffusion

- Activity 13 - barometric response and earth-tide analysis

- Activity 14 - distribution coefficients for radionuclides

The selected activities are synergistic to some extent in that each provides a different type of data that may be useful together in interpreting or calibrating the results of others, as well as providing a broad range of information to the flow and transport modeling.

\section{Group 5 - Source Term}

Group 5 is focused on the characterization of the hydrologic source-term. The activities included in Group 5 are as follows:

- Activity 4 - test cavity sampling

- Activity 7 - isotopic and geochemistry-based investigations

- Activity 11 - study of radionuclide release from test cavities 
Activities 4 and 11 work together to provide the best anticipated information for the source-term. Activity 4 would provide information for Activity 11 and should supply better information than is currently available. Activity 7 potentially can supply information also useful in Activity 11 , but perhaps more useful in the far-field transport modeling.

\section{Group 6 - Low Cost}

This grouping is based on the theme of chcosing the lowest cost activities for the most sensitive parameters. The activities included in Group 6 are as follows:

- Activity 7 - isotopic and geochemistry-based investigation

- Activity 8 - 2-dimensional seismic survey

- Activity 9 - resistivity, AMT/MT, and gravity surveys

- Activity 10 - laboratory study of matrix diffusion

- Activity 12 - geologic and geophysical modeling

- Activity 13 - barometric response and earth-tide analysis

- Activity 14 - distribution coefficients for radionuclides

The flux-oriented activities (Activities 7, 8, 9, 12) work together, particularly Activities 8, 9, and 12 for the geologic model; and Activity 7 may work with Activity 10 for calibrating matrix diffusion rates.

\section{Group 7 - Transport (specific)}

This group presents an advanced approach to optimizing transport parameter characterization that focuses on in situ transport experiments, and includes the expensive BULLION-type experiments. This is a comprehensive, direct approach to the most important transport parameters using controlled tests rather than trying to calibrate with indirect data. The activities included in Group 7 are as follows:

- Activity 5 - huff-puff tracer testing

- Activity 6 - BULLION-type tracer testing

- Activity 10 - laboratory study of matrix diffusion

- Activity 13 - barometric response and earth-tide analysis

The advantage of conducting both Activities 5 and 6 is the increased number of tests run (more locations and more rock types) for much less money than all BULLION-type tests while allowing calibration of the huff-puff tests to the more accurate BULLION-type tests. These may then be used to calibrate laboratory tests for diffusion to field-scale diffusion and general porosity data to effective porosity. 


\section{Group 8 - Value}

This group is designed to provide great benefit for a moderate cost, and address the most significant uncertainties with sufficient characterization to produce an acceptable result. The activities included in Group 8 are as follows:

- Activity 2 - Timber Mountain investigation

- Activity 7 - isotopic and geochemistry-based investigations

- Activity 10 - laboratory study of matrix diffusion

- Activity 12 - geologic and geophysical modeling

- Activity 13 - barometric response and earth-tide analysis

There are no synergisms in this group.

\section{Group 9 - Comprehensive}

This group includes activities that are perceived as providing the best information for all of the sensitive parameters (groundwater flux, diffusion parameter, source, porosity) without regard to cost. The activities included in Group 9 are as follows:

- Activity 3 - exploratory drilling SW of Pahute Mesa

- Activity 6 - BULLION-type tracer testing

- Activity 7 - isotopic and geochemistry-based investigations

- Activity 8 - 2-dimensional seismic survey

- Activity 9 - resistivity, AMT/MT, and gravity surveys

- Activity 10 - laboratory study of matrix diffusion

- Activity 11 - study of radionuclide release from test cavities

- Activity 12 - geologic and geophysical modeling

- Activity 13 - barometric response and earth-tide analysis

Within this group, activities addressing the same parameter are synergistic.

\section{Group 10 - Public Acceptance}

Activities included under the theme of public acceptance are those topics that the TWG subcommittee perceive the public would be most interested in and most assured by. This group emphasizes direct investigation and monitoring of groundwater downgradient of Pahute Mesa, the concern over a fast path along a transmissive fault, and the magnitude of the contaminant source-term. The activities included in Group 10 are as follows:

- Activity 1 - fault characterization

- Activity 3 - exploratory drilling SW of Pahute Mesa 
- Activity 4 - test cavity sampling

- Activity 7 - isotopic and geochemistry-based investigations

- Activity 11 - study of radionuclide release from test cavities

Synergism exists between Activities 3 and 7 because Activity 3 provides additional information to Activity 7. The two source-term activities are also synergistic because Activity 4 provides information for Activity 11.

\section{C.3.2 Estimated Costs for Activity Giroups}

The intent of this cost estimating was to assign representative costs for the generalized type of activity and specified quantity of work for use in comparing the different activities and groups. Specifications were speculative and general, and were not refined enough to produce more elaborate or accurate estimates. The estimates have been rounded to the nearest $\$ 1,000$ to avoid the appearance of specific accuracy.

The estimated costs for groups of activities are shown on Table C-7. Except for Group 9, the cost for each group is the sum of the individual costs of the activities in the group. For Group 9, it was assumed that the BULLION-type tracer tests of Activity 6 would be conducted on the exploration sites of Activity 3, and that the exploration holes could also serve as one of the three wells needed for the tracer tests. Consequently the cost of one well for each of the three tracer test sites was eliminated from Activity 6 for this group. 


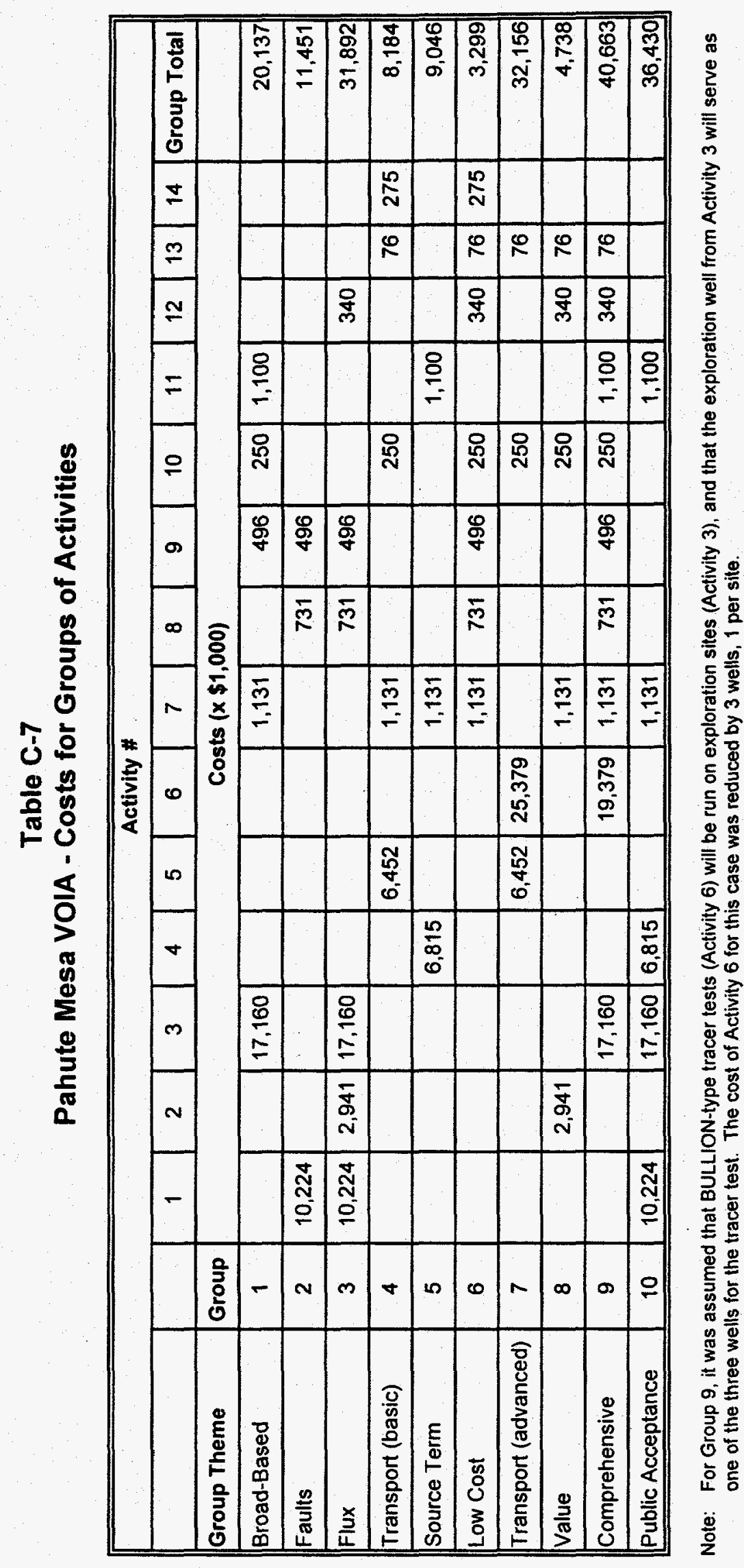




\section{C.4.0 References}

Bechtel Nevada. 1996. Facsimile of ER Baseline Worksheets, Characterization Well Data, and Cost Scaling of Generic Multifunction Well, 6 March. Las Vegas, NV: IT, Pahute Mesa VOIA project files.

Fryer, W.M. HSI GeoTrans. 1996. Record of Telecon with George Juniel, Bechtel Nevada, about cost estimates for flow logging and deviation surveys, 26 August. Las Vegas, NV: IT Corporation, Pahute Mesa Soil project files.

Fryer, W.M. HSI GeoTrans. 1997a. Record of Telecon with Chris Aresmyk of Schlumberger about costs for crosshole seismic and borehole radar, 3 September. Las Vegas, NV: IT Corporation, Pahute Mesa VOIA project files.

Fryer, W.M. HSI GeoTrans. 1997b. Record of Telecon with Paul Reimus, Los Alamos National Laboratory, about a laboratory study of diffusion into rock, 4 August. Las Vegas, NV: IT Corporation, Pahute Mesa VOIA project files.

Hampton, M. 1997. BULLION FGE-Actuals Projects, 8 August. Las Vegas, NV: IT Corporation, Pahute Mesa VOIA project files.

IT Corporation. 1997. Total Project Cost, Cost Schedule and Technical Baseline. Las Vegas, NV.

Laczniak, R.J. U.S. Geological Survey. 1997. Facsimile to Bill Fryer, HSI GeoTrans (IT subcontractor), with cost estimates for geophysical support activities for Oasis Valley, 21 August. Las Vegas, NV: IT Corporation, Pahute Mesa VOIA project files.

Meigs, L.C. Sandia National Laboratories. 1997. Letter to Bill Fryer, HSI GeoTrans (IT subcontractor), about proposed matrix diffusion studies in Pahute Mesa, 8 August. Albuquerque, NM: SNL Geohydrology Department.

Pawloski, G. Lawrence Livermore National Laboratory. 1997a. Facsimile to Bill Fryer, HSI GeoTrans (IT subcontractor), with cost estimates for a seismic survey of Pahute Mesa and Oasis Valley, 6 August. Las Vegas, NV: IT Corporation, Pahute Mesa VOIA project files.

Pawloski, G. Lawrence Livermore National Laboratory. 1997b. E-mail transmittal to Bill Fryer, HSI GeoTrans (IT subcontractor), about Pahute Mesa VOIA Costs, 6 August. Las Vegas, NV: IT Corporation, Pahute Mesa VOIA project files.

Russell, C. Desert Research Institute. 1997. Facsimile transmittal to Bill Fryer, HSI GeoTrans (IT subcontractor), about Cultural Resources Survey for Oasis Valley UGTA Well locations, 8 August. Las Vegas, NV: IT Corporation, Pahute Mesa VOIA project files. 
U.S. Department of Energy. 1997a. Summary Basis of Estimate for BULLION FGE, 21 August. Las Vegas, NV: DOE/NV Environmental Restoration Program.

U.S. Department of Energy. 1997b. Sumrnary Basis of Estimate for Data Acquisition and Monitoring Well Construction Contingency, 26 August. Las Vegas, NV: DOE/NV Environmental Restoration Program.

U.S. Department of Energy. 1997c. Sumrnary Basis of Estimate for Sampling and Testing (Bullion Experiment), 21 August. Las Vegas, NV: DOE/NV Environmental Restoration Program.

U.S. Department of Energy. 1997d. Summary Basis of Estimate for Drilling at Pahute Mesa CAU, 21 August. Las Vegas, NV: DOE/NV Environmental Restoration Program.

U.S. Department of Energy. 1997e. Sumrnary Basis of Estimate for Oasis Valley Geochemistry, 21 August. Las Vegas, NV: DOE/NV Environmental Restoration Program.

U.S. Geological Survey. 1997. Facsimile of Collaborative Characterization of the

Geochemistry of the Oasis Valley Subbasin, Death Valley Ground-Water Flow System, 8 July. Las Vegas, NV: IT Corporation, Pahute Mesa VOIA project files.

Weigand, W. 1997. Baseline Characterization Well Construction Estimate, August. Las Vegas, NV: IT Corporation, VOIA project files. 
Appendix D

\section{Prior Probability Assessment}




\section{Table of Contents}

List of Figures

List of Tables D-ii

D.1.0 Introduction D-1

D.2.0 Elicitation Procedure

D.3.1 Source Term

D-3

D.3.2 Effective Porosity

D-3

D.3.3 Diffusion Parameter

D-4

D.3.4 Groundwater Flux Multiplier

D-7

D.3.5 Distribution Coefficients

D.4.0

References

D-15 


\section{List of Figures}

Number

Title

Page

D-1 Cumulative Density Function of the Matrix Diffusion Mass

Transfer Coefficient ............................... D-9

D-2 Prior Cumulative Density Function of the Diffusion Mass

Transfer Coefficient ............................... D-10

\section{List of Tables}

Number

Title

Page

D-1 Source Term Constituent Prior Distributions $\ldots \ldots \ldots \ldots \ldots \ldots \ldots \ldots$ D-4

D-2 Fracture Porosity Ranges by Hydrostratigraphic Unit $\ldots \ldots \ldots \ldots \ldots \ldots$ D-5

D-3 Comparison of Two Versions of the Regional

Groundwater Flow Model to Assess Uncertainty in Groundwater Flux ..... D-12

D-4 Range in $\mathrm{K}_{\mathrm{d}}$ Values as Reported in Triay et al. (1997) ............ D-14

D-5 Prior Distribution for the Distribution Coefficient, $K_{d} \ldots \ldots \ldots \ldots \ldots$ D-14 


\section{D.1.0 Introduction}

Five groundwater flow and transport parameters were identified as having the greatest impact on the contaminant boundary. Probability distributions describing these parameters were elicited from the expert panel. A description of the elicitation process is provided, followed by the details associated with each sensitive parameter.

\section{D.2.0 Elicitation Procedure}

The expert panel typically provided the 5 and 95 percent fractiles of the distributions, and then specified the mathematical forms. In all cases, the specified distributions are named distributions characterized by two parameters. Consequently, two fractiles were sufficient to compute numerical values for the distribution parameters.

In most cases, the expert panel provided 5 and 95 percent fractiles for the distributions. The diffusion parameter ( $\alpha$, mass transfer coefficient), however, was treated differently. In this case, 5 and 95 percent fractiles were obtained using an equation that relates alpha to fracture spacing $(B)$, diffusion coefficient $\left(D_{m}\right)$, and matrix porosity $\left(\theta_{m}\right)$ :

$$
\alpha=\frac{3 \theta_{m} D_{m}}{B^{2}}
$$

The expert panel specified fractiles and distribution forms for $\mathrm{B}, \mathrm{D}_{\mathrm{m}}$, and $\theta_{\mathrm{m}}$, and the 5 and 95 percent fractiles for the alpha prior distribution were derived indirectly using Monte Carlo simulation. As explained later in this appendix, a named distribution was fit to the derived alpha distribution. During the transport simulations, the diffusion transfer coefficient was used directly to better control the distribution of alpha. Subsequent assessments of the posterior distribution were performed on alpha directly, again to better control the probability distribution.

Another exception occurred for the parameter $K_{d}$, the distribution coefficient. $K_{d}$ was specified by the expert panel to be uniformly distributed. Therefore, rather than provide 5 and 95 percent fractiles, the Panel provided absolute minimum and maximum values (denoted $a$ and $b$ ). The mean and standard deviation (denoted $v$ and $\sigma$ ) for the uniform distribution were then calculated 
from

$$
v=\frac{(a+b)}{2}
$$

and

$$
\sigma=\frac{(b-a)}{\sqrt{12}}
$$

Given the 5 and 95 percent fractiles, the method for obtaining distributions for the remaining parameters depended on the specified form of the probability distribution. In the case of source term, the expert panel specified the distribıtion to be normal. The mean and standard deviation (denoted $v$ and $\sigma$ ) for the distribution were calculated from 5 and 95 percent fractiles (denoted $F_{5}$ and $F_{95}$ ) using standard statistical measures (Benjamin and Cornell, 1970):

$$
\begin{gathered}
v=F_{50}=\frac{\left(F_{95}-F_{5}\right)}{2} \\
\sigma=\frac{\left(F_{95}-F_{50}\right)}{N^{-1}(0.95)},
\end{gathered}
$$

where $\mathrm{N}^{-1}(0.95)$ is the inverse of the standard normal distribution at the $95^{\text {th }}$ percentile $(\approx 1.6443)$.

The distributions for diffusion parameter, flux multiplier, and effective porosity were specified to be lognormal. The means and standard deviations of the underlying normal distributions in natural $\log$ space (denoted $v_{\mathrm{x}}$ and $\sigma_{\mathrm{x}}$ ) were calculated from

$$
v_{x}=\ln \left(\mathrm{F}_{50}\right)=\frac{\ln \left(\mathrm{F}_{95}\right)-\ln \left(\mathrm{F}_{5}\right)}{2}
$$




$$
v_{x}=\frac{\ln \left(F_{95}\right)-\ln \left(F_{50}\right)}{N^{-1}(0.95)}
$$

where, again, $\mathrm{N}^{-1}(0.95)$ is the inverse of the standard normal distribution at the $95^{\text {th }}$ percentile. The random number generator used in the transport simulations required $v_{\mathrm{x}}$ and $\sigma_{\mathrm{x}}$ of the lognormal distribution in terms of $\log$ base 10 . The natural $\log$ values were divided by 2.303 to convert to log base 10 .

Table 3-4 in the main text summarizes the prior distributions calculated from the expert panel's consensus judgments of the form and specified fractiles of each sensitive parameter.

\section{D.3.0 Detailed Assessment}

Detailed descriptions of the prior probability distributions for the five sensitive parameters are provided in the following order: source term, effective porosity, diffusion parameter, flux multiplier, and distribution coefficients $\left(\mathrm{K}_{\mathrm{d}} \mathrm{s}\right)$.

\section{D.3.1 Source Term}

As used here, the source term represents the amount of each radionuclide that is available to be transported by groundwater. The nature of the source term is very complex, because of a variety of factors (e.g., the specific configuration of the device, rock type, cooling history, and depth of burial). As a result, there is a great deal of uncertainty regarding the appropriate value to use for source term. The expert panel solicited input on the source term from the members of the UGTA Technical Working Group Source Term Subcommittee. The source term that was supplied is not specific to the TYBO test, but represents a "typical" source term for Pahute Mesa. The Source Term Subcommittee emphasized that the hydrologic source term values are quite uncertain, but adopted a conservative approach to define upper-bound values based on observed concentrations of cavity fluids. Lower-bound values were even more difficult to define because of complexities of the near-field environment. Based on their expert opinion, the Source Term Subcommittee chose a range of three orders-of-magnitude for each of the radionuclides. In addition to providing a range of values, the subcommittee also provided a nominal confidence level for each radionuclide minimum and maximum $(1=$ least confident, $10=$ most confident $)$. Each 
radionuclide was assigned a normal distribution per the request of the Source Term Subcommittee. The minimum and maximum values for each nuclide are expressed in $\mathrm{pCi} / \mathrm{L}$ (corrected to 1994) and are presented in Table D-1.

Table D-1

Source Term Coristituent Prior Distributions

\begin{tabular}{|c|c|c|c|c|c|c|c|}
\hline \multirow{2}{*}{$\begin{array}{l}\text { Radionuclide } \\
\mathrm{H}-3\end{array}$} & \multirow{2}{*}{$\begin{array}{c}\begin{array}{c}\text { Half-life } \\
\text { (years) }\end{array} \\
12.3\end{array}$} & \multicolumn{2}{|c|}{$\underset{(p C i / L)}{\text { Minimum }}$} & \multicolumn{2}{|c|}{$\begin{array}{l}\text { Maximum } \\
(\mathrm{pCi} / L)\end{array}$} & \multirow{2}{*}{$\begin{array}{c}\begin{array}{c}\text { Mean } \\
(p \mathrm{Ci} / \mathrm{L})\end{array} \\
5.005 \times 10^{9}\end{array}$} & \multirow{2}{*}{$\begin{array}{c}\begin{array}{c}\text { Standard } \\
\text { Deviation } \\
\text { (pCi/L) }\end{array} \\
3.006 \times 10^{9}\end{array}$} \\
\hline & & $1 \times 10^{7}$ & (cl 2) & $1 \times 10^{10}$ & (c) 8) & & \\
\hline Cs-137 & 30.17 & 1 & (cl 2) & 1000 & (cl 6) & 500.5 & 300.6 \\
\hline Pu-239/240 & 24000 & 0.001 & (cl 2) & 1 & (cl 2) & $5.005 \times 10^{-1}$ & $3.006 \times 10^{-1}$ \\
\hline C-14 & 5730 & 100 & (cl 2) & 100000 & (cl 2) & $5.005 \times 10^{4}$ & $3.006 \times 10^{4}$ \\
\hline Sr-90 & 29.1 & 1 & (cl 2) & 1000 & (cl 2) & 500.5 & 300.6 \\
\hline U-238 & $4.5 \times 10^{9}$ & .001 & (cl 1) & 1 & (cl 1) & $5.005 \times 10^{-1}$ & $3.006 \times 10^{-1}$ \\
\hline $1-129$ & $1.7 \times 10^{7}$ & .001 & (cl 1) & 1 & (c) 1) & $5.005 \times 10^{-1}$ & $3.006 \times 10^{-1}$ \\
\hline
\end{tabular}

\begin{tabular}{|c|c|c|c|}
\hline $\begin{array}{l}\mathrm{Cl} \\
\mathrm{H}-3 \\
\mathrm{Cs} \\
\mathrm{Pu}\end{array}$ & $\begin{array}{l}=\text { Confidence level } \\
=\text { Tritium Sr } \\
=\text { Cesium } \\
=\text { Plutonium }\end{array}$ & $\begin{array}{l}C=\text { Carbon } \\
=\text { Strontium } \\
U=\text { Uranium } \\
I=\text { lodine }\end{array}$ & $\mathrm{pCi} / \mathrm{L}=$ Picocurie(s) per liter \\
\hline
\end{tabular}

\section{D.3.2 Effective Porosity}

The flux and effective porosity control the velocity of groundwater via the relationship: relative velocity = groundwater flux/effective porosity. Measurements of effective porosity are difficult to obtain and are usually determined from a tracer migration experiment. Unfortunately, tracer data are limited and approximate values were sought from other sources. For the fractured Timber Mountain Aquifer it is recognized that fracture porosity will control the rapid movement of radionuclides and therefore fracture porosity was examined as a surrogate for effective porosity. This approach is expected to produce lower bound estimates for the effective porosity. Lee and Farmer (1993) summarized fracture porosity data from a wide variety of rock types. They showed that porosity decreases somewhat with depth but is typically in the range of $2 \times 10^{-6}$ to $1 \times 10^{-4}$.

A second approach examined the fracture data summarized in DOE/NV (1997b). Core from volcanic rock units in Areas 18, 19, and 20 of the NTS were retrieved from the U.S. Geological Survey core library and subjected to a number of analyses, including the measurement of the density and distribution of open fractures per linear $1.5-\mathrm{m}(5-\mathrm{ft})$ interval, the fracture dip, the fracture aperture and openness, and fracture coating. The data are summarized per well per HSU. 
Accounting for variation in the fracture dip angle and the percent openness, these data are combined to establish fracture porosity. A summary is presented in Table D-2.

\section{Table D-2}

\section{Fracture Porosity Ranges by Hydrostratigraphic Unit}

\begin{tabular}{|l|c|c|}
\hline \hline Hydrostratigraphic Unit & Minimum Fracture Porosity & Maximum Fracture Porosity \\
\hline \hline Timber Mountain Aquifer & $2.2 \times 10^{-5}$ & $1.9 \times 10^{-4}$ \\
\hline Tuff Cones & $2.6 \times 10^{-6}$ & $4.6 \times 10^{-4}$ \\
\hline Belted Range Aquifer & $1.2 \times 10^{-6}$ & $4.4 \times 10^{-5}$ \\
\hline Basal Aquifer & $6.1 \times 10^{-6}$ & $2.3 \times 10^{-4}$ \\
\hline \hline
\end{tabular}

The range of values for fracture porosity from NTS-specific data is similar to the range of values identified in Lee and Farmer (1993). However, these values are quite low and produce extremely fast groundwater flow velocities. For example, taking a groundwater flux of $10 \mathrm{~m}(33 \mathrm{ft})$ per year, the velocity of groundwater will be $1 \times 10^{6} \mathrm{~m}$ per year $\left(3,281 \times 10^{6} \mathrm{ft}\right.$ per year $)(1,000 \mathrm{~km}$ per year [ 620 miles per year]) if the porosity is $1 \times 10^{-5}$. These velocities are simply too fast to be realistic.

A third approach to estimating the value of effective porosity again utilizes the fracture information included in DOE/NV (1997b). According to Snow (1968), the hydraulic conductivity of a parallel array of planar joints of aperture $b$, with $N$ joints per length, $L$, measured perpendicular to the fractures can be represented by the following formula:

$$
K=\frac{\rho g N b^{3}}{12 \mu \mathrm{L}}
$$

where

$$
\begin{aligned}
& K=\text { bulk hydraulic conductivity of the aquifer } \\
& \rho=\text { fluid density } \\
& g=\text { acceleration of gravity } \\
& N=\text { number of fractures per length, } L, \text { measured perpendicular to the fractures } \\
& b=\text { fracture aperture } \\
& \mu=\text { viscosity of the fluid } \\
& L=\text { length over which the number of fractures is measured }
\end{aligned}
$$


The number of fractures, $\mathrm{N}$, can also be represented by

$$
\mathrm{N}=\frac{\mathrm{L}}{\mathrm{b}+\mathrm{B}}
$$

where $B$ is the width of the block between fractures.

With this definition, the hydraulic conductivity can be written as

$$
K=\frac{\rho g b^{3}}{12 \mu(B+b)}
$$

or, recognizing that $B>>b$, as

$$
\mathrm{K}:=\frac{\rho g b^{3}}{12 \mu \mathrm{B}}
$$

Again using $B$ and $b$ as parameters, the fracture porosity is represented by

$$
n_{e}=\frac{b}{b+B}
$$

Choosing the hydraulic conductivity value from the calibration of the regional groundwater flow model and using the range of fracture spacing values $0.26 \mathrm{~m}$ to $10 \mathrm{~m}$ from the fracture study, it is possible to calculate a range of fracture porosity values from $2 \times 10^{-4}$ to $2 \times 10^{-3}$ (Rehfeldt, 1997). These values are significantly larger than the values obtained from fracture data alone.

The final set of effective porosity data come from the forced gradient tracer test conducted on Pahute Mesa at the Bullion Tracer Test site. Preliminary interpretation of the tracer breakthrough data gives a range of effective porosity values of $1 \times 10^{-3}$ to $7 \times 10^{-3}$ (Rehfeldt, 1997). Preliminary interpretation of other tracer experiments in fractured tuff near Yucca Mountain have yielded porosity values of $7 \times 10^{-3}$ to $4 \times 10^{-2}$ (Reimus, 1997).

Based on all these data, the expert panel chose a range of porosity values from $1.0 \times 10^{-4}$ to $3.0 \times 10^{-2}$ to represent the 5 and 95 percent values. This range most closely corresponds to the tracer test data, but also includes the larger values from the fracture study. The effective porosity 
was taken to be lognormally distributed because of the large range of values and the desire to prohibit negative values.

\section{D.3.3 Diffusion Parameter}

The diffusion parameter as defined in the transport model is a function of the matrix porosity, diffusion coefficient, and the fracture spacing (Appendix B). Initial parameter distributions for each of those parameters were defined separately and presented to the expert panel. An initial range of values for matrix porosity from 0.08 to 0.5 was presented to the panel as determined from measured values. The expert panel felt the range was not appropriate for the matrix material of a fractured welded tuff unit and suggested a narrower and shifted range. The matrix porosity was assigned as a uniformly distributed variable with a lower bound of 0.035 and an upper bound of 0.27 .

The mean fracture spacing was determined to range from $0.2 \mathrm{~m}$ to $5.8 \mathrm{~m}$. This range is based on data from the fracture study (DOE $/ \mathrm{NV}, 1997 \mathrm{~b}$ ). The data required by the transport model is onehalf the fracture spacing. The expert panel settled on a range of $0.2 \mathrm{~m}$ to $2.6 \mathrm{~m}$ for the fracture half spacing.

Finally, the effective diffusion coefficient was presented to the subcommittee members. This diffusion coefficient value was obtained from limited data available at the time and from literature values from other sources. The expert panel chose a lognormally distributed range to be $6.3 \times 10^{-4}$ to $9.5 \times 10^{-3}$ based on the 5 percent and 95 percent levels. This range is slightly larger than the original as used in the regional model (DOE/NV, 1997a) and reflects the expert panel member's belief that uncertainty is larger.

These parameters were combined into a single diffusion mass transfer coefficient using the formula

$$
\alpha=\frac{3 \theta_{m} D_{m}}{B^{2}}
$$

where

$\alpha=$ diffusion mass transfer coefficient,

$\theta_{\mathrm{m}}=$ matrix porosity,

$D_{m}=$ effective diffusion coefficient, and

$\mathrm{B}$ = fracture half spacing. 
The resulting distribution for $\alpha$ is given in Figure D-1 for the case of 1,000 realizations. The mean and standard deviation of the distribution is estimated from $\log _{10}$ transformed the 5 percent and 95 percent fractile values as

$$
\begin{aligned}
& \text { mean }=\frac{5 \% \text { value }+95 \% \text { value }}{2}=\frac{-4.197+(-1.844)}{2}=-3.021 \\
& \text { std. dev. }=\frac{\text { mean }-5 \% \text { value }}{1.645}=\frac{-3.021-(-4.197)}{1.645}=0.715
\end{aligned}
$$

Where 1.645 is the standard normal variate corresponding to a probability of 90 percent (45 percent on both sides of the mean).

This prior distribution of the matrix diffusion transfer coefficient is determined as a function of three other prior distributions. To make the VOIA successful, the expert panel members concurred that the number of variables in the VOIA should be minimized. Therefore, the diffusion mass transfer coefficient was evaluated directly rather than evaluating the three input parameters. To facilitate direct input of alpha into the transport model, several approximations were made.

In the diffusion mass transfer coefficient equation, the fracture spacing was set to 1 , the matrix porosity was set to a value of $1 / 6(0.1666)$ to be close to the mean value of 0.153 . If the distribution of $2 \alpha$ would be input as the diffusion coefficient, then

$$
\alpha=\frac{3(1 / 6) 2 \alpha}{1^{2}}=\alpha
$$

In this manner, the distribution of alpha can be input directly into the transport model. Therefore, the prior distribution that was presented to the expert panel and used in the evaluation process was actually $2 \alpha$. This distribution along with the lognormal distribution that approximates it, called the diffusion mass transfer coefficient prior distribution, is given in Figure D-2. The parameters of the diffusion mass transfer coefficient prior distribution are

Mean

$$
=-2.823
$$

Standard deviation $=0.636$. 


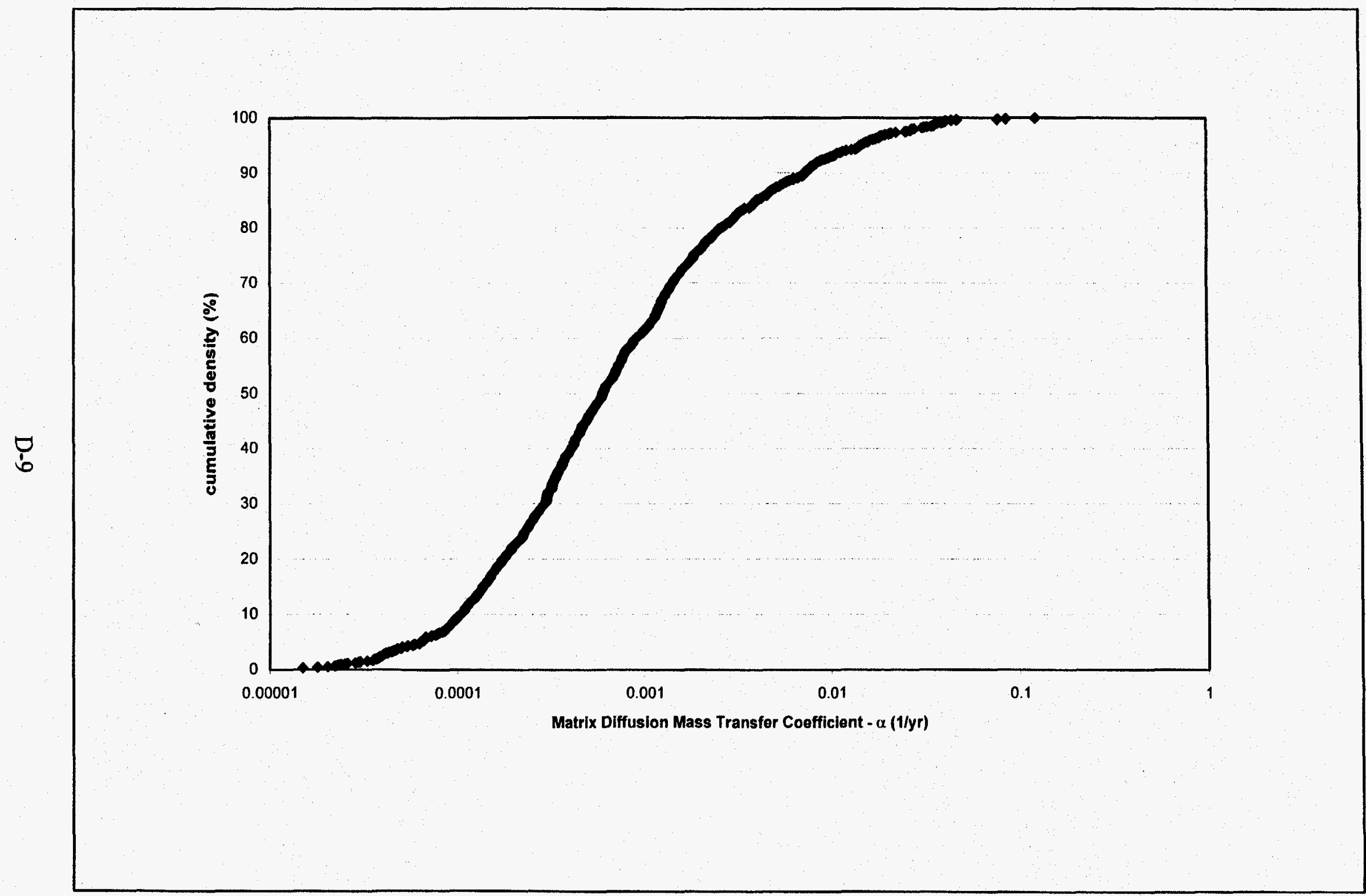

Figure D-1

Cumulative Density Function of the Matrix Diffusion Mass Transfer Coefficient 


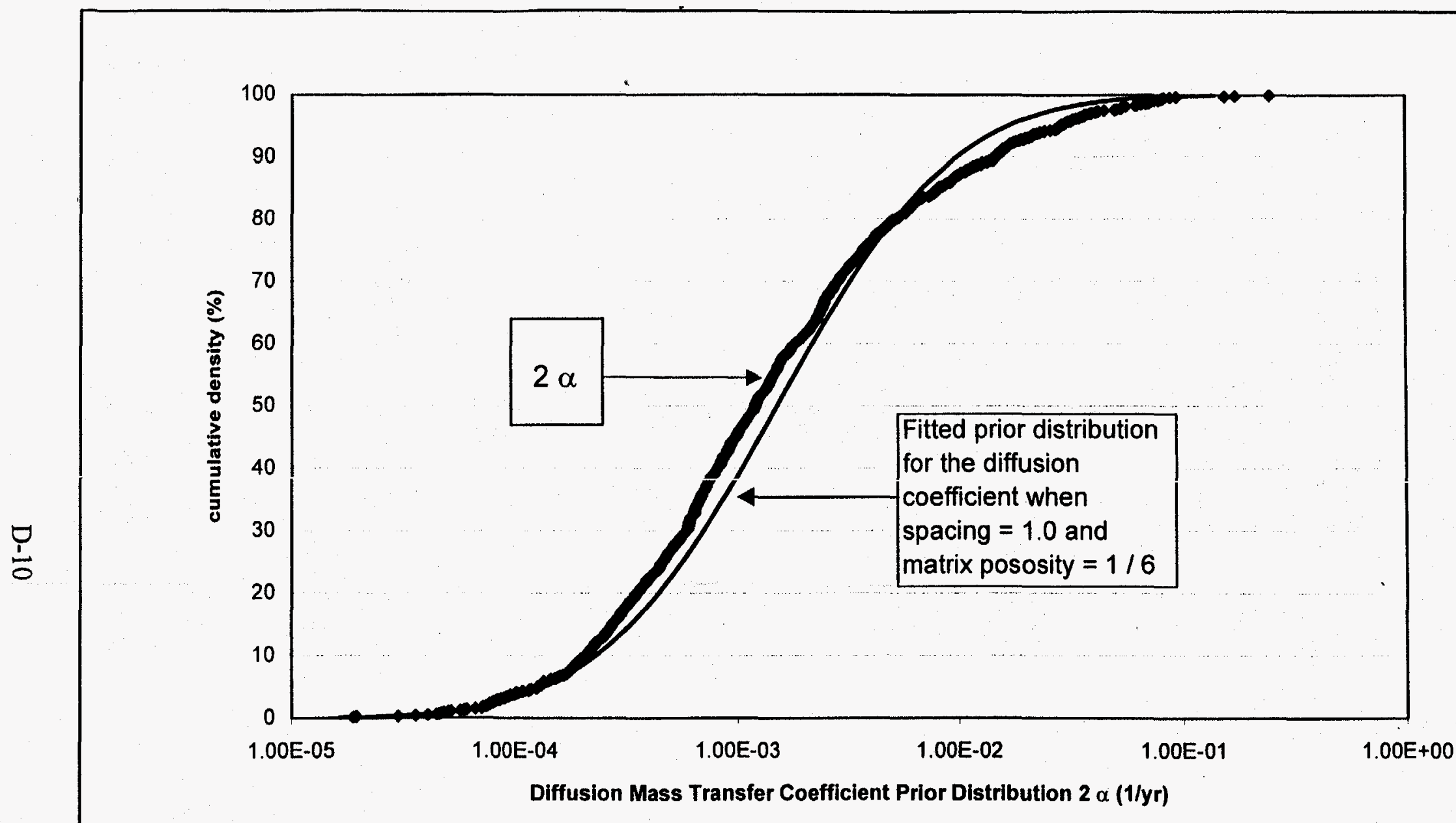

Figure D-2

Prior Cumulative Density Function of the Diffusion Mass Transfer Coefficient 
This distribution is the solid line in Figure D-2 and was the starting point for elicitation process.

\section{D.3.4 Groundwater Flux Multiplier}

The groundwater flux multiplier was created to account for the uncertainty in the groundwater flow. Uncertainty in the groundwater flow estimates are a result of uncertainty in hydraulic conductivity, recharge, or boundary conditions. The groundwater flux (itself a function of those flow parameters) is the only flow parameter included directly in the transport model. Therefore, to account for flow system uncertainty, a groundwater flux multiplier was created to increase or decrease the groundwater flux to approximate the effect of flow system uncertainty.

In simplest terms, the groundwater flux is given by

$$
\mathrm{q}=\mathrm{KJ}
$$

where $\mathrm{q}$ is the groundwater flux, $\mathrm{K}$ is the hydraulic conductivity, and $\mathrm{J}$ is the hydraulic gradient.

The flux multiplier, $r$, is defined by

$$
\mathrm{rq}=\mathrm{rKJ}
$$

In the current version of the regional groundwater flow model, the groundwater flux varies along the TYBO flow path as a function of the hydraulic gradient, recharge, and hydraulic conductivity. At each point along the flow path, the groundwater flux from the calibrated groundwater flow model represents the base case flux and corresponds to a flux multiplier of 1.0. The uncertainty in the groundwater flux has been estimated from a comparison of the two versions of the groundwater flow model, dated April 1996 and December 1996. The latter version of the flow model was created per peer review comments on the earlier version and resulted in an increase in the simulated recharge and groundwater flow from Pahute Mesa. The comparisons are tabulated in Table D-3.

As presented in the regional evaluation documentation (IT, 1997), the uncertainty in measured hydraulic conductivity from aquifer tests is as much as 4 orders of magnitude. Therefore we have a gradation of uncertainty in groundwater flux measurements that reflect the scale of the measurement. The smallest scale is the individual aquifer test, followed by the calibrated 


\section{Table D-3 \\ Comparison of Two Versions of the Regional \\ Groundwater Flow Model to Assess Uncertainty in Groundwater Flux}

\begin{tabular}{|l|l||}
\hline Measure & $\begin{array}{l}\text { Chiange in the parameter from the 4/1996 to the 12/1996 version } \\
\text { of the regional groundwater flow model }\end{array}$ \\
\hline $\begin{array}{l}\text { Hydraulic conductivity of the Timber } \\
\text { Mountain Aquifer }\end{array}$ & Increased by a factor of between 9 and 11 \\
\hline Groundwater flux along the TYBO flow path & Increased by a factor of between 4 and 5 \\
\hline Discharge at Oasis Valley & Increased by a factor of 1.6 \\
\hline Total model discharge & Increased by a factor of 1.22 \\
\hline
\end{tabular}

hydraulic conductivity of the Timber Mountain aquifer because it represents an integration of values within a HSU. The groundwater flux along the TYBO flow path integrates the effects of multiple HSUs along and near the flow path. The discharge at Oasis Valley is a measure of many flow paths, and finally, the total model discharge represents the entire flow system. As one might expect, the greater the amount of averaging, or integration, the smaller the uncertainty in the groundwater flux. Therefore, choosing the appropriate scale helps to constrain the amount of uncertainty for the groundwater flux.

The scale of the VOIA simulations is on the order of the TYBO flow path, therefore the appropriate maximum uncertainty is on the order of a factor of 5. This level of uncertainty underestimates uncertainty at a small scale, but overestimates the uncertainty at the scale of the entire Oasis Valley flow system. Based on consultation with the expert panel, the range of values for the flux multiplier was chosen to be from 0.1 to 6.0. Over this range, the flux multiplier was assumed to be lognormally distributed because the panel believed that smaller values, rather than larger values were more likely to occur. The log transformed mean and standard deviation were -0.1109 and 0.5405 , respectively.

Initial simulations with this prior distribution produced a large number of realizations (approximately 32 percent of all realizations) that yielded tritium concentrations in Oasis Valley that are inconsistent with observations. Recent sampling of springs in Oasis Valley by the U.S. Geologic Survey identified no springs for which the tritium concentration was above $300 \mathrm{pCi} / \mathrm{L}$ (the method detection limit). The sampling took place approximately 22 years after the TYBO device was tested. Therefore, any realization that produced tritium greater than 300 $\mathrm{pCi} / \mathrm{L}$ in less than 22 years was considered unrealistic. Per discussions with the expert panel on 
ways to reduce the number of unrealistic simulations, the decision was made to reduce the flux multiplier by scaling the flux prior distribution toward smaller values. The flux multiplier was progressively scaled toward smaller values until none of the realizations using only the prior distributions produced unrealistic realizations. This resulted in a distribution for flux with a $\log _{10}$ mean value of -1.0 and $\log _{10}$ standard deviation of 0.6079 . The amount of variability in the flux multiplier was maintained but the smaller mean value reduced the total number of unrealistic realizations to 11 percent.

\section{D.3.5 Distribution Coefficients}

Some radionuclides may sorb to aquifer materials, thereby causing them to travel at an average velocity that is slower than that of groundwater. The ratio of the water velocity to the solute velocity is called the retardation coefficient. In a dual porosity flow system, the bulk of the flow occurs in the fractures, but most of the water volume is in the matrix. Additionally, the surface area available for adsorption is much larger in the matrix than in the fractures. Therefore, a conservative assumption was made that retardation of a radionuclide occurs in the matrix only and not on the fracture wall. The retardation coefficient can be described via a distribution coefficient, which is based on the assumption of a linear adsorption isotherm.

The retardation coefficient is calculated from the relationship

$$
\mathrm{R}_{\mathrm{m}}=1+\frac{\rho_{\mathrm{bm}} \mathrm{K}_{\mathrm{dm}}}{\theta_{\mathrm{m}}}
$$

Where

$$
\begin{aligned}
& \rho_{\mathrm{bm}}=\text { the bulk density of the matrix material } \\
& \mathrm{K}_{\mathrm{dm}} \quad=\text { the linear adsorption isotherm distribution coefficient } \\
& \theta_{\mathrm{m}} \quad=\text { the matrix porosity }
\end{aligned}
$$

The matrix porosity was presented under the matrix diffusion mass transfer coefficient and the bulk density is given a value of 1.85 based on Smith (1995). The distribution coefficient may be different for each radionuclide and in many cases is quite variable depending on the chemical form of the radionuclide, the water chemistry, and the rock type. If a radionuclide does not sorb significantly and can be assumed to travel with the water, the $\mathrm{K}_{\mathrm{d}}$ of that radionuclide was assigned a value of zero. This was the case for tritium, carbon-14 and iodine-129, all of which are assumed to move with the water. Literature values for $\mathrm{K}_{\mathrm{d}}$ of the other radionuclides are quite 
variable as exemplified from data reported in Triay et al. (1997) (Table D-4) for volcanic tuffs at Yucca Mountain.

Table D-4

Range in $K_{d}$ Values as Reported in Triay et al. (1997)

\begin{tabular}{|c|c|c|}
\hline Nuclide & $\begin{array}{c}\text { Minimum } \\
\mathbf{K}_{d}(\mathbf{m L} \mathbf{g})\end{array}$ & $\begin{array}{c}\text { Maximum } \\
\mathbf{K}_{\mathrm{d}}(\mathbf{m L} \mathbf{g})\end{array}$ \\
\hline Pu-239/240 & 16 & 7600 \\
\hline Cs-137 & 10 & 180000 \\
\hline Sr-90 & 9 & 160000 \\
\hline U-238 & -3 & 820 \\
\hline
\end{tabular}

$\mathrm{Pu}=$ Plutonium

Cs $=$ Cesium

$U \quad=$ Uranium

= Strontium

$\mathrm{mL} / \mathrm{g}=$ Milliliter(s) per gram

Based on these ranges, an initial range of values for the $K_{d}$ of plutonium-239/240, cesium-137, and strontium-90 was defined as 10 to 1,000 . For uranium, the initial range was given as 1 to 100. These ranges preserved the lower bound, but decreased the upper bound significantly. This was done to emphasize the more conservative lower bound $\mathrm{K}_{d}$ values, and de-emphasize the upper bound. Per discussion with the expert panel the $K_{d}$ ranges for plutonium-239/240 and uranium-238 were reduced further to the range of 0 to 10 . This very low range of values was adopted to account, in a very approximate way, for the potential of transport of radionuclides on colloidal particles. The expert panel also adopted a uniform distribution for the $K_{d}$ values because the entire range of values was felt to be equally likely. Prior distributions for the distribution coefficients $\left(\mathrm{K}_{d} \mathrm{~s}\right)$ are provided in Table $\mathrm{D}-5$.

Table D-5

Prior Distribution for the Distribution Coefficient, $\mathbf{K}_{\mathbf{d}}$

\begin{tabular}{|c|c|c|c|}
\hline Radionuclide & Lower Bound $\mathbf{K}_{\mathbf{d}}(\mathbf{m} \mathbf{L} \mathbf{g})$ & Upper Bound $\mathbf{K}_{\mathbf{d}}(\mathbf{m} \mathbf{L} \mathbf{g})$ & Probability Distribution \\
\hline H-3 & 0 & 0 & constant \\
\hline Cs-137 & 10 & 1,000 & uniform \\
\hline Pu-238/239 & 0 & 10 & uniform \\
\hline C-14 & 0 & 0 & constant \\
\hline Sr-90 & 10 & 1,000 & uniform \\
\hline U-238 & 0 & 10 & uniform \\
\hline -129 & 0 & 0 & constant \\
\hline
\end{tabular}

$\mathrm{H}-3=$ Tritium

Cs $=$ Cesium

$\mathrm{Pu}=$ Plutonium

C $=$ Carbon
$\mathrm{Sr}=$ Strontiurn

$U$ = Uranium

1 = lodine

$\mathrm{mL} / \mathrm{g}=$ Milliliter(s) per gram 


\section{D.4.0 References}

Benjamin, J.R., and C.A. Cornell. 1970. Probability, Statistics, and Decision for Civil Engineers. New York, NY: McGraw-Hill, Inc.

DOE/NV, see U.S. Department of Energy, Nevada Operations Office.

IT, see IT Corporation.

IT Corporation. 1997. Underground Test Area Subproject Phase I Data Analysis Task, Volume I Through VIII Documentation Package, ITLV-10972-181. Las Vegas, NV.

Lee, C.H., and I. Farmer. 1993. Fluid Flow in Discontinuous Rocks. London, England: Chapman and Hall.

Reimus, P. Los Alamos National Laboratory. 1997. Personal communication with IT Corporation staff regarding a preliminary interpretation of tracer tests in fractured tuff at the "C" well complex at Yucca Mountain. Las Vegas, NV.

Rehfeldt, K.R. 1997. Memorandum to Files Regarding Pahute Mesa Value of Information Analysis-Calculations of Fracture Porosity, August 18, 1997. Las Vegas, NV: HSI-GeoTrans, Inc.

Smith, D.K. 1995. Phenomenology of Underground Nuclear Explosions conducted at the Nevada Test Site with Emphasis on Recent Experience at Baseball (U7ba) and Ingot (U2gz), Lawrence Livermore National Laboratory report. Prepared for the DOE/NV Environmental Restoration Division of the Underground Test Area Operable Unit.

Snow, D.T. 1968. "Rock fracture spacings, openings, and porosities." In Journal of Soil Mechanics Foundation Division, Proceedings, 94: 73-91. New York, NY: American Society of Civil Engineers.

Triay, I.R., A. Meijer, J.L. Conca, K.S. Kung, R.S. Rundberg, and E.A. Strietelmeier. 1997. Summary and Synthesis Report on Radionuclide Retardation for the Yucca Mountain Site Characterization Project. Los Alamos National Laboratory report, prepared by the Chemical Science and Technology Division. Los Alamos, NM.

U.S. Department of Energy, Nevada Operations Office. 1997a. Regional Groundwater Flow and Tritium Transport Modeling and Risk Assessment of Underground Test Area, Nevada Test Site, NV, DOE/NV-477. Las Vegas, NV: Environmental Restoration Division.

U.S. Department of Energy, Nevada Operations Office. 1997b. Analysis of Fractures in Volcanic Cores from Pahute Mesa, Nevada Test Site, DOE/NV/11718-160. Las Vegas, NV. 
Appendix E

Assessment of Distributions Describing the Accuracy of Characterization Options 


\section{Table of Contents}

List of Tables $\ldots \ldots \ldots \ldots \ldots \ldots \ldots \ldots \ldots \ldots \ldots \ldots \ldots \ldots \ldots \ldots \ldots \ldots \ldots \ldots$

E.1.0 Assessment of Distributions Describing the Accuracy of

Characterization Options

E-1 
E-1 Parameter Estimate Ranges for Activities Addressing the Flux Multiplier . . . . . E-3

E-2 Parameter Estimate Ranges for Subgroups Addressing the Flux Multiplier . . . . E E-3

E-3 Parameter Estimate Ranges for Activities Addressing Source Term $\ldots \ldots \ldots \ldots$ E-4

E-4 Parameter Estimate Ranges for Siubgroups Addressing Source Term $\ldots \ldots \ldots \ldots$ E-4

E-5 Parameter Estimate Ranges for Activities Addressing Effective Porosity . . . . . E-4

E-6 Parameter Estimate Ranges for Subgroups Addressing Effective Porosity . . . . . E-4

E-7 Parameter Estimate Ranges for Activities Addressing Diffusion (alpha) ....... E-4

E-8 Parameter Estimate Ranges for Siubgroups Addressing Diffusion (alpha) $\ldots \ldots \ldots$ E-5

E-9 Parameter Estimate Ranges for Activities Addressing $\mathrm{K}_{d} \ldots \ldots \ldots \ldots \ldots \ldots$ E-5 


\section{E.1.0 Assessment of Distributions Describing the Accuracy of Characterization Options}

The expert panel was asked to provide assessments of the ability of the activities and subgroups of activities to provide accurate estimates of the sensitive parameters. The activity assessments were obtained in the following manner. First, the uncertain parameter addressed by the test was represented by three (in the case of diffusion, flux, $K_{d}$, and source) or four (in the case of porosity) discrete levels. These levels were chosen to be the $5^{\text {th }}, 50^{\text {th }}, 95^{\text {th }}$, and for porosity, the $99^{\text {th }}$ fractiles of the prior distributions. Next, the expert panel specified the distribution form for each of the test outcome variables. The panel agreed that the parameter estimates from tests addressing diffusion, flux, and porosity, would have a lognormal distribution, the parameter estimate from tests addressing source would have a normal distribution, and the parameter estimate from tests addressing $\mathrm{K}_{d}$ would have a uniform distribution. Finally, the panel was asked to estimate the $5^{\text {th }}$ and $95^{\text {th }}$ fractiles of the parameter estimates that would result from each activity given a specific assumption for the actual parameter value. For example, panel members answered questions of the following form:

Assume Activity No. 1 (Fault zone characterization) is applied.

Assume the groundwater flux multiplier ( $r$ ) along the flow path is $\mathrm{X}=0.1$

Due to uncertainties associated with the fault zone characterization option (see influence diagram), the estimate of the groundwater flux multiplier ( $r$ ) resulting from this activity is a random variable (assumed to be lognormal).

Based on the fault characterization results and your assessment of the relevant uncertainties as shown in the influence diagram, the estimate of $r$ will almost certainly be less than times X (i.e., specify the $95^{\text {th }}$ fractile).

Based on the fault characterization results and your assessment of the relevant uncertainties as shown in the influence diagram, the estimate of $r$ will almost certainly be greater than times $X$ (i.e., specify the $5^{\text {th }}$ fractile).

As indicated by the instructions, the expert panel was instructed to ignore the fact that the parameter is actually unknown and to assume that it takes on a particular specified value (e.g., $X=0.1$ ), which was either the $5^{\text {th }}, 50^{\text {th }}, 95^{\text {th }}$, or (for porosity) the $99^{\text {th }}$ fractile of the prior distribution. Performing the assessments assuming a range of values for the uncertain parameter allowed the expert panel to represent the sensitivity of the test to actual conditions - to indicate, 
for example, that a test is more or less accurate at determining low values than at determining high values. Thus, the panel provided 3 (or 4 ) different accuracy assessments for each activity.

For each assessment of activity accuracy, the expert panel provided the $5^{\text {th }}$ and $95^{\text {th }}$ fractiles (or min and max values, for uniform distributions) of the distribution corresponding to the parameter estimate derived from the test. Since the prarameter estimate derived from the test is itself a random variable, the fractiles were then used to compute the parameters (e.g., mean and variance) of the test outcome distribution. Note that the expert panel assumed lognormal, normal or uniform, as the distribution form for the test outcome random variables depending on the distribution of the prior. These distributions are two parameter distributions, so the assigned fractiles were sufficient to compute the distribution parameter values needed to fit the distributions, as detailed in Appendix D. Also, note that in these assessments, the $5^{\text {th }}$ and $95^{\text {th }}$ fractiles of parameter estimates resulting from tests addressing the diffusion parameter were assessed in terms of alpha (or diffusion parameter) directly, not in terms of $B, D_{m}, \theta_{m}$, as in the prior distributions (see Appendix D).

As discussed in the main text of this repor: (Section 3.3), consensus judgments of the expert panel were obtained through two-phase elicitation process wherein each panel member expressed and discussed their individual best estimates and then agreed upon a set of estimates to use for the analysis.

Tables E-1, E-3, E-5, E-7, and E-9 below provide parameter estimate ranges for all of the activities. For tests addressing porosity and diffusion, the Bayesian analysis required activity accuracy assessment for 5 discrete levels of the "actual" parameter value (see Appendix F for discussion of the Bayesian updating procedures). Expert panel members provided direct estimates for 3 (diffusion) or 4 (porosity) levels. The remaining values, corresponding to the $1^{\text {st }}$ percentile of the prior distributions (for diffusion and porosity) and the $99^{\text {th }}$ percentile (for porosity) were extrapolated from the assessed judgments.

For tests addressing the flux multiplier, the assessments of test accuracies were conditional on the $5^{\text {th }}, 50^{\text {th }}$, and $95^{\text {th }}$ percentiles of the original prior distribution. As discussed in Appendix D, this original prior was scaled to ensure more reasonable outputs from the contaminant transport model. The accuracy estimates for flux-related activities then, are based on the relative values of the $5^{\text {th }}$ and $95^{\text {th }}$ fractile estimates for the original flux values, scaled to match the modified prior. 
The process of obtaining activity subgroup estimates was similar to the activity assessments. No subgroups addressing the $K_{d}$ parameter were proposed, so all parameter estimates resulting from test subgroups were assumed to have a lognormal or normal distribution. As discussed in Section 3.3, the expert panel was shown box plots indicating their assessments of the accuracy of each component activity and an estimate of the "composite" accuracy of the subgroup, assuming the activity accuracies could be combined as in independent sampling. They then provided the $5^{\text {th }}$ and $95^{\text {th }}$ fractiles of the distribution of the parameter estimate resulting from the results of the specified subgroup, conditional on assumption of the actual parameter value. For the subgroups, the panel provided accuracy assessments corresponding to 3 (for source), 4 (for flux), and 5 (for porosity and diffusion) specified values for the "actual" parameter. These corresponded to the $1^{\text {st }}, 5^{\text {th }}, 50^{\text {th }}, 95^{\text {th }}$, and $99^{\text {th }}$ fractiles of the prior distributions.

Tables E-2, E-4, E-6, and E-8 are the parameter estimate ranges for all subgroups.

Table E-1

Parameter Estimate Ranges for Activities Addressing the Flux Multiplier

\begin{tabular}{|c|c|c|c|c|c|c|c|c||}
\hline \multirow{2}{*}{ Activity } & \multicolumn{2}{|c|}{ flux multiplier $=\mathbf{0 . 0 1}$} & \multicolumn{2}{|c|}{ flux multiplier $=0.1$} & \multicolumn{2}{c|}{ flux multiplier $=1.0$} & \multicolumn{2}{c|}{ flux multiplier $=2.6$} \\
\cline { 2 - 9 } & $5 \%$ & $95 \%$ & $5 \%$ & $95 \%$ & $5 \%$ & $95 \%$ & $5 \%$ & $95 \%$ \\
\hline 1 & 0.0016 & 0.214 & 0.015 & 1.51 & 0.13 & 9.4 & 0.51 & 15.7 \\
\hline 2 & 0.0019 & 0.206 & 0.016 & 1.46 & 0.13 & 8.0 & 0.51 & 13.6 \\
\hline 3 & 0.0026 & 0.110 & 0.022 & 0.81 & 0.18 & 4.9 & 0.63 & 9.2 \\
\hline 7 & 0.0023 & 0.084 & 0.024 & 0.60 & 0.20 & 4.3 & 0.71 & 8.2 \\
\hline 8 & 0.0016 & 0.240 & 0.014 & 1.70 & 0.11 & 9.0 & 0.46 & 14.4 \\
\hline 9 & 0.0016 & 0.277 & 0.013 & 1.94 & 0.09 & 10.4 & 0.31 & 19.7 \\
\hline 12 & 0.0015 & 0.168 & 0.015 & 1.21 & 0.16 & 6.7 & 0.80 & 8.6 \\
\hline
\end{tabular}

Table E-2

Parameter Estimate Ranges for Subgroups Addressing the Flux Multiplier

\begin{tabular}{||c|c|c|c|c|c|c|c|c||}
\hline \multirow{2}{*}{ Subgroup } & \multicolumn{2}{|c|}{ flux multiplier $\mathbf{0 . 0 1}$} & \multicolumn{2}{|c|}{ flux multiplier $=\mathbf{0 . 1}$} & \multicolumn{2}{|c|}{ flux multiplier=1.0 } & \multicolumn{2}{c|}{ flux multiplier = 2.6 } \\
\cline { 2 - 9 } & $5 \%$ & $95 \%$ & $5 \%$ & $95 \%$ & $5 \%$ & $95 \%$ & $5 \%$ & $95 \%$ \\
\hline 5 & 0.0045 & 0.078 & 0.039 & 0.60 & 0.33 & 4.0 & 0.85 & 8.9 \\
\hline 6 & 0.0026 & 0.103 & 0.027 & 0.76 & 0.25 & 4.5 & 0.67 & 9.9 \\
\hline 7 & 0.0052 & 0.074 & 0.046 & 0.53 & 0.42 & 3.3 & 1.08 & 7.0 \\
\hline 8 & 0.0025 & 0.228 & 0.017 & 1.62 & 0.16 & 7.3 & 0.44 & 13.0 \\
\hline 9 & 0.0043 & 0.102 & 0.038 & 0.71 & 0.34 & 4.1 & 0.90 & 8.5 \\
\hline 10 & 0.0040 & 0.078 & 0.031 & 0.57 & 0.28 & 3.7 & 0.72 & 7.9 \\
\hline 11 & 0.0033 & 0.096 & 0.030 & 0.77 & 0.31 & 4.3 & 0.91 & 8.8 \\
\hline
\end{tabular}


Table E-3

Parameter Estimate Ranges for Activities Addressing Source Term

\begin{tabular}{|c|c|c|c|c|c|c|}
\hline \multirow{2}{*}{ Activity } & \multicolumn{2}{|c|}{ source term = 1 } & \multicolumn{2}{c|}{ source term $=\mathbf{5 0 0 . 5}$} & \multicolumn{2}{c|}{ source term = 1000 } \\
\cline { 2 - 7 } & $5 \%$ & $95 \%$ & $5 \%$ & $95 \%$ & $5 \%$ & $95 \%$ \\
\hline 4 & 0.12 & 250.6 & 86.2 & 3330.5 & 202.1 & 7230.0 \\
\hline 11 & 0.14 & 303.5 & 122.1 & 4233.0 & 283.1 & 8080 \\
\hline
\end{tabular}

Table E-4

Parameter Estimate Ranges for Subgroups Addressing Source Term

\begin{tabular}{|c|c|c|c|c|c|c|}
\hline \multirow{2}{*}{ Subgroup } & \multicolumn{2}{|c|}{ source term $=1$} & \multicolumn{2}{c|}{ source term $=\mathbf{5 0 0 . 5}$} & \multicolumn{2}{c|}{ source term $=\mathbf{1 0 0 0}$} \\
\cline { 2 - 7 } & $5 \%$ & $95 \%$ & $5 \%$ & $95 \%$ & $5 \%$ & $95 \%$ \\
\hline 1 & 0.23 & 185.7 & 167.9 & 3421.1 & 342.5 & 5920.7 \\
\hline
\end{tabular}

Table E-5

Parameter Estimate Ranges for Activities Addressing Effective Porosity

\begin{tabular}{|c|c|c|c|c|c|c|c|c||}
\hline \multirow{2}{*}{ Activity } & \multicolumn{2}{|c|}{ porosity $=3.1 \mathrm{E}-05$} & \multicolumn{2}{c|}{ porosity $=1.0 \mathrm{E}-04$} & \multicolumn{2}{c|}{ porosity =1.7E-03 } & \multicolumn{2}{c|}{ porosity = 3.0E-02 } \\
\cline { 2 - 9 } & $5 \%$ & $95 \%$ & $5 \%$ & $95 \%$ & $5 \%$ & $95 \%$ & $5 \%$ & $95 \%$ \\
\hline $6 \mathrm{p}$ & $2.2 \mathrm{E}-06$ & $7.1 \mathrm{E}-04$ & $9.5 \mathrm{E}-06$ & $2.3 \mathrm{E}-03$ & $1.7 \mathrm{E}-04$ & $2.5 \mathrm{E}-02$ & $4.9 \mathrm{E}-03$ & $1.8 \mathrm{E}-01$ \\
\hline 13 & $1.1 \mathrm{E}-06$ & $1.8 \mathrm{E}-03$ & $6.1 \mathrm{E}-06$ & $6.2 \mathrm{E}-03$ & $1.1 \mathrm{E}-04$ & $5.2 \mathrm{E}-02$ & $2.2 \mathrm{E}-03$ & $3.1 \mathrm{E}-01$ \\
\hline
\end{tabular}

Table E-6

Parameter Estimate Ranges for Subgroups Addressing Effective Porosity

\begin{tabular}{|c|c|c|c|c|c|c|c|c|}
\hline \multirow{2}{*}{ Subgroup } & \multicolumn{2}{|c|}{ porosity $=3.1 \mathrm{E}-05$} & \multicolumn{2}{c|}{ porosity $=1.0 \mathrm{E}-04$} & \multicolumn{2}{c|}{ porosity $=1.7 \mathrm{E}-03$} & \multicolumn{2}{c|}{ porosity $=3.0 \mathrm{E}-02$} \\
\cline { 2 - 9 } & $5 \%$ & $95 \%$ & $5 \%$ & $95 \%$ & $5 \%$ & $95 \%$ & $5 \%$ & $95 \%$ \\
\hline 2 & $7.2 \mathrm{E}-06$ & $8.5 \mathrm{E}-04$ & $1.5 \mathrm{E}-05$ & $1.7 \mathrm{E}-03$ & $2.2 \mathrm{E}-04$ & $2.0 \mathrm{E}-02$ & $5.9 \mathrm{E}-03$ & $1.6 \mathrm{E}-01$ \\
\hline
\end{tabular}

Table E-7

Parameter Estimate Ranges for Activities Addressing Diffusion (alpha)

\begin{tabular}{|c|c|c|c|c|c|c|c|c||}
\hline \multirow{2}{*}{ Activity } & \multicolumn{2}{|c|}{ alpha $=\mathbf{3 . 0 \mathrm { E } - \mathbf { 0 5 }}$} & \multicolumn{2}{c|}{ alpha $=\mathbf{8 . 5 \mathrm { E } - \mathbf { 0 5 }}$} & \multicolumn{2}{c|}{ alpha $=1.1 \mathrm{E}-\mathbf{0 3}$} & \multicolumn{2}{c|}{ alpha $=1.3 \mathrm{E}-\mathbf{0 2}$} \\
\cline { 2 - 9 } & $5 \%$ & $95 \%$ & $5 \%$ & $95 \%$ & $5 \%$ & $95 \%$ & $5 \%$ & $95 \%$ \\
\hline 5 & $2.6 \mathrm{E}-06$ & $1.2 \mathrm{E}-03$ & $7.1 \mathrm{E}-06$ & $2.2 \mathrm{E}-03$ & $7.2 \mathrm{E}-05$ & $1.6 \mathrm{E}-02$ & $1.1 \mathrm{E}-03$ & $1.1 \mathrm{E}-01$ \\
\hline $6 \mathrm{a}$ & $4.7 \mathrm{E}-06$ & $7.7 \mathrm{E}-04$ & $1.1 \mathrm{E}-05$ & $1.6 \mathrm{E}-03$ & $1.0 \mathrm{E}-04$ & $1.2 \mathrm{E}-02$ & $1.7 \mathrm{E}-03$ & $8.4 \mathrm{E}-02$ \\
\hline 10 & $4.5 \mathrm{E}-06$ & $3.2 \mathrm{E}-03$ & $9.4 \mathrm{E}-06$ & $6.8 \mathrm{E}-03$ & $6.1 \mathrm{E}-05$ & $4.6 \mathrm{E}-02$ & $5.3 \mathrm{E}-04$ & $3.9 \mathrm{E}-01$ \\
\hline
\end{tabular}


Table E-8

Parameter Estimate Ranges for Subgroups Addressing Diffusion (alpha)

\begin{tabular}{|c|c|c|c|c|c|c|c|c||}
\hline \hline \multirow{2}{*}{ Subgroup } & \multicolumn{2}{|c|}{ alpha $=\mathbf{3 . 0 \mathrm { E } - 0 5}$} & \multicolumn{2}{|c|}{ alpha $=\mathbf{8 . 5 \mathrm { E } - 0 5}$} & \multicolumn{2}{c|}{ alpha $=1.1 \mathrm{E}-03$} & \multicolumn{2}{c|}{ alpha = 1.3E - 02 } \\
\cline { 2 - 9 } & $5 \%$ & $95 \%$ & $5 \%$ & $95 \%$ & $5 \%$ & $95 \%$ & $5 \%$ & $95 \%$ \\
\hline 3 & $4.3 \mathrm{E}-06$ & $8.9 \mathrm{E}-04$ & $8.0 \mathrm{E}-06$ & $1.6 \mathrm{E}-03$ & $8.6 \mathrm{E}-05$ & $1.2 \mathrm{E}-02$ & $2.6 \mathrm{E}-03$ & $1.2 \mathrm{E}-01$ \\
\hline 4 & $9.3 \mathrm{E}-06$ & $6.0 \mathrm{E}-04$ & $1.7 \mathrm{E}-05$ & $1.1 \mathrm{E}-03$ & $1.6 \mathrm{E}-04$ & $1.0 \mathrm{E}-02$ & $2.2 \mathrm{E}-03$ & $7.1 \mathrm{E}-02$ \\
\hline $12^{\star}$ & $6.9 \mathrm{E}-06$ & $7.5 \mathrm{E}-04$ & $1.3 \mathrm{E}-05$ & $1.4 \mathrm{E}-03$ & $1.2 \mathrm{E}-04$ & $1.1 \mathrm{E}-02$ & $2.4 \mathrm{E}-03$ & $9.7 \mathrm{E}-02$ \\
\hline
\end{tabular}

*Parameter estimate ranges for Subgroup 12 were derived from the accuracy assessments for Activity 6a and Subgroup 4.

Subgroup 12 contained Activity 6 a and was itself a subset of Subgroup 4, so its accuracy must lie between the accuracy of the two. The estimates were sufficiently close that interpolating the estimate for Subgroup 12 was reasonable.

Table E-9

Parameter Estimate Ranges for Activities Addressing $\mathbf{K}_{\mathrm{d}}{ }^{*}$

\begin{tabular}{|c|c|c|c|c|c|c|}
\hline \multirow{2}{*}{ Activity } & \multicolumn{2}{|c|}{$\mathrm{K}_{\mathrm{d}}=\mathbf{0}$} & \multicolumn{2}{c|}{$\mathrm{K}_{\mathrm{d}}=5$} & \multicolumn{2}{c|}{$\mathrm{K}_{\mathrm{d}}=10$} \\
\cline { 2 - 7 } & $\min$ & $\max$ & $\min$ & $\max$ & $\min$ & $\max$ \\
\hline 14 & 0.0 & 4.9 & 1.6 & 12.9 & 5.1 & 37.4 \\
\hline
\end{tabular}

* $K_{f}$ follows a uniform distribution, therefore, the minimum and maximum are reported instead of the $5 \%$ and $95 \%$ values. 


\section{Appendix F}

Bayesian Updating 


\section{Table of Contents}

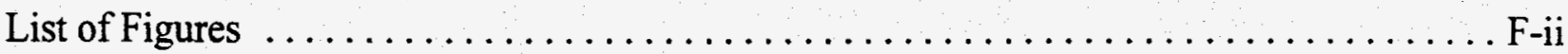

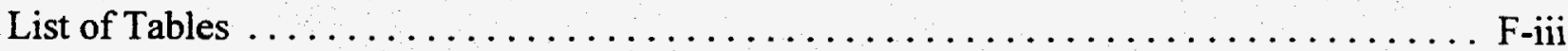

F.1.0 Bayesian Updating $\ldots \ldots \ldots \ldots \ldots \ldots \ldots \ldots \ldots \ldots \ldots \ldots \ldots \ldots \ldots \ldots \ldots \ldots \ldots$

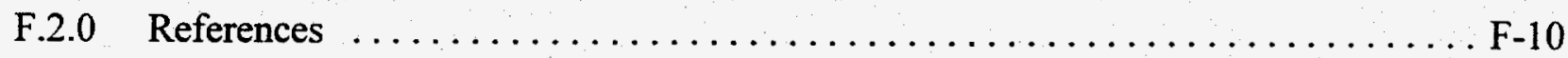




\section{List of Figures}

Number

Title

Page

F-1 Event Tree that is "Reversed" Using Bayes' Theorem .............. F-1

F-2 Discretization of Prior Distribution $\ldots \ldots \ldots \ldots \ldots \ldots \ldots \ldots \ldots \ldots \ldots \ldots \ldots \ldots \ldots$

F-3 Discretization of the Distributions for Test Outcomes $\ldots \ldots \ldots \ldots \ldots \ldots \ldots \ldots-3$

F-4 Bayesian Updating - Reversing the Decision Tree $\ldots \ldots \ldots \ldots \ldots \ldots \ldots \ldots \ldots$. $\ldots \ldots$ 


\section{List of Tables}

Number

Title

Page

F-1 Posterior Distributions for Activities Addressing the Flux Multiplier ....... F-8

F-2 Posterior Distributions for Subgroups Addressing the Flux Multiplier $\ldots \ldots \ldots$ F-8

F-3 Posterior Distributions for Activities Addressing Source Term ........... F-9

F-4 Posterior Distributions for Subgroups Addressing Effective Porosity . . . . . . . F F-9

F-5 Posterior Distributions for Activities Addressing Diffusion $\ldots \ldots \ldots \ldots \ldots$ F-9

F-6 Posterior Distributions for Subgroups Addressing Diffusion $\ldots \ldots \ldots \ldots \ldots$ F-9

F-7 Posterior Distributions for Activities Addressing $\mathrm{K}_{\mathrm{d}}{ }^{*} \ldots \ldots \ldots \ldots \ldots \ldots \ldots$ F-9 


\section{F.1.0 Bayesian Updating}

According to the theory of Bayesian updating, a test that provides an estimate of an uncertain quantity will cause a revision, or updating, of the probability distribution assigned to that quantity. The original distribution is referred to as the prior distribution, and the updated distribution is referred to as the posterior distribution.

Bayesian updating was implemented through the method of event trees. In this approach, uncertain events with a continuum of possible outcomes are represented by a finite number of probability/outcome pairs, and the probabilities of the states of one of the events (test outcome) are conditional on the other event (actual value). We then represent this relationship in an event tree and apply Bayes' theorem to solve for all the probabilities that result from reversing the order of the uncertain events. Figure F-1 illustrates the form of the tree for obtaining input probability estimates for discrete variables as well as the tree resulting when the order of the uncertainties is reversed. As detailed later, this process of applying Bayes' theorem allows us to compute the posterior distributions.

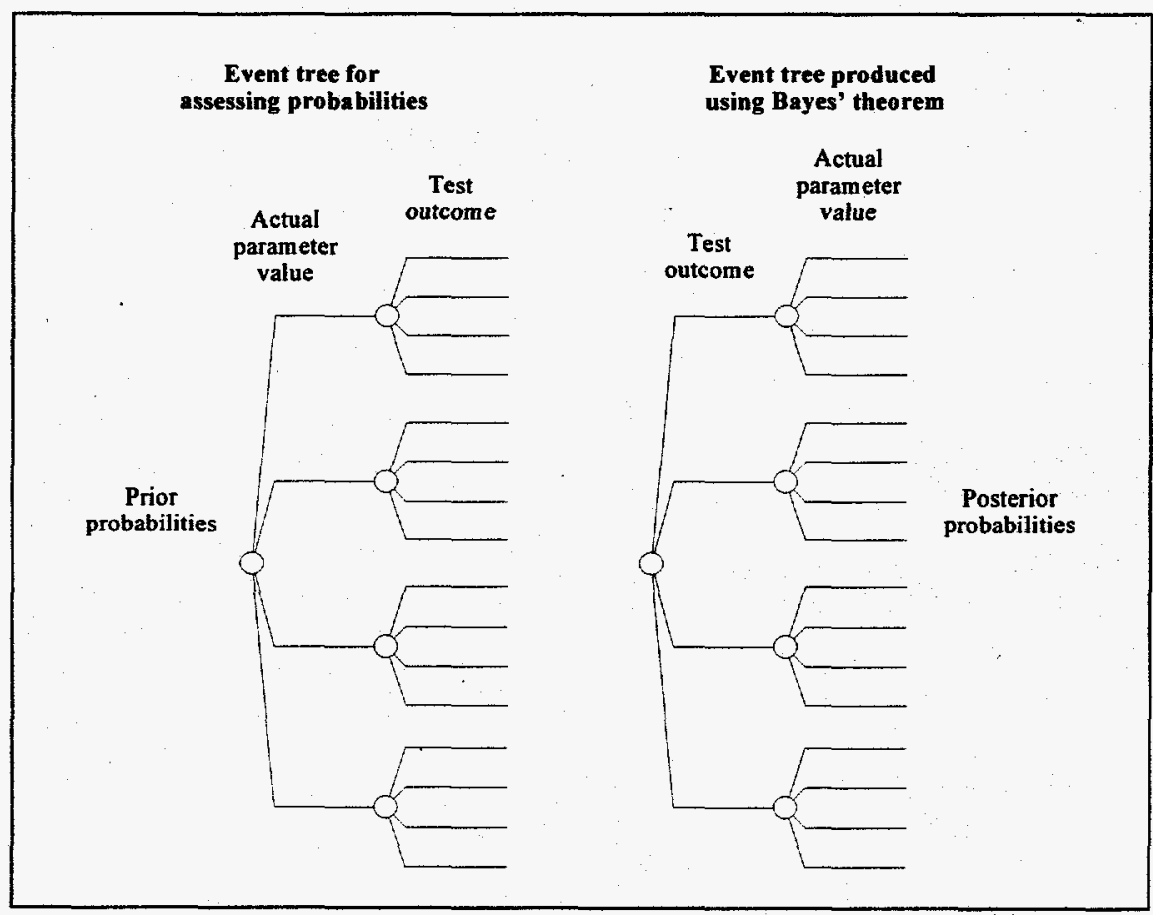

Figure F-1

Event Tree that is "Reversed" Using Bayes' Theorem 
To apply the approach, the first step was to discretize the prior distributions for the sensitive parameters. Discretizing a continuous distribution means using a finite number of probability/outcome pairs to approximate the continuous distribution. Figure F-2 illustrates the discretizing process. Note that the tree shows a four-level discretization, but in general, the number of discretized levels used varies depending on the parameter. Discretizing continuous distributions is common practice in decision analysis and there are several different approaches available (for example, see Smith 1993; Keefer and Bodily, 1983; Miller and Rice, 1983). This analysis used a modified moment matching method based on (Smith, 1993). First, outcome values were chosen to span the range of possible values. Then probabilities were assigned to those outcomes such that the mean and variance calculated from the discrete probability/outcome pairs matched as closely as possible the mean and variance of the prior distribution. Because the lognormal distribution is highly skewed, and the analysis was constrained to values spanning all reasonable values of the priors, it was not always possible to match the mean and variance exactly. Specifically, the goal was to minimize the sum of the squares of the relative error in matching the mean and variance, defined as the squared error.

For diffusion and effective porosity, 5-level discrete approximations were chosen, with the values selected for the discrete approximations were the $1^{\text {st }}, 5^{\text {th }}, 50^{\text {th }}, 95^{\text {th }}$, and $99^{\text {th }}$ fractiles of the priors. For flux and source, 4-level discrete approximations were chosen, with the values selected for the discrete approximations being the $5^{\text {th }}, 50^{\text {th }}, 95^{\text {th }}$, and $99^{\text {th }}$ fractiles of the priors. For $\mathrm{K}_{d}$, which was described by a uniform distribution, the endpoints and midpoint were used for the discretization. The discretization for porosity had a squared error of approximately 30 percent, and the discretizations of the other prior distributions had squared error less than 5 percent. Next, the activity accuracy estimates (Appendix E) were similarly discretized

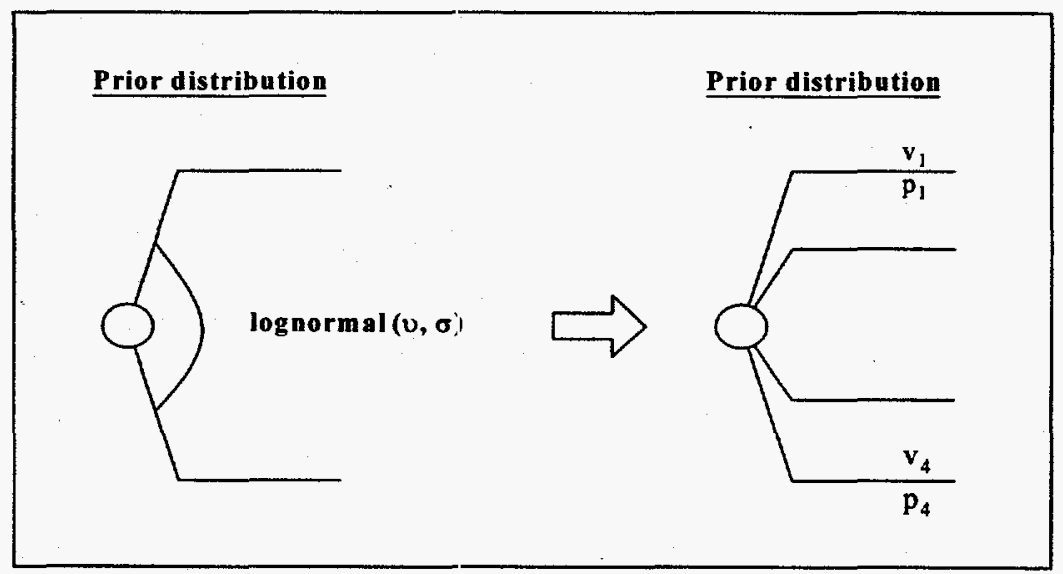

Figure F-2

Discretization of Prior Distribution 
(Figure F-3). In this case, it was necessary that the values chosen for the discretization $\left(\mathrm{v}_{1}{ }^{\prime}, \ldots \mathrm{v}_{4}{ }^{\prime}\right.$ in Figure F-3) be the same for each of the conditioning values of the prior $\left(v_{1}\right.$ through $\left.v_{4}\right)$, so that the event tree could be reversed, as shown in Figure F-1 and explained below. Again, values were chosen to span the range of values possible from the continuous distributions. Specifically, the low value was chosen to correspond to the $5^{\text {th }}$ percentile of the test outcome distribution conditional on the lowest discretized value of the prior, and the high value was chosen to correspond to the $95^{\text {th }}$ percentile of the test outcome distribution conditional on the highest discretized value of the priors. Probabilities were then found such that the resulting probability/value pairs matched the mean and variance of the continuous distribution as closely as possible. Again, because of the shape of the distribution and the restriction on the values, it was not possible to match the mean and variance precisely. While Activity 9 had squared error of 22 percent and Activity 10 had squared error of 90 percent, all the remaining activities had squared error of less than 14 percent.

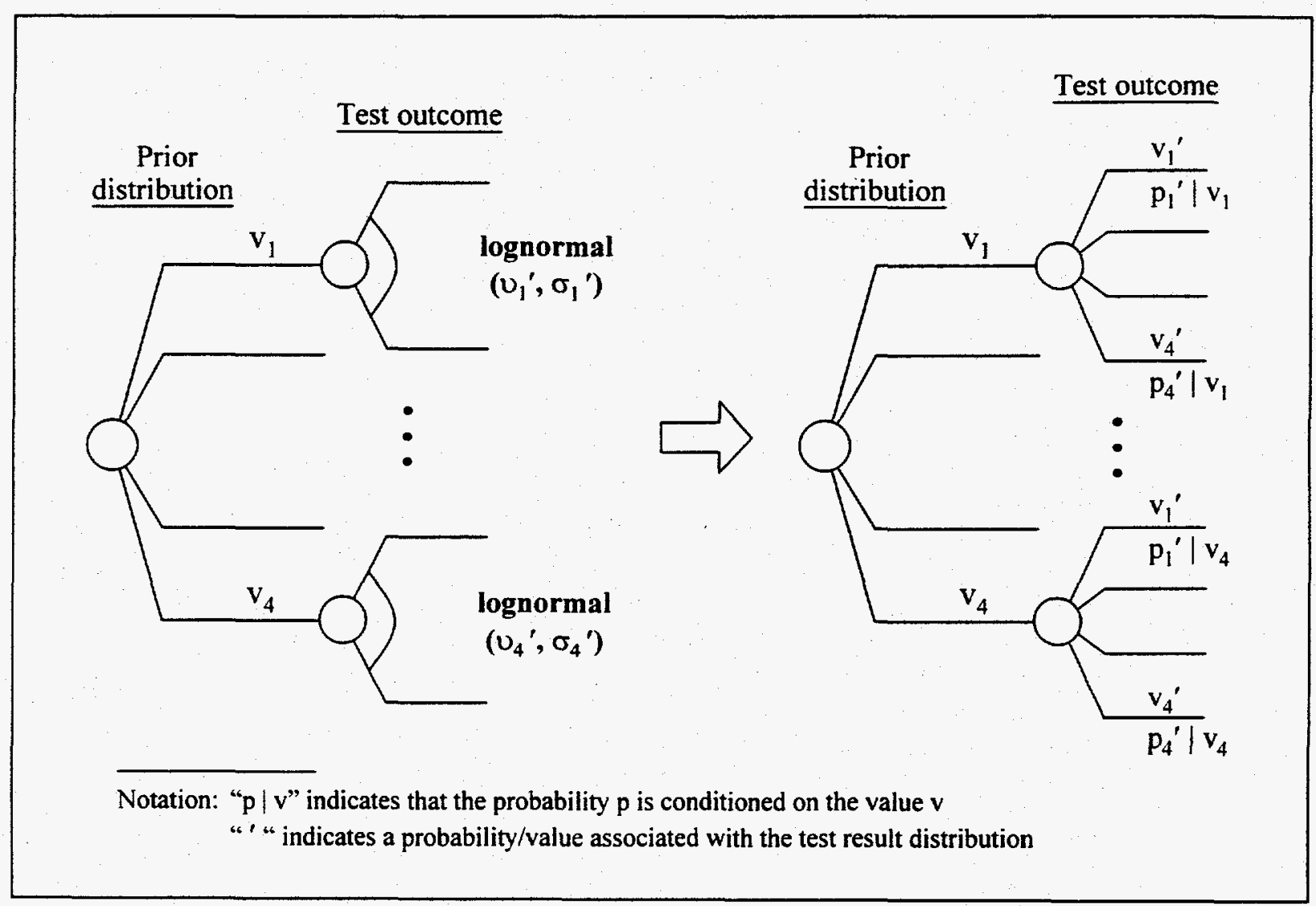

Figure F-3

Discretization of the Distributions for Test Outcomes 
Again note that while four probability/value pairs are shown, the number of discretized levels used varies depending on the parameter addressed. For tests addressing groundwater flux and source, four probability/value pairs were used, while for tests addressing diffusion, $\mathrm{K}_{\mathrm{d}}$, and porosity, five probability/value pairs were used. While a higher number of discretized levels ensures a better approximation to the continuous distribution, it also increases the number of resulting posterior distributions. To obtain the probability distributions for the uncertainty reduction measures related to the maximal extent using the contaminant boundary, the posterior distributions were used as inputs for the Monte Carlo simulation of the contaminant transport model. To limit the number of Monte Carlo simulations, it was important to restrict the number of discretized levels used with these measures. However, because Monte Carlo simulations were not required to compute the parameter uncertainty reduction measure, a large number of levels could be used for the discretization. Thus, for the parameter uncertainty reduction measure, a separate set of discretizations using sixteen probability/outcome pairs was computed, ensuring a better approximation of the continuous distributions. ${ }^{1}$

The event tree in Figure F-3 shows that the: assessed accuracy values are conditioned on the possible discrete values for the parameter. However, in the actual process of conducting and interpreting a test, the sequence of events must be reversed as indicated in Figure F-1. This is accomplished by applying Bayes' theorem. Figure F-4 shows the "flipped" tree. Note that there are several possible outcomes for the test cutcome. The test might tell us the parameter value is lower than we expected, higher than we expected, or close to what we expected. This information is reflected in the posterior distributions. Mathematically, the posterior distribution conditional on a specific test outcome is calculated as follows. Using the notation in Figures F-3 and $F-4$, let $v_{i}{ }^{\prime}$ 'represent a test outcome, $v_{j}(j=1, \ldots, 4)$ represent discretized values of the prior and $\left(p_{j} \mid v_{i}{ }^{\prime}\right)$ represent the probability for the updated, posterior distribution conditional on the test outcome $v_{i}{ }^{\prime}$ associated with the value $v_{j}$.

$$
p_{j} \mid v_{i}^{\prime}=\frac{\left(p_{i}^{\prime} \mid v_{j}\right) p_{j}}{\sum_{k=1}^{n}\left(p_{i} \mid v_{k}\right) p_{k}} \frac{\left(p_{i}^{\prime} \mid v_{j}\right) p_{j}}{\sum_{k=1}^{n}\left(p_{i}^{\prime} \mid v_{k}\right) p_{k}}
$$

\footnotetext{
1 A sixteen level discretization was used for all activities addressing parameters other than flux plus the flux Activity 9. Additional levels were not used for the other flux activities because discretizing error was minimal with the lower number of discretizing levels.
} 


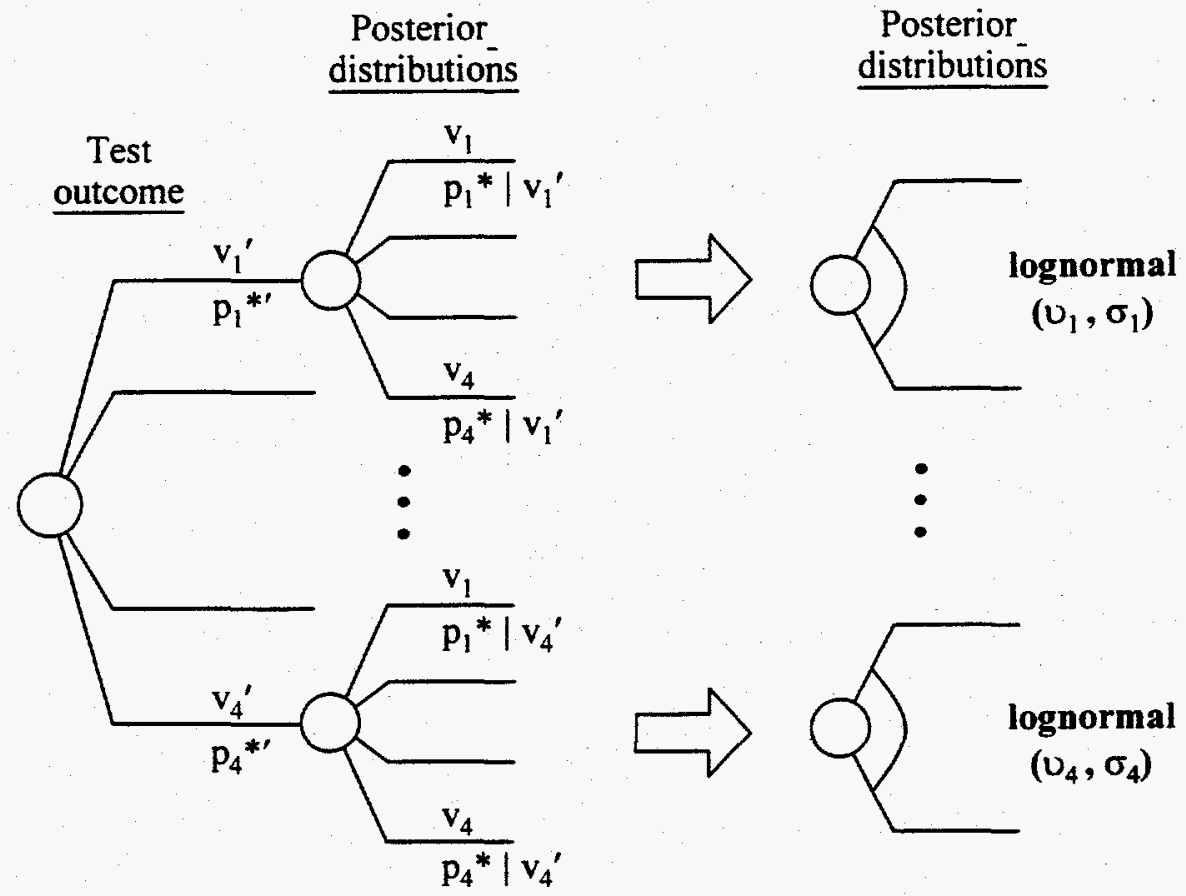

Notation: " $p / v$ " indicates that the probability $p$ is conditioned on the value $v$ " " $"$ indicates a probability/value associated with the test result distribution "* " indicates a probability in the reversed tree computed from Bayes' theorem

\section{Figure F-4 \\ Bayesian Updating - Reversing the Decision Tree}

The final step, also shown in Figure F-4, is to transform the discrete representation of the posterior distributions into continuous form. As with other steps in this analysis, the expert panel assigned specific named distributions to the posterior distributions corresponding to various parameters. Specifically, the expert panel specified that the posterior distributions would have the same form as the prior distributions. Thus, diffusion, flux, and porosity have lognormal posterior distributions, source has normal posterior distributions, and $K_{d}$ has uniform posterior distributions. To transform from discrete to continuous distributions, the first step is to compute the mean and variance $\left(v\right.$ and $\left.\sigma^{2}\right)$ of the discrete form of the posterior distribution. In the general case with $n$ probability value pairs denoted $p_{i}$ and $v_{i}, i=1 \ldots n$, the formula is

$$
v=p_{1} v_{1}+\ldots+p_{n}^{*} v_{n}
$$




$$
\sigma^{2}=\left(p_{1}^{*} v_{1}^{2}+\ldots+p_{n}^{*} v_{n}^{2}\right)-v^{2}
$$

For the posteriors related to source term, assumed to be normal, $v$ and $\sigma^{2}$ define the means and variances of the distribution. For the posteriors related to $K_{d}$, assumed to be uniform, $v$ and $\sigma^{2}$ were used to specify the minimum and maximum values of the distribution, denoted $a$ and $b$ :

$$
\begin{aligned}
& v=\frac{(a+b)}{2} \\
& \sigma^{2}=\frac{(a-b)^{2}}{12}
\end{aligned}
$$

Inverting these equations yields

$$
\begin{aligned}
& a=v-\sqrt{ } 3 \sigma \\
& b=v+\sqrt{3} \sigma
\end{aligned}
$$

For diffusion, flux, and porosity, the posterior distributions were specified by the expert panel to be lognormal, and for the purposes of the transport model, the distribution parameters needed to be given in terms of the underlying normal distribution in log space (as opposed to natural log space). Therefore $v$ and $\sigma^{2}$ were transformed to $v_{x}$ and $\sigma_{x}{ }^{2}$ (the normal parameters in $\ln$ space) and $v_{\mathrm{x}}$ and $\sigma_{\mathrm{x}}{ }^{2}$ were transformed to $v_{\mathrm{x} \varepsilon}$ and $\sigma_{\mathrm{x}^{\prime}}{ }^{2}$ (the normal parameters in log space).

To transform $v$ and $\sigma^{2}$ to $v_{x}$ and $\sigma_{x}^{2}$, the following equations were used:

$$
\begin{gathered}
v=\exp \left(v_{x}+\frac{\sigma_{x}^{2}}{2}\right) \\
\sigma^{2}=\exp \left(2 v_{x}+2 \sigma_{x}^{2}\right)-\exp \left(2 v_{x}+\sigma_{x}^{2}\right)
\end{gathered}
$$


Inverting the equations yields

$$
v_{x}=\ln \left(v^{2}\right)-\frac{\ln \left(v^{2}+\sigma^{2}\right)}{2}
$$

$$
\sigma_{x}^{2}=\ln \left(v^{2}\right)-2 v_{x}
$$

Next, to transform $v_{x}$ and $\sigma_{x}{ }^{2}$ to $v_{x^{\prime}}$ and $\sigma_{x^{\prime}}{ }^{2}$, consider a lognormal distribution in real space, denoted $Y$. Then $X=\ln Y$ is the underlying normal distribution in $\ln$ space, and $X^{\prime}=\log Y$ is the underlying normal distribution in log space. Then

$$
X=\ln Y=\frac{\log _{10} Y}{\log _{10} e}=\frac{X^{\prime}}{\log _{10} e}
$$

and, thus

$$
v_{x^{\prime}}=E\left[X^{\prime}\right]=E\left[\log _{10} e X\right]=\log _{10} e E[X]=\log _{10} e v_{x}=K v_{x}
$$

where $\mathrm{K}=\log _{10} \mathrm{e}$.

Similarly,

$$
\sigma_{x^{\prime}}{ }^{2}=\operatorname{Var}\left[X^{\prime}\right]=\operatorname{Var}\left[\log _{10} e X\right]=\left(\log _{10} e\right)^{2} \sigma_{x}^{2}=K^{2} \sigma_{x}^{2}
$$


Combining equations (F-9), (F-13) and (F-11), (F-14) yields

$$
\begin{gathered}
v_{\mathrm{x}^{\prime}}=\mathrm{K}\left(\ln \left(v^{2}\right)-\frac{\ln \left(v^{2}+\sigma^{2}\right)}{2}\right) \\
\sigma_{\mathrm{x}^{\prime}}{ }^{2}=\mathrm{K}^{2}\left(\ln \left(v^{2}\right)-2 v_{\mathrm{x}}\right)
\end{gathered}
$$

Tables F-1 through F-7 provide the mean and standard deviations for posterior distributions for the activities and subgroups, where the parameters for the lognormal distributions are the underlying mean and standard deviation (sigma) in log space.

Table F-1

Posterior Distributions for Activities Addressing the Flux Multiplier

\begin{tabular}{|c|c|c|c|c|c|c|c|c||}
\hline \multirow{2}{*}{ Activity } & \multicolumn{2}{|c|}{ Test result = low } & \multicolumn{2}{c|}{ Test result = nominal } & \multicolumn{2}{c|}{ Test result = high } & \multicolumn{2}{c|}{ Test result = very high } \\
\cline { 2 - 9 } & mean & sigma & mean & sigma & mean & sigma & mean & sigma \\
\hline 1 & -2.08 & 0.44 & -0.79 & 0.55 & -0.30 & 0.43 & 0.27 & 0.17 \\
\hline 2 & -1.85 & 0.45 & -0.83 & 0.56 & -0.15 & 0.37 & 0.27 & 0.16 \\
\hline 3 & -2.18 & 0.41 & -1.14 & 0.59 & 0.14 & 0.24 & 0.33 & 0.12 \\
\hline 7 & -1.98 & 0.46 & -1.11 & 0.54 & 0.2 & 0.20 & 0.34 & 0.12 \\
\hline 8 & -2.01 & 0.46 & -0.85 & 0.57 & -0.30 & 0.40 & 0.24 & 0.18 \\
\hline 9 & -2.04 & 0.45 & -1.05 & 0.61 & -0.05 & 0.32 & 0.27 & 0.17 \\
\hline 12 & -1.93 & 0.45 & -1.09 & 0.57 & 0.12 & 0.27 & 0.22 & 0.19 \\
\hline
\end{tabular}

Table F-2

\section{Posterior Distributions for Subgroups Addressing the Flux Multiplier}

\begin{tabular}{|c|c|c|c|c|c|c|c|c||}
\hline \multirow{2}{*}{ Subgroup } & \multicolumn{2}{|c|}{ Test result $=$ low } & \multicolumn{2}{c|}{ Test result $=$ nominal } & \multicolumn{2}{c|}{ Test result = high } & \multicolumn{2}{c|}{ Test result = very high } \\
\cline { 2 - 9 } & mean & sigma & mean & sigma & mean & sigma & mean & sigma \\
\hline 5 & -2.03 & 0.19 & -1.06 & 0.48 & 0.20 & 0.20 & 0.38 & 0.08 \\
\hline 6 & -2.03 & 0.19 & -1.10 & 0.57 & 0.16 & 0.22 & 0.37 & 0.10 \\
\hline 7 & -2.03 & 0.18 & -1.06 & 0.47 & 0.21 & 0.19 & 0.38 & 0.08 \\
\hline 8 & -2.03 & 0.19 & -0.89 & 0.58 & -0.17 & 0.34 & 0.29 & 0.16 \\
\hline 9 & -2.03 & 0.19 & -1.10 & 0.49 & 0.19 & 0.20 & 0.37 & 0.09 \\
\hline 10 & -2.03 & 0.18 & -1.06 & 0.51 & 0.20 & 0.20 & 0.37 & 0.09 \\
\hline 11 & -2.03 & 0.19 & -1.15 & 0.51 & 0.18 & 0.21 & 0.37 & 0.1 \\
\hline
\end{tabular}


Table F-3

Posterior Distributions for Activities Addressing Source Term

\begin{tabular}{|c|c|c|c|c|c|c|c|c|}
\hline \multirow{2}{*}{ Activity } & \multicolumn{2}{|c|}{ Test result = low } & \multicolumn{2}{c|}{ Test result = nominal } & \multicolumn{2}{c|}{ Test result = high } & \multicolumn{2}{|c|}{ Test result $=$ very high } \\
\cline { 2 - 9 } & mean & sigma & mean & sigma & mean & sigma & mean & sigma \\
\hline 4 & 327.4 & 322.1 & 571.7 & 174.7 & 677.9 & 239.0 & 788.3 & 308.9 \\
\hline 11 & 317.6 & 319.9 & 572.5 & 175.5 & 677.5 & 238.9 & 740.7 & 317 \\
\hline
\end{tabular}

Table F-4

Posterior Distributions for Subgroups Addressing Effective Porosity

\begin{tabular}{|c|c|c|c|c|c|c|c|c|}
\hline \multirow{2}{*}{ Subgroup } & \multicolumn{2}{|c|}{ Test result = very low } & \multicolumn{2}{c|}{ Test result = low } & \multicolumn{2}{c|}{ Test result = nominal } & \multicolumn{2}{c|}{ Test result = high } \\
\cline { 2 - 9 } & mean & sigma & mean & sigma & mean & sigma & mean & sigma \\
\hline 2 & -3.17 & 0.69 & -2.90 & 0.63 & -2.52 & 0.63 & -1.26 & 0.23 \\
\hline
\end{tabular}

Table F-5

Posterior Distributions for Activities Addressing Diffusion

\begin{tabular}{|c|c|c|c|c|c|c|c|c|}
\hline \multirow{2}{*}{ Activity } & \multicolumn{2}{|c|}{ Test result = very low } & \multicolumn{2}{c|}{ Test result = low } & \multicolumn{2}{c|}{ Test result = nominal } & \multicolumn{2}{c|}{ Test result $=$ high } \\
\cline { 2 - 9 } & mean & sigma & mean & sigma & mean & sigma & mean & sigma \\
\hline 5 & -3.11 & 0.69 & -2.81 & 0.59 & -2.05 & 0.30 & -1.54 & 0.15 \\
\hline $6 a$ & -3.14 & 0.70 & -2.75 & 0.58 & -2.03 & 0.27 & -1.50 & 0.12 \\
\hline 10 & -3.01 & 0.66 & -2.71 & 0.58 & -2.26 & 0.39 & -1.68 & 0.23 \\
\hline
\end{tabular}

Table F-6

Posterior Distributions for Subgroups Addressing Diffusion

\begin{tabular}{|c|c|c|c|c|c|c|c|c||}
\hline \multirow{2}{*}{ Subgroup } & \multicolumn{2}{|c|}{ Test result = very low } & \multicolumn{2}{c|}{ Test result = low } & \multicolumn{2}{c|}{ Test result = nominal } & \multicolumn{2}{c|}{ Test result = high } \\
\cline { 2 - 10 } & mean & sigma & mean & sigma & mean & sigma & mean & sigma \\
\hline 3 & -3.14 & 0.70 & -2.74 & 0.57 & -2.01 & 0.30 & -1.55 & 0.15 \\
\hline 4 & -3.21 & 0.72 & -2.83 & 0.58 & -1.87 & 0.28 & -1.49 & 0.10 \\
\hline 12 & -3.18 & 0.71 & -2.72 & 0.56 & -1.98 & 0.27 & -1.51 & 0.13 \\
\hline
\end{tabular}

Table F-7

Posterior Distributions for Activities Addressing $\mathrm{K}_{\mathrm{d}}{ }^{*}$

\begin{tabular}{|c|c|c|c|c|c|c|c|c|}
\hline Activity & \multicolumn{2}{|c|}{ Test result = very low } & \multicolumn{2}{c|}{ Test result $=$ low } & \multicolumn{2}{c|}{ Test result = nominal } & \multicolumn{3}{|c|}{ Test result = high } \\
\hline & $\min$ & $\max$ & $\min$ & $\max$ & $\min$ & $\max$ & $\min$ & $\max$ \\
\hline 14 & 0.0 & 0.0 & 0.0 & 6.7 & 4.2 & 5.7 & 3.3 & 12.1 \\
\hline
\end{tabular}

${ }^{*} K_{d}$ follows a uniform distribution, therefore, the minimum and maximum are reported instead of the 5 and 95 percent values. 
Keefer, D.L., and S.E. Bodily. 1983. "Three-Point Approximations for Continuous Random Variables." In Management Science, 29 (5): 595. Stanford, CA: The Institute of Management Science.

Miller, A.C., and T.R. Rice. 1983. "Discrete Approximations of Probability Distributions." In Management Science, 29 (3): 352-362. Stanford, CA: The Institute of Management Science.

Smith, J.E. 1993. "Moment Methods for Decision Analysis." In Management Science, 39 (3): 340. Stanford, CA: The Institute of Management Science. 


\section{Appendix G}

\section{Transport Simulations for Individual Activities, Subgroups, and Groups}




\section{Table of Contents}

List of Tables

G-ii

G.1.0 Introduction

G-1

G.2.0 Preliminary Transport Simulations

G.2.1 Example 1 - Flux Multiplier

G-2

G.2.2 Example 2 - Effective Porosity G-3

G.2.3 Example 3-Diffusion Transfer Coefficient $\mathrm{G}-4$

G.2.4 Example 4 - Source Concentration G-5

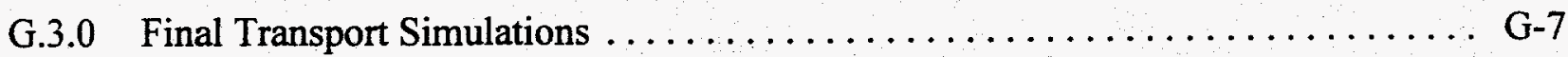

G.3.1 Transport Simulation Procedure $\ldots \ldots \ldots \ldots \ldots \ldots \ldots \ldots \ldots \ldots \ldots \ldots \ldots \ldots \ldots \ldots \ldots \ldots$

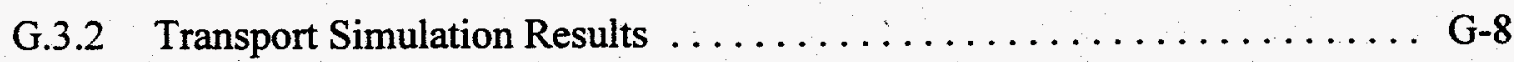

G.3.2.1 Individual Activities . . . . . . . . . . . . . . .

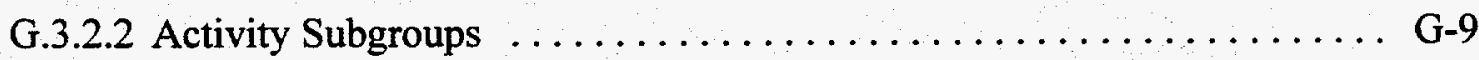

G.3.2.3 Activity Groups $\ldots \ldots \ldots \ldots \ldots \ldots \ldots \ldots \ldots \ldots \ldots \ldots \ldots \ldots \ldots \ldots \ldots \ldots \ldots$

G.3.2.4 Final Transport Simulation Tables ................. G-10

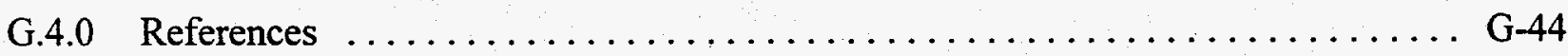


G-1 Initial Prior Values for Sensitive Parameters

G-2 Maximum Distance $(\mathrm{km})$ to the $4 \mathrm{mrem} / \mathrm{yr}$ Boundary for the Case of Different Flux Multiplier Values

G-3 Maximum Distance $(\mathrm{km})$ to the $4 \mathrm{mrem} / \mathrm{yr}$ Boundary for the Case of Different Effective Porosity Values

G-4 Maximum Distance $(\mathrm{km})$ to the $4 \mathrm{mrem} / \mathrm{yr}$ Boundary for the Case of Different Diffusion Transfer Coefficient Values G-5

G-5 Maximum Distance $(\mathrm{km})$ to the $4 \mathrm{mrem} / \mathrm{yr}$ Boundary for the Case of Different Source Concentration Values G-6

G-6 Transport Simulation Results for Individual Characterization Activity 1 Location of Contaminant Boundary for Various Fractiles G-11

G-7 Transport Simulation Results for Individual Characterization Activity 2 Location of Contaminant Boundary for Various Fractiles G-11

G-8 Transport Simulation Results for Individual Characterization Activity 3 Location of Contaminant Boundary for Various Fractiles G-12

G-9 Transport Simulation Results for Individual Characterization Activity 4 Location of Contaminant Boundary for Various Fractiles

G-10 Transport Simulation Results for Individual Characterization Activity 5 Location of Contaminant Boundary for Various Fractiles 
Number

Title

Page

G-11 Transport Simulation Results for Individual Characterization Activity 6a Location of Contaminant Boundary for Various Fractiles

G-12 Transport Simulation Results for Individual Characterization Activity 6p Location of Contaminant Boundary for Various Fractiles

G-13 Transport Simulation Results for Individual Characterization Activity 7 Location of Contaminant Boundary for Various Fractiles G-14

G-14 Transport Simulation Results for Individual Characterization Activity 8 Location of Contaminant Boundary for Various Fractiles G-15

G-15 Transport Simulation Results for Individual Characterization Activity 9 Location of Contaminant Boundary for Various Fractiles G-15

G-16 Transport Simulation Results for Individual Characterization Activity 10 Location of Contaminant Boundary for Various Fractiles G-16

G-17 Transport Simulation Results for Individual Characterization Activity 11 Location of Contaminant Boundary for Various Fractiles G-16

G-18 Transport Simulation Results for Individual Characterization Activity 12 Location of Contaminant Boundary for Various Fractiles

G-19 Transport Simulation Results for Individual Characterization Activity 13 Location of Contaminant Boundary for Various Fractiles

G-20 Transport Simulation Results for Characterization Activity Subgroup 1 Location of Contaminant Boundary for Various Fractiles 
G-21 Transport Simulation Results for Characterization Activity Subgroup 2 Location of Contaminant Boundary for Various Fractiles

G-22 Transport Simulation Results for Characterization Activity Subgroup 3 Location of Contaminant Boundary for Various Fractiles

G-23 Transport Simulation Results for Characterization Activity Subgroup 4 Location of Contaminant Boundary for Various Fractiles

G-24 Transport Simulation Results for Characterization Activity Subgroup 5 Location of Contaminant Boundary for Various Fractiles

G-25 Transport Simulation Results for Characterization Activity Subgroup 6 Location of Contaminant Boundary for Various Fractiles

G-26 Transport Simulation Results for Characterization Activity Subgroup 7 Location of Contaminant Boundary for Various Fractiles

G-27 Transport Simulation Results for Characterization Activity Subgroup 8 Location of Contaminant Boundary for Various Fractiles

G-28 Transport Simulation Results for Characterization Activity Subgroup 9 Location of Contaminant Boundary for Various Fractiles

G-29 Transport Simulation Results for Characterization Activity Subgroup 10 Location of Contaminant Boundary for Various Fractiles

G-30 Transport Simulation Results for Characterization Activity Subgroup 11 Location of Contaminant Boundary for Various Fractiles 


\section{List of Tables (Continued)}

Number

Title

Page

G-31 Transport Simulation Results for Characterization Activity Subgroup 12 Location of Contaminant Boundary for Various Fractiles

G-32 Transport Simulation Results for Characterization Activity Group 1 Location of Contaminant Boundary for Various Fractiles

G-33 Transport Simulation Results for Characterization Activity Group 2 Location of Contaminant Boundary for Various Fractiles

G-34 Transport Simulation Results for Characterization Activity Group 3 Location of Contaminant Boundary for Various Fractiles

G-35 Transport Simulation Results for Characterization Activity Group 4 Location of Contaminant Boundary for Various Fractiles

G-36 Transport Simulation Results for Characterization Activity Group 5 Location of Contaminant Boundary for Various Fractiles

G-37 Transport Simulation Results for Characterization Activity Group 6 Location of Contaminant Boundary for Various Fractiles

G-38 Transport Simulation Results for Characterization Activity Group 7 Location of Contaminant Boundary for Various Fractiles

G-39 Transport Simulation Results for Characterization Activity Group 8 Location of Contaminant Boundary for Various Fractiles

G-40 Transport Simulation Results for Characterization Activity Group 10 Location of Contaminant Boundary for Various Fractiles 


\section{G.1.0 Introduction}

This appendix presents the results of the preliminary and final transport simulations performed in support of the VOIA.

\section{G.2.0 Preliminary Transport Simulations}

During the early stages of the VOIA, the regional transport model was set-up to simulate the concentrations of seven radionuclides along the TYBO pathline. The seven radionuclides are: tritium, plutonium-239/240, carbon-14, uranium-238, cesium-137, strontium-90, and iodine-129. However, to reduce the number of simulations required, some simplifying assumptions were made. First, cesium-137 and strontium-90 were eliminated because of their relatively short half lives and low starting concentrations compared with tritium. Both nuclides will decay to a concentration that will produce less than $4 \mathrm{mrem} / \mathrm{yr}$ in less than 200 years, which is approximately the same timeframe as for tritium. Both nuclides sorb to the rock material which means that they will move at a much slower velocity than the non-sorbing radionuclides such as tritium, carbon-14, and iodine-129. Preliminary simulations showed that over the first 200 years, the composite $4 \mathrm{mrem} / \mathrm{yr}$ boundary will be controlled by the tritium concentration. As a result, it is expected that the cesium- 137 and strontium- 90 dose will not contribute to the maximum extent of the $4 \mathrm{mrem} / \mathrm{yr}$ boundary. Thus, cesium- 137 and strontium- 90 were eliminated from further consideration.

Preliminary simulations were performed with the five remaining nuclides: tritium, carbon-14, plutonium-239/240, uranium-238, and iodine-129. The results of example simulations are presented below.

The initial prior values for the parameters are given in Table G-1.

Four examples are presented where a parameter has been changed and the resulting distance to the $4 \mathrm{mrem} / \mathrm{yr}$ boundary is given for each of the radionuclides and then as a composite of all five nuclides. The four examples each represent one of the main parameters: flux multiplier, effective porosity, diffusion transfer coefficient, and source term. 
Table G-1

Initial Prior Values for Sensitive Parameters

\begin{tabular}{|c|c|c|c|c|}
\hline Parameter & Units & Mean $^{\mathrm{a}}$ & $\begin{array}{l}\text { Standard } \\
\text { Deviation }^{\mathrm{b}}\end{array}$ & Distribution \\
\hline Effective porosity & $\sim$ & -2.7614 & 0.7529 & Lognormal \\
\hline Matrix porosity & $\sim$ & 0.035 & 0.27 & Uniform \\
\hline Diffusion Coefficient & $1 / y r$ & -2.6124 & 0.3576 & Lognormal \\
\hline Fracture half spacing & $m$ & 0.2 & 2.6 & Uniform \\
\hline Flux Scaling & $\sim$ & -0.1109 & 0.5405 & Lognormal \\
\hline Source concentration - tritium & $\mathrm{pCi} / \mathrm{L}$ & $5.005 E+09$ & $3.036 \mathrm{E}+09$ & Normal \\
\hline Source concentration - uranium-238 & $\mathrm{pCi} / \mathrm{L}$ & $5.005 E-01$ & $3.036 \mathrm{E}-01$ & Normal \\
\hline Source concentration - plutonium-239/240 & $\mathrm{pCi} / \mathrm{L}$ & $5.005 E-01$ & $3.036 \mathrm{E}-01$ & Normal \\
\hline Source concentration - iodine-129 & $\mathrm{pCi} / \mathrm{L}$ & $5.005 E-01$ & $3.036 \mathrm{E}-01$ & Normal \\
\hline Source concentration - carbon-14 & pCill & $5.005 E+04$ & $3.036 \mathrm{E}+04$ & Normal \\
\hline$K_{d}-$ tritium & $\mathrm{mL} / \mathrm{g}$ & 0 & 0 & Constant \\
\hline$K_{d}-$ uranium-238 & $\mathrm{mL} / \mathrm{g}$ & 0 & 10 & Uniform \\
\hline $\mathrm{K}_{\mathrm{d}}-$ plutonium-239/240 & $\mathrm{mL} / \mathrm{g}$ & 0 & 10 & Uniform \\
\hline$K_{d}-$ iodine-129 & $\mathrm{mL} / \mathrm{g}$ & 0 & 0 & Constant \\
\hline$K_{d}-$ carbon-14 & $\mathrm{mL} / \mathrm{g}$ & 0 & 0 & Constant \\
\hline Dispersivity & $\mathrm{m}$ & 100 & 1000 & Uniform \\
\hline
\end{tabular}

$a_{\log _{10}}$ mean for a lognormal distribution; lower bound for al uniform distribution

${ }^{b} \log _{10}$ standard deviation for a lognormal distribution; upper bound for a uniform distribution

\section{G.2.1 Example 1 - Flux Multiplier}

Activity 7 is designed to reduce uncertainty in the flux multiplier. Three cases were simulated corresponding to indicator value at the 5,50, and 99 percent fractiles of the prior distribution. The $\log _{10}$ mean and $\log _{10}$ standard deviation of the flux multiplier for each of these three cases are as follows:

Indicator is at

$$
\begin{gathered}
5 \% \\
50 \% \\
99 \%
\end{gathered}
$$

$\log _{10}$ mean

$-1.0439$

$-0.1259$

0.9780

G-2 $\log _{10}$ standard deviation

0.2502

0.4700

0.2491 
From the output of the 200 realizations, the maximum distance to the $4 \mathrm{mrem} / \mathrm{yr}$ boundary was calculated for 5 levels: $50,65,75,85$, and 95 percent. These levels represent the maximum distances for which $\mathrm{x}$ percent of the values are smaller. For example, if 75 percent is chosen, the maximum distance presented in the table is greater than 75 percent of all the distance recorded for the 200 realizations.

Table G-2 contains the results for Example 1. In this example, the composite dose is controlled by tritium alone. A zero means that the dose for that radionuclide was less than $4 \mathrm{mrem} / \mathrm{yr}$, even for the observation point $1 \mathrm{~km}$ away from the test location.

\section{Table G-2}

Maximum Distance $(\mathrm{km})$ to the $4 \mathrm{mrem} / \mathrm{yr}$ Boundary for the Case of Different Flux Multiplier Values

\begin{tabular}{|l|l|r|r|r|r|r|}
\hline Indicator \% & Radionuclide & \multicolumn{1}{|c|}{$\mathbf{5 0 \%}$} & \multicolumn{1}{|c|}{$\mathbf{6 5 \%}$} & \multicolumn{1}{|c|}{$\mathbf{7 5 \%}$} & \multicolumn{1}{|c|}{$\mathbf{8 5 \%}$} & \multicolumn{1}{c|}{$95 \%$} \\
\hline $5 \%$ & carbon-14 & 2.63 & 3.14 & 3.54 & 4.45 & 5.60 \\
& iodine-129 & 0.00 & 0.00 & 0.00 & 0.00 & 0.00 \\
& plutonium-239/240 & 0.00 & 0.00 & 0.00 & 0.00 & 0.00 \\
& tritium & 3.41 & 4.19 & 5.75 & 7.96 & 13.43 \\
& uranium-238 & 0.00 & 0.00 & 0.00 & 0.00 & 0.00 \\
& composite & 3.41 & 4.19 & 5.75 & 7.98 & 13.44 \\
\hline $50 \%$ & carbon-14 & 2.29 & 3.54 & 4.76 & 6.86 & 12.16 \\
& iodine-129 & 0.00 & 0.00 & 0.00 & 0.00 & 0.00 \\
& plutonium-239/240 & 0.00 & 0.00 & 0.00 & 0.00 & 0.00 \\
& tritium & 15.20 & 22.81 & 30.50 & 30.50 & 30.50 \\
& uranium-238 & 0.00 & 0.00 & 0.00 & 0.00 & 0.00 \\
& composite & 15.21 & 22.85 & 30.50 & 30.50 & 30.50 \\
\hline \multirow{5}{95\%}{} & carbon-14 & 1.42 & 1.44 & 3.46 & 4.86 & 9.68 \\
& iodine-129 & 0.00 & 0.00 & 0.00 & 0.00 & 0.00 \\
& plutonium-239/240 & 0.00 & 0.00 & 0.00 & 0.00 & 0.00 \\
& tritium & 30.50 & 30.50 & 30.50 & 30.50 & 30.50 \\
& uranium-238 & 0.00 & 0.00 & 0.00 & 0.00 & 0.00 \\
& composite & 30.50 & 30.50 & 30.50 & 30.50 & 30.50 \\
\hline
\end{tabular}

\section{G.2.2 Example 2 - Effective Porosity}

Activity 5 is designed to reduce uncertainty in the effective porosity. Three cases were simulated corresponding to indicator values at the 5,50, and 99 percent fractiles of the prior distribution. The $\log _{10}$ mean and $\log _{10}$ standard deviation of the effective porosity for each of these three cases are as follows: 
Indicator is at

$5 \%$

$50 \%$

$99 \%$ $\log _{10}$ mean

$-3.3343$

$-3.0520$

$-1.4449$ $\log _{10}$ standard deviation

0.7401

0.6728

0.0569

Table G-3 contains the results for Example 2. In this example, tritium dominated the composite boundary except when porosity was very large. At the 95 percent indicator, carbon-14 controlled the boundary location.

Table G-3

Maximum Distance $(\mathrm{km})$ to the $4 \mathrm{mrem} / \mathrm{yr}$ Boundary for the Case of Different Effective Porosity Values

\begin{tabular}{|l|l|r|r|r|r|r||}
\hline Indicator \% & Radionuclide & \multicolumn{1}{|c|}{$\mathbf{5 0 \%}$} & \multicolumn{1}{c|}{$\mathbf{6 5 \%}$} & \multicolumn{1}{c|}{$\mathbf{7 5 \%}$} & \multicolumn{1}{c|}{$\mathbf{8 5 \%}$} & \multicolumn{1}{c|}{$\mathbf{9 5 \%}$} \\
\hline \hline $5 \%$ & carbon-14 & 2.62 & 3.30 & 4.23 & 6.22 & 11.00 \\
& iodine-129 & 0.00 & 0.00 & 0.00 & 0.00 & 0.00 \\
& plutonium-239/240 & 0.00 & 0.00 & 0.00 & 0.00 & 0.00 \\
& tritium & 18.63 & 30.50 & 30.50 & 30.50 & 30.50 \\
& uranium-238 & 0.00 & 0.00 & 0.00 & 0.00 & 0.00 \\
& composite & 18.63 & 30.50 & 30.50 & 30.50 & 30.50 \\
\hline \multirow{3}{*}{$5 \% \%$} & carbon-14 & 2.37 & 3.30 & 4.29 & 5.90 & 8.73 \\
& iodine-129 & 0.00 & 0.00 & 0.00 & 0.00 & 0.00 \\
& plutonium-239/240 & 0.00 & 0.00 & 0.00 & 0.00 & 0.00 \\
& tritium & 13.34 & 22.35 & 30.50 & 30.50 & 30.50 \\
& uranium-238 & 0.00 & 0.00 & 0.00 & 0.00 & 0.00 \\
& composite & 13.34 & 22.36 & 30.50 & 30.50 & 30.50 \\
& carbon-14 & 2.30 & 3.87 & 6.12 & 8.74 & 15.06 \\
& iodine-129 & 0.00 & 0.00 & 0.00 & 0.00 & 0.00 \\
& llutonium-239/240 & 0.00 & 0.00 & 0.00 & 0.00 & 0.00 \\
& tritium & 2.78 & 3.44 & 4.24 & 5.65 & 9.35 \\
& uranium-238 & 0.00 & 0.00 & 0.00 & 0.00 & 0.00 \\
& composite & 2.79 & 3.87 & 6.13 & 8.76 & 15.06 \\
\hline
\end{tabular}

\section{G.2.3 Example 3 - Diffusion Transfer Coefficient}

Activity 10 is designed to reduce uncertainty in the diffusion transfer coefficient. Three cases were simulated corresponding to indicator value at the 5,50, and 99 percent fractiles of the prior distribution. The $\log _{10}$ mean and $\log _{10}$ standard deviation of the diffusion transfer coefficient $(1 / \mathrm{yr})$ for each of these three cases are as follows: 
Indicator is at

$$
\begin{aligned}
& 5 \% \\
& 50 \% \\
& 99 \%
\end{aligned}
$$

$\log _{10}$ mean

$-3.3036$

$-2.9084$

1.5101 $\log _{10}$ standard deviation

0.7304

0.6470

0.1475

Table G-4 contains the results for Example 3. As was the case for Example 2, tritium dominates the composite dose results except for the 95 percent indicator value. For Example 3, both tritium and carbon- 14 combine to produce the composite dose when the indicator is at 95 percent:

Table G-4

Maximum Distance $(\mathrm{km})$ to the $4 \mathrm{mrem} / \mathrm{yr}$ Boundary for the Case of Different Diffusion Transfer Coefficient Values

\begin{tabular}{|l|l|r|r|r|r|r||}
\hline \hline Indicator \% & Radionuclide & \multicolumn{1}{|c|}{$\mathbf{5 0 \%}$} & \multicolumn{1}{c|}{$\mathbf{6 5 \%}$} & \multicolumn{1}{c|}{$\mathbf{7 5 \%}$} & $\mathbf{8 5 \%}$ & \multicolumn{1}{c|}{$\mathbf{9 5 \%}$} \\
\hline \hline $5 \%$ & carbon-14 & 2.64 & 3.41 & 4.26 & 6.13 & 10.14 \\
& iodine-129 & 0.00 & 0.00 & 0.00 & 0.00 & 0.00 \\
& plutonium-239/240 & 0.00 & 0.00 & 0.00 & 0.00 & 0.00 \\
& tritium & 19.70 & 30.50 & 30.50 & 30.50 & 30.50 \\
& uranium-238 & 0.00 & 0.00 & 0.00 & 0.00 & 0.00 \\
& composite & 19.71 & 30.50 & 30.50 & 30.50 & 30.50 \\
\hline $50 \%$ & carbon-14 & 2.44 & 3.74 & 4.81 & 6.75 & 11.64 \\
& iodine-129 & 0.00 & 0.00 & 0.00 & 0.00 & 0.00 \\
& plutonium-239/240 & 0.00 & 0.00 & 0.00 & 0.00 & 0.00 \\
& tritium & 13.34 & 20.73 & 30.50 & 30.50 & 30.50 \\
& uranium-238 & 0.00 & 0.00 & 0.00 & 0.00 & 0.00 \\
& composite & 13.34 & 20.74 & 30.50 & 30.50 & 30.50 \\
\hline \multirow{3}{*}{$95 \%$} & carbon-14 & 2.57 & 4.14 & 6.50 & 10.89 & 19.42 \\
& iodine-129 & 0.00 & 0.00 & 0.00 & 0.00 & 0.00 \\
& plutonium-239/240 & 0.00 & 0.00 & 0.00 & 0.00 & 0.00 \\
& tritium & 4.41 & 5.77 & 8.30 & 10.93 & 17.43 \\
& uranium-238 & 0.00 & 0.00 & 0.00 & 0.00 & 0.00 \\
& composite & 4.41 & 5.79 & 8.31 & 11.17 & 19.59 \\
\hline
\end{tabular}

\section{G.2.4 Example 4 - Source Concentration}

Activity 11 is designed to reduce uncertainty in the source concentration. Three cases were simulated corresponding to indicator value at the 5, 50, and 99 percent fractiles of the prior distribution. The mean and standard deviation of the tritium source concentration ( $\mathrm{pCi} / \mathrm{L}$ ) for each of these three cases are as follows: 
Indicator is at

$5 \%$
$50 \%$
$99 \%$

$\log _{10}$ mean

$3.1757 \mathrm{E}+09$

$5.2751 \mathrm{E}+09$

$\because .4068 \mathrm{E}+09$ $\log _{10}$ standard deviation

\section{$3.1993 \mathrm{E}+09$}

$1.7545 \mathrm{E}+09$

$3.1698 \mathrm{E}+09$

Table G-5 contains the results for Example 4. In this example, tritium dominates the composite result in all cases.

\section{Table G-5}

Maximum Distance ( $\mathrm{km}$ ) to the $4 \mathrm{mrem} / \mathrm{yr}$ Boundary for the Case of Different Source Concentration Values

\begin{tabular}{|l|l|r|r|r|r|r||}
\hline Indicator \% & Radionuclide & \multicolumn{1}{|c|}{$\mathbf{5 0 \%}$} & \multicolumn{1}{c|}{$\mathbf{6 5 \%}$} & \multicolumn{1}{c|}{$\mathbf{7 5 \%}$} & \multicolumn{1}{c|}{$\mathbf{8 5 \%}$} & \multicolumn{1}{c|}{$95 \%$} \\
\hline \hline $5 \%$ & carbon-14 & 1.38 & 2.12 & 2.99 & 4.20 & 8.13 \\
& iodine-129 & 0.00 & 0.00 & 0.00 & 0.00 & 0.00 \\
& plutonium-239/240 & 0.00 & 0.00 & 0.00 & 0.00 & 0.00 \\
& tritium & 12.52 & 19.18 & 30.50 & 30.50 & 30.50 \\
& uranium-238 & 0.00 & 0.00 & 0.00 & 0.00 & 0.00 \\
& composite & 12.52 & 19.19 & 30.50 & 30.50 & 30.50 \\
\hline $50 \%$ & carbon-14 & 2.57 & 3.60 & 4.59 & 6.11 & 10.33 \\
& iodine-129 & 0.00 & 0.00 & 0.00 & 0.00 & 0.00 \\
& plutonium-239/240 & 0.00 & 0.00 & 0.00 & 0.00 & 0.00 \\
& tritium & 17.18 & 30.50 & 30.50 & 30.50 & 30.50 \\
& uranium-238 & 0.00 & 0.00 & 0.00 & 0.00 & 0.00 \\
& composite & 17.18 & 30.50 & 30.50 & 30.50 & 30.50 \\
\hline \multirow{3}{*}{$95 \%$} & carbon-14 & 3.49 & 5.16 & 7.00 & 9.26 & 15.52 \\
& iodine-129 & 0.00 & 0.00 & 0.00 & 0.00 & 0.00 \\
& plutonium-239/240 & 0.00 & 0.00 & 0.00 & 0.00 & 0.00 \\
& tritium & 17.81 & 30.50 & 30.50 & 30.50 & 30.50 \\
& uranium-238 & 0.00 & 0.00 & 0.00 & 0.00 & 0.00 \\
& composite & 17.82 & 30.50 & 30.50 & 30.50 & 30.50 \\
\hline
\end{tabular}

In all four of these example cases, the maximum extent of the $4 \mathrm{mrem} / \mathrm{yr}$ composite boundary is controlled by either the tritium or carbon-14 results. A zero in all the other cases means that the dose was less than $4 \mathrm{mrem} / \mathrm{yr}$ at the first observation location at $1 \mathrm{~km}$ away from the shot working point. These results support the decision to remove all radionuclides except tritium and carbon-14.

In summary, simulations with the five remaining nuclides, tritium, plutonium-239/240, carbon-14, uranium-238, and iodine-129, demonstrated that plutonium-239/240, uranium-238, 
and iodine-129 did not contribute to the maximum extent of the composite $4 \mathrm{mrem} / \mathrm{yr}$ boundary. The reasons for this are several: (1) the initial uranium-238 concentration is already below the $4 \mathrm{mrem} / \mathrm{yr}$ level; (2) the iodine- 129 concentration is less than $8 \mathrm{mrem} / \mathrm{yr}$ and decreases quickly

due to dispersion and diffusion; and (3) both plutonium-239/240 and uranium-238 are sorbed and move slowly compared with tritium and carbon-14. The result is that only tritium and carbon-14 contributed to the maximum extent of the $4 \mathrm{mrem} / \mathrm{yr}$ boundary.

\section{G.3.0 Final Transport Simulations}

This section presents the procedure and results of the final transport simulations which were performed using two radionuclides and the scaled flux multiplier prior probability distribution.

\section{G.3.1 Transport Simulation Procedure}

The contaminant boundary simulations were performed with the MC_TRANS code for each of the parameter characterization options, subgroups, and groups. Within each option or group, a four or five level discrete approximation was chosen. If four values were used, the fractile values were chosen to be at the $5,50,95$, and 99 percent probability of the prior cumulative distribution. If five values were used, the 1 percent probability was added. For each fractile value, a mean and standard deviation for the parameter (Appendix E) were determined by elicitation of the expert panel members.

Two hundred realizations of the parameters were generated using the Latin hypercube sampling method for each of the fractile values of each characterization option or groups of options. In addition, each radionuclide, tritium and carbon-14, required separate simulations. Overall the activities, subgroups and groups, a total of 188,800 model runs, were performed. When parameters were grouped, the number of runs increased substantially. For example, if a parameter group included activities that improved flux, porosity, and diffusion parameter, the number of possible combinations of indicator values is the product of the number of fractiles for each parameter ( $4 \times 5 \times 4=80$ in this case). One parameter group was not simulated, that being group 9 which included 4 parameters and would have resulted in 320 combinations. For 200 realizations and 2 radionuclides per combination, the additional number of runs would have been 128,000 . The time that would have been required for this was not feasible within the schedule. 
The output of each set of Monte Carlo runs was postprocessed through two separate programs, one which calculated the distance to the 4 rnrem/yr boundary for different percentages of the realizations and a second which calculated the contaminant boundary uncertainty.

\section{G.3.2 Transport Simulation Results}

The results of the transport simulations for each of the activities, subgroups, and groups are provided in this section.

\section{G.3.2.1 Individual Activities}

For each individual characterization activity, posterior distributions of a single parameter were provided for each fractile variable. Two hundred realizations of the parameters were generated for each fractile value and simulations were performed using the transport model. The maximum distance to the $4 \mathrm{mrem} / \mathrm{yr}$ contaminant boundary and the average deviation are presented for each fractile of each activity in the tables to follow.

The maximum distance and the corresponding time at which the maximum occurred (rounded to the nearest 5 years) are calculated from the output of the transport model simulations. Each set of simulations consists of 200 realizations for each of the two radionuclides, tritium and carbon-14. For each realization, concentration values are saved at each of the 60 observation locations (spaced $0.5 \mathrm{~km}$ apart) and every five years up to year 1,000. Each concentration is converted into a radiation dose ( $\mathrm{mrem} / \mathrm{yr}$ ) using a drinking water ingestion scenario. The dose from the two radionuclides is then summed to produce the composite dose for each realization. At each of the 12,060 points in space and time (60 locations $\times 201$ time intervals), the dose is sorted across the 200 realizations and stored from smallest to largest. The sorted data are then partitioned to examine the model results at various levels to assess the uncertainty in the $4 \mathrm{mrem} / \mathrm{yr}$ contaminant boundary location. When the sorted realizations are partitioned in the middle such that half the dose values are greater and half values are smaller, it is called the 50 percent fractile. This fractile corresponds to the median dose based on the 200 realizations. Similarly, the 95 percent fractile is partitioned such that 95 percent of the realizations produced a smaller dose at each location and time. Each partition produces a set of 12,060 values in distance and time from which the maximum extent of the $4 \mathrm{mrem} / \mathrm{yr}$ boundary, and the corresponding time are determined.

A second analysis of the data examines the uncertainty in the contaminant boundary location via the average deviation. For this analysis, the distance to the $4 \mathrm{mrem} / \mathrm{yr}$ contaminant boundary is 
calculated from the composite dose for each realization. The average deviation is calculated as the average over the two hundred realizations of the absolute value of the maximum distance to the $4 \mathrm{mrem} / \mathrm{yr}$ boundary minus the average maximum distance. This measure is similar to the standard deviation, but is more robust because it is less susceptible to bias from outliers.

Tables G-6 through G-19 in Section G.3.2.4 summarize the model results for each of the individual activities. The distance to the contaminant boundary, at the $50,65,75,85$, and 95 percent fractiles are presented along with the average deviation. For activities other than $5,6 \mathrm{p}$, and 13 , four indicator values representing $5,50,95$, and 99 percent values of the prior distribution were presented. Activities 5,6p, and 13 have an additional indicator value at 1 , percent of the prior distribution.

\section{G.3.2.2 Activity Subgroups}

An intermediate step in the creation of parameter groups was the establishment of subgroups of activities that addressed the same parameter. As many as 6 individual activities were combined into one subgroup. For each subgroup, only one parameter differed from the prior distributions, as was the case for the individual activities. The results are presented in Tables G-20 through G-31 in Section G.3.2.4. The presentation of the results follows the same format as for the individual activities.

\section{G.3.2.3 Activity Groups}

The parameter groups, as outlined previously, are combinations of activities that addressed one or more of the parameters of interest. If multiple activities for the same parameter were defined, the appropriate subgroup was used in the group. If only one activity was defined for a parameter, then the individual activity was used. Two of the groups, G2 and G3, addressed only the flux multiplier. Those same groups of activities had been previously defined as subgroups S8 and S9, respectively. The reader will note that the results for $\mathrm{G} 2$ and $\mathrm{S} 8$ are identical, as are G3 and S9.

For the other groups, multiple parameters were included. For example, group Gl included activities or subgroups that addressed the diffusion transfer coefficient, source term concentration, and flux multiplier. Each of the activities or subgroups had 4 indicator values for the parameter probability distribution. To account for all possible combinations of indicator values among the 3 parameters, a total of $4 \times 4 \times 4=64$ combinations were simulated. All possible combinations of parameters were simulated for each of the groups, except for group 9. Group 9 was the only group to address all 4 parameters, which produced 320 possible 
combinations $(4 \times 4 \times 4 \times 5=320)$. This number of combinations exceeded the computational resources available and prevented the simulation of group 9.

The results for all groups except group 9 are presented in Tables G-32 through G-41 in Section G.3.2.4. The format for presentation of the results of the groups differs slightly from the activities and subgroups. The results are presented in a hierarchical manner on the basis of the indicator value of each of the parameters addressed.

\section{G.3.2.4 Final Transport Simulation Tables}

This section includes the tables summarizing the results of the final transport simulations.

Tables G-6 through G-19 summarize the results of the individual characterization activities.

Tables G-20 through G-31 summarize the results of the activity subgroups, and Tables G-32 through $\mathrm{G}-41$ those of the activity groups. 
Table G-6

Transport Simulation Results for Individual Characterization Activity 1 Location of Contaminant Boundarya for Various Fractiles ${ }^{b}$

\begin{tabular}{|c|c|c|c|c|c|c|c|c|c|c|c|}
\hline \multirow{3}{*}{$\begin{array}{l}\text { Fractile } \\
\text { Value }\end{array}$} & \multicolumn{2}{|c|}{$50 \%$} & \multicolumn{2}{|c|}{$65 \%$} & \multicolumn{2}{|c|}{$75 \%$} & \multicolumn{2}{|c|}{$85 \%$} & \multicolumn{2}{|c|}{$95 \%$} & \multirow{3}{*}{$\begin{array}{c}\text { Average } \\
\text { Deviation } \\
\text { km }\end{array}$} \\
\hline & Distance & Time & Distance & Time & Distance & Time & Distance & Time & Distance & Time & \\
\hline & $\mathrm{km}$ & $y r$ & $\mathrm{~km}$ & $y r$ & $\mathrm{~km}$ & $y r$ & km & $y r$ & km & yr & \\
\hline $5 \%$ & 1.50 & 0.00 & 1.50 & 0.00 & 1.88 & 50.00 & 1.99 & 55.00 & 2.86 & 45.00 & 0.39 \\
\hline $50 \%$ & 4.72 & 30.00 & 6.54 & 45.00 & 9.01 & 80.00 & 13.61 & 60.00 & 24.53 & 65.00 & 5.86 \\
\hline $95 \%$ & 9.37 & 35.00 & 14.32 & 40.00 & 21.67 & 65.00 & 30.50 & 35.00 & 30.50 & 20.00 & 9.06 \\
\hline $99 \%$ & 30.37 & 25.00 & 30.50 & 10.00 & 30.50 & 10.00 & 30.50 & 5.00 & 30.50 & 5.00 & 6.39 \\
\hline
\end{tabular}

Table G-7

Transport Simulation Results for Individual Characterization Activity 2 Location of Contaminant Boundary ${ }^{a}$ for Various Fractiles ${ }^{b}$

\begin{tabular}{|c|c|c|c|c|c|c|c|c|c|c|c|}
\hline \multirow{3}{*}{$\begin{array}{c}\text { Fractile } \\
\text { Value }\end{array}$} & \multicolumn{2}{|c|}{$50 \%$} & \multicolumn{2}{|c|}{$65 \%$} & \multicolumn{2}{|c|}{$75 \%$} & \multicolumn{2}{|c|}{$85 \%$} & \multicolumn{2}{|c|}{$95 \%$} & \multirow{3}{*}{$\begin{array}{c}\text { Average } \\
\text { Deviation } \\
\text { km }\end{array}$} \\
\hline & Distance & Time & Distance & Time & Distance & Time & Distance & Time & Distance & Time & \\
\hline & $\mathbf{k m}$ & $y r$ & km & yr & km & yr & km & $y r$ & km & yr & \\
\hline $5 \%$ & 1.50 & 0.00 & 1.91 & 25.00 & 2.12 & 50.00 & 2.50 & 55.00 & 3.65 & 45.00 & 0.63 \\
\hline $50 \%$ & 4.46 & 30.00 & 6.15 & 50.00 & 8.53 & 55.00 & 12.88 & 55.00 & 22.15 & 65.00 & 5.58 \\
\hline $95 \%$ & 12.24 & 30.00 & 18.45 & 55.00 & 30.50 & 60.00 & 30.50 & 20.00 & 30.50 & 10.00 & 9.08 \\
\hline $99 \%$ & 30.50 & 25.00 & 30.50 & 10.00 & 30.50 & 5.00 & 30.50 & 5.00 & 30.50 & 5.00 & 6.30 \\
\hline
\end{tabular}

Notes

1) 200 realizations running on a Pentium II Computer - 5 parameters

2) Percentage of outcomes with distances smaller than the given value

- Defined as a dose of 4 millirem per year

- These fractiles correspond to the confidence levels referred to in the FFACO (1996) 
Table G-8

Transport Simulation Results for Individual Characterization Activity 3 Location of Contaminant Boundary ${ }^{a}$ for Various Fractiles ${ }^{b}$

\begin{tabular}{|c|c|c|c|c|c|c|c|c|c|c|c|}
\hline \multirow{3}{*}{$\begin{array}{c}\text { Fractile } \\
\text { Value }\end{array}$} & \multicolumn{2}{|c|}{$50 \%$} & \multicolumn{2}{|c|}{$65 \%$} & \multicolumn{2}{|c|}{$75 \%$} & \multicolumn{2}{|c|}{$85 \%$} & \multicolumn{2}{|c|}{$95 \%$} & \multirow{3}{*}{$\begin{array}{c}\text { Average } \\
\text { Deviation } \\
\text { km }\end{array}$} \\
\hline & Distance & Time & Distance & Time & Distance & Time & Distance & Time & Distance & Time & \\
\hline & km & yr & km & yr & km & yr & km & yr & km & yr & \\
\hline $5 \%$ & 1.50 & 0.00 & 1.50 & 0.00 & 1.50 & 0.00 & 1.92 & 25.00 & 2.47 & 55.00 & 0.29 \\
\hline $50 \%$ & 3.08 & 35.00 & 4.13 & 40.00 & 5.35 & 45.00 & 7.79 & 55.00 & 12.02 & 55.00 & 3.25 \\
\hline $95 \%$ & 21.55 & 45.00 & 30.50 & 25.00 & 30.50 & 10.00 & 30.50 & 10.00 & 30.50 & 5.00 & 7.53 \\
\hline $99 \%$ & 30.50 & 20.00 & 30.50 & 10.00 & 30.50 & 5.00 & 30.50 & 5.00 & 30.50 & 5.00 & 5.71 \\
\hline
\end{tabular}

Table G-9

Transport Simulation Results for Individual Characterization Activity 4 Location of Contaminant Boundary ${ }^{a}$ for Various Fractiles ${ }^{\mathrm{b}}$

\begin{tabular}{|c|c|c|c|c|c|c|c|c|c|c|c|}
\hline \multirow{3}{*}{$\begin{array}{c}\text { Fractile } \\
\text { Value }\end{array}$} & \multicolumn{2}{|c|}{$50 \%$} & \multicolumn{2}{|c|}{$65 \%$} & \multicolumn{2}{|c|}{$75 \%$} & \multicolumn{2}{|c|}{$85 \%$} & \multicolumn{2}{|c|}{$95 \%$} & \multirow{3}{*}{$\begin{array}{c}\text { Average } \\
\text { Deviation } \\
\text { km }\end{array}$} \\
\hline & Distance & Time & Distance & Time & Distance & Time & Distance & Time & Distance & Time & \\
\hline & km & yr & km & yr & km & yr & km & yr & km & $y r$ & \\
\hline $5 \%$ & 3.32 & 25.00 & 4.40 & 40.00 & 5.90 & 70.00 & 9.49 & 50.00 & 15.34 & 65.00 & 4.09 \\
\hline $50 \%$ & 3.82 & 30.00 & 5.55 & 65.00 & 7.71 & 60.00 & 10.81 & 60.00 & 15.59 & 65.00 & 4.54 \\
\hline $95 \%$ & 3.87 & 30.00 & 5.67 & 65.00 & 7.75 & 60.00 & 11.00 & 60.00 & 15.87 & 70.00 & 4.74 \\
\hline $99 \%$ & 3.90 & 35.00 & 5.74 & 65.00 & 7.80 & 60.00 & 11.15 & 60.00 & 16.19 & 70.00 & 4.93 \\
\hline
\end{tabular}

Notes

1) 200 realizations running on a Pentium II Computer - 5 parameters

2) Percentage of outcomes with distances smaller than the given value

- Defined as a dose of 4 millirem per year

- These fractiles correspond to the confidence levels referred to in the FFACO (1996) 
Table G-10

Transport Simulation Results for Individual Characterization Activity 5 Location of Contaminant Boundary ${ }^{a}$ for Various Fractiles ${ }^{b}$

\begin{tabular}{|c|c|c|c|c|c|c|c|c|c|c|c|}
\hline \multirow{3}{*}{$\begin{array}{c}\text { Fractile } \\
\text { Value }\end{array}$} & \multicolumn{2}{|c|}{$50 \%$} & \multicolumn{2}{|c|}{$65 \%$} & \multicolumn{2}{|c|}{$75 \%$} & \multicolumn{2}{|c|}{$85 \%$} & \multicolumn{2}{|c|}{$95 \%$} & \multirow{3}{*}{$\begin{array}{c}\text { Average } \\
\text { Deviation } \\
\text { km }\end{array}$} \\
\hline & Distance & Time & Distance & Time & Distance & Time & Distance & Time & Distance & Time & \\
\hline & km & yr & km & yr & km & $y r$ & $\mathrm{~km}$ & yr & km & yr & \\
\hline $5 \%$ & 4.41 & 45.00 & 6.23 & 55.00 & 8.52 & 75.00 & 12.99 & 75.00 & 21.94 & 95.00 & 5.64 \\
\hline $50 \%$ & 3.58 & 30.00 & 4.81 & 30.00 & 6.57 & 55.00 & 9.75 & 50.00 & 15.29 & 60.00 & 4.21 \\
\hline $95 \%$ & 2.00 & 995.00 & 2.70 & 1000.00 & 3.51 & 1000.00 & 4.74 & 1000.00 & 8.26 & 1000.00 & 2.15 \\
\hline $99 \%$ & 1.94 & 985.00 & 2.65 & 1000.00 & 3.44 & 970.00 & 4.78 & 990.00 & 8.39 & 965.00 & 2.18 \\
\hline
\end{tabular}

$\stackrel{0}{\omega}$

Table G-11

Transport Simulation Results for Individual Characterization Activity 6a Location of Contaminant Boundary ${ }^{a}$ for Various Fractiles ${ }^{b}$

\begin{tabular}{|c|c|c|c|c|c|c|c|c|c|c|c|}
\hline \multirow{3}{*}{$\begin{array}{l}\text { Fractile } \\
\text { Value }\end{array}$} & \multicolumn{2}{|c|}{$50 \%$} & \multicolumn{2}{|c|}{$65 \%$} & \multicolumn{2}{|c|}{$75 \%$} & \multicolumn{2}{|c|}{$85 \%$} & \multicolumn{2}{|c|}{$95 \%$} & \multirow{3}{*}{$\begin{array}{c}\text { Average } \\
\text { Deviation } \\
\text { km }\end{array}$} \\
\hline & Distance & Time & Distance & Time & Distance & Time & Distance & Time & Distance & Time & \\
\hline & $\mathbf{k m}$ & $y r$ & km & yr & $\mathrm{km}$ & $y r$ & km & $y r$ & km & $y r$ & \\
\hline $5 \%$ & 4.49 & 40.00 & 6.38 & 55.00 & 8.66 & 65.00 & 13.32 & 75.00 & 22.46 & 75.00 & 5.77 \\
\hline $50 \%$ & 3.45 & 30.00 & 4.48 & 30.00 & 6.23 & 50.00 & 8.97 & 45.00 & 14.43 & 60.00 & 3.95 \\
\hline $95 \%$ & 2.00 & 1000.00 & 2.69 & 995.00 & 3.51 & 1000.00 & 4.72 & 1000.00 & 8.55 & 960.00 & 2.14 \\
\hline $99 \%$ & 1.94 & 1000.00 & 2.65 & 1000.00 & 3.44 & 970.00 & 4.78 & 990.00 & 8.39 & 1000.00 & 2.18 \\
\hline
\end{tabular}

Notes

1) 200 realizations running on a Pentium II Computer - 5 parameters

2) Percentage of outcomes with distances smaller than the given value

- Defined as a dose of 4 millirem per year

- These fractiles correspond to the confidence levels referred to in the FFACO (1996) 
Table G-12

Transport Simulation Results for Individual Characterization Activity $6 p$ Location of Contaminant Boundary ${ }^{a}$ for Various Fractiles ${ }^{b}$

\begin{tabular}{|c|c|c|c|c|c|c|c|c|c|c|c|}
\hline \multirow{3}{*}{$\begin{array}{l}\text { Fractile } \\
\text { Value }\end{array}$} & \multicolumn{2}{|c|}{$50 \%$} & \multicolumn{2}{|c|}{$65 \%$} & \multicolumn{2}{|c|}{$75 \%$} & \multicolumn{2}{|c|}{$85 \%$} & \multicolumn{2}{|c|}{$95 \%$} & \multirow{3}{*}{$\begin{array}{c}\text { Average } \\
\text { Deviation } \\
\text { km }\end{array}$} \\
\hline & Distance & Time & Distance & Time & Distance & Time & Distance & Time & Distance & Time & \\
\hline & km & $y r$ & km & $y r$ & km & yr & km & $y r$ & km & $y r$ & \\
\hline $1 \%$ & 3.87 & 20.00 & 6.05 & 35.00 & 9.84 & 40.00 & 13.09 & 30.00 & 30.50 & 65.00 & 5.99 \\
\hline $5 \%$ & 3.67 & 30.00 & 5.03 & 35.00 & 7.29 & 70.00 & 10.15 & 60.00 & 17.20 & 110.00 & 4.49 \\
\hline $50 \%$ & 3.45 & 40.00 & 4.72 & 35.00 & 6.40 & 60.00 & 8.89 & 65.00 & 14.39 & 70.00 & 3.89 \\
\hline $95 \%$ & 1.99 & 1000.00 & 2.67 & 1000.00 & 3.39 & 995.00 & 4.19 & 1000.00 & 7.61 & 745.00 & 1.96 \\
\hline $39 \%$ & 1.82 & 345.00 & 2.33 & 835.00 & 2.38 & 045.00 & 3.86 & 1000.00 & 6.87 & 955.00 & 1.82 \\
\hline
\end{tabular}

Table G-13

Transport Simulation Results for Individual Characterization Activity 7 Location of Contaminant Boundary ${ }^{a}$ for Various Fractiles ${ }^{b}$

\begin{tabular}{|c|c|c|c|c|c|c|c|c|c|c|c|}
\hline \multirow{3}{*}{$\begin{array}{l}\text { Fractile } \\
\text { Value }\end{array}$} & \multicolumn{2}{|c|}{$50 \%$} & \multicolumn{2}{|c|}{$65 \%$} & \multicolumn{2}{|c|}{$75 \%$} & \multicolumn{2}{|c|}{$85 \%$} & \multicolumn{2}{|c|}{$95 \%$} & \multirow{3}{*}{$\begin{array}{c}\text { Average } \\
\text { Deviation } \\
\text { km }\end{array}$} \\
\hline & Distance & Time & Distance & Time & Distance & Time & Distance & Time & Distance & Time & \\
\hline & km & $y r$ & km & yr & km & $y r$ & km & $y r$ & km & $y r$ & \\
\hline $5 \%$ & 1.50 & 0.00 & 1.58 & 30.00 & 1.97 & 40.00 & 2.34 & 50.00 & 3.24 & 45.00 & 0.50 \\
\hline $50 \%$ & 3.15 & 35.00 & 4.08 & 45.00 & 5.36 & 45.00 & 7.64 & 65.00 & 12.30 & 50.00 & 3.11 \\
\hline $95 \%$ & 23.78 & 35.00 & 30.50 & 15.00 & 30.50 & 10.00 & 30.50 & 5.00 & 30.50 & 5.00 & 6.98 \\
\hline $99 \%$ & 30.50 & 20.00 & 30.50 & 10.00 & 30.50 & 5.00 & 30.50 & 5.00 & 30.50 & 5.00 & 5.62 \\
\hline
\end{tabular}

Notes

1) 200 realizations running on a Pentium II Computer -5 parameters

2) Percentage of outcomes with distances smaller than the given value

- Defined as a dose of 4 millirem per year

- These fractiles correspond to the confidence levels referred to in the FFACO (1996) 
Table G-14

Transport Simulation Results for Individual Characterization Activity 8 Location of Contaminant Boundary ${ }^{a}$ for Various Fractiles ${ }^{b}$

\begin{tabular}{|c|c|c|c|c|c|c|c|c|c|c|c|}
\hline \multirow{3}{*}{$\begin{array}{l}\text { Fractile } \\
\text { Value }\end{array}$} & \multicolumn{2}{|c|}{$50 \%$} & \multicolumn{2}{|c|}{$65 \%$} & \multicolumn{2}{|c|}{$75 \%$} & \multicolumn{2}{|c|}{$85 \%$} & \multicolumn{2}{|c|}{$95 \%$} & \multirow{3}{*}{$\begin{array}{c}\text { Average } \\
\text { Deviation } \\
\text { km }\end{array}$} \\
\hline & Distance & Time & Distance & Time & Distance & Time & Distance & Time & Distance & Time & \\
\hline & km & yr & $\mathbf{k m}$ & yr & km & yr & km & $y r$ & km & yr & \\
\hline $5 \%$ & 1.50 & 0.00 & 1.50 & 35.00 & 1.95 & 40.00 & 2.23 & 55.00 & 3.03 & 50.00 & 0.46 \\
\hline $50 \%$ & 4.37 & 30.00 & 5.99 & 40.00 & 8.39 & 55.00 & 12.60 & 55.00 & 21.42 & 60.00 & 5.51 \\
\hline $95 \%$ & 9.40 & 40.00 & 22.00 & 65.00 & 14.14 & 45.00 & 30.50 & 40.00 & 30.50 & 20.00 & 8.96 \\
\hline $99 \%$ & 27.00 & 35.00 & 30.50 & 15.00 & 30.50 & 10.00 & 30.50 & 5.00 & 30.50 & 5.00 & 6.60 \\
\hline
\end{tabular}

Table G-15

Transport Simulation Results for Individual Characterization Activity 9 Location of Contaminant Boundary ${ }^{a}$ for Various Fractiles ${ }^{b}$

\begin{tabular}{|c|c|c|c|c|c|c|c|c|c|c|c|}
\hline \multirow{3}{*}{$\begin{array}{l}\text { Fractile } \\
\text { Value }\end{array}$} & \multicolumn{2}{|c|}{$50 \%$} & \multicolumn{2}{|c|}{$65 \%$} & \multicolumn{2}{|c|}{$75 \%$} & \multicolumn{2}{|c|}{$85 \%$} & \multicolumn{2}{|c|}{$95 \%$} & \multirow{3}{*}{$\begin{array}{c}\text { Average } \\
\text { Deviation } \\
\text { km }\end{array}$} \\
\hline & Distance & Time & Distance & Time & Distance & Time & Distance & Time & Distance & Time & \\
\hline & km & yr & km & yr & km & yr & km & yr & km & yr & \\
\hline $5 \%$ & 1.50 & 0.00 & 1.50 & 0.00 & 1.93 & 40.00 & 2.14 & 55.00 & 2.97 & 50.00 & 0.44 \\
\hline $50 \%$ & 3.38 & 35.00 & 4.58 & 40.00 & 6.18 & 60.00 & 9.10 & 55.00 & 14.25 & 65.00 & 4.01 \\
\hline $95 \%$ & 14.72 & 30.00 & 22.19 & 40.00 & 30.50 & 30.00 & 30.50 & 15.00 & 30.50 & 10.00 & 8.70 \\
\hline $99 \%$ & 30.21 & 25.00 & 30.50 & 10.00 & 30.50 & 10.00 & 30.50 & 5.00 & 30.50 & 5.00 & 6.36 \\
\hline
\end{tabular}

Notes

1) 200 realizations running on a Pentium II Computer - 5 parameters

2) Percentage of outcomes with distances smaller than the given value

- Defined as a dose of 4 millirem per year

- These fractiles correspond to the confidence levels referred to in the FFACO (1996) 
Table G-16

Transport Simulation Results for Individual Characterization Activity 10 Location of Contaminant Boundary ${ }^{a}$ for Various Fractiles ${ }^{b}$

\begin{tabular}{|c|c|c|c|c|c|c|c|c|c|c|c|}
\hline \multirow{3}{*}{$\begin{array}{c}\text { Fractile } \\
\text { Value }\end{array}$} & \multicolumn{2}{|c|}{$50 \%$} & \multicolumn{2}{|c|}{$65 \%$} & \multicolumn{2}{|c|}{$75 \%$} & \multicolumn{2}{|c|}{$85 \%$} & \multicolumn{2}{|c|}{$95 \%$} & \multirow{3}{*}{$\begin{array}{c}\text { Average } \\
\text { Deviation } \\
\text { km }\end{array}$} \\
\hline & Distance & Time & Distance & Time & Distance & Time & Distance & Time & Distance & Time & \\
\hline & $\mathbf{k m}$ & yr & $\mathbf{k m}$ & yr & km & $y r$ & km & yr & km & yr & \\
\hline $5 \%$ & 4.13 & 45.00 & 5.76 & 50.00 & 7.92 & 65.00 & 11.87 & 70.00 & 19.73 & 65.00 & 5.17 \\
\hline $50 \%$ & 3.34 & 25.00 & 4.38 & 35.00 & 6.03 & 65.00 & 8.54 & 45.00 & 14.03 & 100.00 & 3.84 \\
\hline $95 \%$ & 2.36 & 30.00 & 3.26 & 30.00 & 3.81 & 40.00 & 4.74 & 40.00 & 8.85 & 50.00 & 2.36 \\
\hline $99 \%$ & 1.97 & 1000.00 & 2.69 & 980.00 & 3.47 & 925.00 & 4.78 & 995.00 & 8.42 & 965.00 & 2.16 \\
\hline
\end{tabular}

Table G-17

Transport Simulation Results for Individual Characterization Activity 11 Location of Contaminant Boundary ${ }^{a}$ for Various Fractiles ${ }^{b}$

\begin{tabular}{|c|c|c|c|c|c|c|c|c|c|c|c|}
\hline \multirow{3}{*}{$\begin{array}{l}\text { Fractile } \\
\text { Value }\end{array}$} & \multicolumn{2}{|c|}{$\mathbf{5 0} \%$} & \multicolumn{2}{|c|}{$65 \%$} & \multicolumn{2}{|c|}{$75 \%$} & \multicolumn{2}{|c|}{$85 \%$} & \multicolumn{2}{|c|}{$95 \%$} & \multirow{3}{*}{$\begin{array}{c}\text { Average } \\
\text { Deviation } \\
\text { km }\end{array}$} \\
\hline & Distance & Time & Distance & Time & Distance & Time & Distance & Time & Distance & Time & \\
\hline & km & yr & km & yr & km & $y r$ & km & $y r$ & km & yr & \\
\hline $5 \%$ & 3.30 & 25.00 & 4.37 & 40.00 & 5.89 & 70.00 & 9.43 & 50.00 & 15.31 & 65.00 & 4.06 \\
\hline $50 \%$ & 3.82 & 30.00 & 5.55 & 65.00 & 7.70 & 60.00 & 10.80 & 60.00 & 15.58 & 65.00 & 4.54 \\
\hline $95 \%$ & 3.86 & 30.00 & 5.67 & 65.00 & 7.75 & 60.00 & 10.99 & 60.00 & 15.87 & 70.00 & 4.74 \\
\hline $99 \%$ & 3.88 & 30.00 & 5.65 & 65.00 & 7.48 & 60.00 & 11.06 & 60.00 & 16.12 & 70.00 & 4.85 \\
\hline
\end{tabular}

Notes

1) 200 realizations running on a Pentium II Computer - 5 parameters

2) Percentage of outcomes with distances smaller than the given value

- Defined as a dose of 4 millirem per year

- These fractiles correspond to the confidence levels referred to in the FFACO (1996) 


\section{Table G-18}

Transport Simulation Results for Individual Characterization Activity 12 Location of Contaminant Boundary ${ }^{a}$ for Various Fractiles ${ }^{b}$

\begin{tabular}{|c|c|c|c|c|c|c|c|c|c|c|c|}
\hline \multirow{3}{*}{$\begin{array}{l}\text { Fractile } \\
\text { Value }\end{array}$} & \multicolumn{2}{|c|}{$50 \%$} & \multicolumn{2}{|c|}{$65 \%$} & \multicolumn{2}{|c|}{$75 \%$} & \multicolumn{2}{|c|}{$85 \%$} & \multicolumn{2}{|c|}{$95 \%$} & \multirow{3}{*}{$\begin{array}{c}\text { Average } \\
\text { Deviation } \\
\text { km }\end{array}$} \\
\hline & Distance & Time & Distance & Time & Distance & Time & Distance & Time & Distance & Time & \\
\hline & $\mathbf{k m}$ & $y r$ & $\mathrm{~km}$ & $y r$ & km & yr & km & yr & km & yr & \\
\hline $5 \%$ & 1.50 & 0.00 & 1.78 & 35.00 & 1.99 & 40.00 & 2.42 & 55.00 & 3.40 & 50.00 & 0.55 \\
\hline $50 \%$ & 3.29 & 35.00 & 4.33 & 50.00 & 5.72 & 45.00 & 8.34 & 55.00 & 12.92 & 60.00 & 3.49 \\
\hline $95 \%$ & 20.91 & 35.00 & 30.50 & 25.00 & 30.50 & 15.00 & 30.50 & 10.00 & 30.50 & 5.00 & 7.86 \\
\hline $99 \%$ & 24.60 & 35.00 & 30.50 & 15.00 & 30.50 & 10.00 & 30.50 & 5.00 & 30.50 & 5.00 & 6.83 \\
\hline
\end{tabular}

$\frac{a}{1}$

Table G-19

Transport Simulation Results for Individual Characterization Activity 13 Location of Contaminant Boundary ${ }^{a}$ for Various Fractiles ${ }^{b}$

\begin{tabular}{|c|c|c|c|c|c|c|c|c|c|c|c|}
\hline \multirow{3}{*}{$\begin{array}{c}\text { Fractile } \\
\text { Value }\end{array}$} & \multicolumn{2}{|c|}{$50 \%$} & \multicolumn{2}{|c|}{$65 \%$} & \multicolumn{2}{|c|}{$75 \%$} & \multicolumn{2}{|c|}{$85 \%$} & \multicolumn{2}{|c|}{$95 \%$} & \multirow{3}{*}{$\begin{array}{c}\text { Average } \\
\text { Deviation } \\
\text { km }\end{array}$} \\
\hline & Distance & Time & Distance & Time & Distance & Time & Distance & Time & Distance & Time & \\
\hline & km & yr & km & yr & km & yr & km & $y r$ & $\mathbf{k m}$ & $y r$ & \\
\hline $1 \%$ & 3.74 & 25.00 & 5.31 & 30.00 & 8.05 & 60.00 & 11.18 & 60.00 & 21.24 & 100.00 & 4.91 \\
\hline $5 \%$ & 3.42 & 35.00 & 4.61 & 50.00 & 6.18 & 60.00 & 8.55 & 70.00 & 13.91 & 70.00 & 3.73 \\
\hline $50 \%$ & 3.12 & 45.00 & 4.20 & 55.00 & 4.96 & 70.00 & 6.73 & 75.00 & 10.76 & 100.00 & 2.91 \\
\hline $95 \%$ & 2.21 & 65.00 & 2.83 & 75.00 & 3.61 & 1000.00 & 4.39 & 1000.00 & 8.06 & 700.00 & 2.10 \\
\hline $99 \%$ & 2.16 & 65.00 & 2.75 & 1000.00 & 3.55 & 995.00 & 4.37 & 1000.00 & 8.03 & 710.00 & 2.12 \\
\hline
\end{tabular}

Notes

1) 200 realizations running on a Pentium II Computer - 5 parameters

2) Percentage of outcomes with distances smaller than the given value

"Defined as a dose of 4 millirem per year

- These fractiles correspond to the confidence levels referred to in the FFACO (1996) 
Table G-20

Transport Simulation Results for Characterization Activity Subgroup 1 Location of Contaminant Boundary ${ }^{a}$ for Various Fractiles ${ }^{b}$

\begin{tabular}{|c|c|c|c|c|c|c|c|c|c|c|c|}
\hline \multirow{3}{*}{$\begin{array}{c}\text { Fractile } \\
\text { Value }\end{array}$} & \multicolumn{2}{|c|}{$50 \%$} & \multicolumn{2}{|c|}{$65 \%$} & \multicolumn{2}{|c|}{$75 \%$} & \multicolumn{2}{|c|}{$85 \%$} & \multicolumn{2}{|c|}{$95 \%$} & \multirow{3}{*}{$\begin{array}{c}\text { Average } \\
\text { Deviation } \\
\text { km }\end{array}$} \\
\hline & Distance & Time & Distance & Time & Distance & Time & Distance & Time & Distance & Time & \\
\hline & km & yr & km & yr & km & $y r$ & km & yr & km & yr & \\
\hline $5 \%$ & 3.23 & 25.00 & 4.34 & 45.00 & 5.87 & 70.00 & 9.38 & 50.00 & 15.27 & 65.00 & 4.03 \\
\hline $50 \%$ & 3.81 & 30.00 & 5.53 & 65.00 & 7.55 & 60.00 & 10.74 & 60.00 & 15.53 & 70.00 & 4.53 \\
\hline $95 \%$ & 3.86 & 30.00 & 5.67 & 65.00 & 7.75 & 60.00 & 10.99 & 60.00 & 15.87 & 70.00 & 4.74 \\
\hline $99 \%$ & 3.91 & 35.00 & 5.78 & 65.00 & 7.96 & 65.00 & 11.21 & 60.00 & 16.14 & 65.00 & 4.95 \\
\hline
\end{tabular}

Table G-21

Transport Simulation Results for Characterization Activity Subgroup 2 Location of Contaminant Boundary for Various Fractiles ${ }^{b}$

\begin{tabular}{|c|c|c|c|c|c|c|c|c|c|c|c|}
\hline \multirow{3}{*}{$\begin{array}{c}\text { Fractile } \\
\text { Value }\end{array}$} & \multicolumn{2}{|c|}{$50 \%$} & \multicolumn{2}{|c|}{$65 \%$} & \multicolumn{2}{|c|}{$75 \%$} & \multicolumn{2}{|c|}{$85 \%$} & \multicolumn{2}{|c|}{$95 \%$} & \multirow{3}{*}{$\begin{array}{c}\text { Average } \\
\text { Deviation } \\
\text { km }\end{array}$} \\
\hline & Distance & - Time & Distance & Time & Distance & Time & Distance & Time & Distance & Time & \\
\hline & km & yr & km & yr & km & $y \mathbf{r}$ & km & $y r$ & km & $y r$ & \\
\hline $1 \%$ & 3.87 & 20.00 & 6.12 & 30.00 & 9.98 & 40.00 & 13.28 & 30.00 & 30.50 & 60.00 & 6.08 \\
\hline $5 \%$ & 3.81 & 20.00 & 5.48 & 25.00 & 8.75 & 55.00 & 12.02 & 50.00 & 24.29 & 90.00 & 5.37 \\
\hline $50 \%$ & 3.43 & 35.00 & 4.67 & 35.00 & 6.22 & 60.00 & 8.60 & 70.00 & 13.98 & 70.00 & 3.74 \\
\hline $95 \%$ & 1.96 & 1000.00 & 2.59 & 1000.00 & 3.38 & 1000.00 & 4.15 & 1000.00 & 7.34 & 1000.00 & 1.94 \\
\hline $99 \%$ & 1.85 & 945.00 & 2.38 & 940.00 & 3.10 & 975.00 & 3.93 & 1000.00 & 7.16 & 1000.00 & 1.81 \\
\hline
\end{tabular}

Notes

1) 200 realizations running on a Pentium II Computer - 5 parameters

2) Percentage of outcomes with distances smaller than the given value

- Defined as a dose of 4 millirem per year

b These fractiles correspond to the confidence levels referred to in the FFACO (1996) 
Table G-22

Transport Simulation Results for Characterization Activity Subgroup 3 Location of Contaminant Boundarya for Various Fractiles ${ }^{b}$

\begin{tabular}{|c|c|c|c|c|c|c|c|c|c|c|c|}
\hline \multirow{3}{*}{$\begin{array}{c}\text { Fractile } \\
\text { Value }\end{array}$} & \multicolumn{2}{|c|}{$50 \%$} & \multicolumn{2}{|c|}{$65 \%$} & \multicolumn{2}{|c|}{$75 \%$} & \multicolumn{2}{|c|}{$85 \%$} & \multicolumn{2}{|c|}{$95 \%$} & \multirow{3}{*}{$\begin{array}{c}\text { Average } \\
\text { Deviation } \\
\text { km }\end{array}$} \\
\hline & Distance & Time & Distance & Time & Distance & Time & Distance & Time & Distance & Time & \\
\hline & km & $y r$ & $\mathbf{k m}$ & yr & km & $y r$ & km & yr & $\mathbf{k m}$ & yr & \\
\hline $5 \%$ & 4.49 & 40.00 & 6.38 & 55.00 & 8.67 & 65.00 & 13.32 & 75.00 & 22.47 & 70.00 & 5.78 \\
\hline $50 \%$ & 3.45 & 30.00 & 4.48 & 45.00 & 6.20 & 50.00 & 8.91 & 45.00 & 14.42 & 60.00 & 3.92 \\
\hline $95 \%$ & 2.00 & 1000.00 & 2.69 & 1000.00 & 3.51 & 1000.00 & 4.72 & 1000.00 & 8.50 & 1000.00 & 2.16 \\
\hline $99 \%$ & 1.94 & 985.00 & 2.65 & 1000.00 & 3.44 & 970.00 & 4.78 & 990.00 & 8.40 & 965.00 & 2.18 \\
\hline
\end{tabular}

Table G-23

Transport Simulation Results for Characterization Activity Subgroup 4 Location of Contaminant Boundary ${ }^{\mathrm{a}}$ for Various Fractiles ${ }^{\mathrm{b}}$

\begin{tabular}{|c|c|c|c|c|c|c|c|c|c|c|c|}
\hline \multirow{3}{*}{$\begin{array}{c}\text { Fractile } \\
\text { Value }\end{array}$} & \multicolumn{2}{|c|}{$50 \%$} & \multicolumn{2}{|c|}{$65 \%$} & \multicolumn{2}{|c|}{$75 \%$} & \multicolumn{2}{|c|}{$85 \%$} & \multicolumn{2}{|c|}{$95 \%$} & \multirow{3}{*}{$\begin{array}{c}\text { Average } \\
\text { Deviation } \\
\text { km }\end{array}$} \\
\hline & Distance & Time & Distance & Time & Distance & Time & Distance & Time & Distance & Time & \\
\hline & km & yr & $\mathbf{k m}$ & $y r$ & km & yr & km & yr & km & yr & \\
\hline $5 \%$ & 4.81 & 45.00 & 6.75 & 45.00 & 9.23 & 65.00 & 14.01 & 80.00 & 23.75 & 105.00 & 6.05 \\
\hline $50 \%$ & 3.65 & 30.00 & 4.87 & 35.00 & 6.63 & 55.00 & 9.83 & 50.00 & 15.62 & 65.00 & 4.22 \\
\hline $95 \%$ & 1.99 & 1000.00 & 2.70 & 1000.00 & 3.45 & 915.00 & 4.78 & 1000.00 & 8.49 & $965: 00$ & 2.16 \\
\hline $99 \%$ & 1.94 & 980.00 & 2.65 & 1000.00 & 3.44 & 970.00 & 4.78 & 990.00 & 8.39 & 1000.00 & 2.18 \\
\hline
\end{tabular}

Notes

1) 200 realizations running on a Pentium II Computer - 5 parameters

2) Percentage of outcomes with distances smaller than the given value

- Defined as a dose of 4 millirem per year

b These fractiles correspond to the confidence levels referred to in the FFACO (1996) 
Table G-24

Transport Simulation Results for Characterization Activity Subgroup 5 Location of Contaminant Boundary ${ }^{a}$ for Various Fractiles ${ }^{b}$

\begin{tabular}{|c|c|c|c|c|c|c|c|c|c|c|c|}
\hline \multirow{3}{*}{$\begin{array}{l}\text { Fractile } \\
\text { Value }\end{array}$} & \multicolumn{2}{|c|}{$50 \%$} & \multicolumn{2}{|c|}{$65 \%$} & \multicolumn{2}{|c|}{$75 \%$} & \multicolumn{2}{|c|}{$85 \%$} & \multicolumn{2}{|c|}{$95 \%$} & \multirow{3}{*}{$\begin{array}{c}\text { Average } \\
\text { Deviation } \\
\mathbf{k m}\end{array}$} \\
\hline & Distance & Time & Distance & Time & Distance & Time & Distance & Time & Distance & Time & \\
\hline & km & $y r$ & km & yr & km & $y r$ & km & $y r$ & km & $y r$ & \\
\hline $5 \%$ & 1.50 & 0.00 & 1.50 & 0.00 & 1.83 & 45.00 & 1.99 & 30.00 & 2.75 & 45.00 & 0.38 \\
\hline $50 \%$ & 3.30 & 40.00 & 4.28 & 40.00 & 5.74 & 45.00 & 7.72 & 55.00 & 12.80 & 55.00 & 3.03 \\
\hline $95 \%$ & 23.69 & 35.00 & 30.50 & 20.00 & 30.50 & 10.00 & 30.50 & 5.00 & 30.50 & 5.00 & 7.00 \\
\hline $99 \%$ & 30.50 & 15.00 & 30.50 & 5.00 & 30.50 & 5.00 & 30.50 & 5.00 & 30.50 & 5.00 & 5.41 \\
\hline
\end{tabular}

Table G-25

Transport Simulation Results for Characterization Activity Subgroup 6 Location of Contaminant Boundary ${ }^{a}$ for Various Fractiles ${ }^{b}$

\begin{tabular}{|c|c|c|c|c|c|c|c|c|c|c|c|}
\hline \multirow{3}{*}{$\begin{array}{l}\text { Fractile } \\
\text { Value }\end{array}$} & \multicolumn{2}{|c|}{$50 \%$} & \multicolumn{2}{|c|}{$65 \%$} & \multicolumn{2}{|c|}{$75 \%$} & \multicolumn{2}{|c|}{$85 \%$} & \multicolumn{2}{|c|}{$95 \%$} & \multirow{3}{*}{$\begin{array}{c}\text { Average } \\
\text { Deviation } \\
\text { km }\end{array}$} \\
\hline & Distance & Time & Distance & Time & Distance & Time & Distance & Time & Distance & Time & \\
\hline & km & $y r$ & km & yr & km & $y r$ & km & $y r$ & $\mathbf{k m}$ & yr & \\
\hline $5 \%$ & 1.50 & 0.00 & 1.50 & 0.00 & 1.84 & 40.00 & 1.99 & 30.00 & 2.75 & 45.00 & 0.38 \\
\hline $50 \%$ & 3.24 & 35.00 & 4.26 & 50.00 & 5.55 & 45.00 & 8.05 & 55.00 & 12.53 & 60.00 & 3.38 \\
\hline $95 \%$ & 22.09 & 35.00 & 30.50 & 20.00 & 30.50 & 10.00 & 30.50 & 10.00 & 30.50 & 5.00 & 7.36 \\
\hline $99 \%$ & 30.50 & 15.00 & 30.50 & 10.00 & 30.50 & 5.00 & 30.50 & 5.00 & 30.50 & 5.00 & 5.47 \\
\hline
\end{tabular}

Notes

1) 200 realizations running on a Pentium II Computer - 5 parameters

2) Percentage of outcomes with distances smaller than the given value

- Defined as a dose of 4 millirem per year

- These fractiles correspond to the confidence levels referred to in the FFACO (1996) 
Table G-26

Transport Simulation Results for Characterization Activity Subgroup 7 Location of Contaminant Boundary ${ }^{a}$ for Various Fractiles ${ }^{b}$

\begin{tabular}{|c|c|c|c|c|c|c|c|c|c|c|c|}
\hline \multirow{3}{*}{$\begin{array}{c}\text { Fractile } \\
\text { Value }\end{array}$} & \multicolumn{2}{|c|}{$50 \%$} & \multicolumn{2}{|c|}{$65 \%$} & \multicolumn{2}{|c|}{$75 \%$} & \multicolumn{2}{|c|}{$85 \%$} & \multicolumn{2}{|c|}{$95 \%$} & \multirow{3}{*}{$\begin{array}{c}\text { Average } \\
\text { Deviation } \\
\text { km }\end{array}$} \\
\hline & Distance & Time & Distance & Time & Distance & Time & Distance & Time & Distance & Time & \\
\hline & km & yr & km & $y r$ & km & yr & km & yr & km & yr & \\
\hline $5 \%$ & 1.50 & 0.00 & 1.50 & 0.00 & 1.83 & 40.00 & 1.99 & 30.00 & 2.75 & 45.00 & 0.38 \\
\hline $50 \%$ & 3.28 & 40.00 & 4.25 & 40.00 & 5.72 & 45.00 & 7.54 & 55.00 & 12.68 & 60.00 & 2.98 \\
\hline $95 \%$ & 24.05 & 35.00 & 30.50 & 15.00 & 30.50 & 10.00 & 30.50 & 5.00 & 30.50 & 5.00 & 6.92 \\
\hline $99 \%$ & 30.50 & 15.00 & 30.50 & 5.00 & 30.50 & 5.00 & 30.50 & 5.00 & 30.50 & 5.00 & 5.39 \\
\hline
\end{tabular}

Table G-27

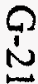

Transport Simulation Results for Characterization Activity Subgroup 8 Location of Contaminant Boundary ${ }^{a}$ for Various Fractiles ${ }^{b}$

\begin{tabular}{|c|c|c|c|c|c|c|c|c|c|c|c|}
\hline \multirow{3}{*}{$\begin{array}{l}\text { Fractile } \\
\text { Value }\end{array}$} & \multicolumn{2}{|c|}{$50 \%$} & \multicolumn{2}{|c|}{$65 \%$} & \multicolumn{2}{|c|}{$75 \%$} & \multicolumn{2}{|c|}{$85 \%$} & \multicolumn{2}{|c|}{$95 \%$} & \multirow{3}{*}{$\begin{array}{c}\text { Average } \\
\text { Deviation } \\
\text { km }\end{array}$} \\
\hline & Distance & Time & Distance & Time & Distance & Time & Distance & Time & Distance & Time & \\
\hline & km & yr & $\mathrm{km}$ & yr & km & yr & km & $y r$ & km & $y r$ & \\
\hline $5 \%$ & 1.50 & 0.00 & 1.50 & 0.00 & 1.84 & 40.00 & 1.99 & 30.00 & 2.75 & 45.00 & 0.38 \\
\hline $50 \%$ & 4.08 & 35.00 & 5.67 & 45.00 & 7.86 & 55.00 & 11.67 & 55.00 & 19.18 & 6.00 & 5.19 \\
\hline $95 \%$ & 12.09 & 30.00 & 17.28 & 35.00 & 30.20 & 65.00 & 30.50 & 20.00 & 30.50 & 15.00 & 8.94 \\
\hline $99 \%$ & 30.50 & 20.00 & 30.50 & 10.00 & 30.50 & 5.00 & 30.50 & 5.00 & 30.50 & 5.00 & 6.15 \\
\hline
\end{tabular}

Notes

1) 200 realizations running on a Pentium II Computer - 5 parameters

2) Percentage of outcomes with distances smaller than the given value

- Defined as a dose of 4 millirem per year

These fractiles correspond to the confidence levels referred to in the FFACO (1996) 
Table G-28

Transport Simulation Results for Characterization Activity Subgroup 9 Location of Contaminant Boundary ${ }^{a}$ for Various Fractiles ${ }^{b}$

\begin{tabular}{|c|c|c|c|c|c|c|c|c|c|c|c|}
\hline \multirow{3}{*}{$\begin{array}{l}\text { Fractile } \\
\text { Value }\end{array}$} & \multicolumn{2}{|c|}{$50 \%$} & \multicolumn{2}{|c|}{$65 \%$} & \multicolumn{2}{|c|}{$75 \%$} & \multicolumn{2}{|c|}{$85 \%$} & \multicolumn{2}{|c|}{$95 \%$} & \multirow{3}{*}{$\begin{array}{c}\text { Average } \\
\text { Deviation } \\
\text { km }\end{array}$} \\
\hline & Distance & Time & Distance & Time & Distance & Time & Distance & Time & Distance & Time & \\
\hline & km & $y \mathbf{r}$ & km & yr & km & yr & km & yr & km & yr & \\
\hline $5 \%$ & 1.50 & 0.00 & 1.50 & 0.00 & 1.83 & 45.00 & 1.99 & 30.00 & 2.75 & 45.00 & 0.38 \\
\hline $50 \%$ & 3.12 & 40.00 & 3.98 & 35.00 & 5.40 & 45.00 & 7.33 & 60.00 & 12.06 & 55.00 & 2.84 \\
\hline $95 \%$ & 23.46 & 35.00 & 30.50 & 20.00 & 30.50 & 10.00 & 30.50 & 5.00 & 30.50 & 5.00 & 7.05 \\
\hline $99 \%$ & 30.50 & 15.00 & 30.50 & 5.00 & 30.50 & 5.00 & 30.50 & 5.00 & 30.50 & 5.00 & 5.44 \\
\hline
\end{tabular}

Table G-29

Transport Simulation Results for Characterization Activity Subgroup 10 Location of Contaminant Boundary ${ }^{a}$ for Various Fractiles ${ }^{b}$

\begin{tabular}{|c|c|c|c|c|c|c|c|c|c|c|c|}
\hline \multirow{3}{*}{$\begin{array}{l}\text { Fractile } \\
\text { Value }\end{array}$} & \multicolumn{2}{|c|}{$50 \%$} & \multicolumn{2}{|c|}{$65 \%$} & \multicolumn{2}{|c|}{$75 \%$} & \multicolumn{2}{|c|}{$85 \%$} & \multicolumn{2}{|c|}{$95 \%$} & \multirow{3}{*}{$\begin{array}{c}\text { Average } \\
\text { Deviation } \\
\text { km }\end{array}$} \\
\hline & Distance & Time & Distance & Time & Distance & Time & Distance & Time & Distance & Time & \\
\hline & km & yr & km & yr & km & yr & km & yr & km & yr & \\
\hline $5 \%$ & 1.50 & 0.00 & 1.50 & 0.00 & 1.83 & 40.00 & 1.99 & 30.00 & 2.75 & 45.00 & 0.38 \\
\hline $50 \%$ & 3.35 & 35.00 & 4.33 & 35.00 & 5.75 & 45.00 & 8.02 & 60.00 & 13.26 & 55.00 & 3.21 \\
\hline $95 \%$ & 23.62 & 35.00 & 30.50 & 20.00 & 30.50 & 10.00 & 30.50 & 5.00 & 30.50 & 5.00 & 7.01 \\
\hline $99 \%$ & 30.50 & 15.00 & 30.50 & 5.00 & 30.50 & 5.00 & 30.50 & 5.00 & 30.50 & 5.00 & 5.44 \\
\hline
\end{tabular}

Notes

1) 200 realizations running on a Pentium II Computer - 5 parameters

2) Percentage of outcomes with distances smaller than the given value

- Defined as a dose of 4 millirem per year

- These fractiles correspond to the confidence levels referred to in the FFACO (1996) 
Table G-30

Transport Simulation Results for Characterization Activity Subgroup 11 Location of Contaminant Boundary ${ }^{a}$ for Various Fractiles ${ }^{b}$

\begin{tabular}{|c|c|c|c|c|c|c|c|c|c|c|c|}
\hline \multirow{3}{*}{$\begin{array}{c}\text { Fractile } \\
\text { Value }\end{array}$} & \multicolumn{2}{|c|}{$50 \%$} & \multicolumn{2}{|c|}{$65 \%$} & \multicolumn{2}{|c|}{$75 \%$} & \multicolumn{2}{|c|}{$85 \%$} & \multicolumn{2}{|c|}{$95 \%$} & \multirow{3}{*}{$\begin{array}{c}\text { Average } \\
\text { Deviation } \\
\text { km }\end{array}$} \\
\hline & Distance & Time & Distance & Time & Distance & Time & Distance & Time & Distance & Time & \\
\hline & $\mathbf{k m}$ & yr & km & yr & km & yr & $\mathbf{k m}$ & yr & km & yr & \\
\hline $5 \%$ & 1.50 & 0.00 & 1.50 & 0.00 & 1.84 & 40.00 & 1.99 & 30.00 & 2.75 & 45.00 & 0.38 \\
\hline $50 \%$ & 2.98 & 40.00 & 3.86 & 35.00 & 5.07 & 45.00 & 6.93 & 55.00 & 11.25 & 55.00 & 2.68 \\
\hline $95 \%$ & 23.17 & 35.00 & 30.50 & 20.00 & 30.50 & 10.00 & 30.50 & 5.00 & 30.50 & 5.00 & 7.13 \\
\hline $99 \%$ & 30.50 & 15.00 & 30.50 & 10.00 & 30.50 & 5.00 & 30.50 & 5.00 & 30.50 & 5.00 & 5.47 \\
\hline
\end{tabular}

Table G-31

Transport Simulation Results for Characterization Activity Subgroup 12 Location of Contaminant Boundary ${ }^{a}$ for Various Fractiles ${ }^{b}$

\begin{tabular}{|c|c|c|c|c|c|c|c|c|c|c|c|}
\hline \multirow{3}{*}{$\begin{array}{c}\text { Fractile } \\
\text { Value }\end{array}$} & \multicolumn{2}{|c|}{$50 \%$} & \multicolumn{2}{|c|}{$65 \%$} & \multicolumn{2}{|c|}{$75 \%$} & \multicolumn{2}{|c|}{$85 \%$} & \multicolumn{2}{|c|}{$95 \%$} & \multirow{3}{*}{$\begin{array}{c}\text { Average } \\
\text { Deviation } \\
\text { km }\end{array}$} \\
\hline & Distance & Time & Distance & Time & Distance & Time & Distance & Time & Distance & Time & \\
\hline & $\mathbf{k m}$ & yr & km & yr & $\mathrm{km}$ & yr & km & yr & $\mathrm{km}$ & yr & \\
\hline $5 \%$ & 4.64 & 45.00 & 6.50 & 45.00 & 8.95 & 60.00 & 13.64 & 80.00 & 23.08 & 100.00 & 5.93 \\
\hline $50 \%$ & 3.37 & 30.00 & 4.43 & 45.00 & 6.01 & 65.00 & 8.50 & 50.00 & 14.10 & 55.00 & 3.81 \\
\hline $95 \%$ & 2.00 & 990.00 & 2.69 & 1000.00 & 3.48 & 1000.00 & 4.74 & 1000.00 & 8.53 & 960.00 & 2.16 \\
\hline $99 \%$ & 1.94 & 1000.00 & 2.65 & 1000.00 & 3.44 & 970.00 & 4.78 & 990.00 & 8.39 & 965.00 & 2.18 \\
\hline
\end{tabular}

1) 200 realizations running on a Pentium II Computer - 5 parameters

2) Percentage of outcomes with distances smaller than the given value

- Defined as a dose of 4 millirem per year

- These fractiles correspond to the confidence levels referred to in the FFACO (1996) 
Table G-32

Transport Simulation Results for Characterization Activity Group 1

Location of Contaminant Boundary ${ }^{\mathrm{a}}$ for Various Fractiles ${ }^{\mathrm{b}}$

(Page 1 of 4)

\begin{tabular}{|c|c|c|c|c|c|c|c|c|c|c|c|}
\hline \multicolumn{12}{|c|}{ Flux Fractile Value at $5 \%$} \\
\hline \multirow{3}{*}{$\begin{array}{c}\text { Source } \\
\text { Fractile } \\
\text { Value }\end{array}$} & \multicolumn{2}{|c|}{$50 \%$} & \multicolumn{2}{|c|}{$65 \%$} & \multicolumn{2}{|c|}{$75 \%$} & \multicolumn{2}{|c|}{$85 \%$} & \multicolumn{2}{|c|}{$95 \%$} & \multirow{3}{*}{$\begin{array}{c}\text { Average } \\
\text { Deviation } \\
\mathbf{k m}\end{array}$} \\
\hline & distance & time & distance & time & distance & time & distance & time & distance & time & \\
\hline & km & yr & km & yr & km & yr & km & yr & km & yr & \\
\hline \multicolumn{12}{|c|}{ Diffusion Parameter Fractile at $5 \%$} \\
\hline $5 \%$ & 1.50 & 0.00 & 1.50 & 0.00 & 1.90 & 45.00 & 2.03 & 35.00 & 2.89 & 55.00 & 0.40 \\
\hline $50 \%$ & 1.50 & 0.00 & 1.86 & 40.00 & 1.97 & 35.00 & 2.40 & 40.00 & 3.12 & 50.00 & 0.50 \\
\hline $95 \%$ & 1.50 & 0.00 & 1.89 & 40.00 & 1.98 & 35.00 & 2.42 & 40.00 & 3.16 & 50.00 & 0.52 \\
\hline $99 \%$ & 1.50 & 0.00 & 1.90 & 40.00 & 1.98 & 35.00 & 2.43 & 40.00 & 3.19 & 60.00 & 0.53 \\
\hline \multicolumn{12}{|c|}{ Diffusion Parameter Fractile at $50 \%$} \\
\hline $5 \%$ & 1.50 & 0.00 & 1.50 & 0.00 & 1.50 & 0.00 & 1.81 & 30.00 & 2.39 & 30.00 & 0.25 \\
\hline $50 \%$ & 1.50 & 0.00 & 1.50 & 0.00 & 1.57 & 40.00 & 1.96 & 25.00 & 2.48 & 30.00 & 0.32 \\
\hline $95 \%$ & 1.50 & 0.00 & 1.50 & 0.00 & 1.64 & 40.00 & 1.97 & 30.00 & 2.49 & 30.00 & 0.33 \\
\hline $99 \%$ & 1.50 & 0.00 & 1.50 & 0.00 & 1.68 & 40.00 & 1.97 & 30.00 & 2.49 & 30.00 & 0.33 \\
\hline \multicolumn{12}{|c|}{ Diffusion Parameter Fractile at $95 \%$} \\
\hline $5 \%$ & 1.50 & 0.00 & 1.50 & 0.00 & 1.50 & 0.00 & 1.50 & 0.00 & 1.50 & 30.00 & 0.04 \\
\hline $50 \%$ & 1.50 & 0.00 & 1.50 & 0.00 & 1.50 & 0.00 & 1.50 & 0.00 & 1.76 & 25.00 & 0.06 \\
\hline $95 \%$ & 1.50 & 0.00 & 1.50 & 0.00 & 1.50 & 0.00 & 1.50 & 0.00 & 1.77 & 25.00 & 0.07 \\
\hline $99 \%$ & 1.50 & 0.00 & 1.50 & 0.00 & 1.50 & 0.00 & 1.50 & 0.00 & 1.76 & 30.00 & 0.07 \\
\hline \multicolumn{12}{|c|}{ Diffusion Parameter Fractile at $99 \%$} \\
\hline $5 \%$ & 1.50 & 0.00 & 1.50 & 0.00 & 1.50 & 0.00 & 1.50 & 0.00 & 1.50 & 0.00 & 0.00 \\
\hline $50 \%$ & 1.50 & 0.00 & 1.50 & 0.00 & 1.50 & 0.00 & 1.50 & 0.00 & 1.50 & 0.00 & 0.00 \\
\hline $95 \%$ & 1.50 & 0.00 & 1.50 & 0.00 & 1.50 & 0.00 & 1.50 & 0.00 & 1.50 & 0.00 & 0.00 \\
\hline $99 \%$ & 1.50 & 0.00 & 1.50 & 0.00 & 1.50 & 0.00 & 1.50 & 0.00 & 1.50 & 0.00 & 0.00 \\
\hline
\end{tabular}


Table G-32

Transport Simulation Results for Characterization Activity Group 1 Location of Contaminant Boundary ${ }^{a}$ for Various Fractiles ${ }^{b}$

(Page 2 of 4 )

\begin{tabular}{|c|c|c|c|c|c|c|c|c|c|c|c|}
\hline \multicolumn{12}{|c|}{ Flux Fractile Value at $\mathbf{5 0} \%$} \\
\hline \multirow{3}{*}{$\begin{array}{c}\text { Source } \\
\text { Fractlle } \\
\text { Value }\end{array}$} & \multicolumn{2}{|c|}{$50 \%$} & \multicolumn{2}{|c|}{$65 \%$} & \multicolumn{2}{|c|}{$75 \%$} & \multicolumn{2}{|c|}{$85 \%$} & \multicolumn{2}{|c|}{$95 \%$} & \multirow{3}{*}{$\begin{array}{c}\text { Average } \\
\text { Deviation } \\
\mathrm{km}\end{array}$} \\
\hline & distance & time & distance & time & distance & time & distance & time & distance & time & \\
\hline & $\mathbf{k m}$ & yr & $\mathrm{km}$ & $y r$ & $\mathbf{k m}$ & $y r$ & $\mathbf{k m}$ & yr & $\mathbf{k m}$ & $y r$ & \\
\hline \multicolumn{12}{|c|}{ Diffusion Parameter Fractile at $5 \%$} \\
\hline $5 \%$ & 3.33 & 25.00 & 4.33 & 35.00 & 5.87 & 50.00 & 8.05 & 60.00 & 14.31 & 80.00 & 3.28 \\
\hline $50 \%$ & 3.93 & 25.00 & 5.37 & 45.00 & 7.04 & 75.00 & 9.62 & 60.00 & 15.24 & 80.00 & 3.74 \\
\hline $95 \%$ & 3.96 & 25.00 & 5.47 & 70.00 & 7.10 & 70.00 & 9.76 & 60.00 & 15.57 & 80.00 & 3.90 \\
\hline $99 \%$ & 3.96 & 25.00 & 5.48 & 60.00 & 7.16 & 70.00 & 9.87 & 65.00 & 15.74 & 80.00 & 4.00 \\
\hline \multicolumn{12}{|c|}{ Diffusion Parameter Fractile at $50 \%$} \\
\hline $5 \%$ & 2.75 & 25.00 & 3.43 & 30.00 & 4.35 & 35.00 & 6.28 & 60.00 & 10.20 & 40.00 & 2.35 \\
\hline $50 \%$ & 3.21 & 35.00 & 4.19 & 40.00 & 5.32 & 40.00 & 7.35 & 50.00 & 10.96 & 55.00 & 2.66 \\
\hline $95 \%$ & 3.28 & 35.00 & 4.25 & 40.00 & 5.39 & 40.00 & 7.46 & 50.00 & 10.86 & 45.00 & 2.77 \\
\hline $99 \%$ & 3.27 & 35.00 & 4.24 & 40.00 & 5.35 & 40.00 & 7.48 & 55.00 & 11.03 & 80.00 & 2.83 \\
\hline \multicolumn{12}{|c|}{ Diffusion Parameter Fractile at $95 \%$} \\
\hline $5 \%$ & 1.99 & 15.00 & 2.48 & 30.00 & 2.96 & 35.00 & 3.72 & 25.00 & 5.49 & 40.00 & 1.37 \\
\hline $50 \%$ & 2.52 & 1000.00 & 3.14 & 990.00 & 3.76 & 1000.00 & 4.54 & 975.00 & 6.80 & 1000.00 & 1.61 \\
\hline $95 \%$ & 2.65 & 1000.00 & 3.31 & 1000.00 & 3.95 & 1000.00 & 4.80 & 1000.00 & 7.65 & 980.00 & 1.70 \\
\hline $99 \%$ & 2.69 & 1000.00 & 3.35 & 1000.00 & 4.07 & 1000.00 & 5.02 & 1000.00 & 7.97 & 1000.00 & 1.75 \\
\hline \multicolumn{12}{|c|}{ Diffusion Parameter Fractile at $99 \%$} \\
\hline $5 \%$ & 1.65 & 980.00 & 2.23 & 1000.00 & 2.76 & 1000.00 & 3.29 & 1000.00 & 5.39 & 1000.00 & 1.13 \\
\hline $50 \%$ & 2.48 & 1000.00 & 3.10 & 1000.00 & 3.68 & 1000.00 & 4.45 & 1000.00 & 6.77 & 1000.00 & 1.43 \\
\hline $95 \%$ & 2.55 & 995.00 & 3.19 & 1000.00 & 3.83 & 1000.00 & 4.60 & 1000.00 & 7.11 & 1000.00 & 1.51 \\
\hline $99 \%$ & 2.58 & 1000.00 & 3.22 & 1000.00 & 3.86 & 1000.00 & 4.67 & 1000.00 & 7.33 & 995.00 & 1.55 \\
\hline
\end{tabular}


Table G-32

Transport Simulation Results for Characterization Activity Group 1

Location of Contaminant Boundary ${ }^{a}$ for Various Fractiles ${ }^{b}$

(Page 3 of 4)

\begin{tabular}{|c|c|c|c|c|c|c|c|c|c|c|c|}
\hline \multicolumn{12}{|c|}{ Flux Fractile Value at $95 \%$} \\
\hline \multirow{3}{*}{$\begin{array}{c}\text { Source } \\
\text { Fractile } \\
\text { Value }\end{array}$} & \multicolumn{2}{|c|}{$50 \%$} & \multicolumn{2}{|c|}{$65 \%$} & \multicolumn{2}{|c|}{$75 \%$} & \multicolumn{2}{|c|}{$85 \%$} & \multicolumn{2}{|c|}{$95 \%$} & \multirow{3}{*}{$\begin{array}{c}\text { Average } \\
\text { Deviation } \\
\text { km }\end{array}$} \\
\hline & distance & time & distance & time & distance & time & distance & time & distance & time & \\
\hline & $\mathbf{k m}$ & yr & $\mathbf{k m}$ & yr & km & yr & km & yr & km & yr & \\
\hline \multicolumn{12}{|c|}{ Diffusion Parameter Fractile at $5 \%$} \\
\hline $5 \%$ & 25.83 & 40.00 & 30.50 & 15.00 & 30.50 & 10.00 & 30.50 & 5.00 & 30.50 & 5.00 & 8.02 \\
\hline $50 \%$ & 30.50 & 20.00 & 30.50 & 10.00 & 30.50 & 10.00 & 30.50 & 5.00 & 30.50 & 5.00 & 5.39 \\
\hline $95 \%$ & 30.50 & 20.00 & 30.50 & 10.00 & 30.50 & 10.00 & 30.50 & 5.00 & 30.50 & 5.00 & 4.91 \\
\hline $99 \%$ & 30.50 & 20.00 & 30.50 & 10.00 & 30.50 & 10.00 & 30.50 & 5.00 & 30.50 & 5.00 & 4.80 \\
\hline \multicolumn{12}{|c|}{ Diffusion Parameter Fractile at $50 \%$} \\
\hline $5 \%$ & 17.39 & 30.00 & 28.83 & 45.00 & 30.50 & 15.00 & 30.50 & 10.00 & 30.50 & 5.00 & 8.50 \\
\hline $50 \%$ & 24.41 & 50.00 & 30.50 & 20.00 & 30.50 & 10.00 & 30.50 & 5.00 & 30.50 & 5.00 & 6.69 \\
\hline $95 \%$ & 24.78 & 50.00 & 30.50 & 20.00 & 30.50 & 10.00 & 30.50 & 5.00 & 30.50 & 5.00 & 6.32 \\
\hline $99 \%$ & 23.42 & 45.00 & 30.50 & 20.00 & 30.50 & 10.00 & 30.50 & 5.00 & 30.50 & 5.00 & 6.23 \\
\hline \multicolumn{12}{|c|}{ Diffusion Parameter Fractile at $95 \%$} \\
\hline $5 \%$ & 10.56 & 20.00 & 13.30 & 45.00 & 17.87 & 30.00 & 22.93 & 25.00 & 30.50 & 15.00 & 7.44 \\
\hline $50 \%$ & 12.82 & 30.00 & 16.19 & 40.00 & 22.14 & 35.00 & 30.42 & 55.00 & 30.50 & 10.00 & 6.55 \\
\hline $95 \%$ & 13.09 & 45.00 & 16.49 & 45.00 & 22.67 & 35.00 & 30.50 & 35.00 & 30.50 & 10.00 & 6.58 \\
\hline $99 \%$ & 13.03 & 40.00 & 16.29 & 30.00 & 22.73 & 40.00 & 30.50 & 35.00 & 30.50 & 10.00 & 6.83 \\
\hline \multicolumn{12}{|c|}{ Diffusion Parameter Fractile at $99 \%$} \\
\hline $5 \%$ & 6.30 & 55.00 & 7.43 & 55.00 & 9.72 & 465.00 & 14.55 & 820.00 & 22.10 & 955.00 & 5.84 \\
\hline $50 \%$ & 9.65 & 535.00 & 12.98 & 660.00 & 16.12 & 915.00 & 22.05 & 950.00 & 30.50 & 945.00 & 5.68 \\
\hline $95 \%$ & 12.02 & 650.00 & 16.18 & 785.00 & 20.70 & 815.00 & 29.01 & 965.00 & 30.50 & 770.00 & 6.37 \\
\hline $99 \%$ & 12.83 & 670.00 & 19.05 & 885.00 & 24.58 & 955.00 & 30.50 & 940.00 & 30.50 & 700.00 & 7.04 \\
\hline
\end{tabular}


Table G-32

Transport Simulation Results for Characterization Activity Group 1 Location of Contaminant Boundary ${ }^{\mathrm{a}}$ for Various Fractiles ${ }^{\mathrm{b}}$

(Page 4 of 4)

\begin{tabular}{|c|c|c|c|c|c|c|c|c|c|c|c|}
\hline \multicolumn{12}{|c|}{ Flux Fractile Value at $99 \%$} \\
\hline \multirow{3}{*}{$\begin{array}{c}\text { Source } \\
\text { Fractile } \\
\text { Value }\end{array}$} & \multicolumn{2}{|c|}{$50 \%$} & \multicolumn{2}{|c|}{$65 \%$} & \multicolumn{2}{|c|}{$75 \%$} & \multicolumn{2}{|c|}{$85 \%$} & \multicolumn{2}{|c|}{$95 \%$} & \multirow{3}{*}{$\begin{array}{c}\text { Average } \\
\text { Deviation } \\
\mathrm{km}\end{array}$} \\
\hline & distance & time & distance & time & distance & time & distance & time & distance & time & \\
\hline & $\mathbf{k m}$ & $y r$ & $\mathbf{k m}$ & yr & km & yr & km & yr & km & yr & \\
\hline \multicolumn{12}{|c|}{ Diffusion Parameter Fractile at $5 \%$} \\
\hline $5 \%$ & 30.50 & 15.00 & 30.50 & 5.00 & 30.50 & 5.00 & 30.50 & 5.00 & 30.50 & 5.00 & 6.67 \\
\hline $50 \%$ & 30.50 & 10.00 & 30.50 & 5.00 & 30.50 & 5.00 & 30.50 & 5.00 & 30.50 & 5.00 & 3.70 \\
\hline $95 \%$ & 30.50 & 10.00 & 30.50 & 5.00 & 30.50 & 5.00 & 30.50 & 5.00 & 30.50 & 5.00 & 2.95 \\
\hline $99 \%$ & 30.50 & 10.00 & 30.50 & 5.00 & 30.50 & 5.00 & 30.50 & 5.00 & 30.50 & 5.00 & 2.78 \\
\hline \multicolumn{11}{|c|}{ Diffusion Parameter Fractile at $50 \%$} & $\dot{5}$ \\
\hline $5 \%$ & 25.14 & 35.00 & 30.50 & 10.00 & 30.50 & 5.00 & 30.50 & 5.00 & 30.50 & 5.00 & 7.85 \\
\hline $50 \%$ & 30.50 & 15.00 & 30.50 & 5.00 & 30.50 & 5.00 & 30.50 & 5.00 & 30.50 & 5.00 & 4.87 \\
\hline $95 \%$ & 30.50 & 15.00 & 30.50 & 5.00 & 30.50 & 5.00 & 30.50 & 5.00 & 30.50 & 5.00 & 4.25 \\
\hline $99 \%$ & 30.50 & 15.00 & 30.50 & 5.00 & 30.50 & 5.00 & 30.50 & 5.00 & 30.50 & 5.00 & 4.15 \\
\hline \multicolumn{12}{|c|}{ Diffusion Parameter Fractile at $95 \%$} \\
\hline $5 \%$ & 14.82 & 45.00 & 20.45 & 25.00 & 24.88 & 40.00 & 30.50 & 15.00 & 30.50 & 5.00 & 8.22 \\
\hline $50 \%$ & 18.10 & 35.00 & 24.06 & 25.00 & 30.50 & 20.00 & 30.50 & 10.00 & 30.50 & 5.00 & 6.45 \\
\hline $95 \%$ & 18.61 & 35.00 & 24.59 & 25.00 & 30.50 & 20.00 & 30.50 & 10.00 & 30.50 & 5.00 & 6.19 \\
\hline $99 \%$ & 18.66 & 35.00 & 24.44 & 30.00 & 30.50 & 20.00 & 30.50 & 10.00 & 30.50 & 5.00 & 6.10 \\
\hline \multicolumn{12}{|c|}{ Diffusion Parameter Fractile at $99 \%$} \\
\hline $5 \%$ & 9.01 & 60.00 & 9.88 & 60.00 & 13.11 & 500.00 & 21.61 & 775.00 & 30.50 & 790.00 & 6.95 \\
\hline $50 \%$ & 14.38 & 545.00 & 20.11 & 730.00 & 24.01 & 875.00 & 30.50 & 840.00 & 30.50 & 730.00 & 7.38 \\
\hline $95 \%$ & 20.70 & 730.00 & 30.50 & 950.00 & 30.50 & 795.00 & 30.50 & 730.00 & 30.50 & 640.00 & 7.24 \\
\hline $99 \%$ & 23.51 & 820.00 & 30.50 & 820.00 & 30.50 & 740.00 & 30.50 & 690.00 & 30.50 & 610.00 & 7.30 \\
\hline
\end{tabular}

Notes

1) 200 realizations running on a Pentium II Computer - 5 parameters

2) Percentage of outcomes with distances smaller than the given value

- Defined as a dose of 4 millirem per year

- These fractiles correspond to the confidence levels referred to in the FFACO (1996) 
Table G-33

Transport Simulation Results for Characterization Activity Group 2 Location of Contaminant Boundary ${ }^{a}$ for Various Fractiles ${ }^{b}$

\begin{tabular}{|c|c|c|c|c|c|c|c|c|c|c|c|}
\hline \multirow{3}{*}{$\begin{array}{c}\text { Fractile } \\
\text { Value }\end{array}$} & \multicolumn{2}{|c|}{$50 \%$} & \multicolumn{2}{|c|}{$65 \%$} & \multicolumn{2}{|c|}{$75 \%$} & \multicolumn{2}{|c|}{$85 \%$} & \multicolumn{2}{|c|}{$95 \%$. } & \multirow{3}{*}{$\begin{array}{c}\text { Average } \\
\text { Deviation } \\
\text { km }\end{array}$} \\
\hline & Distance & Time & Distance & Time & Distance & Time & Distance & Time & Distance & Time & \\
\hline & $\mathbf{k m}$ & yr & km & $y r$ & km & yr & km & yr & km & yr & \\
\hline $5 \%$ & 1.50 & 0.00 & 1.50 & 0.00 & 1.84 & 40.00 & 1.99 & 30.00 & 2.75 & 45.00 & 0.38 \\
\hline $50 \%$ & 4.09 & 35.00 & 5.67 & 45.00 & 7.86 & 55.00 & 11.68 & 55.00 & 19.22 & 60.00 & 5.19 \\
\hline $95 \%$ & 12.10 & 30.00 & 17.30 & 35.00 & 30.24 & 65.00 & 30.50 & 20.00 & 30.50 & 15.00 & 8.94 \\
\hline $99 \%$ & 30.50 & 20.00 & 30.50 & 10.00 & 30.50 & 5.00 & 30.50 & 5.00 & 30.50 & 5.00 & 6.15 \\
\hline
\end{tabular}

Table G-34

Transport Simulation Results for Characterization Activity Group 3 Location of Contaminant Boundary ${ }^{a}$ for Various Fractiles ${ }^{b}$

\begin{tabular}{|c|c|c|c|c|c|c|c|c|c|c|c|}
\hline \multirow{3}{*}{$\begin{array}{c}\text { Fractile } \\
\text { Value }\end{array}$} & \multicolumn{2}{|c|}{$50 \%$} & \multicolumn{2}{|c|}{$65 \%$} & \multicolumn{2}{|c|}{$75 \%$} & \multicolumn{2}{|c|}{$85 \%$} & \multicolumn{2}{|c|}{$95 \%$} & \multirow{3}{*}{$\begin{array}{c}\text { Average } \\
\text { Deviation } \\
\text { km }\end{array}$} \\
\hline & Distance & Time & Distance & Time & Distance & Time & Distance & Time & Distance & Time & \\
\hline & $\mathrm{km}$ & yr & $\mathrm{km}$ & yr & km & yr & $\mathbf{k m}$ & yr & km & yr & \\
\hline $5 \%$ & 1.50 & 0.00 & 1.50 & 0.00 & 1.83 & 45.00 & 1.99 & 30.00 & 2.75 & 45.00 & 0.38 \\
\hline $50 \%$ & 3.13 & 40.00 & 3.98 & 35.00 & 5.40 & 45.00 & 7.33 & 60.00 & 12.07 & 55.00 & 2.85 \\
\hline $95 \%$ & 23.47 & 35.00 & 30.50 & 20.00 & 30.50 & 10.00 & 30.50 & 5.00 & 30.50 & 5.00 & 7.05 \\
\hline $99 \%$ & 30.50 & 15.00 & 30.50 & 5.00 & 30.50 & 5.00 & 30.50 & 5.00 & 30.50 & 5.00 & 5.43 \\
\hline
\end{tabular}

Notes

1) 200 realizations running on a Pentium II Computer - 5 parameters

2) Percentage of outcomes with distances smaller than the given value

- Defined as a dose of 4 millirem per year

- These fractiles correspond to the confidence levels referred to in the FFACO (1996) 
Table G-35

Transport Simulation Results for Characterization Activity Group 4 Location of Contaminant Boundary ${ }^{a}$ for Various Fractiles ${ }^{b}$

(Page 1 of 4)

\begin{tabular}{|c|c|c|c|c|c|c|c|c|c|c|c|}
\hline \multicolumn{12}{|c|}{ Flux Fractile Value at $5 \%$} \\
\hline \multirow{3}{*}{$\begin{array}{l}\text { Diffusion } \\
\text { Fractile } \\
\text { Value }\end{array}$} & \multicolumn{2}{|c|}{$50 \%$} & \multicolumn{2}{|c|}{$65 \%$} & \multicolumn{2}{|c|}{$75 \%$} & \multicolumn{2}{|c|}{$85 \%$} & \multicolumn{2}{|c|}{$95 \%$} & \multirow{3}{*}{$\begin{array}{c}\text { Average } \\
\text { Deviation } \\
\mathrm{km}\end{array}$} \\
\hline & distance & time & distance & time & distance & time & distance & time & distance & time & \\
\hline & $\mathbf{k m}$ & yr & $\mathbf{k m}$ & yr & $\mathbf{k m}$ & yr & $\mathrm{km}$ & yr & $\mathbf{k m}$ & yr & \\
\hline \multicolumn{12}{|c|}{ Effective Porosity Fractile Value at $1 \%$} \\
\hline $5 \%$ & 1.75 & 35.00 & 1.98 & 45.00 & 2.46 & 50.00 & 2.90 & 60.00 & 4.00 & 65.00 & 0.76 \\
\hline $50 \%$ & 1.50 & 0.00 & 1.61 & 50.00 & 1.96 & 30.00 & 2.38 & 40.00 & 3.02 & 45.00 & 0.48 \\
\hline $95 \%$ & 1.50 & 0.00 & 1.50 & 0.00 & 1.50 & 0.00 & 1.55 & 1000.00 & 1.99 & 1000.00 & 0.16 \\
\hline $99 \%$ & 1.50 & 0.00 & 1.50 & 0.00 & 1.50 & 0.00 & 1.53 & 1000.00 & 1.98 & 1000.00 & 0.14 \\
\hline \multicolumn{12}{|c|}{ Effective Porosity Fractile Value at $5 \%$} \\
\hline $5 \%$ & 1.50 & 0.00 & 1.89 & 50.00 & 2.00 & 55.00 & 2.44 & 55.00 & 3.27 & 80.00 & 0.56 \\
\hline $50 \%$ & 1.50 & 0.00 & 1.50 & 0.00 & 1.81 & 45.00 & 2.00 & 55.00 & 2.74 & 55.00 & 0.37 \\
\hline $95 \%$ & 1.50 & 0.00 & 1.50 & 0.00 & 1.50 & 0.00 & 1.52 & 1000.00 & 1.97 & 1000.00 & 0.14 \\
\hline $99 \%$ & 1.50 & 0.00 & 1.50 & 0.00 & 1.50 & 0.00 & 1.50 & 0.00 & 1.97 & 1000.00 & 0.12 \\
\hline \multicolumn{12}{|c|}{ Effective Porosity Fractile Value at $50 \%$} \\
\hline $5 \%$ & 1.50 & 0.00 & 1.59 & 55.00 & 1.91 & 60.00 & 2.00 & 70.00 & 2.98 & 1000.00 & 0.43 \\
\hline $50 \%$ & 1.50 & 0.00 & 1.50 & 0.00 & 1.50 & 0.00 & 1.93 & 50.00 & 2.37 & 65.00 & 0.28 \\
\hline $95 \%$ & 1.50 & 0.00 & 1.50 & 0.00 & 1.50 & 0.00 & 1.50 & 0.00 & 1.93 & 1000.00 & 0.12 \\
\hline $99 \%$ & 1.50 & 0.00 & 1.50 & 0.00 & 1.50 & 0.00 & 1.50 & 0.00 & 1.91 & 1000.00 & 0.11 \\
\hline \multicolumn{12}{|c|}{ Effective Porosity Fractile Value at $95 \%$} \\
\hline $5 \%$ & 1.50 & 0.00 & 1.50 & 0.00 & 1.53 & 1000.00 & 1.83 & 1000.00 & 2.42 & 1000.00 & 0.22 \\
\hline $50 \%$ & 1.50 & 0.00 & 1.50 & 0.00 & 1.50 & 0.00 & 1.59 & 1000.00 & 2.11 & 1000.00 & 0.14 \\
\hline $95 \%$ & 1.50 & 0.00 & 1.50 & 0.00 & 1.50 & 0,00 & 1.50 & 0.00 & 1.82 & 1000.00 & 0.08 \\
\hline $99 \%$ & 1.50 & 0.00 & 1.50 & 0.00 & 1.50 & 0.00 & 1.50 & 0.00 & 1.80 & 1000.00 & 0.08 \\
\hline \multicolumn{12}{|c|}{ Effective Porosity Fractile Value at $99 \%$} \\
\hline $5 \%$ & 1.50 & 0.00 & 1.50 & 0.00 & 1.50 & 0.00 & 1.82 & 1000.00 & 2.38 & 1000.00 & 0.22 \\
\hline $50 \%$ & 1.50 & 0.00 & 1.50 & 0.00 & 1.50 & 0.00 & 1.58 & 1000.00 & 2.09 & 1000.00 & 0.14 \\
\hline $95 \%$ & 1.50 & 0.00 & 1.50 & 0.00 & 1.50 & 0.00 & 1.50 & 0.00 & 1.84 & 1000.00 & 0.08 \\
\hline $99 \%$ & 1.50 & 0.00 & 1.50 & 0.00 & 1.50 & 0.00 & 1.50 & 0.00 & 1.82 & 1000.00 & 0.08 \\
\hline
\end{tabular}


Table G-35

Transport Simulation Results for Characterization Activity Group 4 Location of Contaminant Boundary ${ }^{\mathrm{a}}$ for Various Fractiles ${ }^{\mathrm{b}}$

(Page 2 of 4)

\begin{tabular}{|c|c|c|c|c|c|c|c|c|c|c|c|}
\hline \multicolumn{12}{|c|}{ Flux Fractile Value at $50 \%$} \\
\hline \multirow{3}{*}{$\begin{array}{c}\text { Diffusion } \\
\text { Fractile } \\
\text { Value }\end{array}$} & \multicolumn{2}{|c|}{$50 \%$} & \multicolumn{2}{|c|}{$65 \%$} & \multicolumn{2}{|c|}{$75 \%$} & \multicolumn{2}{|c|}{$85 \%$} & \multicolumn{2}{|c|}{$95 \%$} & \multirow{3}{*}{$\begin{array}{c}\text { Average } \\
\text { Deviation } \\
\mathrm{km}\end{array}$} \\
\hline & distance & time & distance & time & distance & time & distance & time & distance & time & \\
\hline & $\mathbf{k m}$ & $y r$ & $\mathrm{~km}$ & $y \mathbf{y}$ & $\mathbf{k m}$ & yr & km & $y \mathbf{y r}$ & $\mathrm{km}$ & yr & \\
\hline \multicolumn{12}{|c|}{ Effective Porosity Fractile Value at $1 \%$} \\
\hline $5 \%$ & 4.17 & 35.00 & 5.91 & 65.00 & 7.87 & 55.00 & 11.43 & 70.00 & 17.10 & 95.00 & 4.67 \\
\hline $50 \%$ & 3.11 & 25.00 & 4.11 & 30.00 & 5.61 & 45.00 & 7.60 & 40.00 & 12.67 & 85.00 & 3.12 \\
\hline $95 \%$ & 1.93 & 30.00 & 2.51 & 985.00 & 3.18 & 1000.00 & 3.88 & 1000.00 & 6.51 & 850.00 & 1.64 \\
\hline $99 \%$ & 1.88 & 1000.00 & 2.48 & 960.00 & 3.14 & 1000.00 & 3.91 & 1000.00 & 6.56 & 995.00 & 1.62 \\
\hline \multicolumn{12}{|c|}{ Effective Porosity Fractile Value at $5 \%$} \\
\hline $5 \%$ & 3.66 & 45.00 & 4.77 & 60.00 & 6.05 & 60.00 & 8.09 & 95.00 & 1203 & 80.00 & 328 \\
\hline $50 \%$ & 2.91 & 35.00 & 3.66 & 35.00 & 4.57 & 70.00 & 6.22 & 60.00 & 9.03 & 55.00 & 2.30 \\
\hline $95 \%$ & 1.93 & 1000.00 & 2.53 & 1000.00 & 3.18 & 1000.00 & 3.91 & 1000.00 & 6.65 & 975.00 & 1.50 \\
\hline $99 \%$ & 1.90 & 990.00 & 2.53 & 985.00 & 3.11 & 1000.00 & 3.94 & 990.00 & 6.79 & 1000.00 & 1.50 \\
\hline \multicolumn{12}{|c|}{ Effective Porosity Fractile Value at $50 \%$} \\
\hline $5 \%$ & 3.34 & 50.00 & 3.97 & 65.00 & 4.85 & 80.00 & 6.12 & 75.00 & 8.81 & 100.00 & 2.55 \\
\hline $50 \%$ & 2.71 & 45.00 & 3.35 & 50.00 & 3.93 & 60.00 & 5.08 & 75.00 & 7.30 & 70.00 & 1.82 \\
\hline $95 \%$ & 1.93 & 1000.00 & 2.52 & 990.00 & 3.12 & 1000.00 & 3.90 & 1000.00 & 6.54 & 995.00 & 1.41 \\
\hline $99 \%$ & 1.90 & 960.00 & 2.53 & 1000.00 & 3.00 & 935.00 & 3.90 & 1000.00 & 6.53 & 1000.00 & 1.41 \\
\hline \multicolumn{12}{|c|}{ Effective Porosity Fractile Value at $95 \%$} \\
\hline $5 \%$ & 2.15 & 1000.00 & 2.79 & 1000.00 & 3.42 & 985.00 & 4.48 & 990.00 & 7.71 & 1000.00 & 1.78 \\
\hline $50 \%$ & 1.99 & 990.00 & 2.56 & 1000.00 & 3.15 & 1000.00 & 3.78 & 1000.00 & 6.64 & 1000.00 & 1.40 \\
\hline $95 \%$ & 1.89 & 1000.00 & 2.43 & 900.00 & 2.91 & 1000.00 & 3.52 & 1000.00 & 5.75 & 1000.00 & 1.22 \\
\hline $99 \%$ & 1.90 & 990.00 & 2.41 & 1000.00 & 2.85 & 1000.00 & 3.51 & 1000.00 & 5.59 & 1000.00 & 1.20 \\
\hline \multicolumn{12}{|c|}{ Effective Porosity Fractile Value at $99 \%$} \\
\hline $5 \%$ & 2.14 & 1000.00 & 2.76 & 1000.00 & 3.42 & 990.00 & 4.47 & 995.00 & 7.96 & 1000.00 & 1.79 \\
\hline $50 \%$ & 1.98 & 1000.00 & 2.55 & 1000.00 & 3.12 & 1000.00 & 3.78 & 1000.00 & 6.62 & 1000.00 & 1.41 \\
\hline $95 \%$ & 1.89 & 965.00 & 2.42 & 1000.00 & 2.90 & 1000.00 & 3.49 & 1000.00 & 5.76 & 1000.00 & 1.22 \\
\hline $99 \%$ & 1.89 & 1000.00 & 2.39 & 1000.00 & 2.85 & 1000.00 & 3.49 & 1000.00 & 5.62 & 1000.00 & 1.21 \\
\hline
\end{tabular}



Table G-35

Transport Simulation Results for Characterization Activity Group 4 Location of Contaminant Boundary for Various Fractiles $^{b}$

(Page 4 of 4)

\begin{tabular}{|c|c|c|c|c|c|c|c|c|c|c|c|}
\hline \multicolumn{12}{|c|}{ Flux Fractile Value at $99 \%$} \\
\hline \multirow{3}{*}{$\begin{array}{c}\text { Diffusion } \\
\text { Fractile } \\
\text { Value }\end{array}$} & \multicolumn{2}{|c|}{$50 \%$} & \multicolumn{2}{|c|}{$65 \%$} & \multicolumn{2}{|c|}{$75 \%$} & \multicolumn{2}{|c|}{$85 \%$} & \multicolumn{2}{|c|}{$95 \%$} & \multirow{3}{*}{$\begin{array}{c}\text { Average } \\
\text { Deviation } \\
\text { km }\end{array}$} \\
\hline & distance & time & distance & time & distance & time & distance & time & distance & time & \\
\hline & $\mathbf{k m}$ & $\overline{y r}$ & $\mathbf{k m}$ & $\overline{y r}$ & $\mathbf{k m}$ & $\overline{y r}$ & $\mathbf{k m}$ & $\overline{y r}$ & $\mathbf{k m}$ & $\overline{y r}$ & \\
\hline \multicolumn{12}{|c|}{ Effective Porosity Fractile Value at $1 \%$} \\
\hline $5 \%$ & 30.50 & 10.00 & 30.50 & 5.00 & 30.50 & 5.00 & 30.50 & 5.00 & 30.50 & 5.00 & 3.97 \\
\hline $50 \%$ & 30.50 & 15.00 & 30.50 & 10.00 & 30.50 & 5.00 & 30.50 & 5.00 & 30.50 & 5.00 & 5.46 \\
\hline $95 \%$ & 12.34 & 40.00 & 14.50 & 35.00 & 17.07 & 25.00 & 21.72 & 865.00 & 30.50 & 30.00 & 6.98 \\
\hline $99 \%$ & 10.59 & 490.00 & 15.54 & 625.00 & 22.64 & 740.00 & 30.50 & 855.00 & 30.50 & 680.00 & 8.95 \\
\hline \multicolumn{12}{|c|}{ Effective Porosity Fractile Value at $5 \%$} \\
\hline $5 \%$ & 30.50 & 15.00 & 30.50 & 10.00 & 30.50 & 10.00 & 30.50 & 5.00 & 30.50 & 5.00 & 4.72 \\
\hline $50 \%$ & 30.50 & 30.00 & 30.50 & 15.00 & 30.50 & 10.00 & 30.50 & 5.00 & 30.50 & 5.00 & 6.09 \\
\hline $95 \%$ & 11.88 & 50.00 & 13.90 & 40.00 & 16.08 & 30.00 & 22.36 & 905.00 & 30.50 & 860.00 & 6.89 \\
\hline $99 \%$ & 11.19 & 505.00 & 16.27 & 720.00 & 23.52 & 875.00 & 30.50 & 865.00 & 30.50 & 715.00 & 9.06 \\
\hline \multicolumn{12}{|c|}{ Effective Porosity Fractile Value at $50 \%$} \\
\hline $5 \%$ & 30.50 & 30.00 & 30.50 & 20.00 & 30.50 & 15.00 & 30.50 & 10.00 & 30.50 & $5: 00$ & 5.47 \\
\hline $50 \%$ & 24.81 & 45.00 & 30.50 & 25.00 & 30.50 & 15.00 & 30.50 & 10.00 & 30.50 & 5.00 & 6.66 \\
\hline $95 \%$ & 11.31 & 45.00 & 13.06 & 40.00 & 16.18 & 755.00 & 23.00 & 1000.00 & 30.50 & 865.00 & 6.78 \\
\hline $99 \%$ & 11.53 & 535.00 & 17.15 & 760.00 & 23.51 & 895.00 & 30.50 & 875.00 & 30.50 & 730.00 & 9.06 \\
\hline \multicolumn{12}{|c|}{ Effective Porosity Fractile Value at $95 \%$} \\
\hline $5 \%$ & 16.75 & 80.00 & 21.93 & 100.00 & 25.18 & 105.00 & 30.50 & 75.00 & 30.50 & 40.00 & 7.21 \\
\hline $50 \%$ & 14.43 & 80.00 & 17.48 & 75.00 & 21.02 & 90.00 & 24.66 & 85.00 & 30.50 & 55.00 & 7.00 \\
\hline $95 \%$ & 9.36 & 65.00 & 14.26 & 685.00 & 19.86 & 950.00 & 24.76 & 1000.00 & 30.50 & 925.00 & 6.73 \\
\hline $99 \%$ & 12.65 & 600.00 & 20.57 & 900.00 & 25.21 & 1000.00 & 30.50 & 980.00 & 30.50 & 870.00 & 8.80 \\
\hline \multicolumn{12}{|c|}{ Effective Porosity Fractile Value at $99 \%$} \\
\hline $5 \%$ & 15.97 & 85.00 & 20.50 & 100.00 & 23.24 & 90.00 & 30.50 & 95.00 & 30.50 & 50.00 & 7.10 \\
\hline $50 \%$ & 13.87 & 85.00 & 16.45 & 80.00 & 19.79 & 90.00 & 22.97 & 85.00 & 30.50 & 80.00 & 6.70 \\
\hline $95 \%$ & 9.23 & 435.00 & 14.32 & 715.00 & 20.44 & 970.00 & 24.60 & 1000.00 & 30.50 & 940.00 & 6.79 \\
\hline $99 \%$ & 12.89 & 620.00 & 20.73 & 905.00 & 25.52 & 1000.00 & 30.50 & 975.00 & 30.50 & 880.00 & 8.75 \\
\hline
\end{tabular}

Notes.

1) 200 realizations running on a Pentium II Computer - 5 parameters

2) Percentage of outcomes with distances smaller than the given value

- Defined as a dose of 4 millirem per year

b These fractiles correspond to the confidence levels referred to in the FFACO (1996) 



\section{Table G-37}

Transport Simulation Results for Characterization Activity Group 6 Location of Contaminant Boundary ${ }^{a}$ for Various Fractiles ${ }^{b}$

(Page 1 of 4)

\begin{tabular}{|c|c|c|c|c|c|c|c|c|c|c|c|}
\hline \multicolumn{12}{|c|}{ Flux Fractile Value at $5 \%$} \\
\hline \multirow{3}{*}{$\begin{array}{c}\text { Diffusion } \\
\text { Fractile } \\
\text { Value }\end{array}$} & \multicolumn{2}{|c|}{$50 \%$} & \multicolumn{2}{|c|}{$65 \%$} & \multicolumn{2}{|c|}{$75 \%$} & \multicolumn{2}{|c|}{$85 \%$} & \multicolumn{2}{|c|}{$95 \%$} & \multirow{3}{*}{$\begin{array}{c}\text { Average } \\
\text { Deviation } \\
\text { km }\end{array}$} \\
\hline & distance & time & distance & time & distance & time & distance & time & distance & time & \\
\hline & km & $y r$ & $\mathbf{k m}$ & yr & $\mathbf{k m}$ & $y r$ & $\mathbf{k m}$ & $y r$ & $\mathbf{k m}$ & yr & \\
\hline \multicolumn{12}{|c|}{ Effective Porosity Fractile at $1 \%$} \\
\hline $5 \%$ & 1.50 & 0.00 & 1.88 & 30.00 & 1.98 & 35.00 & 2.38 & 30.00 & 3.00 & 55.00 & 0.48 \\
\hline $50 \%$ & 1.50 & 0.00 & 1.50 & 0.00 & 1.72 & 35.00 & 1.96 & 35.00 & 2.47 & 55.00 & 0.31 \\
\hline $95 \%$ & 1.50 & 0.00 & 1.50 & 0.00 & 1.50 & 0.00 & 1.50 & 0.00 & 1.77 & 20.00 & 0.06 \\
\hline $99 \%$ & 1.50 & 0.00 & 1.50 & 0.00 & 1.50 & 0.00 & 1.50 & 0.00 & 1.50 & 0.00 & 0.00 \\
\hline \multicolumn{12}{|c|}{ Effective Porosity Fractile at $5 \%$} \\
\hline $5 \%$ & 1.50 & 0.00 & 1.56 & 50.00 & 1.89 & 45.00 & 2.00 & 50.00 & 2.57 & 50.00 & 0.36 \\
\hline $50 \%$ & 1.50 & 0.00 & 1.50 & 0.00 & 1.50 & 0.00 & 1.88 & 30.00 & 2.27 & 45.00 & 0.23 \\
\hline $95 \%$ & 1.50 & 0.00 & 1.50 & 0.00 & 1.50 & 0.00 & 1.50 & 0.00 & 1.50 & 35.00 & 0.04 \\
\hline $99 \%$ & 1.50 & 0.00 & 1.50 & 0.00 & 1.50 & 0.00 & 1.50 & 0.00 & 1.50 & 0.00 & 0.00 \\
\hline \multicolumn{12}{|c|}{ Effective Porosity Fractile at $50 \%$} \\
\hline $5 \%$ & 1.50 & 0.00 & 1.50 & 0.00 & 1.52 & 50.00 & 1.93 & 55.00 & 2.30 & 65.00 & 0.26 \\
\hline $50 \%$ & 1.50 & 0.00 & 1.50 & 0.00 & 1.50 & 0.00 & 1.64 & 45.00 & 1.98 & 45.00 & 0.15 \\
\hline $95 \%$ & 1.50 & 0.00 & 1.50 & 0.00 & 1.50 & 0.00 & 1.50 & 0.00 & 1.50 & 0.00 & 0.02 \\
\hline $99 \%$ & 1.50 & 0.00 & 1.50 & 0.00 & 1.50 & 0.00 & 1.50 & 0.00 & 1.50 & 0.00 & 0.00 \\
\hline \multicolumn{12}{|c|}{ Effective Porosity Fractile at $95 \%$} \\
\hline $5 \%$ & 1.50 & 0.00 & 1.50 & 0.00 & 1.50 & 0.00 & 1.50 & 0.00 & 1.69 & 1000.00 & 0.05 \\
\hline $50 \%$ & 1.50 & 0.00 & 1.50 & 0.00 & 1.50 & 0.00 & 1.50 & 0.00 & 1.50 & 0.00 & 0.01 \\
\hline $95 \%$ & 1.50 & 0.00 & 1.50 & 0.00 & 1.50 & 0.00 & 1.50 & 0.00 & 1.50 & 0.00 & 0.00 \\
\hline $99 \%$ & 1.50 & 0.00 & 1.50 & 0.00 & 1.50 & 0.00 & 1.50 & 0.00 & 1.50 & 0.00 & 0.00 \\
\hline \multicolumn{12}{|c|}{ Effective Porosity Fractile at $99 \%$} \\
\hline $5 \%$ & 1.50 & 0.00 & 1.50 & 0.00 & 1.50 & 0.00 & 1.50 & 0.00 & 1.69 & 1000.00 & 0.04 \\
\hline $50 \%$ & 1.50 & 0.00 & 1.50 & 0.00 & 1.50 & 0.00 & 1.50 & 0.00 & 1.50 & 0.00 & 0.01 \\
\hline $95 \%$ & 1.50 & 0.00 & 1.50 & 0.00 & 1.50 & 0.00 & 1.50 & 0.00 & 1.50 & 0.00 & 0.00 \\
\hline $99 \%$ & 1.50 & 0.00 & 1.50 & 0.00 & 1.50 & 0.00 & 1.50 & 0.00 & 1.50 & 0.00 & 0.00 \\
\hline
\end{tabular}


Table G-37

Transport Simulation Results for Characterization Activity Group 6 Location of Contaminant Boundary ${ }^{a}$ for Various Fractiles ${ }^{b}$

(Page 2 of 4 )

\begin{tabular}{|c|c|c|c|c|c|c|c|c|c|c|c|}
\hline \multicolumn{12}{|c|}{ (Page 2 of 4 ) } \\
\hline \multirow{3}{*}{$\begin{array}{c}\text { Diffusion } \\
\text { Fractile } \\
\text { Value }\end{array}$} & \multicolumn{2}{|c|}{$50 \%$} & \multicolumn{2}{|c|}{$65 \%$} & \multicolumn{2}{|c|}{$75 \%$} & \multicolumn{2}{|c|}{$85 \%$} & \multicolumn{2}{|c|}{$95 \%$} & \multirow{3}{*}{$\begin{array}{c}\text { Average } \\
\text { Deviation } \\
\text { km }\end{array}$} \\
\hline & distance & time & distance & time & distance & time & distance & time & distance & time & \\
\hline & km & yr & $\mathbf{k m}$ & yr & km & $\mathbf{y r}$ & km & $y r$ & $\mathbf{k m}$ & yr & \\
\hline \multicolumn{12}{|c|}{ Effective Porosity Fractile at $1 \%$} \\
\hline $5 \%$ & 3.83 & 25.00 & 5.43 & 45.00 & 7.49 & 70.00 & 10.46 & 60.00 & 16.53 & 115.00 & 4.42 \\
\hline $50 \%$ & 2.99 & 20.00 & 3.99 & 25.00 & 5.74 & 55.00 & 7.86 & 50.00 & 13.59 & 85.00 & 3.35 \\
\hline $95 \%$ & 2.06 & 20.00 & 2.89 & 25.00 & 3.42 & 20.00 & 4.28 & 30.00 & 7.50 & 35.00 & 2.03 \\
\hline $99 \%$ & 1.84 & 790.00 & 2.46 & 1000.00 & 3.12 & 965.00 & 4.13 & 1000.00 & 6.90 & 1000.00 & 1.83 \\
\hline \multicolumn{12}{|c|}{ Effective Porosity Fractile at $5 \%$} \\
\hline $5 \%$ & 3.46 & 45.00 & 4.55 & 55.00 & 5.80 & 65.00 & 8.12 & 75.00 & 12.01 & 80.00 & 3.24 \\
\hline $50 \%$ & 2.87 & 30.00 & 3.68 & 35.00 & 4.73 & 60.00 & 6.40 & 55.00 & 9.49 & 55.00 & 2.50 \\
\hline $95 \%$ & 2.00 & 20.00 & 2.77 & 35.00 & 3.25 & 1000.00 & 4.02 & 975.00 & 6.69 & 1000.00 & 1.77 \\
\hline $99 \%$ & 1.88 & 1000.00 & 2.53 & 1000.00 & 3.16 & 990.00 & 4.00 & 1000.00 & 7.05 & 925.00 & 1.70 \\
\hline \multicolumn{12}{|c|}{ Effective Porosity Fractile at $50 \%$} \\
\hline $5 \%$ & 3.04 & 50.00 & 3.92 & 65.00 & 4.58 & 70.00 & 6.06 & 95.00 & 9.15 & 95.00 & 2.48 \\
\hline $50 \%$ & 2.67 & 45.00 & 3.38 & 50.00 & 3.98 & 60.00 & 5.22 & 80.00 & 7.85 & 75.00 & 1.98 \\
\hline $95 \%$ & 1.99 & 35.00 & 2.61 & 35.00 & 3.22 & 1000.00 & 4.05 & 1000.00 & 6.42 & 1000.00 & 1.61 \\
\hline $99 \%$ & 1.88 & 1000.00 & 2.54 & 1000.00 & 3.15 & 1000.00 & 3.94 & 1000.00 & 7.06 & 980.00 & 1.62 \\
\hline \multicolumn{12}{|c|}{ Effective Porosity Fractile at $95 \%$} \\
\hline $5 \%$ & 2.05 & 1000.00 & 2.71 & 990.00 & 3.30 & 985.00 & 4.08 & 780.00 & 8.12 & 1000.00 & 1.76 \\
\hline $50 \%$ & 1.98 & 1000.00 & 2.50 & 935.00 & 3.17 & 1000.00 & 3.85 & 1000.00 & 6.71 & 885.00 & 1.52 \\
\hline $95 \%$ & 1.90 & .1000 .00 & 2.46 & 1000.00 & 3.04 & 1000.00 & 3.66 & 1000.00 & 6.17 & 960.00 & 1.37 \\
\hline $99 \%$ & 1.88 & 990.00 & 2.40 & 965.00 & 2.95 & 1000.00 & 3.61 & 990.00 & 6.16 & 1000.00 & 1.38 \\
\hline \multicolumn{12}{|c|}{ Effective Porosity Fractile at $99 \%$} \\
\hline $5 \%$ & 2.02 & 945.00 & 2.66 & 1000.00 & 3.29 & 1000.00 & 4.07 & 785.00 & 8.06 & 955.00 & 1.77 \\
\hline $50 \%$ & 1.97 & 55.00 & 2.49 & 855.00 & 3.17 & 1000.00 & 3.82 & 1000.00 & 6.69 & 875.00 & 1.53 \\
\hline $95 \%$ & 1.89 & 1000.00 & 2.44 & 1000.00 & 2.99 & 1000.00 & 3.68 & 1000.00 & 6.19 & 950.00 & 1.38 \\
\hline $99 \%$ & 1.88 & 985.00 & 2.37 & 975.00 & 2.94 & 980.00 & 3.60 & 1000.00 & 6.13 & 1000.00 & 1.39 \\
\hline
\end{tabular}


Table G-37

Transport Simulation Results for Characterization Activity Group 6 Location of Contaminant Boundary ${ }^{\mathrm{a}}$ for Various Fractiles ${ }^{\mathrm{b}}$

(Page 3 of 4 )

\begin{tabular}{|c|c|c|c|c|c|c|c|c|c|c|c|}
\hline \multicolumn{12}{|c|}{ Flux Fractile Value at $95 \%$} \\
\hline \multirow{3}{*}{$\begin{array}{c}\text { Diffusion } \\
\text { Fractile } \\
\text { Value }\end{array}$} & \multicolumn{2}{|c|}{$50 \%$} & \multicolumn{2}{|c|}{$65 \%$} & \multicolumn{2}{|c|}{$75 \%$} & \multicolumn{2}{|c|}{$85 \%$} & \multicolumn{2}{|c|}{$95 \%$} & \multirow{3}{*}{$\begin{array}{c}\text { Average } \\
\text { Deviation } \\
\text { km }\end{array}$} \\
\hline & distance & time & distance & time & distance & time & distance & time & distance & time & \\
\hline & km & yr & km & yr & km & yr & km & yr & $\mathbf{k m}$ & yr & \\
\hline \multicolumn{12}{|c|}{ Effective Porosity Fractile at $1 \%$} \\
\hline $5 \%$ & 30.50 & 20.00 & 30.50 & 10.00 & 30.50 & 10.00 & 30.50 & 5.00 & 30.50 & 5.00 & 6.26 \\
\hline $50 \%$ & 20.62 & 45.00 & 30.50 & 20.00 & 30.50 & 10.00 & 30.50 & 10.00 & 30.50 & 5.00 & 7.65 \\
\hline $95 \%$ & 11.58 & 30.00 & 15.05 & 40.00 & 20.63 & 35.00 & 27.24 & 30.00 & 30.50 & 10.00 & 7.08 \\
\hline $99 \%$ & 6.83 & 50.00 & 9.33 & 485.00 & 13.56 & 830.00 & 19.90 & 1000.00 & 30.50 & 950.00 & 6.53 \\
\hline \multicolumn{12}{|c|}{ Effective Porosity Fractile at $5 \%$} \\
\hline $5 \%$ & 26.96 & 55.00 & 30.50 & 20.00 & 30.50 & 15.00 & 30.50 & 10.00 & 30.50 & 5.00 & 6.78 \\
\hline $50 \%$ & 17.90 & 35.00 & 27.47 & 50.00 & 30.50 & 20.00 & 30.50 & 15.00 & 30.50 & 10.00 & 7.87 \\
\hline $95 \%$ & 11.08 & 45.00 & 13.89 & 45.00 & 17.74 & 35.00 & 23.10 & 50.00 & 30.50 & 20.00 & 6.83 \\
\hline $99 \%$ & 6.68 & 55.00 & 10.00 & 520.00 & 14.00 & 860.00 & 20.36 & 995.00 & 30.50 & 940.00 & 6.49 \\
\hline \multicolumn{12}{|c|}{ Effective Porosity Fractile at $50 \%$} \\
\hline $5 \%$ & 22.42 & 55.00 & 30.50 & 40.00 & 30.50 & 25.00 & 30.50 & 20.00 & 30.50 & 10.00 & 7.23 \\
\hline $50 \%$ & 15.80 & 40.00 & 22.47 & 50.00 & 30.50 & 65.00 & 30.50 & 25.00 & 30.50 & 15.00 & 7.94 \\
\hline $95 \%$ & 10.38 & 45.00 & 12.76 & 45.00 & 15.85 & 45.00 & 19.90 & 40.00 & 30.50 & 45.00 & 6.32 \\
\hline $99 \%$ & 7.01 & 455.00 & 10.66 & 630.00 & 14.22 & 875.00 & 21.24 & 995.00 & 30.50 & 920.00 & 6.44 \\
\hline \multicolumn{12}{|c|}{ Effective Porosity Fractile at $95 \%$} \\
\hline $5 \%$ & 12.01 & 85.00 & 13.78 & 80.00 & 15.56 & 105.00 & 18.98 & 110.00 & 22.33 & 95.00 & 5.70 \\
\hline $50 \%$ & 10.49 & 80.00 & 11.88 & 75.00 & 13.61 & 85.00 & 16.50 & 85.00 & 20.18 & 130.00 & 4.92 \\
\hline $95 \%$ & 7.94 & 60.00 & 9.16 & 75.00 & 11.57 & 945.00 & 15.91 & 985.00 & 20.22 & 1000.00 & 4.30 \\
\hline $99 \%$ & 7.68 & 605.00 & 12.11 & 815.00 & 15.37 & 1000.00 & 19.58 & 985.00 & 27.39 & 1000.00 & 5.92 \\
\hline \multicolumn{12}{|c|}{ Effective Porosity Fractile at $99 \%$} \\
\hline $5 \%$ & 11.53 & 90.00 & 13.24 & 85.00 & 14.67 & 80.00 & 17.68 & 105.00 & 20.47 & 210.00 & 5.35 \\
\hline $50 \%$ & 10.13 & 80.00 & 11.59 & 75.00 & 12.86 & 85.00 & 15.51 & 90.00 & 19.22 & 1000.00 & 4.69 \\
\hline $95 \%$ & 7.81 & 60.00 & 8.84 & 70.00 & 11.57 & 915.00 & 15.64 & 1000.00 & 20.13 & 940.00 & 4.26 \\
\hline $\mathbf{9 9 \%}$ & 7.64 & 565.00 & 11.76 & 780.00 & 15.02 & 1000.00 & 19.54 & 1000.00 & 27.12 & 1000.00 & 5.88 \\
\hline
\end{tabular}


Table G-37

Transport Simulation Results for Characterization Activity Group 6 Location of Contaminant Boundary ${ }^{a}$ for Various Fractiles ${ }^{b}$

(Page 4 of 4)

\begin{tabular}{|c|c|c|c|c|c|c|c|c|c|c|c|}
\hline \multicolumn{12}{|c|}{ Flux Fractile Value at $99 \%$} \\
\hline \multirow{3}{*}{$\begin{array}{l}\text { Diffusion } \\
\text { Fractile } \\
\text { Value }\end{array}$} & \multicolumn{2}{|c|}{$50 \%$} & \multicolumn{2}{|c|}{$65 \%$} & \multicolumn{2}{|c|}{$75 \%$} & \multicolumn{2}{|c|}{$85 \%$} & \multicolumn{2}{|c|}{$95 \%$} & \multirow{3}{*}{$\begin{array}{c}\text { Average } \\
\text { Deviation } \\
\text { km }\end{array}$} \\
\hline & distance & time & distance & time & distance & time & distance & time & distance & time & \\
\hline & km & yr & km & $y \mathbf{r}$ & $\mathbf{k m}$ & yr & km & yr & km & yr & \\
\hline \multicolumn{12}{|c|}{ Effective Porosity Fractile at $1 \%$} \\
\hline $5 \%$ & 30.50 & 10.00 & 30.50 & 5.00 & 30.50 & 5.00 & 30.50 & 5.00 & 30.50 & 5.00 & 4.22 \\
\hline $50 \%$ & 30.50 & 15.00 & 30.50 & 10.00 & 30.50 & 5.00 & 30.50 & 5.00 & 30.50 & 5.00 & 5.47 \\
\hline $95 \%$ & 16.64 & 30.00 & 23.33 & 25.00 & 30.50 & 20.00 & 30.50 & 10.00 & 30.50 & 5.00 & 7.46 \\
\hline $99 \%$ & 10.25 & 385.00 & 16.21 & 645.00 & 22.14 & 745.00 & 30.50 & 825.00 & 30.50 & 665.00 & 8.42 \\
\hline \multicolumn{12}{|c|}{ Effective Porosity Fractile at $5 \%$} \\
\hline $5 \%$ & 30.50 & 15.00 & 30.50 & 10.00 & 30.50 & 10.00 & 30.50 & 5.00 & 30.50 & 5.00 & 4.95 \\
\hline $50 \%$ & 30.50 & 30.00 & 30.50 & 15.00 & 30.50 & 10.00 & 30.50 & 5.00 & 30.50 & 5.00 & 6.09 \\
\hline $95 \%$ & 15.91 & 30.00 & 21.96 & 45.00 & 27.90 & 40.00 & 30.50 & 15.00 & 30.50 & 10.00 & 7.64 \\
\hline $99 \%$ & 11.09 & 470.00 & 17.17 & 685.00 & 23.12 & 885.00 & 30.50 & 840.00 & 30.50 & 680.00 & 8.50 \\
\hline \multicolumn{12}{|c|}{ Effective Porosity Fractile at $50 \%$} \\
\hline $5 \%$ & 30.50 & 30.00 & 30.50 & 20.00 & 30.50 & 15.00 & 30.50 & 10.00 & 30.50 & 5.00 & 5.62 \\
\hline $50 \%$ & 24.83 & 45.00 & 30.50 & 25.00 & 30.50 & 15.00 & 30.50 & 10.00 & 30.50 & 5.00 & 6.72 \\
\hline $95 \%$ & 15.01 & 40.00 & 19.87 & 50.00 & 23.43 & 50.00 & 30.50 & 30.00 & 30.50 & 15.00 & 7.51 \\
\hline $99 \%$ & 11.59 & 495.00 & 17.67 & 705.00 & 23.07 & 895.00 & 30.50 & 845.00 & 30.50 & 710.00 & 8.62 \\
\hline \multicolumn{12}{|c|}{ Effective Porosity Fractile at $95 \%$} \\
\hline $5 \%$ & 16.72 & 95.00 & 22.02 & 90.00 & 25.68 & 95.00 & 30.50 & 70.00 & 30.50 & 40.00 & 7.32 \\
\hline $50 \%$ & 14.64 & 75.00 & 17.86 & 75.00 & 21.69 & 90.00 & 26.13 & 90.00 & 30.50 & 45.00 & 7.24 \\
\hline $95 \%$ & 11.51 & 70.00 & 13.11 & 70.00 & 15.13 & 655.00 & 22.12 & 975.00 & 30.50 & 905.00 & 5.98 \\
\hline $99 \%$ & 13.12 & 615.00 & 21.13 & 915.00 & 26.17 & 1000.00 & 30.50 & 945.00 & 30.50 & 850.00 & 8.89 \\
\hline \multicolumn{12}{|c|}{ Effective Porosity Fractile at $99 \%$} \\
\hline $5 \%$ & 16.00 & 80.00 & 20.63 & 95.00 & 23.70 & 100.00 & 30.50 & 90.00 & 30.50 & 45.00 & 7.25 \\
\hline $50 \%$ & 14.17 & 80.00 & 16.86 & 75.00 & 20.47 & 90.00 & 24.14 & 85.00 & 30.50 & 60.00 & 7.03 \\
\hline $95 \%$ & 11.23 & 75.00 & 12.84 & 75.00 & 15.41 & 665.00 & 22.28 & 990.00 & 30.50 & 915.00 & 5.85 \\
\hline $99 \%$ & 13.14 & 625.00 & 21.52 & 940.00 & 25.68 & 1000.00 & 30.50 & 955.00 & 30.50 & 860.00 & 8.89 \\
\hline
\end{tabular}

Notes

1) 200 realizations running on a Pentium II Computer - 5 parameters

2) Percentage of outcomes with distances smaller than the given value

- Defined as a dose of 4 millirem per year

- These fractiles correspond to the confidence levels referred to in the FFACO (1996) 
Table G-38

Transport Simulation Results for Characterization Activity Group 7 Location of Contaminant Boundary ${ }^{\text {a }}$ for Various Fractiles ${ }^{b}$

\begin{tabular}{|c|c|c|c|c|c|c|c|c|c|c|c|}
\hline \multirow{3}{*}{$\begin{array}{c}\text { Diffusion } \\
\text { Fractile } \\
\text { Value }\end{array}$} & \multicolumn{2}{|c|}{$50 \%$} & \multicolumn{2}{|c|}{$65 \%$} & \multicolumn{2}{|c|}{$75 \%$} & \multicolumn{2}{|c|}{$85 \%$} & \multicolumn{2}{|c|}{$95 \%$} & \multirow{3}{*}{$\begin{array}{c}\text { Average } \\
\text { Deviation } \\
\text { km }\end{array}$} \\
\hline & distance & time & distance & time & distance & time & distance & time & distance & time & \\
\hline & km & yr & km & yr & $\mathbf{k m}$ & yr & km & $y r$ & km & $y r$ & \\
\hline \multicolumn{12}{|c|}{ Porosity Fractile Value at $1 \%$} \\
\hline $5 \%$ & 5.85 & 25.00 & 9.62 & 45.00 & 15.38 & 65.00 & 22.30 & 50.00 & 30.50 & 30.00 & 8.41 \\
\hline $50 \%$ & 3.97 & 15.00 & 5.96 & 20.00 & 9.61 & 50.00 & 13.00 & 45.00 & 30.50 & 65.00 & 5.85 \\
\hline $95 \%$ & 1.99 & 1000.00 & 2.67 & 950.00 & 3.41 & 1000.00 & 4.72 & 1000.00 & 8.55 & 1000.00 & 2.35 \\
\hline $99 \%$ & 1.92 & 970.00 & 2.64 & 1000.00 & 3.38 & 935.00 & 4.70 & 995.00 & 8.64 & 980.00 & 2.36 \\
\hline \multicolumn{12}{|c|}{ Porosity Fractile Value at $5 \%$} \\
\hline $5 \%$ & 5.35 & 35.00 & 8.52 & 50.00 & 12.21 & 80.00 & 17.27 & 65.00 & 30.50 & 60.00 & 7.19 \\
\hline $50 \%$ & 3.90 & 20.00 & 5.40 & 35.00 & 8.53 & 45.00 & 12.05 & 55.00 & 22.65 & 80.00 & 5.18 \\
\hline $95 \%$ & 1.99 & 1000.00 & 2.67 & 965.00 & 3.41 & 1000.00 & 4.71 & 1000.00 & 8.51 & 1000.00 & 2.32 \\
\hline $99 \%$ & 1.93 & 975.00 & 2.64 & 1000.00 & 3.38 & 945.00 & 4.70 & 1000.00 & 8.51 & 1000.00 & 2.33 \\
\hline \multicolumn{12}{|c|}{ Porosity Fractile Value at $50 \%$} \\
\hline $5 \%$ & 4.42 & 45.00 & 6.09 & 50.00 & 7.88 & 80.00 & 10.94 & 90.00 & 17.47 & 100.00 & 4.74 \\
\hline $50 \%$ & 3.44 & 30.00 & 4.68 & 35.00 & 6.13 & 65.00 & 8.36 & 65.00 & 13.99 & 75.00 & 3.58 \\
\hline $95 \%$ & 2.00 & 1000.00 & 2.68 & 965.00 & 3.43 & 945.00 & 4.69 & 1000.00 & 8.29 & 1000.00 & 2.20 \\
\hline $99 \%$ & 1.95 & 990.00 & 2.64 & 1000.00 & 3.44 & 965.00 & 4.71 & 1000.00 & 8.29 & 1000.00 & 2.22 \\
\hline \multicolumn{12}{|c|}{ Porosity Fractile Value at $95 \%$} \\
\hline $5 \%$ & 2.03 & 980.00 & 2.77 & 975.00 & 3.44 & 720.00 & 5.09 & 805.00 & 9.24 & 995.00 & 2.57 \\
\hline $50 \%$ & 1.96 & 1000.00 & 2.61 & 1000.00 & 3.37 & 1000.00 & 4.15 & 1000.00 & 7.19 & 690.00 & 1.90 \\
\hline $95 \%$ & 1.86 & 870.00 & 2.47 & 975.00 & 3.12 & 1000.00 & 3.93 & 1000.00 & 6.45 & 815.00 & 1.76 \\
\hline $99 \%$ & 1.84 & 855.00 & 2.46 & 985.00 & 3.03 & 1000.00 & 3.90 & 1000.00 & 6.38 & 1000.00 & 1.77 \\
\hline \multicolumn{12}{|c|}{ Porosity Fractile Value at $99 \%$} \\
\hline $5 \%$ & 1.87 & 955.00 & 2.39 & 990.00 & 3.18 & 1000.00 & 4.50 & 935.00 & 7.14 & 1000.00 & 2.16 \\
\hline $50 \%$ & 1.86 & 945.00 & 2.40 & 1000.00 & 3.09 & 970.00 & 3.90 & 990.00 & 6.79 & 1000.00 & 1.78 \\
\hline $95 \%$ & 1.79 & 980.00 & 2.27 & 1000.00 & 2.86 & 1000.00 & 3.74 & 1000.00 & 6.12 & 960.00 & 1.75 \\
\hline $99 \%$ & 1.77 & 945.00 & 2.24 & 990.00 & 2.85 & 1000.00 & 3.75 & 1000.00 & 6.17 & 1000.00 & 1.76 \\
\hline
\end{tabular}

Notes

1) 200 realizations running on a Pentium II Computer - 5 parameters

2) Percentage of oulcomes with distances smaller than the given value
- Defined as a dose of 4 millirem per year

- These fractiles correspond to the confidence levels referred to in the FFACO (1996) 
Table G-39

Transport Simulation Results for Characterization Activity Group 8 Location of Contaminant Boundary ${ }^{\mathrm{a}}$ for Various Fractiles ${ }^{\mathrm{b}}$

(Page 1 of 4)

\begin{tabular}{|c|c|c|c|c|c|c|c|c|c|c|c|}
\hline \multicolumn{12}{|c|}{ Flux Fractile Value at $5 \%$} \\
\hline \multirow{3}{*}{$\begin{array}{c}\text { Diffusion } \\
\text { Fractile } \\
\text { Value }\end{array}$} & \multicolumn{2}{|c|}{$50 \%$} & \multicolumn{2}{|c|}{$65 \%$} & \multicolumn{2}{|c|}{$75 \%$} & \multicolumn{2}{|c|}{$85 \%$} & \multicolumn{2}{|c|}{$95 \%$} & \multirow{3}{*}{$\begin{array}{c}\text { Average } \\
\text { Deviatior } \\
\text { km }\end{array}$} \\
\hline & distance & time & distance & time & distance & time & distance & time & distance & time & \\
\hline & km & $y r$ & km & yr & $\mathbf{k m}$ & $y r$ & $\mathbf{k m}$ & $y r$ & $\mathbf{k m}$ & $y r$ & \\
\hline \multicolumn{12}{|c|}{ Effective Porosity Fractile at $1 \%$} \\
\hline $5 \%$ & 1.50 & 0.00 & 1.88 & 30.00 & 1.98 & 35.00 & 2.38 & 30.00 & 3.00 & 55.00 & 0.48 \\
\hline $50 \%$ & 1.50 & 0.00 & 1.50 & 0.00 & 1.72 & 35.00 & 1.96 & 35.00 & 2.46 & 55.00 & 0.31 \\
\hline $95 \%$ & 1.50 & 0.00 & 1.50 & 0.00 & 1.50 & 0.00 & 1.50 & 0.00 & 1.77 & 20.00 & 0.06 \\
\hline $99 \%$ & 1.50 & 0.00 & 1.50 & 0.00 & 1.50 & 0.00 & 1.50 & 0.00 & 1.50 & 0.00 & 0.00 \\
\hline \multicolumn{12}{|c|}{ Effective Porosity Fractile at $5 \%$} \\
\hline $5 \%$ & 1.50 & 0.00 & 1.56 & 50.00 & 1.89 & 45.00 & 2.00 & 50.00 & 2.57 & 50.00 & 0.36 \\
\hline $50 \%$ & 1.50 & 0.00 & 1.50 & 0.00 & 1.50 & 0.00 & 1.88 & 30.00 & 2.27 & 45.00 & 0.23 \\
\hline $95 \%$ & 1.50 & 0.00 & 1.50 & 0.00 & 1.50 & 0.00 & 1.50 & 0.00 & 1.50 & 35.00 & 0.04 \\
\hline $99 \%$ & 1.50 & 0.00 & 1.50 & 0.00 & 1.50 & 0.00 & 1.50 & 0.00 & 1.50 & 0.00 & 0.00 \\
\hline \multicolumn{12}{|c|}{ Effective Porosity Fractile at $50 \%$} \\
\hline $5 \%$ & 1.50 & 0.00 & 1.50 & 0.00 & 1.51 & 50.00 & 1.93 & 55.00 & 2.30 & 65.00 & 0.26 \\
\hline $50 \%$ & 1.50 & 0.00 & 1.50 & 0.00 & 1.50 & 0.00 & 1.64 & 45.00 & 1.98 & 45.00 & 0.15 \\
\hline $95 \%$ & 1.50 & 0.00 & 1.50 & 0.00 & 1.50 & 0.00 & 1.50 & 0.00 & 1.50 & 0.00 & 0.02 \\
\hline $99 \%$ & 1.50 & 0.00 & 1.50 & 0.00 & 1.50 & 0.00 & 1.50 & 0.00 & 1.50 & 0.00 & 0.00 \\
\hline \multicolumn{12}{|c|}{ Effective Porosity Fractile at $95 \%$} \\
\hline $5 \%$ & 1.50 & 0.00 & 1.50 & 0.00 & 1.50 & 0.00 & 1.50 & 0.00 & 1.69 & 1000.00 & 0.05 \\
\hline $50 \%$ & 1.50 & 0.00 & 1.50 & 0.00 & 1.50 & 0.00 & 1.50 & 0.00 & 1.50 & 0.00 & 0.01 \\
\hline $95 \%$ & 1.50 & 0.00 & 1.50 & 0.00 & 1.50 & 0.00 & 1.50 & 0.00 & 1.50 & 0.00 & 0.00 \\
\hline $99 \%$ & 1.50 & 0.00 & 1.50 & 0.00 & 1.50 & 0.00 & 1.50 & 0.00 & 1.50 & 0.00 & 0.00 \\
\hline \multicolumn{12}{|c|}{ Effective Porosity Fractile at $99 \%$} \\
\hline $5 \%$ & 1.50 & 0.00 & 1.50 & 0.00 & 1.50 & 0.00 & 1.50 & 0.00 & 1.69 & 1000.00 & 0.04 \\
\hline $50 \%$ & 1.50 & 0.00 & 1.50 & 0.00 & 1.50 & 0.00 & 1.50 & 0.00 & 1.50 & 0.00 & 0.01 \\
\hline $95 \%$ & 1.50 & 0.00 & 1.50 & 0.00 & 1.50 & 0.00 & 1.50 & 0.00 & 1.50 & 0.00 & 0.00 \\
\hline $99 \%$ & 1.50 & 0.00 & 1.50 & 0.00 & 1.50 & 0.00 & 1.50 & 0.00 & 1.50 & 0.00 & 0.00 \\
\hline
\end{tabular}


Table G-39

Transport Simulation Results for Characterization Activity Group 8 Location of Contaminant Boundary ${ }^{\mathrm{a}}$ for Various Fractiles ${ }^{\mathrm{b}}$

(Page 2 of 4)

\begin{tabular}{|c|c|c|c|c|c|c|c|c|c|c|c|}
\hline \multicolumn{12}{|c|}{$\frac{(\text { Page } 2 \text { of } 4)}{\text { Flux Fractile Value at } 50 \%}$} \\
\hline \multirow{3}{*}{$\begin{array}{c}\text { Diffusion } \\
\text { Fractile } \\
\text { Value }\end{array}$} & \multicolumn{2}{|c|}{$50 \%$} & \multicolumn{2}{|c|}{$65 \%$} & \multicolumn{2}{|c|}{$75 \%$} & \multicolumn{2}{|c|}{$85 \%$} & \multicolumn{2}{|c|}{$95 \%$} & \multirow{3}{*}{$\begin{array}{c}\text { Average } \\
\text { Deviation } \\
\mathrm{km}\end{array}$} \\
\hline & distance & time & distance & time & distance & time & distance & time & distance & time & \\
\hline & $\mathbf{k m}$ & yr & km & yr & $\mathbf{k m}$ & yr & km & $y \mathbf{r}$ & $\mathbf{k m}$ & $y r$ & \\
\hline \multicolumn{12}{|c|}{ Effective Porosity Fractile at $1 \%$} \\
\hline $5 \%$ & 3.61 & 30.00 & 4.94 & 55.00 & 6.53 & 45.00 & 9.07 & 75.00 & 13.54 & 75.00 & 3.59 \\
\hline $50 \%$ & 2.92 & 20.00 & 3.86 & 35.00 & 4.91 & 40.00 & 6.80 & 40.00 & 10.58 & 80.00 & 2.58 \\
\hline $95 \%$ & 1.99 & 15.00 & 2.62 & 45.00 & 3.13 & 30.00 & 3.81 & 35.00 & 5.99 & 45.00 & 1.55 \\
\hline $99 \%$ & 1.90 & 995.00 & 2.46 & 945.00 & 3.00 & 990.00 & 3.72 & 985.00 & 6.18 & 1000.00 & 1.34 \\
\hline \multicolumn{12}{|c|}{ Effective Porosity Fractile at $5 \%$} \\
\hline $5 \%$ & 3.26 & 55.00 & 4.01 & 60.00 & 5.25 & 70.00 & 6.76 & 70.00 & 10.07 & 70.00 & 2.57 \\
\hline $50 \%$ & 2.78 & 35.00 & 3.39 & 45.00 & 4.12 & 65.00 & 5.46 & 60.00 & 7.93 & 60.00 & 1.95 \\
\hline $95 \%$ & 1.99 & 20.00 & 2.51 & 1000.00 & 3.09 & 1000.00 & 3.72 & 1000.00 & 5.81 & 1000.00 & 1.37 \\
\hline $99 \%$ & 1.91 & 1000.00 & 2.48 & 1000.00 & 3.01 & 1000.00 & 3.74 & 1000.00 & 6.01 & 1000.00 & 1.25 \\
\hline \multicolumn{12}{|c|}{ Effective Porosity Fractile at $50 \%$} \\
\hline $5 \%$ & 2.94 & 50.00 & 3.50 & 60.00 & 4.25 & 80.00 & 5.34 & 80.00 & 7.56 & 90.00 & 1.93 \\
\hline $50 \%$ & 2.48 & 45.00 & 2.98 & 55.00 & 3.66 & 60.00 & 4.66 & 75.00 & 6.49 & 70.00 & 1.57 \\
\hline $95 \%$ & 1.98 & 1000.00 & 2.52 & 940.00 & 3.03 & 1000.00 & 3.66 & 1000.00 & 5.73 & 1000.00 & 1.24 \\
\hline $99 \%$ & 1.92 & 1000.00 & 2.47 & 1000.00 & 2.95 & 1000.00 & 3.58 & 1000.00 & 5.62 & 1000.00 & 1.17 \\
\hline \multicolumn{12}{|c|}{ Effective Porosity Fractile at $95 \%$} \\
\hline $5 \%$ & 2.10 & 1000.00 & 2.65 & 995.00 & 3.21 & 935.00 & 4.01 & 970.00 & 6.86 & 960.00 & 1.41 \\
\hline $50 \%$ & 1.99 & 970.00 & 2.52 & 1000.00 & 2.98 & 1000.00 & 3.66 & 1000.00 & 6.12 & 1000.00 & 1.20 \\
\hline $95 \%$ & 1.93 & 935.00 & 2.46 & 1000.00 & 2.85 & 1000.00 & 3.34 & 1000.00 & 5.59 & 1000.00 & 1.03 \\
\hline $99 \%$ & 1.92 & 1000.00 & 2.37 & 1000.00 & 2.76 & 1000.00 & 3.33 & 1000.00 & 4.96 & 970.00 & 0.99 \\
\hline \multicolumn{12}{|c|}{ Effective Porosity Fractile at $99 \%$} \\
\hline $5 \%$ & 2.08 & 1000.00 & 2.63 & 1000.00 & 3.20 & 940.00 & 4.01 & 980.00 & 6.81 & 935.00 & 1.41 \\
\hline $50 \%$ & 1.99 & 990.00 & 2.50 & 1000.00 & 2.96 & 1000.00 & 3.67 & 1000.00 & 6.11 & 1000.00 & 1.21 \\
\hline $95 \%$ & 1.93 & 940.00 & 2.44 & 1000.00 & 2.83 & 1000.00 & 3.36 & 1000.00 & 5.67 & 1000.00 & 1.04 \\
\hline $99 \%$ & 1.90 & 1000.00 & 2.35 & 1000.00 & 2.75 & 1000.00 & 3.31 & 1000.00 & 4.98 & 970.00 & 0.99 \\
\hline
\end{tabular}


Table G-39

Transport Simulation Results for Characterization Activity Group 8 Location of Contaminant Boundary ${ }^{a}$ for Various Fractiles ${ }^{b}$

(Page 3 of 4 )

\begin{tabular}{|c|c|c|c|c|c|c|c|c|c|c|c|}
\hline \multicolumn{12}{|c|}{ Flux Fractile Value at $95 \%$} \\
\hline \multirow{3}{*}{$\begin{array}{l}\text { Diffusion } \\
\text { Fractile } \\
\text { Value }\end{array}$} & \multicolumn{2}{|c|}{$50 \%$} & \multicolumn{2}{|c|}{$65 \%$} & \multicolumn{2}{|c|}{$75 \%$} & \multicolumn{2}{|c|}{$85 \%$} & \multicolumn{2}{|c|}{$95 \%$} & \multirow{3}{*}{$\begin{array}{c}\text { Average } \\
\text { Deviation } \\
\mathbf{k m}\end{array}$} \\
\hline & distance & time & distance & time & distance & time & distance & time & distance & time & \\
\hline & $\mathbf{k m}$ & $y r$ & $\mathbf{k m}$ & $y r$ & $\mathbf{k m}$ & $y \mathbf{r}$ & $\mathbf{k m}$ & yr & $\mathbf{k m}$ & yr & \\
\hline $5 \%$ & 30.50 & 20.00 & 30.50 & 10.00 & 30.50 & 10.00 & 30.50 & 5.00 & 30.50 & 5.00 & 6.03 \\
\hline $50 \%$ & 21.60 & 35.00 & 30.50 & 15.00 & 30.50 & 10.00 & 30.50 & 10.00 & 30.50 & 5.00 & 7.38 \\
\hline \multicolumn{12}{|c|}{ Effective Porosity Fractile at $5 \%$} \\
\hline $5 \%$ & 28.78 & 55.00 & 30.50 & 20.00 & 30.50 & 15.00 & 30.50 & 10.00 & 30.50 & 5.00 & 6.53 \\
\hline $50 \%$ & 18.91 & 35.00 & 30.50 & 40.00 & 30.50 & 20.00 & 30.50 & 15.00 & 30.50 & 5.00 & 7.65 \\
\hline $95 \%$ & 11.50 & 50.00 & 14.34 & 45.00 & 18.97 & 35.00 & 23.83 & 50.00 & 30.50 & 20.00 & 6.93 \\
\hline $99 \%$ & 7.01 & 425.00 & 10.55 & 580.00 & 14.18 & 815.00 & 21.58 & 995.00 & 30.50 & 915.00 & 6.67 \\
\hline $99 \%$ & 7.24 & 435.00 & 11.06 & 610.00 & 14.72 & 870.00 & 22.12 & 1000.00 & 30.50 & 935.00 & 6.64 \\
\hline \multicolumn{12}{|c|}{ Effective Porosity Fractile at $95 \%$} \\
\hline $5 \%$ & 12.49 & 95.00 & 14.39 & 80.00 & 16.58 & 105.00 & 20.11 & 95.00 & 23.47 & 115.00 & 5.96 \\
\hline $50 \%$ & 11.07 & 80.00 & 12.38 & 95.00 & 14.24 & 85.00 & 17.43 & 90.00 & 21.30 & 100.00 & 5.11 \\
\hline $95 \%$ & 8.36 & 60.00 & 9.57 & 80.00 & 12.07 & 865.00 & 16.59 & 1000.00 & 21.08 & 1000.00 & 4.42 \\
\hline $99 \%$ & 8.05 & 605.00 & 12.63 & 810.00 & 16.15 & 1000.00 & 20.59 & 990.00 & 28.35 & 1000.00 & 6.16 \\
\hline \multicolumn{12}{|c|}{ Effective Porosity Fractile at $99 \%$} \\
\hline $5 \%$ & 12.08 & 90.00 & 13.74 & 85.00 & 15.46 & 75.00 & 18.51 & 105.00 & 21.71 & 90.00 & 5.53 \\
\hline $50 \%$ & 10.54 & 80.00 & 12.04 & 80.00 & 13.52 & 90.00 & 16.22 & 85.00 & 19.91 & 1000.00 & 4.84 \\
\hline $95 \%$ & 8.12 & 60.00 & 9.28 & 75.00 & 11.81 & 890.00 & 16.40 & 1000.00 & 20.85 & 1000.00 & 4.36 \\
\hline $99 \%$ & 7.93 & 575.00 & 12.30 & 780.00 & 15.67 & 990.00 & 20.58 & 1000.00 & 28.12 & 1000.00 & 6.11 \\
\hline
\end{tabular}




\section{Table G-39}

Transport Simulation Results for Characterization Activity Group 8 Location of Contaminant Boundary ${ }^{\mathrm{a}}$ for Various Fractiles ${ }^{\mathrm{b}}$

(Page 4 of 4 )

\begin{tabular}{|c|c|c|c|c|c|c|c|c|c|c|c|}
\hline \multicolumn{12}{|c|}{ Flux Fractile Value at $99 \%$} \\
\hline \multirow{3}{*}{$\begin{array}{c}\text { Diffusion } \\
\text { Fractile } \\
\text { Value }\end{array}$} & \multicolumn{2}{|c|}{$\mathbf{5 0 \%}$} & \multicolumn{2}{|c|}{$65 \%$} & \multicolumn{2}{|c|}{$75 \%$} & \multicolumn{2}{|c|}{$85 \%$} & \multicolumn{2}{|c|}{$95 \%$} & \multirow{3}{*}{$\begin{array}{c}\text { Average } \\
\text { Deviation } \\
\text { km }\end{array}$} \\
\hline & distance & time & distance & time & distance & time & distance & time & distance & time & \\
\hline & km & $y r$ & km & yr & km & $y r$ & km & $y r$ & km & $y r$ & \\
\hline \multicolumn{12}{|c|}{ Effective Porosity Fractile at $1 \%$} \\
\hline $5 \%$ & 30.50 & 10.00 & 30.50 & 5.00 & 30.50 & 5.00 & 30.50 & 5.00 & 30.50 & 5.00 & 4.24 \\
\hline $50 \%$ & 30.50 & 15.00 & 30.50 & 10.00 & 30.50 & 5.00 & 30.50 & 5.00 & 30.50 & 5.00 & 5.48 \\
\hline $95 \%$ & 16.49 & 30.00 & 23.23 & 25.00 & 30.50 & 20.00 & 30.50 & 10.00 & 30.50 & 5.00 & 7.45 \\
\hline $99 \%$ & 10.11 & 370.00 & 16.06 & 645.00 & 22.05 & 770.00 & 30.50 & 830.00 & 30.50 & 665.00 & 8.41 \\
\hline \multicolumn{12}{|c|}{ Effective Porosity Fractile at $5 \%$} \\
\hline $5 \%$ & 30.50 & 15.00 & 30.50 & 10.00 & 30.50 & 10.00 & 30.50 & 5.00 & 30.50 & 5.00 & 4.96 \\
\hline $50 \%$ & 30.50 & 30.00 & 30.50 & 15.00 & 30.50 & 10.00 & 30.50 & 5.00 & 30.50 & 5.00 & 6.09 \\
\hline $95 \%$ & 15.82 & 30.00 & 21.82 & 40.00 & 27.89 & 40.00 & 30.50 & 15.00 & 30.50 & 10.00 & 7.64 \\
\hline $99 \%$ & 11.04 & 470.00 & 17.08 & 710.00 & 23.00 & 890.00 & 30.50 & 845.00 & 30.50 & 685.00 & 8.49 \\
\hline \multicolumn{12}{|c|}{ Effective Porosity Fractile at $50 \%$} \\
\hline $5 \%$ & 30.50 & 35.00 & 30.50 & 20.00 & 30.50 & 15.00 & 30.50 & 10.00 & 30.50 & 5.00 & 5.63 \\
\hline $50 \%$ & 24.71 & 45.00 & 30.50 & 25.00 & 30.50 & 15.00 & 30.50 & 10.00 & 30.50 & 5.00 & 6.73 \\
\hline $95 \%$ & 14.95 & 40.00 & 19.84 & 50.00 & 23.36 & 50.00 & 30.50 & 30.00 & 30.50 & 15.00 & 7.50 \\
\hline $99 \%$ & 11.56 & 500.00 & 17.25 & 695.00 & 23.04 & 900.00 & 30.50 & 850.00 & 30.50 & 710.00 & 8.60 \\
\hline \multicolumn{12}{|c|}{ Effective Porosity Fractile at $95 \%$} \\
\hline $5 \%$ & 16.69 & 95.00 & 21.96 & 90.00 & 25.57 & 95.00 & 30.50 & 70.00 & 30.50 & 40.00 & 7.32 \\
\hline $50 \%$ & 14.63 & 75.00 & 17.77 & 75.00 & 21.64 & 90.00 & 26.03 & 85.00 & 30.50 & 45.00 & 7.23 \\
\hline $95 \%$ & 11.49 & 70.00 & 13.08 & 70.00 & 15.16 & 655.00 & 22.13 & 985.00 & 30.50 & 910.00 & 5.96 \\
\hline $99 \%$ & 13.09 & 620.00 & 21.01 & 915.00 & 25.72 & 1000.00 & 30.50 & 945.00 & 30.50 & 850.00 & 8.86 \\
\hline \multicolumn{12}{|c|}{ Effective Porosity Fractile at $99 \%$} \\
\hline $5 \%$ & 15.93 & 80.00 & 20.56 & 95.00 & 23.59 & 100.00 & 30.50 & 90.00 & 30.50 & 45.00 & 7.24 \\
\hline $50 \%$ & 14.15 & 80.00 & 16.81 & 75.00 & 20.47 & 90.00 & 24.06 & 85.00 & 30.50 & 60.00 & 7.01 \\
\hline $95 \%$ & 11.21 & 75.00 & 12.81 & 75.00 & 15.41 & 670.00 & 22.24 & 990.00 & 30.50 & 920.00 & 5.83 \\
\hline $99 \%$ & 13.13 & 630.00 & 21.08 & 930.00 & 25.34 & 1000.00 & 30.50 & 990.00 & 30.50 & 860.00 & 8.86 \\
\hline
\end{tabular}


Table G-40

Transport Simulation Results for Characterization Activity Group 10 Location of Contaminant Boundary ${ }^{a}$ for Various Fractiles ${ }^{b}$

\begin{tabular}{|c|c|c|c|c|c|c|c|c|c|c|c|}
\hline \multirow{3}{*}{$\begin{array}{c}\text { Source } \\
\text { Fractile } \\
\text { Value }\end{array}$} & \multicolumn{2}{|c|}{$50 \%$} & \multicolumn{2}{|c|}{$65 \%$} & \multicolumn{2}{|c|}{$75 \%$} & \multicolumn{2}{|c|}{$85 \%$} & \multicolumn{2}{|c|}{$95 \%$} & \multirow{3}{*}{$\begin{array}{c}\text { Average } \\
\text { Deviation } \\
\text { km }\end{array}$} \\
\hline & distance & time & distance & time & distance & time & distance & time & distance & time & \\
\hline & $\mathbf{k m}$ & yr & km & yr & km & yr & km & $y r$ & km & yr & \\
\hline \multicolumn{12}{|c|}{ Flux Fractile Value at $5 \%$} \\
\hline $5 \%$ & 1.50 & 0.00 & 1.50 & 0.00 & 1.67 & 40.00 & 1.94 & 30.00 & 2.63 & 45.00 & 0.31 \\
\hline $50 \%$ & 1.50 & 0.00 & 1.50 & 0.00 & 1.85 & 30.00 & 2.00 & 30.00 & 2.81 & 35.00 & 0.40 \\
\hline $95 \%$ & 1.50 & 0.00 & 1.50 & 0.00 & 1.87 & 30.00 & 2.08 & 30.00 & 2.85 & 35.00 & 0.42 \\
\hline $99 \%$ & 1.50 & 0.00 & 1.50 & 0.00 & 1.89 & 30.00 & 2.14 & 30.00 & 2.89 & 35.00 & 0.43 \\
\hline \multicolumn{12}{|c|}{ Flux Fractile Value at $50 \%$} \\
\hline $5 \%$ & 2.95 & 30.00 & 3.78 & 25.00 & 4.89 & 40.00 & 7.13 & 75.00 & 12.56 & 60.00 & 2.91 \\
\hline $50 \%$ & 3.45 & 40.00 & 4.73 & 40.00 & 6.17 & 55.00 & 8.74 & 60.00 & 13.19 & 50.00 & 3.30 \\
\hline $95 \%$ & 3.48 & 40.00 & 4.82 & 40.00 & 6.30 & 60.00 & 8.88 & 60.00 & 13.45 & 55.00 & 3.50 \\
\hline $99 \%$ & 3.52 & 40.00 & 4.90 & 40.00 & 6.43 & 60.00 & 9.01 & 60.00 & 13.66 & 55.00 & 3.64 \\
\hline \multicolumn{12}{|c|}{ Flux Fractile Value at $95 \%$} \\
\hline $5 \%$ & 20.08 & 30.00 & 30.50 & 25.00 & 30.50 & 15.00 & 30.50 & 10.00 & 30.50 & 5.00 & 8.42 \\
\hline $50 \%$ & 29.69 & 55.00 & 30.50 & 15.00 & 30.50 & 10.00 & 30.50 & 5.00 & 30.50 & 5.00 & 6.36 \\
\hline $95 \%$ & 30.50 & 55.00 & 30.50 & 15.00 & 30.50 & 10.00 & 30.50 & 5.00 & 30.50 & 5.00 & 5.89 \\
\hline $99 \%$ & 30.50 & 45.00 & 30.50 & 15.00 & 30.50 & 10.00 & 30.50 & 5.00 & 30.50 & 5.00 & 5.16 \\
\hline \multicolumn{12}{|c|}{ Flux Fractile Value at $99 \%$} \\
\hline $5 \%$ & 30.50 & 30.00 & 30.50 & 10.00 & 30.50 & 5.00 & 30.50 & 5.00 & 30.50 & 5.00 & 7.65 \\
\hline $50 \%$ & 30.50 & 15.00 & 30.50 & 5.00 & 30.50 & 5.00 & 30.50 & 5.00 & 30.50 & 5.00 & 4.65 \\
\hline $95 \%$ & 30.50 & 10.00 & 30.50 & 5.00 & 30.50 & 5.00 & 30.50 & 5.00 & 30.50 & 5.00 & 3.89 \\
\hline $99 \%$ & 30.50 & 10.00 & 30.50 & 5.00 & 30.50 & 5.00 & 30.50 & 5.00 & 30.50 & 5.00 & 3.17 \\
\hline
\end{tabular}

Notes

1) 200 realizations running on a Pentium II Computer - 5 parameters

2) Percentage of outcomes with distances smaller than the given value

Defined as a dose of 4 millirem per year

b These fractiles correspond to the confidence levels referred to in the FFACO (1996) 


\section{G.4.0 References}

FFACO, see Federal Facility Agreement and Consent Order.

Federal Facility Agreement and Consent Order. 1996. Agreed to by the State of Nevada, the U.S. Department of Energy, and the U.S. Department of Defense. 


\section{Distribution}

\section{Copies}

Paul J. Liebendorfer

Bureau of Federal Facilities

Division of Environmental Protection

333 W. Nye Lane, Room 138

Carson City, NV 89706-0851

Supervisor

Bureau of Federal Facilities

Division of Environmental Protection

555 E. Washington, Suite 4300

Las Vegas, NV 89101

Robert M. Bangerter, Jr.

DOE/Nevada Operations Office

Environmental Restoration Division

P.O. Box 98518, M/S 505

Las Vegas, NV 89193-8518

Doug Trudeau

U.S. Geological Survey

Water Resources Division

6770 South Paradise Road

Las Vegas, NV 89119

Ward L. Hawkins

Los Alamos National Laboratory

P.O. Box 1663 - EES-1M/S F659

Los Alamos, NM 87545

Gayle A. Pawloski

Lawrence Livermore National Laboratory

P.O. Box 808, M/S L-221

700 East Avenue

Livermore, CA 94550

Paul K. Ortego

Bechtel Nevada

2621 Losee Road

M/S NLV082

Las Vegas, NV 89030 
Copies

Chuck Russell

Desert Research Institute

755 E. Flamingo Road

P.O. Box 19040, M/S 505

Las Vegas, NV 89132-0040

Janet Wille

IT Corporation

2621 Losee Road, Bldg. B-1

M/S 439

North Las Vegas, NV 89030

U.S. Department of Energy

Office of Scientific and Technical Information

175 Oak Ridge Turnpike

P.O. Box 62

Oak Ridge, Tennessee 37831

DOE/Nevada Operations Office

Technical Information Resource Center

P.O. Box 98518, M/S 505

Las Vegas, NV 89193-8518

DOE Public Reading Room

P.O. Box 98521, M/S NLV040

Las Vegas, NV 89193-8521

Central Files

IT Corporation

2621 Losee Road, Bldg. B-1

M/S 439

North Las Vegas, NV 89030 